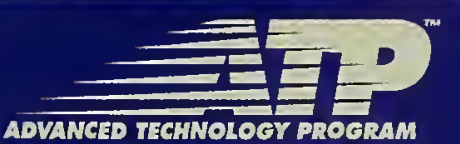

\title{
Performance of
} 50 Completed ATP Projects

STATUS REPORT - NUMBER 2

NIST SP 950-2 

Performance of 50 Completed ATP Projects

\section{STATUS REPORT - NUMBER 2}

NIST SP $950-2$

U.S. DEPARTMEN'T OF COMMERCE

Donald L. Evans, Secretary

TECHNOLOGY ADMINISTRATION

Phillip J. Bond, Under Secretary for Technology

NATIONAL INSTITUTE OF STANDARDS

AND TECHNOLOGY

Arden L. Bement, Jr., Director 
NATIONAL INSTITUTE OF STANDARDS AND TECHNOLOGY

Advanced Technology Program, Economic Assessment Office

NIST Special Publication 950-2

U.S. Government Printing Office

Washington, D.C.

December 2001

Book design and graphics by Linda S. Sherman Design, Inc., Montgomery Village, Maryland 


\section{Table of Contents}

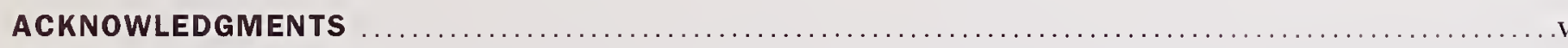

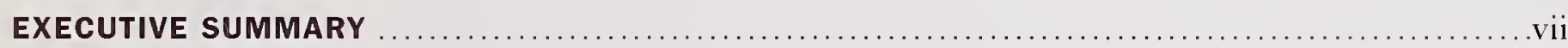

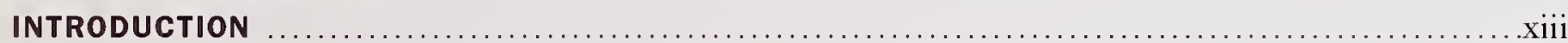

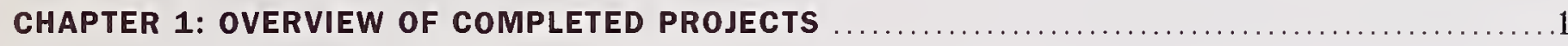

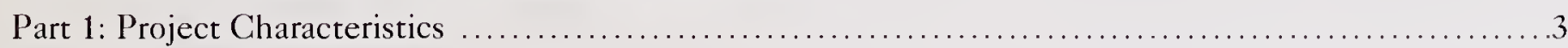

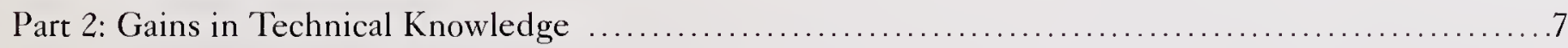

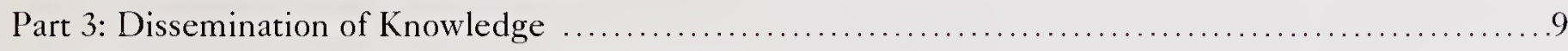

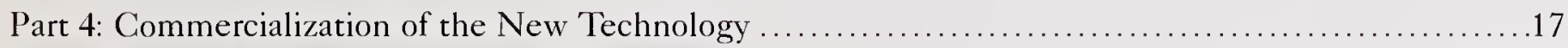

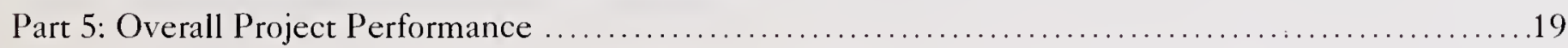

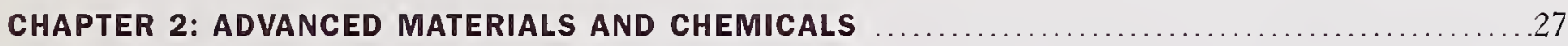

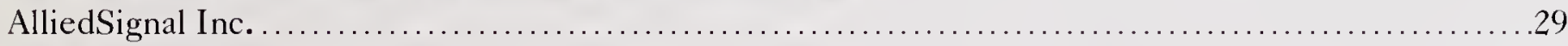

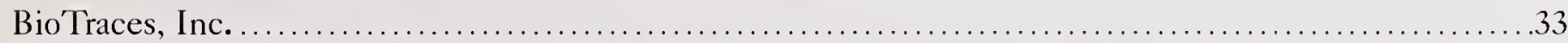

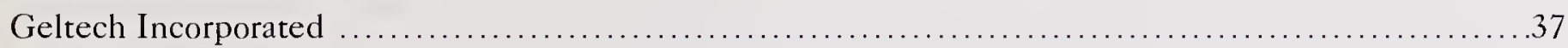

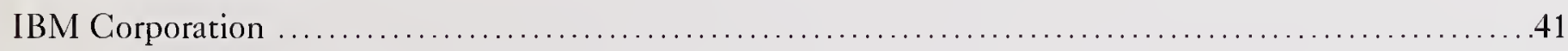

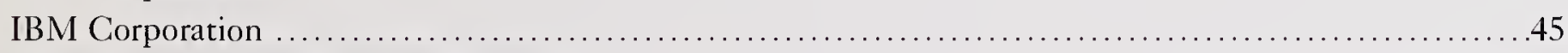

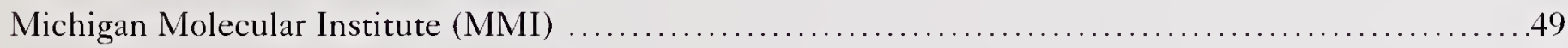

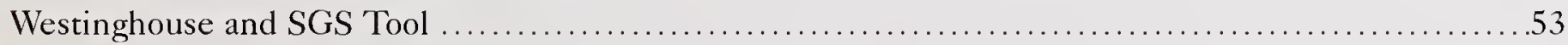

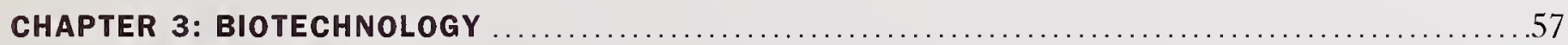

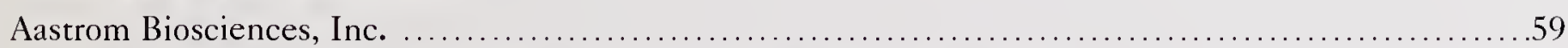

Amersham Pharmacia Biotech (formerly U.S. Biochemical Corporation) . .......................65

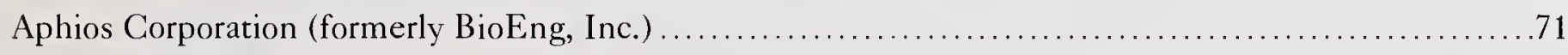

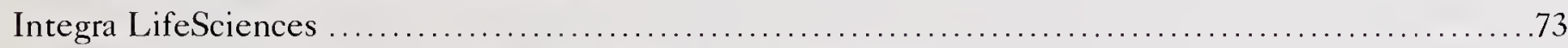

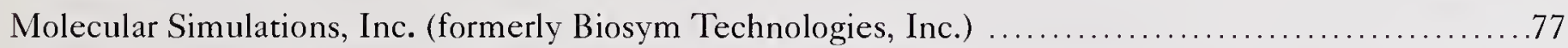

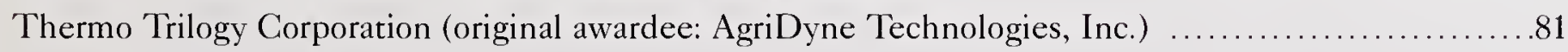

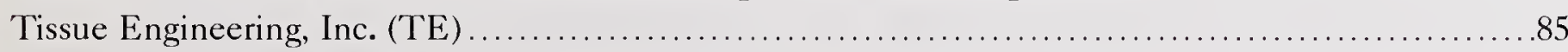

CHAPTER 4: ELECTRONICS/COMPUTER HARDWARE/COMMUNICATIONS $\ldots \ldots \ldots \ldots \ldots \ldots \ldots$

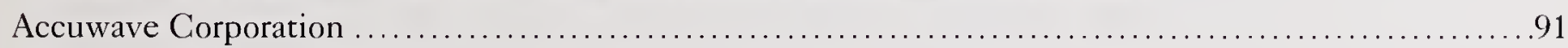

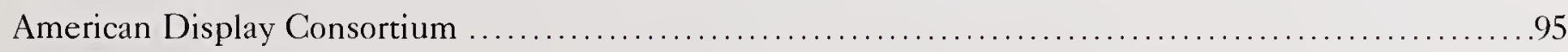

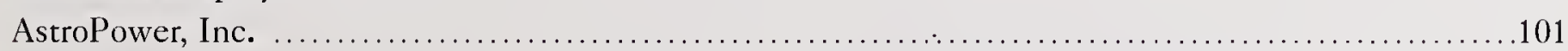

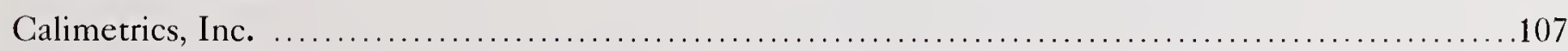

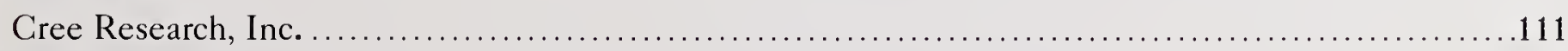

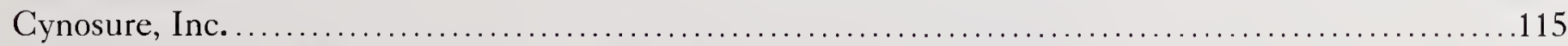

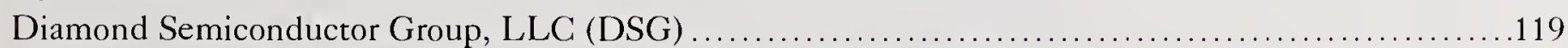

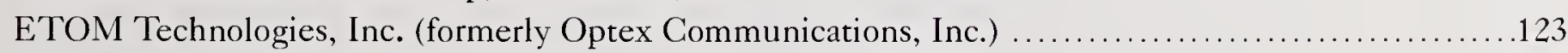

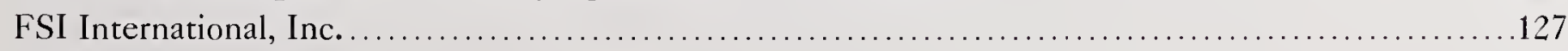

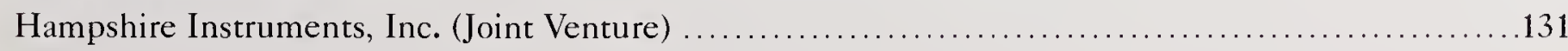




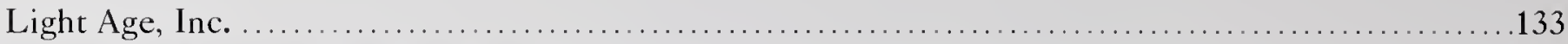

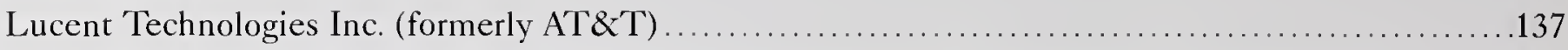

Multi-Film Venture (Joint Venture, formerly the American Scaled-Electronics Corporation) ..........141

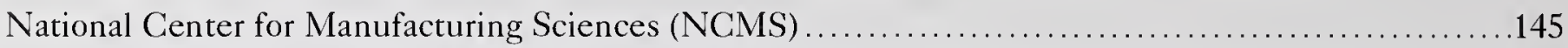

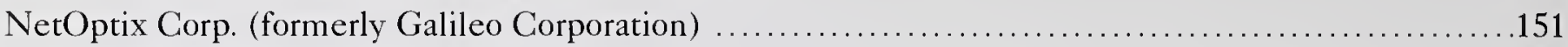

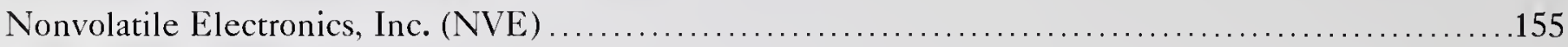

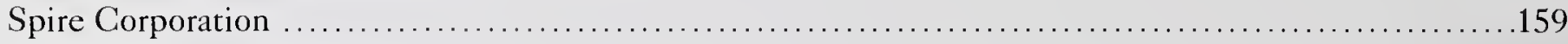

Thomas Electronics, Inc. . . . . . . . . . .

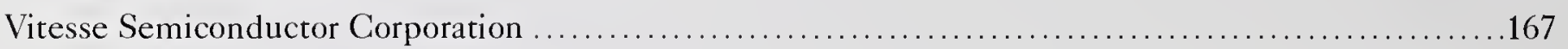

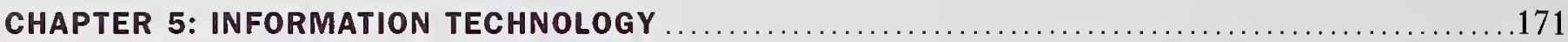

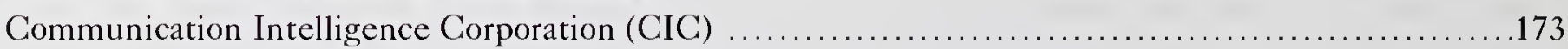

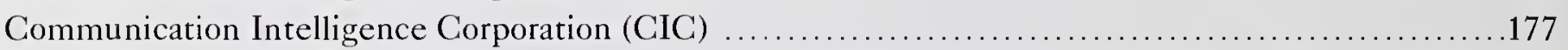

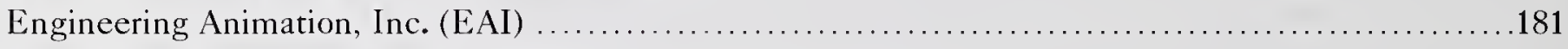

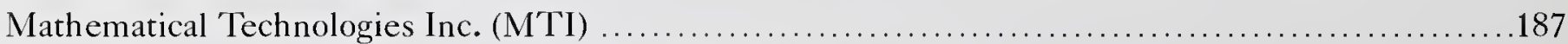

Torrent Systems, Inc. (formerly Applied Parallel Technologies, Inc.) ............................... 191

Union Switch and Signal, Inc. ......................................................... 195

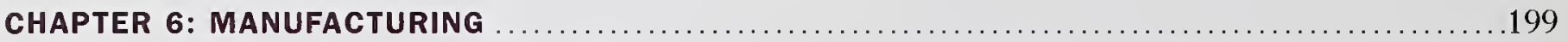

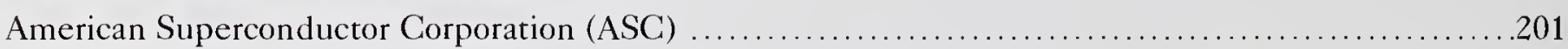

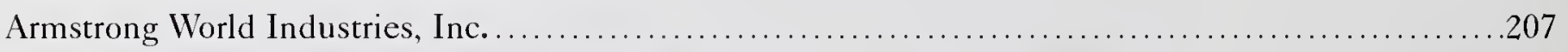

Auto Body Consortium (Joint Venture, formerly 2mm Auto Body Consortium) . ..................211

E.I. du Pont de Nemours and Company .................................................... 215

HelpMate Robotics, Inc. (formerly Transitions Research Corporation) . .........................219

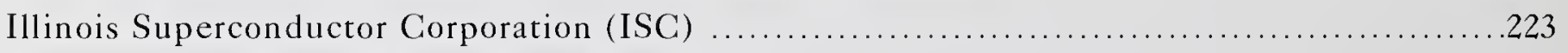

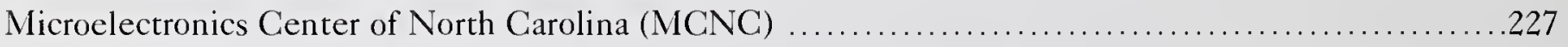

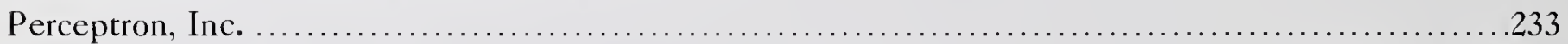

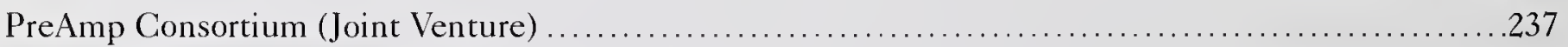

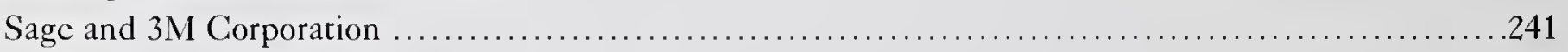

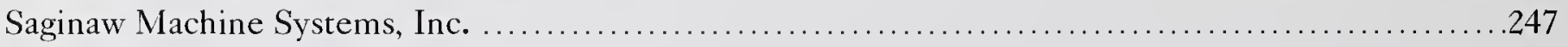

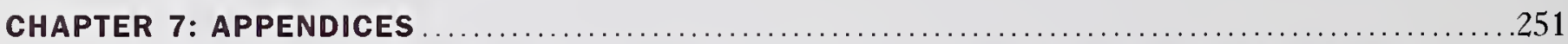

Appendix A: Development of New Knowledge and Early Commercial Products and Processes ........253

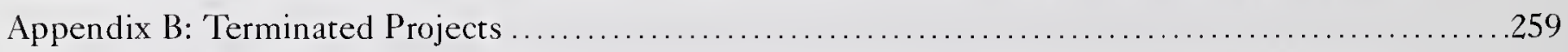

Appendix C: Project Performance Rating System Status Reports - First 50 Completed Projects .......267 


\section{Acknowledgments}

F nies, universities, and other institutions who achieved the technical progress related in this report, and the managers and investors who supported and directed the work. Without their visionary insight, creativity, hard work, and commitment to the innovation process, there would be little to discuss here.

Second, the contributors acknowledge the assistance provided by ATP program managers who assisted the case writers in understanding the projects and the technologies. They provided an invaluable link to the projects and research community.

Finally, the project manager, Darin Boville, acknowledges the collective and individual contributions to this report by the senior author and case writers. Appreciation is extended to Rosalie Ruegg of 'TIA Consulting, in her role as senior author, for compiling and analyzing aggregate statistics, developing composite performance metrics for all the projects, preparing the overview chapter and appendices, editing the new cases, and helping to redesign the report and adding new features. Kathleen Mc'Tigue, the project coordinator, oversaw the entire publication effort, reviewed various drafts, and provided editorial and stylistic input. William Long of Business Performance Associates, the author of the first published status report containing 38 cases which were rolled into this volume, is due thanks. Chris Hansen, Benjamin Fletcher, Kathleen McTigue, Josh Rosenberg, Karen Seeh, Mariah Tanner, Jonathan Tucker, and Michael Walsh — all present or former members of ATP's staff - are deserving of credit for adding a dozen new cases to the report. Linda Sherman and her staff at Linda Sherman Design, Inc., are thanked for their work on the design and layout. ATP and NIST staff who reviewed the draft report are also acknowledged, particularly Stephanie Shipp, Director of the Economic Assessment Office, Jeanne Powell, and Connie Chang.

Finally, appreciation is extended to the reader who takes the time to learn more about the projects and the program. This report is one of several resulting from ATP's ongoing evaluation effort to provide information to the public on the projects it has funded. Other studies are available at ATP's website (www.atp.nist.gov). We welcome your questions and comments.

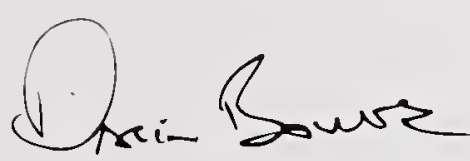

Darin Boville Project Manager Economic Assessment Office 



\section{Executive Summary}

M. capacity to process growing volumes of data, better vehicles, and improved position in the highly competitive international electronics market-these are among the many significant achievements of projects supported by the Advanced Technology Program (ATP) over its first decade. Results from the first 50 completed projects are strong for ATP, with estimated benefits far outweighing the entire cost of ATP to date.

\section{The First 50 Projects}

Policymakers, program administrators, business managers, and others in this country and abroad have eagerly awaited a comprehensive look at results from ATP-funded research projects. This report provides at least partial answers by assessing the first 50 completed projects-approximately 10 percent of the projects funded by the ATP from 1990 through 2000. The performance metrics show how each of the 50 projects performed in terms of new technical knowledge created and disseminated, direct commercialization of new technologies, and overall project effectiveness.

\section{Project Characteristics}

The majority of the first 50 completed projects are singleapplicant projects led by small businesses. Although only 16 percent are joint ventures, 84 percent involved collaborative relationships. Nearly half had close R\&D ties with universities, and more than half formed collaborative arrangements with others to pursue commercialization.

ATP's designated technology area Electronics/Computer Hardware/Communications comprised the largest group of projects, followed by Manufacturing, Biotechnology and Advanced Materials/Chemicals, and, last, Information Technology.

The ATP spent an average of $\$ 1.5$ million per singleapplicant project and an average of $\$ 4.9$ million per jointventure project. Across the 50 projects, the average total cost (ATP plus industry) per project was $\$ 4.2$ million, and the median project length was three years. Together, ATP and industry spent a total of $\$ 208$ million on the 50 projects, with ATP and industry sharing total research costs roughly equally.

\section{ATP's Mission and Operations}

The National Institute of Standards and Technology (NIST), a part of the Department of Commerce's Technology Administration, administers ATP. The ATP and industry share research costs for projects characterized by ambitious scientific and technological goals, and by a strong potential to improve the competitiveness of U.S. businesses and offer substantial economic return to the United States. The ATP seeks to accelerate the development and application of enabling technologies whose benefits will extend well beyond the direct benefits to the ATP award recipients. The focus is on collaborative, multidisciplinary research and on civilian technologies that appear likely to be commercialized in the marketplace with private sector funding once the high technical risks are reduced. The projects funded are selected in rigorous competitions on the basis of their technical and economic merit, as determined by peer review.

Since 1990, ATP has committed funding of $\$ 1.6$ billion in research costs for 522 projects, with companies contributing a similar amount in matching funds for the research, and much more in the post-project periods for follow-on commercialization. More than 1,000 companies, universities, and nonprofit laboratories lead the projects or participate as members of research joint ventures. More than 1,000 additional organizations are involved as subcontractors and informal collaborators. 


\section{Study Scope, Approach, and Organization}

This report comprises one element of ATP's evaluation program, providing a systematic and comprehensive look at a large group of ATP projects, and shedding light on the performance of the program at large.

At the report's core are 50 mini-case studies covering the first-completed projects and investigating the performance of the projects several years after completion.

Chapter 1, an overview, provides aggregate descriptive statistics, and then presents aggregate output statisticsfirst, for knowledge creation/dissemination, and, second, for progress toward commercial goals. It then uses all of the outputs to construct a composite performance score to indicate overall project effectiveness. The result is a fourstar system of ratings, with scores ranging from zero to four stars.

For a group of top-rated, four-star projects, the chapter examines estimates of partial net benefits and considers their implications for the overall success of ATP to date. It also provides summary examples of strong three-star projects.

Because technology development and commercialization take time and are characterized by unexpected breakthroughs and failures, future updates of these projects may alter the findings reported here.

\section{Overall Project Performance}

As expected with projects that tackle difficult research problems, not all of the projects are equally successful. Sixteen percent of the projects are top-rated in terms of overall project performance. Twenty-four percent are in the bottom group in terms of project performance. Sixty percent make up the middle group.

The top performing projects not only solved challenging and significant technical problems, but also made the new technical knowledge available to others, and directly used that knowledge to accelerate commercial use of the technology-three dimensions of performance that figure prominently in achieving the long-run success of the ATP. Among this group, half of the top performing projects received awards for their technical accomplishments from outside organizations, and more than half of the singlecompany project leaders received outside recognition for their business accomplishments. All of the top-rated projects forged collaborative relationships, and all attracted private capital for their follow-on commercialization efforts. Among the single-company projects in the group, all the companies expanded their employment substantially. All had a very strong outlook for continued progress, and, in fact, have continued to make strong progress.
The lowest scoring projects were not without accomplishments. Most performed research and produced patents or technical publications, or gave presentations. But none won awards or showed sustained direct progress toward commercialization, and the outlook for direct commercial action of the award recipients was poor or uncertain at best.

The large mid-scoring group of projects had solidand, in some cases, outstanding- technical accomplishments, and, in some cases, made substantial progress toward commercialization. In other cases, the projects were strong technically, but showed little follow-on commercial progress. In a few cases, the projects produced a technology with commercial strength but did little to disseminate knowledge to others-a public-interest goal of the program. In yet other cases, there was moderate progress in creating and disseminating knowledge and moderate progress toward commercial goals. This middle group, although not featured in the discussion of net benefits in this report, will likely yield substantial net benefits overall.

From a portfolio perspective, the results look strong for ATP: the estimated net benefits attributed to the program from the top-performing projects alone far exceed the entire cost of ATP to date, suggesting that the program is on track to produce a high return for the nation.

In addition, there is evidence that the benefits are extending well beyond those enjoyed by the award recipients. For example, when patients receive superior medical treatments at lower cost, there are spillover benefits. When consumers buy high quality products and do not pay the full value for the additional benefits they receive, there are spillover benefits. When other companies increase their productivity or value added by using ATPfunded technologies, there are spillover benefits. When others acquire and use productively the knowledge from project findings, there are spillover benefits. Several examples illustrate technology developments and commercial progress of this first group of projects. (See box)

\section{Peer Recognition of Technical Achievements}

The knowledge created by each project is the source of its future economic benefit, both for the innovator and for others who acquire the knowledge. Knowledge created by the 50 projects ranges from mathematical algorithms underlying new software tools, to the science of growing human tissue, to new techniques for fabricating high-temperature superconducting devices. Recognition of technical achievements by outside organizations, including trade associations, foundations, and technical journals, indicates 
The National Center of Manufacturing Sciences (NCMS) Ann Arbor, Michigan, led a joint venture to achieve dramatic technical advances in manufacturing printed wiring boards (PWBs). As a foundational component to any larger electronics assembly, PWBs are essential to many other technologies, and are used in the manufacture of products ranging from computers to toys to vehicles. And, advances in PWBs improve the position of U.S. companies in the very competitive world electronics market.

The research team made advances in materials, soldering, imaging, and chemical processes. A new single-ply fiberglass PWB, which allows substantial cost savings, has become the industry standard. New process methods increase dramatically the yield of boards without flaws. A new surface finish protects the board in multiple soldering applications. A new process for attaching thin copper plating to fiberglass reduces processing time and materials cost. A novel interconnect structure has the potential to revolutionize the fabrication of PWBs by enabling much higher wiring density. And, according to an in-depth economic study, because the research effort was collaborative, the new capabilities were developed at a research cost-savings of at least $\$ 35.5$ million.

The various joint-venture participants and their licensees have successfully commercialized component technologies arising from the project, resulting in substantial productivity improvements. Award-winning papers, patents, and new process technology helped convey the information to the hundreds of small companies that make up most of the industry. The president of NCMS credited the project with literally saving what was then the $\$ 7$ billion U.S. PWB industry-a key segment of a $\$ 20$ billion domestic electronic interconnection industry employing over 200,000 people.

Engineering Animation, Inc., Ames, lowa, developed core algorithms that enabled the creation of three-dimensional images from sets of two-dimensional cross-sectional images of human body parts, and animation for selected organs. After an initial failure to commercialize a high-cost system that incorporated the technology, the company adapted the technology for CD-ROMs and print publications in 1995, and then bundled it with medical books. The company went on to leverage its ATP-funded technology in a multiplicity of applications featuring three-dimensional animations which utilize computer visualization and computational dynamics - in sectors as diverse as medical education, entertainment, manufacturing design, transportation, and investigation of the Oklahoma City bombing.

Founded by two professors and two graduate students in 1990, the company had 20 employees at the time of its ATP award. Now its employees number approximately 1,000 , and 1999 sales totaled $\$ 71$ million. The company started receiving recognition from other organizations for its technical progress in 1994, while it was working on the ATP project. It also has received extensive recognition for its business achievements, including acknowledgments by Individual Investor, Business Week, and Forbes ASAP magazines as one of the best technology companies in the country.

Aastrom Biosciences, Inc., Ann Arbor, MI, received an ATP award to develop a process for growing stem cells outside of the body in 1990, when this was a new concept. Aastrom designed, constructed, and validated a desktop-size bioreactor with the capacity to produce large amounts of stem and other cells from small amounts of bone marrow and umbilical cord blood.

The journey from university research to commercializing its AastromReplicall ${ }^{\mathrm{TM}}$ System has been a long path for Aastrom-one that is still underway, despite unabated effort and strong progress. The company has extended the time for its expected commercialization date several times.

An earlier in-depth economic study estimated that the replication system, once implemented, would save approximately $\$ 134$ million (in 1997 dollars) in the costs of providing bone-marrow transplants for cancer treatment, compared to the best alternative technique. The study conservatively attributed about $\$ 47$ million of the cost savings to ATP. The study also identified potential benefits of pain reduction and better patient outcomes from the technology but did not quantify them.

Results from recent clinical trials point to an additional benefit-enabling cancer patients without donors to receive stem cell transplants. Aastrom's replication system can expand tiny amounts of matching cord blood into sufficient quantities for adult transplantation. According to the director of medical oncology at Hackensack University Medical Center, "these results suggest that we may have found a new treatment approach that will enable more patients to receive treatment for this very serious and often fatal disease." According to the American Cancer Society, 30,000 new cases of leukemia are expected in 2000 and approximately 20,000 people will die from the disease this year, making new, more effective treatments of great value to society. 
that others see considerable value in the projects. In 1996 alone, the projects claimed the following awards:

\section{$R \& D$ magazine-an R\&D 100 award to American}

Superconductor, Inc., in Westborough, Massachusetts, for its development of CryoSaver current leads;

Industry Week magazine-one of 25 Technology of the Year Awards to American Superconductor, Inc., for applications of superconducting wire;

Industry Week magazine-one of 25 Technology of the Year Awards to Engineering Animation, Inc., in Ames, Iowa, for its interactive $3 \mathrm{D}$ visualization products used in the manufacturing sector for product development;

Discover magazine-one of 36 finalists for Technology of the Year to HelpMate Robotics, Inc., in Danbury, Connecticut, for the HelpMateRobot used in hospitals;

Microwave \& $R F$ magazine-one of the Top Products of 1996 to Illinois Superconductor, Inc., in Mt. Prospect, Illinois, for cellular phone site filters and superconducting ceramics;

Computerworld magazine-finalist for the Smithsonian Innovator Medal to Molecular Simulations, Inc., in San Diego, California, for advances in software to help scientists simulate and visualize complex molecules.

\section{Dissemination of New Technical Knowledge}

Dissemination of the new knowledge provides spillover benefits to other companies who, in turn, may use the knowledge to increase and broaden the national benefits from the ATP investment. Dissemination takes place in several ways. Patents, publications, and presentations provide a convenient avenue for others to acquire the knowledge. All but 1 of the 50 projects produced one or more of these outputs.

The extensive collaborative activities of the projects have provided another avenue for the spread of knowledge. Eighty-four percent of these projects entailed collaborations, including other companies, universities, national laboratories, nonprofit consortia, and other organizations and individuals.

Release of new products to the market also disseminates new technical knowledge. Others can use the products and they may also attempt to discover how the products work by observation, testing, and reverse engineering. More than 60 percent of the projects placed commercial products or processes in the marketplace, providing others with the ability to collect information about the new technologies.

Workshops, websites, and evaluation studies also facilitate information flows. The ATP has organized and spon- sored numerous public workshops over the years, in which the companies have presented nonconfidential aspects of their ATP-funded research and engaged in open discussions. The ATP has also made project information available on its website (<www.atp.nist>). Evaluation reports, such as this one, are an additional source of information for the public.

\section{Commercial Progress in Applying the New Technologies}

If the new knowledge is to yield economic benefits to the nation, the award recipients, their collaborators, or the companies who acquire that knowledge must put it to use. A second focus of the study, therefore, is on the commercialization progress of the award recipients, and in some cases their direct collaborators. The study does not include commercialization activities of companies who acquire project knowledge indirectly, although these activities may be as important or more important than those of the award recipients and their collaborators.

Sixty-six percent of the 50 projects had one or more products or processes in the market when they were assessed, and another 14 percent expected to shortly. Thus, despite the difficulty of moving from the research stage to commercialization, companies in 80 percent of the projects either sold product, or used or licensed to others process improvements stemming from their research, or they were about to do so at the time they were contacted by study analysts. Whether or not widespread diffusion of a technology results from these commercial activities, it is highly significant that products and processes are actually on the market.

An indicator that a small research-oriented company is on the path toward commercialization is company growth. A recent look at Fortune's "Fastest Growing 100 Companies" list found 2 of the 31 then-small ATP-funded companies on the list.

Capitalized value of some of the ATP-funded companies has increased by hundreds of millions of dollars. Nearly a fifth grew in employment by more than 500 percent from the beginning of the project to several years after the project had completed, and 61 percent grew in employment by more than 100 percent. Several of the companies that were small when they received the ATP award have grown out of that size category. Nineteen of the 31 small companies at least doubled in size; 4 companies grew more than 1,000 percent.

Not all the small companies grew-a little more than one-fifth experienced no change or decreases in staff and not all kept their momentum going beyond the period of ATP funding. But, as a group, the small companies fund- 
ed by ATP grew rapidly as they parlayed their new technical capabilities into business opportunities.

The study results point up the importance of the ATP's two-path approach to realizing national benefits. First, the direct commercialization effort by the award recipient provides a path for the accelerated use of the technology by U.S. companies. Second, the knowledge created by a project may disseminate to others who may use it for economic benefit whether the award recipients do or not. One path may provide an avenue for benefits when the other does not, and both paths may yield larger, accelerated benefits compared to having only a single route to impact.

\section{What Difference Did ATP Make?}

The focus of evaluation is not just on the performance of projects, but on the difference ATP made to the outcomes. The results of the more detailed studies cited here emphasize effects attributed to ATP. In addition, the mini-cases attempt to establish retrospectively the impact that the ATP had on project outcomes.

For 44 of the 50 projects responding to the question of what difference ATP made, 59 percent would not have been undertaken at all without ATP funding, and 41 percent would have begun at a later date or proceeded at a slower pace. (Personnel changes, severe company financial distress, or lack of clarity in responses to interview questions made it impossible to include 6 of the 50 projects in this tabulation.)

Other effects attributed to the ATP by the leaders of these projects include the fostering of collaborative arrangements for research and commercialization activities and the ability to raise additional capital.

Examples of company comments about the role of the ATP include:

Torrent Systems, Inc.- - It is doubtful that the technology could have been successfully developed at all; venture capital funding had been sought but was unavailable.

AlliedSignal, Inc.-The company would have needed another five years to reach this stage of development.

Diamond Semiconductor Group, LLC_-The company would have been unable to do the research or survive as a company; its only other alternative then was to become part of a foreign company.

Integra LifeSciences Corporation-Without ATP I don't know that we could have proceeded. We would be at least five years or more behind where we are.
Nonvolatile Electronics, Inc.-ATP funding enabled the project to be done, prevented the company from failing, and improved the company's ability to attract capital from other sources.

FSI International, Inc.-- The award enabled FSI to collaborate with Massachusetts Institute of Technology researchers.

Light Age, Inc.-The visibility generated by winning the ATP award helped Light Age establish agreements with research partners and, coupled with the success of the ATP project, enabled it to secure additional funding from private investors.

Thomas Electronics, Inc.-Without the ATP award, the company would have struggled along with its conventional CRT technology and would have stood virtually no chance of competing with other display-component suppliers, all of which are foreign companies. 



\section{Introduction}

M. Advanced Technology Program (ATP) since 1990, requesting nearly $\$ 10$ billion in research funding. Approximately 12 percent of the proposals have been selected by the ATP for funding, for a total of 522 funded projects with 1,162 participants and approximately an equal number of subcontractors, through 2000. A growing number of the multiyear projects funded are now completed or nearing completion. This study focuses on the first 50 completed projects, and, to a lesser extent, on 16 projects terminated prior to completion during the same period.

\section{ATP: A Partnership with Industry}

The ATP attracts challenging, visionary projects with the potential to develop the technological foundations of new and improved products, processes, and even industries. The ATP partners with industry on this research, fostering collaborative efforts and sharing costs to bring down high technical risks and accelerate technology development and application. These are projects that industry in many cases will not undertake without ATP support, or will not develop in a timely manner when timing is critical in the highly competitive global market. The program funds only research, not product development. The ATP is managed by the National Institute of Standards and Technology, an agency of the Commerce Department's Technology Administration.

A'TP awards are made on the basis of a rigorous competitive review which considers the scientific and technical merit of each proposal and its potential benefits to the U.S. economy. The ATP issues a proposal preparation kit that presents and explains the selection criteria to prospective applicants and provides guidance on preparing proposals. ${ }^{1}$ U.S. businesses conceive, plan, propose, and lead the projects. Government scientists and engineers who are expert in the relevant technology fields review all proposals for their technical merit. Business, industry, and economic experts review the proposals to judge their potential to deliver broadly based economic benefits to the nation including large benefits extending beyond the innovator (the award recipient).

The ATP delivers benefits to the nation along two pathways: 1) a direct path by which the U.S. award recipient or innovator directly pursues commercialization of the newly developed technologies; and 2) an indirect path which relies on knowledge transfer from the innovator to others who in turn may use the knowledge for economic benefit. Either path may yield spillover benefits. The ATP looks to the direct path as a way to accelerate application of the technology by U.S. businesses. It looks to the indirect path as a means of achieving additional benefits, or benefits even if the award recipient fails to continue. 'The A'TP's two-path approach to realizing national benefits offers advantages: one path may provide an avenue for benefits when the other does not, and both paths together may yield larger, accelerated benefits as compared to having a single route to impact.

\section{Project Evaluation}

The ATP, like other federal programs, is required by law to report on its performance. ${ }^{2}$ The ATP established its evaluation program soon after it began, even before evaluation was widely required by Congress. The Economic Assessment Office (EAO) of ATP plans and coordinates

\footnotetext{
${ }^{1}$ The current edition of the kit and other program materials may be obtained on ATP's website (<www.atp.nist.gov>), by e-mail (atp@nist.gov), by phone (1-800-ATP-Fund or 1-800-287-3863), or by mail (ATP, NIST, 100 Bureau Drive, Stop 4701, Gaithersburg, MD 20899-4701).
} 
the evaluation of funded projects. It is assisted in this effort by leading university and consulting economists and others experienced in evaluation.

Performance is measured against the program's legislated mission. Emphasis is placed on attempting to measure benefits that accrue not only to the direct award recipients, but also to a broader population, i.e., spillover benefits. This emphasis reflects the fact the public funding covers part of the costs of these projects, and, therefore, a relevant question is how the broader public benefits from the expenditure.

This report comprises one element of the EAO's multi-element evaluation plan. The purpose of this report is to provide an interim assessment of the status of ATPfunded projects several years after they are completed. Although the ultimate success of the ATP depends on the long-run impacts of the entire portfolio of ATP projects, the performance-to-date of this partial portfolio of 50 projects provides partial answers. This study addresses the question of what the public investment of $\$ 104$ million in the 50 projects has produced several years after completion of the research and what the outlook is for continued progress.

It utilizes another element of the ATP's larger evaluation program: detailed economic case studies of selected projects. It draws from these more in-depth case studies, where they exist, to amplify the actual and prospective economic impacts of the completed projects. Other evaluation activities of the ATP include database development (i.e., a tracking of project developments through the life of the project and into the post-project period); surveys; statistical and econometric studies; model development; and special issue studies. ${ }^{3}$

\section{Study Approach}

From the moment that ATP funded its first group of 11 projects in the 1990 competition, program administrators, the administration, Congress, technology policymakers, industry, and others in this country and abroad were keenly interested in the outcome. But technology development and commercialization are lengthy processes, and it takes time to produce results.
Now, as the program completes its first decade of operation, there are a growing number of projects that have completed their ATP-funded research and moved into the post-project period. This group of 50 projects makes it possible to look at the projects several years after the ATP-funded research has been completed-allowing sufficient time for knowledge to be disseminated and progress to be made toward commercial goals. The larger group of projects makes it possible to form a portfolio view, compile aggregate statistics, and analyze the results in terms of their implications for overall program success.

A first step was taken toward this goal with the publication of a report in 1999 on the first 38-completed projects. ${ }^{4}$ This report takes the next step, by extending coverage to a total of 50 projects and adding consolidated performance metrics. It draws from and builds on the previous report.

At the core of this study are 50 mini-case studies covering each of the completed projects. Each of these briefly tells the project story, recounting its goals and challenges, describing the innovators and their respective roles, and assessing progress to date and the future outlook. Photographs illustrate many of the projects.

Although the particulars vary for each project, certain types of data are systematically collected for all of them. Consistent with A'TP's mission, the evaluation focuses on collecting data related to the following dimensions of performance:

- Knowledge creation and dissemination, which is assessed using the following criteria: recognition by other organizations of a project's technical accomplishments; numbers of patents filed and granted; citations of patents by others; publications and presentations; collaborative relationships; and knowledge embodied in and disseminated through new products and processes.

- Commercialization progress, which is gauged in terms of the attraction of additional capital for continued pursuit of project goals, including resources provided by collaborative partners; entry into the market with products and services; employment changes at the

\footnotetext{
${ }^{2}$ The Government Performance and Results Act (GPRA) is a legislative framework for requiring federal agencies to set strategic goals, measure performance, and report on the degree to which goals are met. An overview of the GPRA is provided in Appendix 1 of the General Accounting Office Executive Guide, Effectively Implementing the Government Performance and Results Act, GAO, Washington, D.C., GGD-96-118, 1996.

${ }^{3}$ For a description of the ATP evaluation plan, see Ruegg, "Assessment of the ATP," The Advanced Technology Program, Challenges and Opportunities, Board on Science, Technology, and Economic Policy, National Research Council, Washington, D.C., National Academy Press, 1999, pp. 71-81. Published economic studies of the ATP are available at the ATP website (see above), and can be requested by calling (301) 975-4332.

${ }^{4}$ See William F. Long's report, Performance of Completed Projects, Status Report Number 1, NIST SP 950-1, National Institute of Standards and Technology, Washington, D.C., March 1999.
} 
small companies leading projects and other indicators of their growth; awards bestowed by other organizations for business accomplishments of project leaders; and the analyst's assessment of future outlook for the technology based on all the other information.

The approach is to provide in an overview chapter the aggregate statistics of interest across the set of 50 projects, such as the total number of patents and the percentage of projects whose technologies have been commercialized. In addition, the aggregate statistics are combined to produce composite project metrics for overall performance. The composite performance scores allow one to see at a glance the robustness of a project's progress towards its goals. Underlying the simple scores is a wealth of data.

\section{Sources of Information}

Data for the 50 projects were collected from many sources: ATP project records; telephone interviews with company representatives; interviews with A'TP project managers; company websites; the U.S. Patent and Trademark Office; in-depth project studies conducted by other analysts; academic, trade and business literature; news reports; filings at the Securities and Exchange Commission; a previous study of the first 38 completed projects; and business research services, such as Dun and Bradstreet, Hoover's Online, Industry Network, and Corp'Tech. Each one of the individual project write-ups was reviewed for accuracy by the project's lead company and ATP staff.

\section{Study Limitations and Future Directions}

The 50 projects are divided into two groups: 1) the data for the first 38 projects were collected mainly between 1997 and late 1998, and 2) the data for the next 12 projects were collected during 1999 and early 2000.5 Since developments continue to unfold for most of these projects, the output measures for the earlier set of 38 may have changed significantly since the data were collected. ${ }^{6}$ Even outputs for the later set of 12 projects may have changed since the data were collected. ${ }^{7}$

The cases provide a snapshot of progress several years after the completion of the ATP-funded projects. The cases, although undertaken at different calendar dates, are conducted within about the same interval of time after ATP funding ended. Yet, different points in each technol- ogy's life cycle may be captured, depending on the technology area. Information technology projects, for example, may be expected to be further along than advanced materials and chemical projects. Examined at a later time, there may be less (or more) difference in the accomplishments among projects in different technology areas.

This study tracks outputs leading to knowledge dissemination but it does not assess the actual commercialization efforts by others who acquire the knowledge. The tracking of commercialization efforts is limited to the direct path of impact (i.e., commercialization by the award recipients or innovators).

Future studies may add mini-cases for additional completed projects to this group of 50 , which would also be conducted several years after project completion. Such an extension would provide a more comprehensive view of progress made by projects at a comparable interval in time after the ATP-funded research has been completed. Additional future studies may also update these studies by looking at the projects farther out in time. An extension of the study further into the post-project period would allow for a fuller assessment of the value in the use of products and processes commercialized by the award recipients, and of the benefits resulting from the use of the knowledge (developed during the project) by others.

\section{“Completed" and "Terminated" Projects Defined}

Projects do not necessarily finish in the order funded. For one thing, they have different lengths, ranging from approximately two years to no more than five years. For another, they are required to file a final report with the ATP and have financial and other paperwork completed before project closeout. The financial closeout is done through the National Institute for Standards and Technology (NIST) Grants Office, which notifies the ATP that it considers the project completed. This study assesses the first 50 projects the Grants Office declared "completed."

During the time the first 50 were in progress, another 16 projects were stopped short of completion. Some of these were announced as award winners but never officially started. Other projects got off the ground but were closed for various reasons with a substantial amount of the technical work still unfinished. These "terminated" projects are

\footnotetext{
${ }^{5}$ William Long collected the data for the first 38. Jonathan Tucker, Chris Hansen, Josh Rosenberg, Jon Dryfus, Benjamin Fletcher, Kathleen McTigue, Michael Walsh, Mariah Tanner, and Karen Seeh collected the data for the next 12, supplemented by data collected by Rosalie Ruegg.
}

"In several cases, more recent information is brought into the report to determine if the designated "top performing projects" have continued to make progress.

${ }^{7}$ Ibid. 
assessed according to the principal reasons they stopped before completion. They are treated in Appendix B.

While the terminated projects are generally regarded as unsuccessful, some produced potentially useful outputs. Appendix B illustrates a project that made an attempt to achieve its goals, only to be terminated prior to completion. It is reported in a level of detail and style similar to that provided for the 50 completed projects.

\section{Report Organization}

Chapter 1 provides a summary overview of the performance of the 50 completed projects as a group. It identifies some major outputs that appear useful as indicators of the degree of project success, and it uses these outputs in a prototype project performance rating system. A preview also notes some of the broad-based benefits that this portfolio of projects is producing and likely to produce. For additional background, the make-up of the portfolio of projects in terms of technologies, organizational structure, company size, and other features is provided.

The individual project reports presented in Chapters 2 through 6 highlight major accomplishments and the outlook for continued progress. A detailed account of the project under review is given, with attention to technical and commercial goals and achievements, information about technology diffusion, and views about the role played by ATP funding. A performance rating is assigned to each project based on a four-star scoring system. The rating depends on the accomplishments of the project in creating and disseminating new scientific and technical knowledge and in making progress toward generating commercial benefits, as well as the outlook for continued progress.

Two appendices provide supporting information. Appendix A provides a listing of technical and commercial achievements of each completed project. Appendix B provides a discussion and assessment of 16 terminated projects, together with a detailed case that illustrates how a terminated project may yield outputs of potential benefit. 
ADVANCED TECHNOLOGY PROGRAM

CHAPTER 1

Overview 



\section{Project Characteristics}

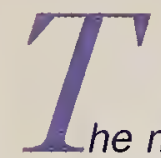

he majority of the first 50 completed projects were led by small businesses, who submitted proposals to ATP as single-company applicants. Almost all of them had collaborative relationships with other firms and universities. Nearly all were funded in ATP's General Competitions. More than one-third of the technologies were classified as "electronics, computer hardware, or communications." ATP and industry shared the \$208 million in total project costs about equally.

\section{Single Applicants and Joint Ventures}

Eighty-four percent of the 50 projects were "single-applicant projects." This means that a single company proposed the project, and that it was subject to an upper limit on ATP funding of $\$ 2$ million and a time limit of 3 years.

The dominance of single-applicant projects occurs for two reasons. First, single-applicant projects make up the majority of all projects. Second, the constraint on singleapplicant project length means they end sooner than most joint ventures.

Sixteen percent of the 50 projects were joint ventures. Each of these projects had a minimum of two for-profit companies sharing research and costs. Typically, the jointventure membership included other organizations, such as other for-profit companies, universities, and nonprofit laboratories. These projects, free of the funding constraint, tended to take on larger problems for longer periods of time.

\section{Project Leaders}

The high percentage of small companies tends to result from a high percentage of single-applicant projects, most of which are led by small businesses. Thirty-one of the 42 single-applicant projects, among the 50 , were led by small businesses. "Small" is defined according to the Small Business Administration's definition and includes companies having fewer than 500 employees.
Medium-sized companies led 3 of the 42 single-applicant projects. Large companies-defined as Fortune 500 or equivalent firms--led 6. Nonprofit institutions led 2. ${ }^{8}$

Of the 8 joint-venture projects, small companies led half of them. A large company led 1 . Industry consortia led the other 3 .

\section{A Variety of Technologies}

The 50 completed projects fall into five different technology areas used by ATP for classification purposes. Figure 1 , the lower of each pair of bars, shows the percentages of completed projects by technology area. The highest concentration, with 19 projects and 38 percent of the total, is in Electronics/Computer Hardware/Communications. Manufacturing follows with 11 projects, comprising 22 percent. Biotechnology and Advanced Materials/Chemicals each have 7 projects or 14 percent each. The lowest concentration is in Information Technology, with 6 projects or 12 percent.

For comparison purposes, Figure 1.1, the upper of each pair of bars, shows the distribution across the same five technology areas for 468 projects awarded through 1999. For the portfolio of ATP projects, Information Technology makes up the largest share of projects, followed by Advanced Materials/Chemicals.

\footnotetext{
${ }^{8}$ Nonprofit institutes were eligible for funding as single applicants in the first two years of the program, before Congress changed the provisions to make them ineligible. Two nonprofits, Michigan Molecular Institute and Microelectronics Center of North Carolina, received awards in ATP's second competition.
} 
Figure 1.1 Distribution of Projects by Technology Area

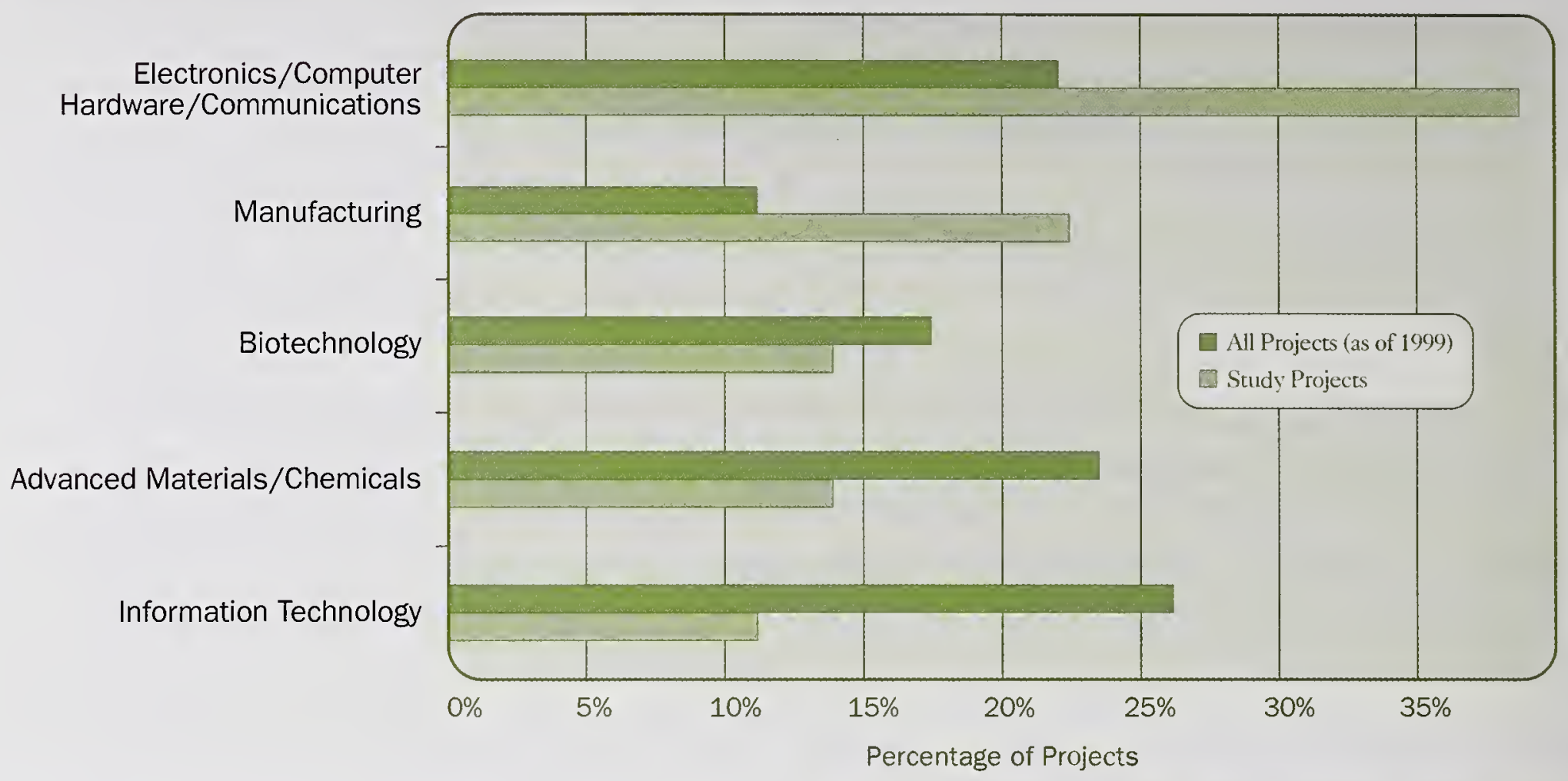

Projects classified as Electronics/Computer Hardware/ Communications and Manufacturing are more strongly represented in the set of 50 completed projects than in the portfolio of all ATP projects, while the other three categories-particularly Information Technology-are underrepresented. Differences in the technology make-up of the 50 study projects and the larger ATP portfolio of projects largely reflect the changing composition of applicants and awardees over time. Nearly all of the 50 first-completed projects come from ATP's general competitions that were open to all technologies. A substantial part of ATP's total portfolio comes from the focused program competitions that were held from 1994 through 1998. These competitions funded technologies in selected areas of focus.

Since successful information technology projects tend to progress faster than some of the other technology areas, it is possible that a set of projects more reflective of ATP's overall technology distribution would show more progress than the current set of 50 .

\section{Collaborative Activity}

Although only 16 percent of the 50 projects were joint ventures, 84 percent had collaborative arrangements. As shown in Table 1 , nearly half the 50 had close R\&D ties with universities, and more than half the projects formed collaborative arrangements to pursue commercialization.?

\section{Table 1. Collaborative Activity}

Type of Collaboration

Number of Projects Percentage

Collaborating on R\&D with other companies or nonuniversity organizations

Close R\&D ties with universities

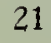
$42 \%$

Collaborating on R\&D with other companies or nonuniversity organizations OR close R\&D ties with universities

Collaborating on commercialization with other organizations

Collaborating in one or more of the above ways

42 $84 \%$

\section{Duration of Projects}

The median length for the 50 projects was three years. Half of the projects lasted 33 to 36 months. Another group clustered around the two-year mark. Five joint-venture projects lasted longer than 36 months.

\section{Costs of the Projects}

As shown in Table 2, ATP and industry together spent a total of $\$ 208$ million on the 50 projects. They shared almost equally in the costs. The ATP spent an average

\footnotetext{
${ }^{9}$ This assessment of collaborative relationships likely understates the number because it focused on the project's lead organization and probably missed some of the informal collaborative relationships of other participants.
} 
of $\$ 1.5$ million per single-applicant project and an average of $\$ 4.9$ million per joint-venture project. Across the 50 projects, the average total cost (ATP plus industry) per project was $\$ 4.2$ million. (Funding amounts and cost-share percentages are displayed project by project in Chapters 2 throough 6).

Table 2. ATP Funding, Industry Cost Share, and Total Costs of 50 Completed Projects

\begin{tabular}{lccc}
$\begin{array}{l}\text { Type of } \\
\text { Project }\end{array}$ & $\begin{array}{c}\text { Single-Applicant } \\
\text { Projects }\end{array}$ & $\begin{array}{c}\text { Joint-Venture } \\
\text { Projects }\end{array}$ & $\begin{array}{c}\text { All Completed } \\
\text { Projects }\end{array}$ \\
$\begin{array}{l}\text { ATP Funding } \\
\text { (\$ Millions) }\end{array}$ & 64.5 & 39.5 & 104.0 \\
$\begin{array}{l}\text { Industry Cost } \\
\text { Share(\$ Millions) }\end{array}$ & 57.0 & 47.0 & 104.0 \\
$\begin{array}{l}\text { Total Project Costs } \\
\text { (\$ Millions) }\end{array}$ & 121.5 & 86.5 & 208.0 \\
$\begin{array}{l}\text { ATP Share of } \\
\text { Costs (Percent) }\end{array}$ & 53 & 46 & 50 \\
$\begin{array}{l}\text { Industry Share of } \\
\text { Costs (Percent) }\end{array}$ & 47 & 54 & 50 \\
\hline
\end{tabular}

Most of the single-applicant projects had total research costs under $\$ 3$ million, and an ATP share between $\$ 1$ and $\$ 2$ million. Twelve percent had total costs in excess of $\$ 5$ million. The ATP funded 53 percent of the total cost of the 42 single-applicant projects.

Nearly half of the joint ventures received $\$ 2$ to $\$ 5$ million from ATP, and all but one received less than $\$ 10$ million. Nearly three-quarters of the projects had total costs (ATP plus industry) between $\$ 5$ and $\$ 20$ million. Joint ventures, which comprised only 16 percent of the total number of projects, accounted for 38 percent of total A'TP funding. 



\section{Gains in Technical Knowledge}

major goal of ATP is to build the nation's scientific and technical knowledge base. Each of the 50 completed ATP projects targeted a number of specific technical goals designed to achieve a new or better way of doing things. The knowledge created by each project is the source of its future economic benefit, both for the innovator and for others who acquire the knowledge. It is a good starting place for assessing completed projects.

\section{A Host of New Technologies and Knowledge Gains}

Knowledge gains by the 50 projects range from mathematical algorithms underlying new software tools, to the science of growing human tissue, to new techniques for fabricating high-temperature superconducting devices, to new chemical formulations. Advances were made in each of the five technology areas.

The technologies developed in the 50 projects are listed in Tables A1-A5 of Appendix A, column B. The set of tables provides the reader with a convenient, quick reference to the entire range of technologies.

The entries are arranged according to the five technology areas shown in Figure 1.1 and used to divide Chapters 2 through 6 . It should be noted, however, that most of these projects and the knowledge developed in them are not easy to classify. Most projects entail a mixture of technologies and interdisciplinary know-how.

Even those projects that were not fully successful in achieving all of their research goals, or those that have not been followed by strong progress in commercialization, have achieved knowledge gains. Moreover, some of the projects carried out by companies that have since ceased operations or stopped work in the technology area yielded knowledge, as indicated by the presence of publications and patents. In these cases the direct market routes of diffusion of knowledge gains by the innovators are likely lost, but the indirect routes remain.

\section{Of What Significance are the Technical Advances?}

Apart from looking downstream at long-term outcomes, measuring the significance of technical advances is challenging. A short-run approach taken here is to look at awards presented by other organizations in recognition of technical achievements.

A total of 15 awards for technical accomplishments were made to participants for achievements related to the ATP-funded projects. Participants in 9 of the 50 projects received awards for their technical achievements. Participants in 4 of the projects received multiple awards. Table 3 lists the awards granted recognizing technical accomplishments. 


\section{Table 3. Outside Recognition of Technical Achievements of the First 50 Completed Projects}

\begin{tabular}{|c|c|c|c|}
\hline Project Awardee & Year & Awarding Organization & Award \\
\hline American Superconductor & 1996 & R\&̊D Magazine & $\begin{array}{l}\text { One of the } 100 \text { most important } \\
\text { innovations of the year. }\end{array}$ \\
\hline American Superconductor & 1996 & Industry Week magazine & Technology of the Year award. \\
\hline Communication Intelligence $\# 1$ & 1997 & Arthritis Foundation & $\begin{array}{l}\text { "Ease-of-Use Seal of Com- } \\
\text { mendation" for the develop } \\
\text { ment of natural handwriting } \\
\text { technology, for use by disabled } \\
\text { people who have trouble with } \\
\text { keyboard entry. }\end{array}$ \\
\hline DuPont & 1993 & Microreave $\&$ Rf magazine & $\begin{array}{l}\text { One of the Top Products of } \\
\text { 1993, for high-temperature } \\
\text { superconductivity component } \\
\text { technology. }\end{array}$ \\
\hline Engineering Animation & 1994 & Computerworld magazine & $\begin{array}{l}\text { Smithsonian Award, for the use of } \\
\text { information technology in the field } \\
\text { of medicine. }\end{array}$ \\
\hline Engineering Animation & 1995 & Association of Medical Illustrators & $\begin{array}{l}\text { Association of Medical Illustrators } \\
\text { Award of Excellence in Animation }\end{array}$ \\
\hline Engineering Animation & 1995 & International ANNIE Awards & $\begin{array}{l}\text { Finalist, received together with Walk } \\
\text { Disney, for best animations in the } \\
\text { film industry. }\end{array}$ \\
\hline Engineering Animation & 1996 & Industry Week magazine & $\begin{array}{l}\text { One of the } 25 \text { Technologies of the } \\
\text { Year, for interactive } 3 \mathrm{D} \text { visualization } \\
\text { and dynamics software used for } \\
\text { product development. }\end{array}$ \\
\hline HelpMate Robotics & 1996 & Discover magazine & $\begin{array}{l}\text { One of } 36 \text { finalists for Technology } \\
\text { of the Year, for the HelpMate robot } \\
\text { used in hospitals. }\end{array}$ \\
\hline HelpMate Robotics & 1997 & $\begin{array}{l}\text { Science Technology Foundation } \\
\text { of Japan }\end{array}$ & $\begin{array}{l}\text { Japan Prize, to CEO Joseph } \\
\text { Engelberger, for "systems engineering } \\
\text { for an artifactual environment." }\end{array}$ \\
\hline Illinois Superconductor & 1996 & Microwave $\& R F$ magazine & $\begin{array}{l}\text { One of the Top Products of } 1996 \text {, } \\
\text { for cellular phone site filters and } \\
\text { superconducting ceramics. }\end{array}$ \\
\hline Illinois Superconductor & 1997 & American Ceramic Society & $\begin{array}{l}\text { Corporate Technical Achievement } \\
\text { Award. }\end{array}$ \\
\hline Integra LifeSciences ${ }^{10}$ & 1999 & $\begin{array}{l}\text { New Jersey Research and } \\
\text { Development Council }\end{array}$ & Thomas Alvin Edison Award \\
\hline Molecular Simulations & 1996 & Computerworld magazine & $\begin{array}{l}\text { Finalist for Smithsonian Award, } \\
\text { the } 1996 \text { Innovator Medal. }\end{array}$ \\
\hline NCMS & 1994 & $\begin{array}{l}\text { Institute for Interconnecting \& } \\
\text { Packaging Electronic Circuits }\end{array}$ & Best Paper of Conference Awards \\
\hline
\end{tabular}

\footnotetext{
${ }^{10}$ The award went to Dr. Kohn of Rutgers University for his collaborative work with Integra on the project.
} 
PART 3

\section{Dissemination of Knowledge}

f knowledge from the projects is disseminated-either through products and processes commercialized by the innovators, or through publications, patents, and other modes of knowledge transfer-it may benefit other producers in the economy and, subsequently, consumers. The resulting national benefits may go far beyond the returns to the innovating firms and the benefits to their customers.

\section{Multiple Ways of Disseminating Knowledge}

New knowledge developed in a project can be diffused in a variety of ways. One way is through the observation and reverse engineering of the new goods or services produced directly by the innovators and their partners. Other ways, discussed here, are patents filed and granted by the U.S. Patent and Trademark Office (USPTO) and cited by others; interactions among research partners, suppliers, customers and others and movement of project staff to other organizations; preparation of technical papers that are published or presented at conferences; distribution of nonproprietary project descriptions by government funding agencies; and project-related workshops and meetings.

These pathways allow others to obtain the fruits of $R \& D$ without having to pay the full cost of it. When the technology is particularly enabling-in the sense of providing radically new ways of doing things, improving the technical bases for entire industry sectors, or being useful in many, diverse areas of application-the spillover benefits to others are likely to be particularly large. ${ }^{.1}$

\section{Balancing Intellectual Property Protection and Knowledge Dissemination}

The ATP encourages broad dissemination of knowledge produced in ATP-funded projects because it increases the number of potential users of the knowledge, and, therefore, may increase national benefits. But, at the same time, ATP does not force innovating companies to compromise their ability and willingness to pursue early commercial applications of the technology by giving away all of their intellectual property. After all, these companies, which contribute a substantial share of the costs, have agreed to tackle difficult research barriers and to take the technology to the marketplace as rapidly as possible.

Thus, it is not surprising that the amount of knowledge dissemination varies among ATP projects. Most of the projects display some forms of deliberate knowledge dissemination, such as publishing scientific papers and giving presentations. Most projects also display considerable unintended knowledge dissemination: for example, as others acquire the innovating company, as its scientists move and work among other companies and universities, and as a myriad of formal and informal discussions occur.

\section{Public Disclosure of Patent Filing Information}

When applying for a patent to protect intellectual property, an inventor must explicitly describe the invention. Because patent law requires that the invention be both novel and useful, the inventor must demonstrate that the invention is essentially different from any other invention and must describe how it can be used. When the USPTO grants a patent, the full application text describing how the invention may be used and how it is related to other technologies is put into the public record and becomes a

\footnotetext{
${ }^{11}$ The generation of spillover benefits, or positive externalities, from technological advancement is an important argument for public support of enabling technologies.
} 
medium through which knowledge is transferred to others. ${ }^{12}$ Hence, patents serve to disseminate knowledge.

At the same time, patent data are not perfect signals of knowledge creation and dissemination. ${ }^{13}$ The decision to seek patent protection for intellectual property is influenced by many factors, including the ease with which others can copy the property's intellectual content and the difficulty of defending the patent position from infringers. Some companies may decide that patent protection is not worth its expense, or that a strategy of trade secrets and speed to market is a more effective strategy. Or, patents may be filed as the basic ideas are forming, and trade secrets used in later stages. Furthermore, the importance of patents as a strategy varies among technology areas, and figures more strongly in electronics and manufacturing, for example, than in computer software. As a consequence,

\section{Figure 1.2 Distribution of Projects by Number of Patents Filed}

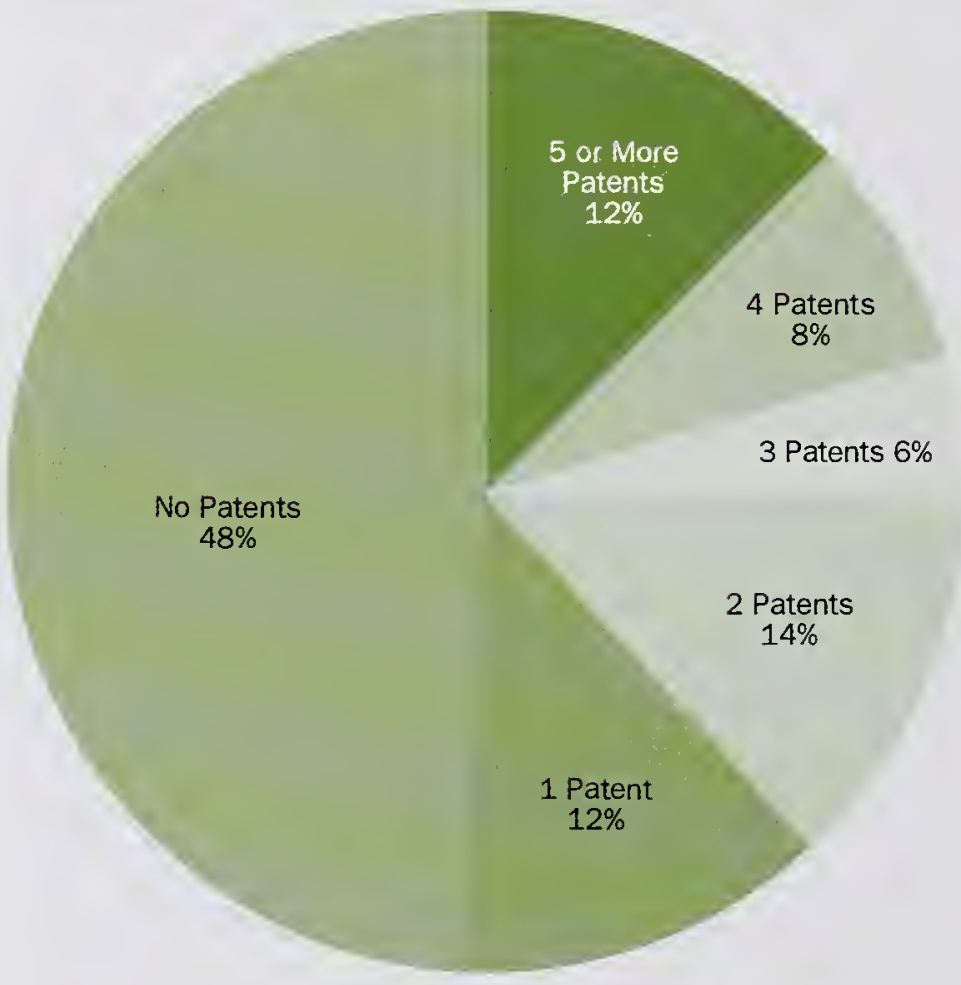

the absence of a patent does not mean that intellectual property was not created. But the presence of a patent is a signal that it was created.

Of the 50 projects, 26 projects had filed 115 patents at the time the study data were collected. ${ }^{14}$ Twenty-one of the projects had among them a total of 64 patents granted. Fifteen of the projects had filed a total of 51 patents that had not yet been granted.

Figure 1.2 displays the distribution of the 50 projects by the number of patents filed-including those granted and not yet granted. Participants in 12 percent of projects had filed a single patent, and in another 12 percent, 5 or more patents. Participants in 18 percent had filed from 1 to 5 patents. Nearly half of the projects had yet to file patents or have them granted.

\section{Knowledge Disseminated by Patents as Revealed by Patent Trees}

Each published patent contains a list of previous patents and scholarly papers which establish the prior art as it relates to the invention. The citations provide a way to track the spread of technical knowledge through patents granted to ATP-funded projects. By following the trail of the patent referenced, it is possible to construct what looks much like an inverted genealogy tree.

Once the pool of ATP-related patents was identified, computerized tools made available by the USPTO were used to track subsequent patents that refer to each of the ATP-related patents as prior art and the links recorded. ${ }^{15}$ The process is then repeated in turn for each of these patents, until the chain of references is complete. Next, the information is converted into graphical form, with the diffusion of knowledge along the path from ATP project patents represented by links from node to node in the tree.

With the passage of additional time, new branches may spring up from nodes at the outer edges of the tree, from nodes deep inside the tree, or from their base. To the extent that later patents are dependent on the earlier

\footnotetext{
${ }^{12}$ The U.S. copyright system, also administered by the USP'TO, works somewhat like the patent system. Although a writer or other creator of a work or expression has an inherent copyright, the creator may register the copyright with the USPTO for added protection. For technology creations, protection via copyright generally is not as useful as patent protection. When patenting is an option, it is usually chosen over copyright registration. Patenting was the option favored by this group of ATP-award recipients, and is the focus here.

${ }^{13}$ Despite the limitations, patent statistics serve as useful indicators of knowledge creation and dissemination, and they are widely used by researchers.

${ }^{14}$ Patents filed and not yet granted are included here, in addition to those filed and granted, despite the fact that there is no public disclosure until patents are actually granted. The reason for including patent filed, not yet granted, is to help offset the problem that there are substantial differences across industries in the lag time between patent filing and grant. Due to the lag time, the absence of patents granted at the time data were collected for the report does not mean that patents filed will not be granted in the future. Any over-count that may result from the inclusion of patents filed that ultimately failed to be granted is likely compensated by inadvertent omissions of patents granted from the data collection.
}

${ }^{15}$ The references to prior patents contained in a published patent are based on information supplied by the applicant and on research by USPTO researchers. There is no way to distinguish between the two sources and no indication that one tends to dominate the other. (USPTO telephone interview with ATP staff, February 11, 2000). 
ones, the patents in the tree represent developments in knowledge that would not have occurred, or at least not in the same time frame, had the ATP not stimulated the creation and dissemination of that platform knowledge.

\section{Patent Tree Illustrating International Knowledge Dissemination}

Figure 1.3 is a patent tree for one of the 50 completed projects, a project to develop wafer ion-implantation, carried out by Diamond Semiconductor Group (DSG), a twoperson start-up company in Gloucester, Massachusetts.

The company received two patents for work in its ATP projects, and had filed two additional patents from project-related work at the time the data were collected for this study. One of the patents granted in 1996, number $5,486,080$, entitled "High speed movement of work pieces in vacuum processing," involved the robotic transfer of wafers in the fabrication of microprocessors. In the following year, two patents - one granted to VLSI Technology and the other to Hitachi-cited the DSG patent. In 1998, three additional patents-granted to Eaton, Fanuc, and Tokyo Ohka Kogyo-directly cited the DSG patent. An additional patent-granted to Jenoptik, cited the Hitachi patent-thus indirectly citing the DSG patent. In 1999, two additional patents-granted to Applied Materials and Dainippon-directly cited the DSG patent, and five new patents indirectly cited the DGS patent. Four of these citations are once removed: a patent granted to Cypress, a second patent granted to Applied Materials, and two patents granted to GaSonics International; and one is twice removed: a patent granted to SEZ.

As explained in the project write-up for DSG (See Diamond Semiconductor Group, LLC, Chapter 4), the ATP award was instrumental in enabling the company to form an early licensing agreement with Varian Associates, a U.S. ion-implant equipment manufacturer located in Massachusetts, that rapidly incorporated the new technology into its equipment. This relationship provided a strong direct path to swift impact through a U.S. company. As illustrated in Figure 1.3, the indirect path for this project was also active and the knowledge has been spreading quickly to companies around the world.

\section{Patent Trees Illustrating Project Impact through Knowledge Dissemination}

The patent tree in Figure 1.4 shows citations of one of three patents that came out of Armstrong's project to develop new materials for next generation thermal insulation. Company reorganizations, strategy shifts, and cost estimates toward the end of the project led Armstrong to drop its plans to produce the materials.

The patent tree illustrates how an ATP project whose direct path appears to have slowed or come to a standstill nevertheless has the potential for impact through knowledge spread by patent citations along the indirect path of project impact. As the patent tree illustrates, other companies, including Dow Corning, are referencing the Armstrong patents, and the potential for beneficial impact from the research continues. (See Armstrong World Industries, Inc., Chapter 6.)

Figure 1.5 shows citations by other companies of 3 patents resulting from a project led by ETOM. ETOM had filed 12 patents that had been granted, and 14 more not yet granted by the end of its ATP project. The small company then went bankrupt. The patent tree illustrates how knowledge can survive a failed creator, and continue to be disseminated. An observer who equates business success of the innovator, one-to-one, with ATP-project success may be mistaken, because the indirect path may nevertheless produce important benefits. (See ETOM Technologies, Inc., Chapter 6.)

\section{Patent Tree Illustrating Extensive Knowledge Flows}

Figure 1.6 illustrates just how complex knowledge flows through patent citations can become. The path shown is for patents resulting from an ATP-funded joint venture led by Kopin. The project developed methods to interconnect thin-film integrated circuits side-by-side or in layers. Obviously, the work has generated substantial interest. This project also has an active direct commercialization path. (See Multi-Film Venture, Chapter 4.)

Chapters 2 through 6 provide patent trees, current as of February 2000, for many of the projects that have received patents. Although representing only one aspect of knowledge dissemination, the patent trees extend awareness of the influence of the new knowledge.

\section{Knowledge Dissemination through Other Means}

Participants in more than half the 50 projects published and presented papers in technical and professional journals and in public forum. Altogether, the companies published at least 180 papers and presented 245 or more papers.

Figure 1.7 gives the distribution of projects by their numbers of publications and presentations. Thirty percent of the projects each yielded 1 to 5 papers published or presented. At the high end, six percent of projects each had more than 20 papers published or presented. 
Figure 1.3 Project Impact Through Patent Citations,

Original Patent

Second Generation Patent

Thlrd Generation Patent

Fourth Generation Patent

Fifth Generation Patent

\section{Paralled by Strong Activity by Innovator}

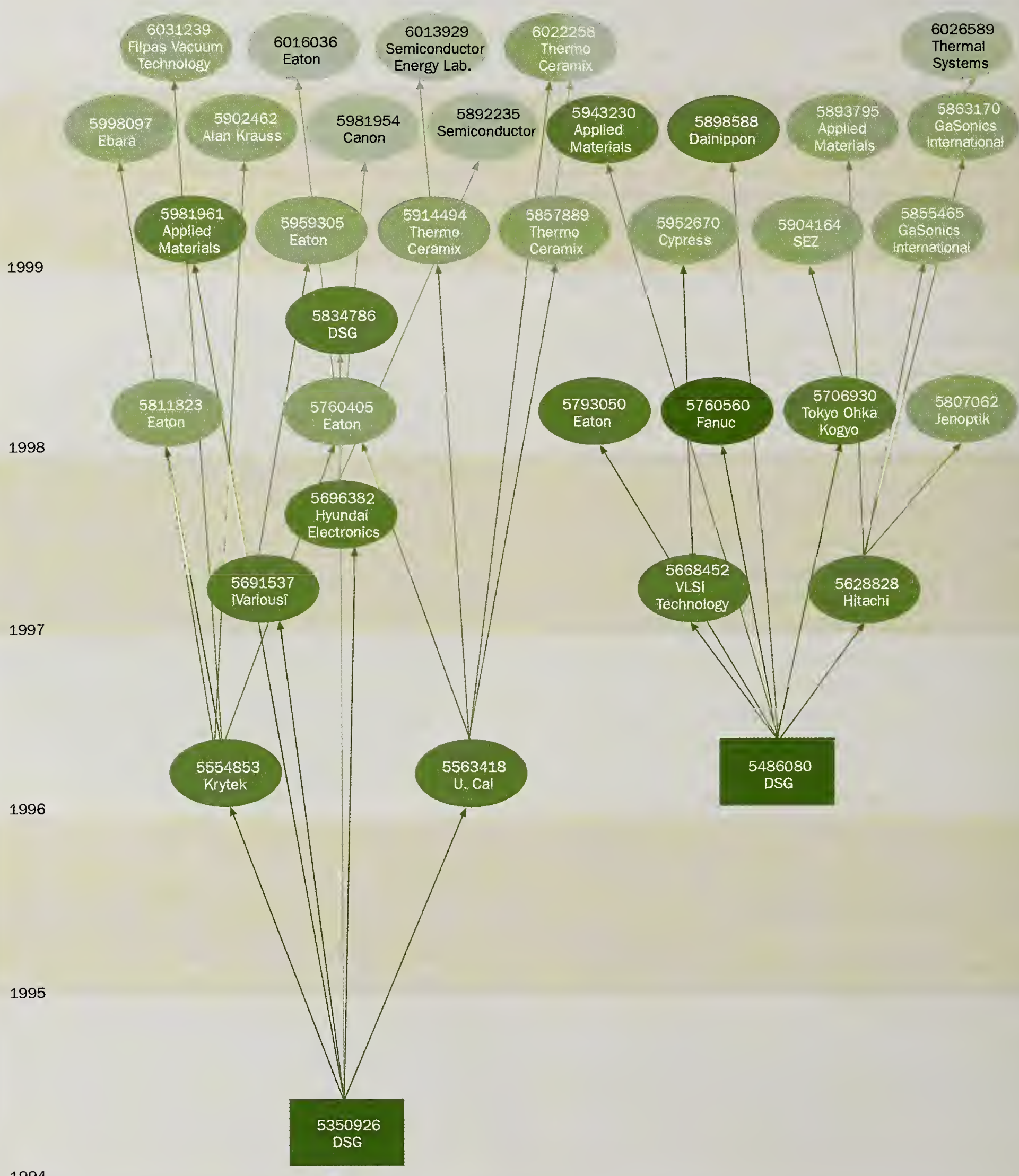


PATENT TREE KEY

original Patent

Second Generation Patent

Third Generation Patent

Fourth Generation Patent

Fifth Generation Patent
Figure 1.4 Project Impact through Patent Citations, after Innovator Reduced Activity

2000

1999

1998

5948482

New Mexico
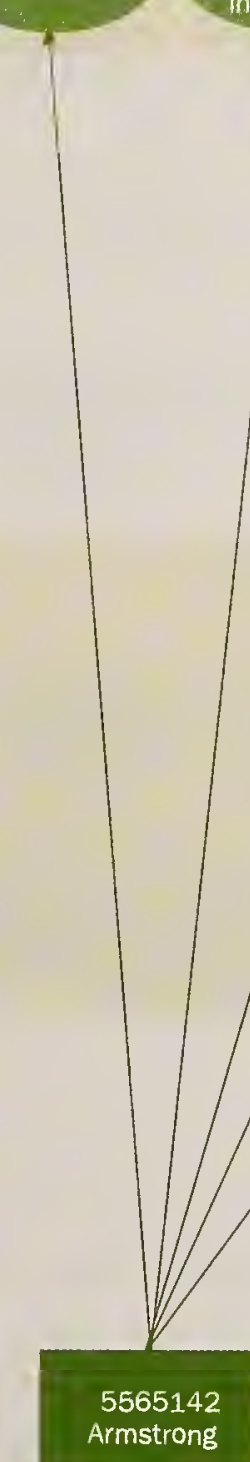

5911658

PPG

ndustries

Hoechst

1997

1996 


\section{PATENT TREE KEY}

Original Patent

Second Generation Patent

Third Generation Patent

Fourth Generation Patent

Fifth Generation Patent
Figure 1.5 Project Impact Through Patent

Citations, after Innovator Went Bankrupt

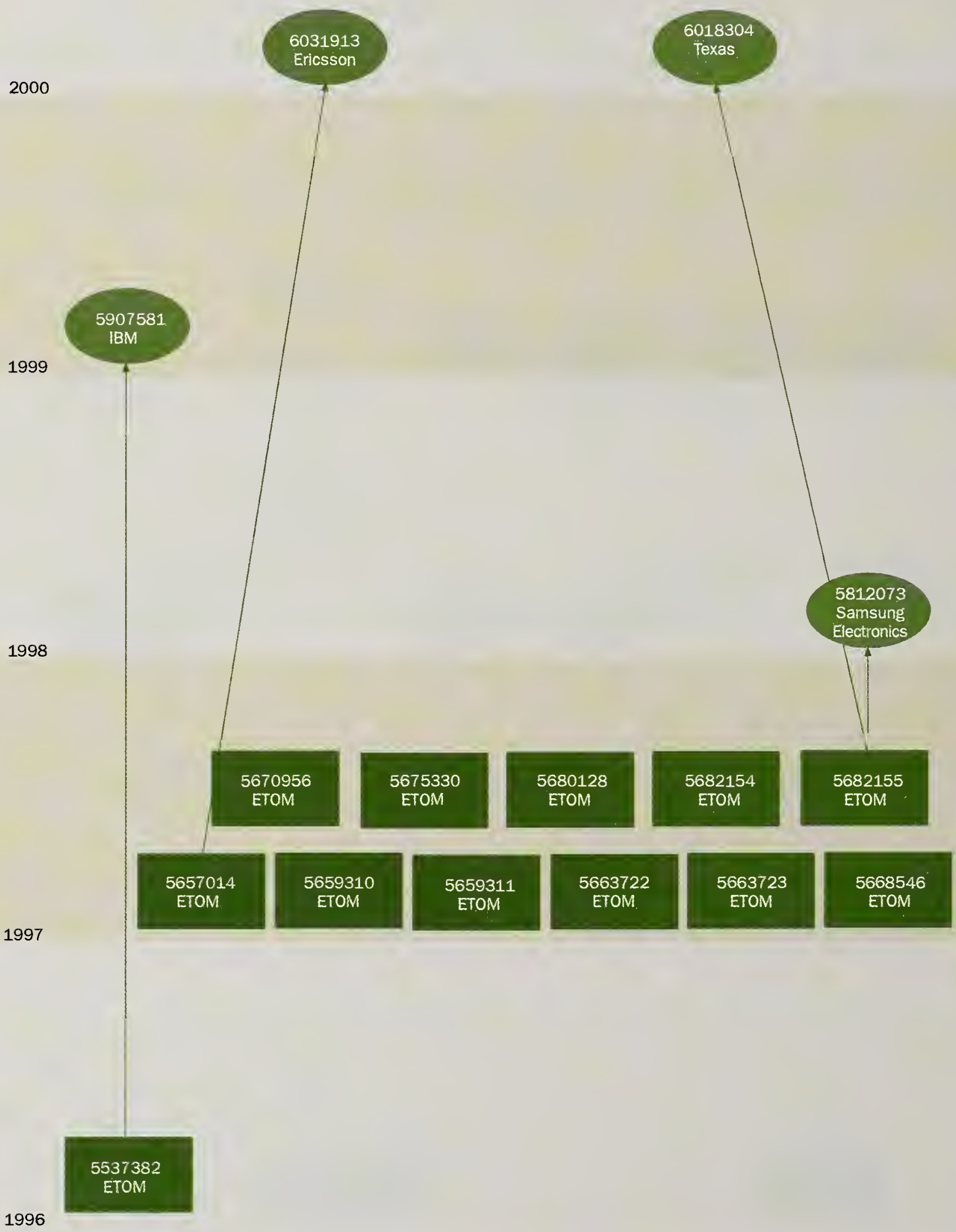


Fourth

Fifth Generation Patent

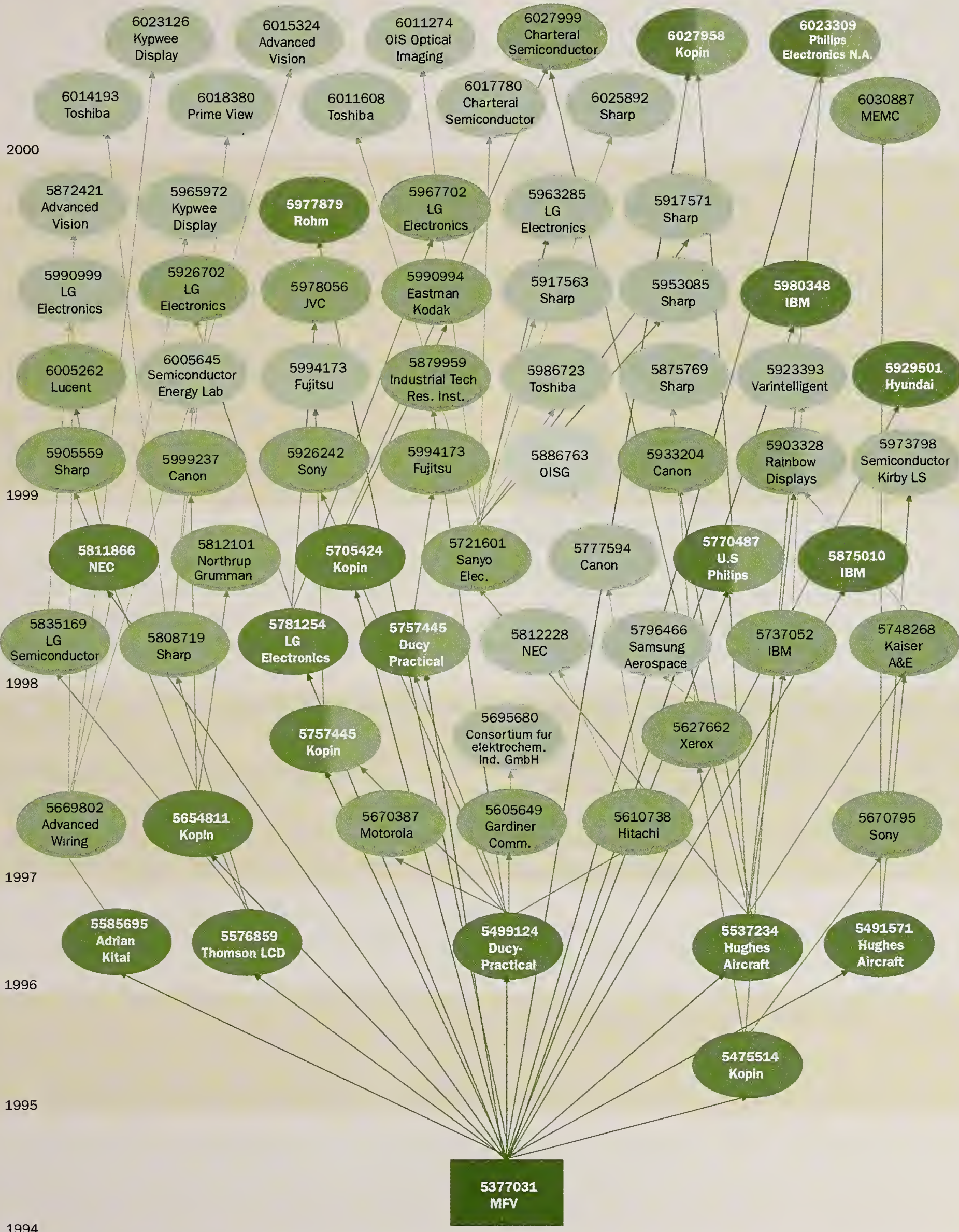


Figure 1.7 Distribution of Projects by Number of Publications and Presentations

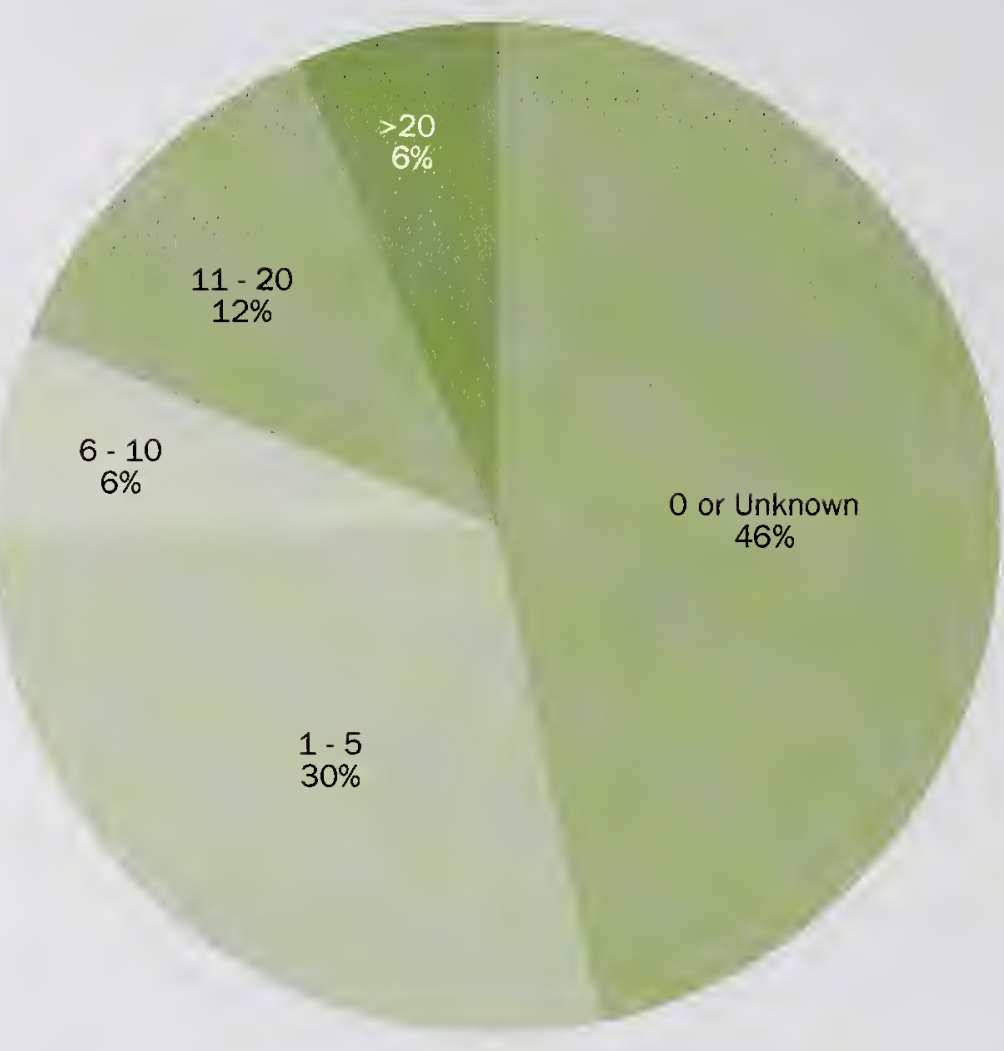

Aside from publishing, presenting, and patenting, ATP projects have a high rate of collaborative activities. (See Table 1). With so many partners, collaborators, and subcontractors involved, it would be difficult to lock up the information. These many participants in the projects provide rich avenues of further interaction with others, and these interactions in turn may increase knowledge flows through personal and professional contact.

When the government enters into an agreement with an organization, certain information about the agreement is generally made public. Such is the case with the ATP and company cost-sharing partnerships. Nonproprietary information has been disclosed to the public for each of the
522 projects funded by the ATP through 2000. Project information is available on the ATP website on the Internet (<www.atp.nist>), and new nonproprietary project descriptions are added to the site as new awards are made. Evaluation reports, such as this one, also provide information to the public.

To help the public learn more about the projects it funds, ATP organizes and sponsors numerous public workshops, where companies present nonconfidential aspects of their ATP-funded research and engage in open discussions. These workshops facilitate information flow among ATP award recipients, and from them to other companies, ATP project managers, other government program managers, the press, potential investors, and universities.

When a good or service incorporating new technology reaches the marketplace, a buyer can learn a great deal about the technology. The mere functioning of a new product reveals some information. Intentional investigation, including reverse engineering, reveals even more. More than 60 percent of the 50 projects reviewed for this study had some commercial products or processes based on the ATP-funded technology already on the market, which means that product use and examination are providing others with information about the new technologies. 


\section{Commercialization of the New Technology}

$N$ means the introduction into the market of a new product or process by the innovating firm, its collaborators, or other companies that acquire the knowledge. In competitive markets, the producer is typically unable to capture all the benefits of a new product or process, and the consumer reaps part of the benefits. The higher up the supply chain the innovation occurs, the more value-added steps there are before final consumption, and the more intermediate firms in the supply chain may benefit, in addition to the final consumer. ${ }^{16}$

\section{Commercialization of Products and Processes- A Critical Step Toward National Benefits}

Thirty-three of the projects had already spawned 62 new products or processes when the data for this report were collected. Companies in seven additional projects expected to achieve their first commercialized results shortly, and companies in nine projects that had already commercialized their technology expected to add new products and processes soon. Thus, nearly 80 percent of the projects had spawned one or more products or processes in the market, or expected to do so shortly. Table 4 summarizes the commercialization results.

\section{A Quick Glance at the New Products}

A variety of new products and processes resulted from the projects. For a convenient, quick reference, brief descriptions of the new products or processes for each project are listed in Tables A1-A5 in Appendix A, in Column C. For each new product or process, the new technology on which it is based is also listed in the tables, in Column B.

\begin{tabular}{l}
$\begin{array}{l}\text { Table 4. Progress of Participating Companies } \\
\text { in Commercializing the New Technologies } \\
\text { Number of } \\
\text { Projects }\end{array}$ \\
$\begin{array}{l}\text { Number of } \\
\text { Products/Process }\end{array}$ \\
$\begin{array}{l}\text { Product/Process } \\
\text { on the Market }\end{array}$ \\
$\begin{array}{l}\text { First Product/ } \\
\text { Process Expected Soon }\end{array}$ \\
$\begin{array}{l}\text { On the Market with Additional } \\
\text { Product/Process Expected Soon }\end{array}$ \\
$\begin{array}{l}\text { On the Market or Expected } \\
\text { Soon-Totals }\end{array}$ \\
\hline
\end{tabular}

\section{Commercialization: A Critical Step, but Not the Final Word}

Commercializing a technology is necessary to achieve economic benefit, but it does not ensure that the project is a full success from the perspective of either the company or the ATP. Widespread diffusion of the technology may or may not ultimately follow the initial commercialization.

\footnotetext{
${ }^{16}$ For a detailed treatment of the relationship between spillover benefits (knowledge, market, and network spillovers) and commercialization, see Jaffe (1997). He notes: "Market spillovers will not be realized unless the innovation is commercialized successfully. Market spillovers accrue to the customers that use the innovative product; they will not come to pass if a technically successful effort does not lead to successful commercialization" (p. 12). In commenting on spillovers that occur because new knowledge is disseminated to others outside the inventing firm, he observes: "Note that even in the case of knowledge spillovers, the social return is created by the commercial use [emphasis in the original] of a new process or product, and the profits and consumer benefits thereby created" (p. 15).
} 
Nevertheless, it is significant that these products and processes are actually on the market.

\section{Rapidly Growing Companies}

Rapid growth is generally a signal that the small innovating company is on the path to taking its technology into the market. And one dimension of company growth typically is its employment growth. ${ }^{17}$

Figure 1.8 shows employment changes at the 31 small, single-company ATP award recipients. ${ }^{18}$ Nearly one-fifth of these companies experienced job growth in excess of 500 percent from the beginning of the project to several years after the project had completed. The largest share experienced job growth between 100 and 500 percent.

A recent look at Fortune's "Fastest Growing 100 Companies" lists 2 of the 31 then-small ATP-funded companies on the list: Vitesse and Cree. Vitesse now has nearly 800 employees and a market capitalization of $\$ 15.6$ billion. Cree has grown to a market capitalization of $\$ 4.9$ billion. ${ }^{19}$

Not all the small companies have grown. A little more than one-fifth of them experienced no change, or a decrease in staff. But taken as a group, the 31 small companies have grown rapidly. Sixty percent have at least doubled in size; four of them have grown more than 1000 percent. The ATP helped these companies develop advanced capabilities, which they have subsequently leveraged into major businesses.
Figure 1.8 Employment Change at 31 Small Companies receiving a Single-Applicant Award

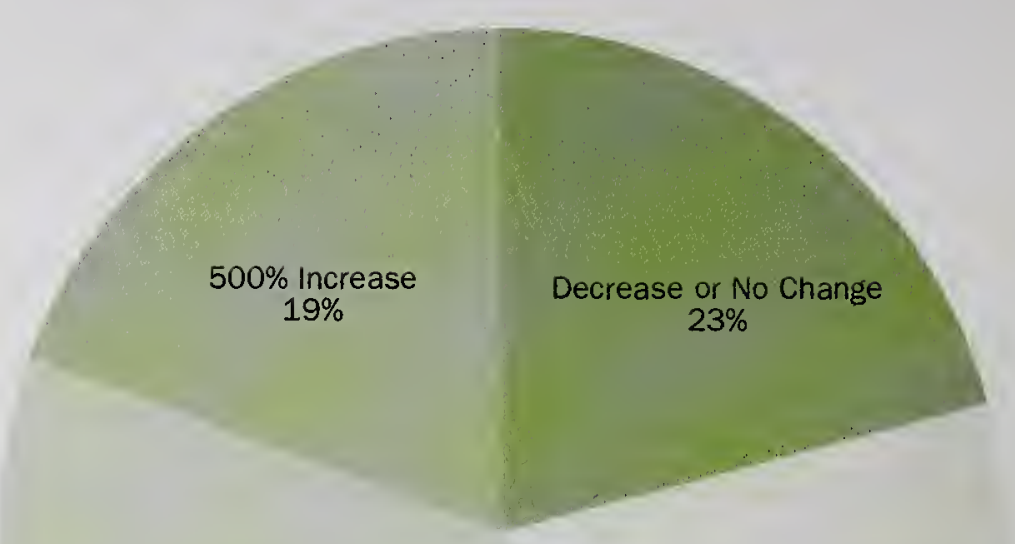

$1-100 \%$ Increase $16 \%$

\footnotetext{
${ }^{17}$ Employment is considered here as an indicator of the commercial progress of small, award-recipient companies. Assessing employment gains in a macroeconomic sense from the technological progress stimulated by the 50 projects is beyond the scope of this project.

${ }^{18}$ Employment changes in joint ventures, larger companies and nonprofit organizations are less closely tied to the success of individual research projects, and, therefore, they are not shown in the figure.

${ }^{19}$ Market capitalization and employment data cited here are from Hoover's Online Company Reports as of August 30, 2000.
} 


\section{Overall Project Performance}

Tros

50 completed projects have exhibited varying levels of success when measured in terms of the creation and dissemination of knowledge and the accelerated use of that knowledge for commercial purposes. Some of the award-recipient companies have grown by leaps and bounds as they translated their knowledge gains from the ATP-funded research into profitable and beneficial products, services and production processes. Others continue to strive towards hard-to-achieve goals, while others show little outward signs of further progress. Several projects were led by companies that had impressive research accomplishments but later failed in the commercialization phase. Participants in the more successful projects have achieved impressive new performance capabilities and have translated these into lower costs and higher quality products and processes. (Commercial benefits achieved indirectly through the use of the knowledge by others remain to be measured.)

\section{Composite Performance Scores}

A variety of output data has been systematically collected for the 50 projects and presented in aggregate form in the preceding sections. The purpose was to assess the performance of the group of projects in two dimensions: 1 ) knowledge creation, 2) dissemination, and 3) progress toward commercialization.

In this section the focus shifts to combining the collection of outputs for each individual project, to measure how it performed overall. 'The result is a composite performance score for each project, computed from an extensive set of outputs linked to the ATP mission and goals. The composite performance scores are reported in chapters 2 through 6 . The distribution of scores is reported here.

The composite performance scores are computed from available output data ${ }^{20}$ indicating the creation and dissemination of knowledge, i.e., a) award-winning technologies, b) patent filings, c) publications and presentations, d) new and improved products/processes now or expected, and e) collaborations. These output measures are combined with available data indicating progress toward commercialization of the new technology, i.e., a) attraction of capital, including resources made available for commercialization through collaborative activities, b) employment gains, c) company awards for business success, d) getting product and processes into the market, and f) outlook for continued future progress by the award-recipient companies. The resulting composite performance scores are computed for each of the 50 projects. The scores are expressed in terms of a zero-to-four star rating system, where a score of one star or less signals poor overall performance; two stars, moderate performance; three stars, strong performance, and four stars, outstanding performance."

These ratings should be viewed as roughly indicative of overall performance. Limitations include the fact that not all relevant effects are captured; alternative algorithms

\footnotetext{
20 The available data do not capture all developments that may be important to ultimate project performance. For example, the data do not capture informal discussions and mobility of workers that may be important avenues for the flow of knowledge. They do not capture details about sales volume and the value of commercialized products and processes. Inclusion of additional effects might produce improved measures of overall performance. Also, changes in the way in which the various output measures are assigned points and combined to compute the composite score may offer potential for improved measures. The scoring system was developed by Rosalie Ruegg, TIA Consulting.

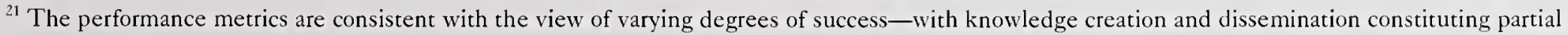
success, and a continuation into commercialization constituting a fuller degree of success in terms of project progress. Some companies carried out their proposed research with a degree of success during the time of ATP funding, but then did not continue pursuit of their project's larger goals after the ATP funding ended. At this stage of evaluation, ATP considers such projects only partial successes, because the direct path for achieving project goals is truncated. Such projects are not among the higher scorers in this report. The reader is reminded, however, that commercial developments along the indirect path may nevertheless occur-particularly if the project produced effective knowledge transmitters, such as patents and publications-and future performance scores may need to be revised to reflect commercial developments along the indirect path of project impact.
} 
for computing the composite ratings may be superior to those used, and the ratings at best reflect performance in terms of the underlying project output metrics, and not in terms of the ultimate national economic benefit from the project. ${ }^{22}$

\section{Scoring the First $\mathbf{5 0}$ Completed Projects}

Figure 1.9 shows the distribution of the 50 projects by their composite performance scores. Perhaps not surprisingly, the largest group of projects, 34 percent, scored in the twostar category-moderate progress, but not particularly robust overall. Sixteen percent (8 projects) scored in the top category, receiving four stars. Another 26 percent (13 projects) scored in the three-star category, also strong projects. Twenty-four percent of the projects scored one star or less-perhaps not surprising for companies taking on difficult goals.

The 8 top-scoring projects overall included 7 singleapplicant projects led by small companies and 1 large joint venture led by an industry nonprofit organization. Leaders of these projects include Engineering Animation, Inc.; Integra LifeSciences; Aastrom Biosciences, Inc.; Cree, Inc.; Tissue Engineering, Inc.; Torrent Systems, Inc.; American Superconductor Corporation; and the National Center for Manufacturing Science.

The next tier of relatively strong projects includes 8 projects led by small companies, 1 project led by a large company, 1 project led by a medium-sized company, and 3 joint venture projects.

\section{Performance by Technology Areas}

Figure 1.10 illustrates the distribution of projects in the five technology areas, according to their composite performance scores. The sample sizes are too small to support the drawing of general conclusions about how projects in the different technology areas will perform. For this group of 50, several observations can be made about performance to date.

The Biotechnology projects exhibit a bimodal distribution, with either outstanding/strong performance or poor performance. The Information Technology projects cluster into the outstanding and moderate performance groups; none are in the weakest categories. The Manufacturing and the Electronics/Computer Hardware/Communications
Figure 1.9 Distribution of Projects by Overall Performance Score

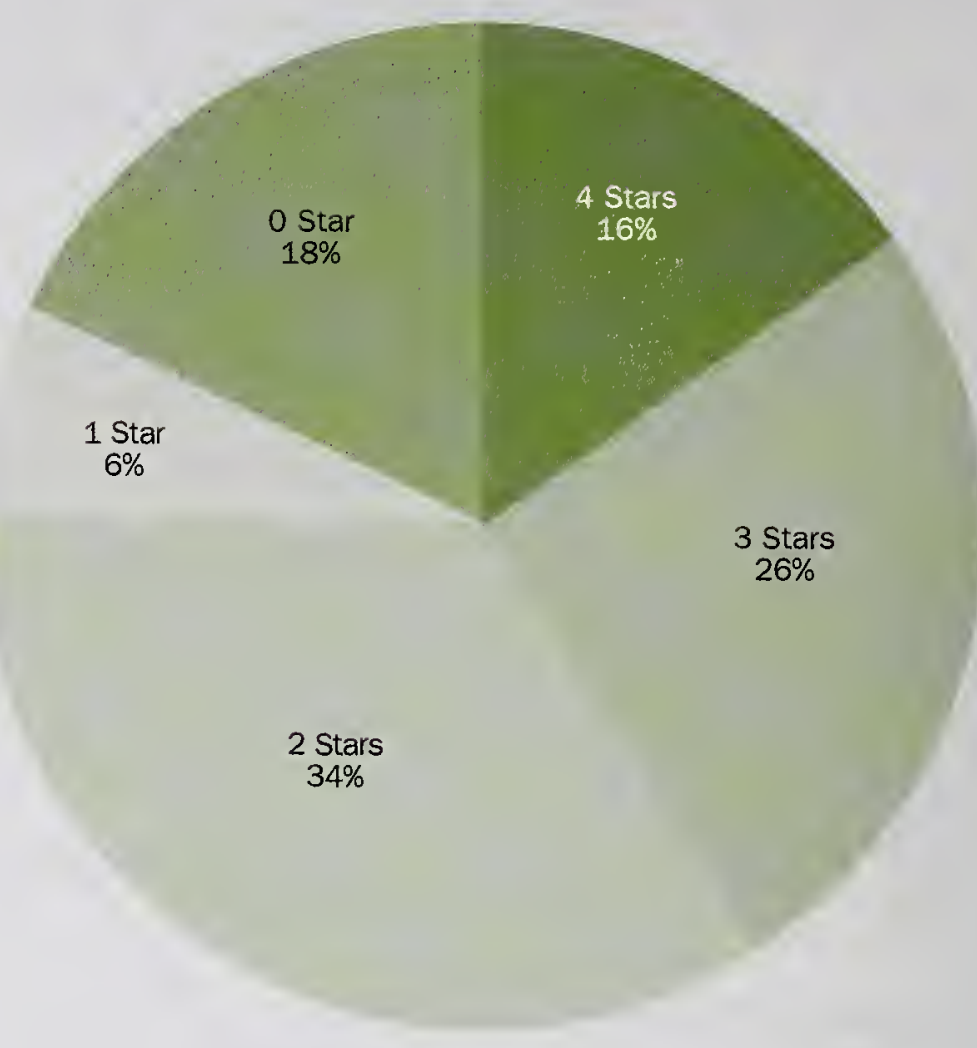

projects are distributed across the spectrum of performance categories. Most of the Advanced Materials/ Chemicals projects are in the moderate performance category, and a sizable fraction is in the weak-performing group. (See "Characteristics of the Projects" earlier in this chapter for the simple distribution of projects by technology area.)

\section{Project Performance Translated into Economic Benefits}

Progress signaled by strong composite performance metrics is translating into economic benefits. Let us consider, for example, estimated benefits of projects among the top scorers.

Three of the top performing projects developed medical technologies that were evaluated by economists at the Research Triangle Institute (RTI), a consulting firm in North Carolina. ${ }^{23}$ RTI economists provided early estimates of the value of a new biopolymer to repair fractures, devel-

\footnotetext{
22 The degree of correlation between a project's performance score and its long-run societal benefits is impossible to know at this time. On the one hand, few outputs and low scores for a project cast doubt on the likelihood that it will attain the large benefits originally envisioned. On the other, it is easy to imagine potential exceptions. For example, a single publication or patent could have enormous enabling influence on other U.S. companies who respond in a timely way with commercial activity. Or, a company may work in secrecy for a long period of time with no visible outputs, and then suddenly explode on the scene with a single output that will yield large societal benefits. Similarly, it should be noted that projects with the same scores are not necessarily equal in their potential benefits. They are, however, somewhat comparable in terms of the robustness of their progress to date.
}

${ }^{23}$ RTI, A Framework for Estimating the National Economic Benefits of ATP Funding of Medical Technologies, Prepared for the Advanced Technology Program, 1998. 


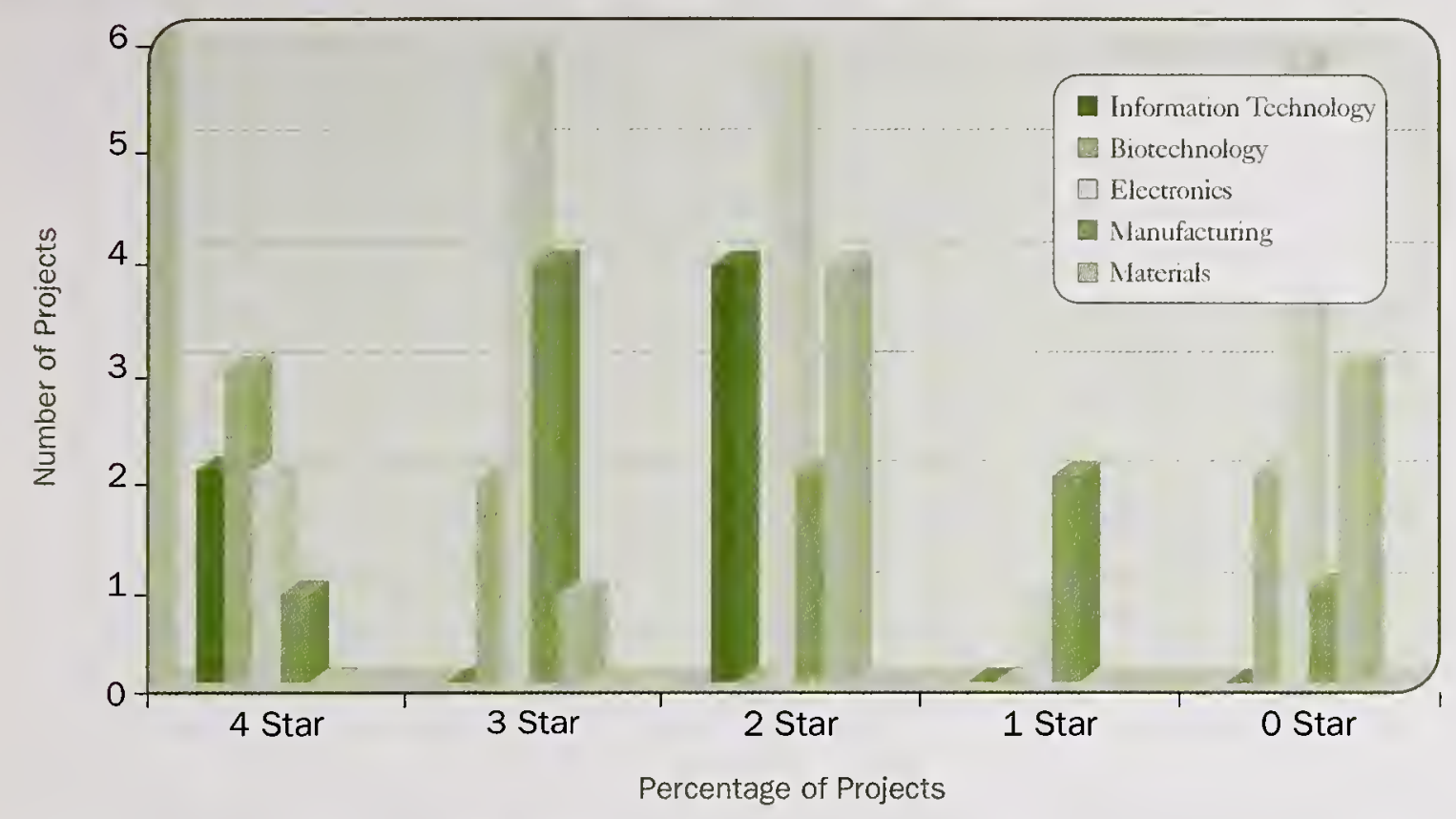

oped by Integra LifeSciences; a system for replicating stem cells, developed by Aastrom Biosciences, Inc. ${ }^{24}$ and a new prosthesis material-animal-derived extracellular matrix, or ADMAT_-developed by Tissue Engineering, Inc.

Biocompatible Polymers for Cartilage Repair: The RTI study estimated the medical cost savings from the project led by Integra, in terms of avoiding second surgeries to remove implants, such as pins and screws, when trouble arises. It estimated benefits at $\$ 98$ million, all attributed to ATP. ${ }^{25}$ Integra has shown continued robust progress since the RTI study was completed several years ago. At the time the project analysis for this mini-study was completed in late 1999, company employment had increased four-fold, and a recent check showed yet another big jump. Through its commercial partners, Integra's technology is becoming embodied in surgical screws, tacks, and other fixation devices for attaching soft tissue to bone in the knee and shoulder. Patient benefits include avoidance of medical complications and further surgeries associated with utilizing existing technologies, as well as lower surgical costs.

Stem Cell Replication: Because of the difficulty of estimating the value of patient pain reduction and improved health outcomes, the RTI study also based the

benefits estimates for Aastrom's stem cell expansion technology only on the reduction in procedure costs, although it is the patient pain-avoidance and improved outcome effects that were the main expected benefit of this technology. By allowing a small amount of stem cells to be multiplied into a larger quantity, the technology reduces donor clinic visits to collect the stem cells; reduces procedure hours; is easier for medical staff to perform; reduces treatment costs; substantially reduces patient pain and negative side effects; and has been shown to result in better treatment outcomes.

R'TI economists estimated that Aastrom's replication system, once implemented, would save about $\$ 87$ million (in 1997 dollars) in the costs of providing bone-marrow transplants for cancer treatment without the acceleration provided by ATP support and $\$ 134$ million with the acceleration. The difference, $\$ 47$ million, is the estimated additional value, in terms of cost savings only, attributed to the ATP, based on this one application area.

Aastrom, the award recipient, has since continued unabated pursuit of the commercialization of its AastromReplicall ${ }^{\mathrm{TM}}$ System. In recent clinical trials, the system was used successfully to enable cancer patients-for which there were otherwise no donors-to receive stem cell

\footnotetext{
${ }^{24}$ Aastrom Biosciences, Inc., utilized human hematopoetic stem cells derived from blood or bone marrow for its ATP supported research and continues to use bone marrow and umbilical cord blood in its development efforts. The bone marrow and cord blood utilized by Aastrom during its ATP supported research complied with the regulations for the protection of human subjects as codified by the Department of Commerce at 15 CFR Part 27.

${ }^{25}$ The quantitative estimate, which was net of costs, did not include benefits of patient health effects and pain avoided.
} 
transplants by expanding tiny amounts of cord blood samples that matched the patients. ${ }^{26}$ According to the director of medical oncology at Hackensack University Medical Center, "These results suggest that we may have found a new treatment approach that will enable more patients to receive treatment for this very serious and often fatal disease." " ${ }^{27}$ According to the American Cancer Society, 30,000 new cases of leukemia are expected in 2000 and approximately 20,000 people will die from the disease this year, making new, more effective treatments of great value to society. ${ }^{28}$

Biomaterials for Prostheses: Focusing on the first expected application of Tissue Engineering's ADMAT technology, namely, the repair of damaged knee ligaments (specifically, anterior cruciate ligaments, or ACLs), RTI economists also estimated benefits. But in this case, unlike the previous two, R'II was able to estimate benefits expected to result from improvements in the quality of life for patients receiving the treatment, by using a "qualityadjusted-life-years" index value. ${ }^{29}$ RTI estimated about $\$ 15$ billion in expected net benefits from the new technology attributable to ATP funding.

Printed Wiring Boards: Another of the top performing projects is a joint venture led by the National Center for Manufacturing Sciences (NCMS) to develop a suite of advanced technologies for producing printed wiring boards, the backbones of electronics products. Two studies conducted by Professor Albert Link of the University of North Carolina-Greensboro assessed the impact of the project's extensive use of collaborative effort. ${ }^{30}$

The Link studies estimate that the project's collaborative effort produced at least a 53 percent reduction in overall research costs, resulting in an R\&D savings of at least $\$ 35.5$ million to produce the new capabilities needed by the industry for international competitiveness.

Evidence is strong that the project produced leap-frog technologies that have yielded productivity improvements for member companies and improved the competitive position in the world market for PWBs of the hundreds of small U.S. suppliers who were themselves lacking in advanced R\&D capability. ${ }^{31}$ The award-winning papers, new products, and other knowledge dissemination activities by the joint venture have helped to spread the new capabilities across the entire industry.

At a recent technology exposition by ATP-funded companies, an advanced circuit board was displayed that incorporated many of the innovations developed by the ATP-funded project. A small U.S. company that did not participate directly in the project was said to have produced it. This new PWB was provided by NCMS as evidence of the effective knowledge flow from the project to others. ${ }^{32}$

Scalable Parallel Programming: Another of the top performing projects is a project led by Torrent Systems, Inc. The project developed a component software system that insulates programmers from the complexities of parallel programming while allowing them to use it productively in scalable applications. Torrent delivered this new capability in its software product, Orchestrate ${ }^{\mathrm{TM}}$. An early company user of the new software reportedly was able to increase its revenue by $\$ 100$ million per year. ${ }^{33}$ Torrent's technology is making it possible for eBusinesses and other companies to process and analyze unlimited volumes of data. Torrent was listed in ComputerWorld's "100 Hot

\footnotetext{
${ }^{26}$ Cord blood, the blood in the umbilical cord and placenta after the birth of a child, has been found to offer an alternative source of stem cells for transplantation that allows a higher degree of tissue mismatching while still providing an acceptable transplant. As a result, a cord-blood banking infrastructure is being established, but the small amount of cells available from this source restricts its use. In recent clinical studies, several adult cancer patients needed very high-dose chemotherapy to be followed by a stem cell transplant, but no suitable bone marrow donors could be found. In the cord blood bank, small samples were found that provided a match, but the amounts were too small to be used. In the clinical trials, the AastromReplicall ${ }^{\mathrm{TM}}$ System was used to replicate the number of matching cord blood cells, allowing the patients (for which there were otherwise no donors) to receive stem cell transplants.
}

${ }^{27}$ PRNewswire, April 19, 2000, Report on results from Hackensack/Aastrom Studies.

${ }^{28}$ Ibid.

${ }^{29}$ For a description of the use of Quality Adjusted Life Years (QALY) in evaluating patient benefits in evaluation studies, see Andrew IVang, "Key Concepts in Evaluating Outcomes of ATP Funding of Medical Technologies," Journal of Technology Transfer, Vol. 23 (2), 1998, pp. 61-66.

${ }^{30}$ See A. N. Link, Advanced Technology Program Case Study: Early Stage Impacts of the Printed Wiring Board Joint Venture, Assessed at Project End, Report prepared for the Advanced Technology Program, 1997.

${ }^{31}$ The president of NCMS credited the ATP project with saving the PWB industry in the United States with its approximately 200,000 jobs.

${ }^{32}$ ATP Technology Showcase, "Ten Years of Innovation and Impact," Russell Senate Building, Caucus Room, April 5, 2000. Discussions with an NCMS spokesperson.

${ }^{33}$ Information from Hoover's on-line company search and 'Torrent's website, current August 31, 2000. 
Emerging Companies" in 1998, in addition to receiving a number of other awards recognizing both its software technology and business acumen. Although Torrent had fewer knowledge-dissemination outputs than the other top performing projects, its exceptional showing on the commercialization side boosted it into the four-star group.

HTS Wire: The project led by American Superconductor Corporation (ASC) was another of the top projects in terms of performance. The new technical capability developed by this company is enabling it to produce high-temperature wire for use by electric utilities and as a component in motors, transformers, and specialty magnets to reduce their energy consumption. With an estimated sales volume of $\$ 15$ million in 2000 , and a rapid sales growth rate, this small company is launching the commercialization of its technology. The technology's ability to reduce energy costs has taken on increased significance in the face of rising energy prices.

Visualization Software: As in the preceding examples, Engineering Animation, Inc., leader of another of the top performing projects, has aggressively and successfully pursued applications of its award-winning imaging software capabilities developed in the ATP-funded project. The company used its ATP-funded technology to improve the training of doctors, as well as to guide medical procedures. Patients in a particular surgical procedure that employed the visualization software reportedly had better outcomes as a result.

Founded by two professors and two graduate students in 1990, the company had 20 employees at the time ATP made the award to it. The company now employs approximately 1,000 , had sales of $\$ 71$ million in 1999 , and experienced a sales growth rate over the past year of 34 percent. According to company officials, the ATP award allowed it to significantly extend its capabilities in computer visualization and computations dynamics and to form important collaborative relationships that it has since been able to leverage in many different directions. Recently, it has extended and deployed its award-winning visualization capabilities to develop a virtual factory technology, implemented recently at Ford, which enables faster design and analysis of factory models. Its many customers and clients have benefited from the company's extended capabilities.

To these examples from the group of four-star projects, we can add examples of other strong projects from among the three-star projects that are delivering important economic benefits. Some of these projects in this group may outperform the four-star projects in some ways, but received lower composite scores based on all the recorded outputs.

Auto Body Manufacturing Assembly: One such project, led by the Auto Body Consortium (ABC), has generated documented production cost savings and improved automobile quality, as well as the potential for extending these same kinds of benefits to the manufacturing assembly of other products. A study by the CONSAD Research Corporation projected economy-wide benefits of about $\$ 3$ billion in 2000, attributable to deployment of the ABC technology in automobile production. ${ }^{3+}$ Efforts are underway to extend the use the technology from the automobile industry to other industry sections. ${ }^{35}$

DNA Sequencing System: Another example from the three-star group is provided by a project led by Amersham Pharmacia Biotech, which is credited with accelerating development of an enzyme important to the speed of the human genome project-where timing is of enormous significance.

Highly Integrated Digital Circuits: An example of a particularly strong commercialization showing from the three-star group is a project led by Vitesse Semiconductor Corporation. Vitesse has successfully applied gallium arsenide (GaAs) material in the volume production of highly integrated and very complex digital circuits. Most of the world's telecommunications companies now use Vitesse chips; virtually every long-distance call passes through its integrated circuits. The project's main avenue for knowledge dissemination was through commercialization, rather than patents and publications.

To these examples, we can add a number of other promising technologies-technologies that may improve productivity, facilitate better weather forecasts, improve communications, enable new drug discovery, reduce energy

\footnotetext{
${ }^{34}$ CONSAD Research Corporation, Advanced Teclnology Program Case Study: The Development of Advanced Technologies and Systems for Controlling Dimensional Variation in Automobile Body Manufacturing, National Institute of Standards and Technology, NIST GCR 97-709, 1997. A new study is currently underway, led by MIT researchers, to extend and update the analysis of this project. Contact ATP's Economic Assessment Office for further information.

${ }^{35}$ ATP has been exploring the diffusion of technologies developed with ATP support through the Manufacturing Extension Program (MEP) that is also operated by NIST, with the ABC project as a case in point. The output measures used in computing the composite scores did not register this type of dissemination activity.
} 
costs, and lower loss of limb and life globally by improving detection of old land mines and toxins.

\section{What Difference Did ATP Make?}

The ATP aims to fund projects that would not take place in the same timeframe, scale, or with the same goals without ATP's support. A project may be successful in terms of achieving its goals, but if the same accomplishments would have occurred in the same timeframe without the ATP, then the program has not had the intended effect. Similarly, evaluation studies of ATP should apply the principle of "additionality" to correctly distinguish between benefits that would likely have occurred anyway and those benefits that are reasonably attributable to the ATP.

In preparing the 50 individual mini-case studies in this report, project leaders were questioned about the role ATP funding played in their projects. ${ }^{36}$ Their answers are presented in the detailed discussions of Chapters 2-6 and summarized in Table 5.

Twenty-six of the 44 project respondents (59 percent) ${ }^{37}$ indicated that they would not have done the project at all without ATP funding. Indeed, some participants said their companies would have gone out of business had the ATP award not been made. ${ }^{38}$

Eighteen respondents (41 percent) said they would have attempted the project at some later date or slower pace, and that the ATP funding enabled them to accelerate the technology development. Thus, for the 44 projects responding-none would have been completed in the same time frame without ATP funding.

The acceleration of some of the projects may seem short, but the value of even a small acceleration can be substantial. The six-month lead in developing ThermoSequenase, a DNA polymerase that is both thermostable

\section{Table 5. Effect of ATP Funding on \\ Conducting Projects}

\section{Effect on \\ Project}

Would not have proceeded without ATP funding

Would have proceeded without ATP funding, but with a delay $^{39}$ of:

- 6 months
- 18 months
- 21 months
- 24 months
- 5 years or more
- unspecified

Total 4 3 $5^{40}$ 4 1 44

and accurate, for DNA sequencing is an example of how a small acceleration may be significant. Speed in developing and commercializing a technology can also mean global market share for U.S. producers.

Receipt of an ATP award also has reportedly enhanced the ability of some companies to raise additional capital and form collaborative relationships for research and commercial activities. Several reported that receipt of the ATP award had enabled them to gain in international competitiveness.

\footnotetext{
${ }^{36}$ Throughout the project selection process, beginning with the application, ATP presses the questions of why the project requires ATP funding in order to be undertaken, what will happen if the ATP funding is not provided, and how will the expected outcome differ with and without ATP involvement. During the evaluation process, the question is again asked in a retrospective way, i.e., what happened that was different as a result of the ATP? In either case, the question is hypothetical, and the accuracy of results is difficult to establish. A recent study by Feldman and Kelley sheds light on the question of additionality. It investigated what happened in the aftermath to projects proposed in ATP's 1998 competition that were and were not funded. The findings provide evidence that ATP made a difference to project outcomes. (See Maryann P. Feldman and Maryellen R. Kelly, Winning an Award from the Advanced Technology Program: Pursuing RED Strategies in the Public Interest and Benefiting From a Halo Effect, NISTIR 6577 (Gaithersburg, Md.: NIST, 2001).
}

${ }^{3}$ Personnel changes, severe company financial distress, or lack of clarity in responses to interview questions made it impossible to include 7 of the 50 projects in this tabulation.

${ }^{38}$ W. Long, Performance of Completed Projects, number 1, March 1999, p. 132, endnote 15.

Another factor potentially influenced by ATP funding-the scope and scale of the project-was not explicitly covered.

${ }^{40}$ The Printed Viring Board Joint Venture project had a split response: half the tasks would not have been done at all and half would have been delayed by at least a year. This result is recorded conservatively in Table 5 as a two-year delay. 
What Constitutes Success and Failure for ATP?

Because individual project failure must be allowed and tolerated in a program that focuses on overcoming challenging technical barriers to innovation, it is essential to take a project-portfolio approach to assessing ATP. And, success should be assessed against the legislated mission of the program.

Three general tests, and several additional specific tests-all derived from ATP's mission-if applied after sufficient passage of time, should reveal the extent to which ATP has successfully met its mission: Test 1: Has the portfolio of ATP-funded projects overall produced large net benefits (i.e., benefits minus costs) for the nation? Test 2: Has a substantial share of the net national benefits accrued to citizens and organizations beyond the ATPaward recipients? Test 3: Did ATP make a substantial positive difference in the size and timing of the benefits? ${ }^{2+1}$

Additional specific tests of success include the following: Did the projects produce new scientific and technical knowledge? Did ATP increase collaboration? Were small businesses able to participate? Were manufacturing capabilities improved? Did U.S. businesses become better able to compete in global markets?

\section{Partial Answers}

While the ultimate answers to these success "test questions" depend on the long-run impacts of the portfolio of ATP projects, the performance-to-date of the subportfolio of 50 projects provides partial answers.

The performance ratings show that the majority of the projects are still alive, in the sense that progress continues to be made. More important, they reveal a core group of highly active and productive projects that are successfully accomplishing their big project goals.
The ATP awarded a total of $\$ 104.0$ million to the 50 completed projects and another $\$ 10.5$ million to 16 terminated projects (see Appendix B), bringing total ATP spending on 66 projects completed or terminated by May 1998 to $\$ 114.5$ million. What is the public investment producing in the way of benefits?

Estimated benefits attributed to ATP from just a few of the top-performing 50 projects not only greatly exceed ATP's funding for all of the 66 projects, they also far exceed the total of ATP costs for all of the 522 projects funded to date.

In addition to benefits exceeding costs, there is strong evidence that benefits are extending well beyond those captured by the award recipients. There is substantial evidence that knowledge was generated by the projects and that it is being disseminated to others through publications, presentations, patents, products, and other means. The patent trees developed for these projects reveal rich citing of the patents by others. The products and processes generated by the projects are also yielding benefits to others: patients are receiving spillover benefits from better medical treatments at lower costs; consumers are receiving spillover benefits when they buy superior products for which they pay less than the full value; and companies are receiving spillovers when they increase their productivity or achieve greater value added by using A'TPfunded technologies.

This completes the portfolio view of the ATP. Now let us look at the 50 individual projects.

\footnotetext{
${ }^{41}$ 'l'he tests of success are taken from a presentation by Rosalie Ruegg before the National Grants Management Association's Annual Conference, Federal Bar Association Panel, April 4, 2000.
} 

ADVANCED TECHNOLOGY PROGRAM

CHAPTER 2

Advanced Materials \& Chemicals 

$A L L I E D S I G N A L, \mid N C$.

\section{A Process for Making Ceramic Parts}

$M$

any types of industrial and commercial equipment contain parts that revolve at very high speeds, under great stress, and in extreme heat. Jet engines, power generation turbines, and automobile engines are a few examples. In the past, metal has been accepted as the only material for making such parts.

COMPOSITE PERFORMANCE SCORE (Based on a four star rating.)

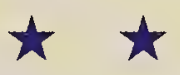

\section{Safe, Low-Cost Fabrication of High-Performance Ceramic Parts}

With the recent development of high-performance structural ceramic materials, this ATP project with AlliedSignal asked whether it was possible to develop a process for fabricating ceramic parts inexpensively enough to allow them to be substituted for metal parts, thereby significantly improving equipment performance and reliability.

\section{... a novel near net-shape \\ . . process for making high-performance ceramic parts for automobile and aircraft engines.}

Ceramic substitutes for metal have performed well in certain critical situations. Space flight is one. Ceramic tile coverings on spacecraft form heat shields that protect astronauts re-entering earth atmosphere. Atmospheric friction heats the tiles to a fiery glow. But the tiles stay in place and dissipate enough heat for safe re-entry. Metal surfaces would melt under these circumstances, with disastrous results.

\section{Cost and Safety Issues Hinder Use}

Despite such performance advantages, the application of advanced ceramics has been held back by the high cost of fabrication. Whereas metal can be meltprocessed or plastically deformed using molding, extruding, stamping, or other standard metalworking techniques, many ceramics cannot be processed by these methods. Ceramic parts must be made by forming ceramic powder into a desired shape at room temperature and then "reacting" the powder compact at various temperatures to densify it. This process is

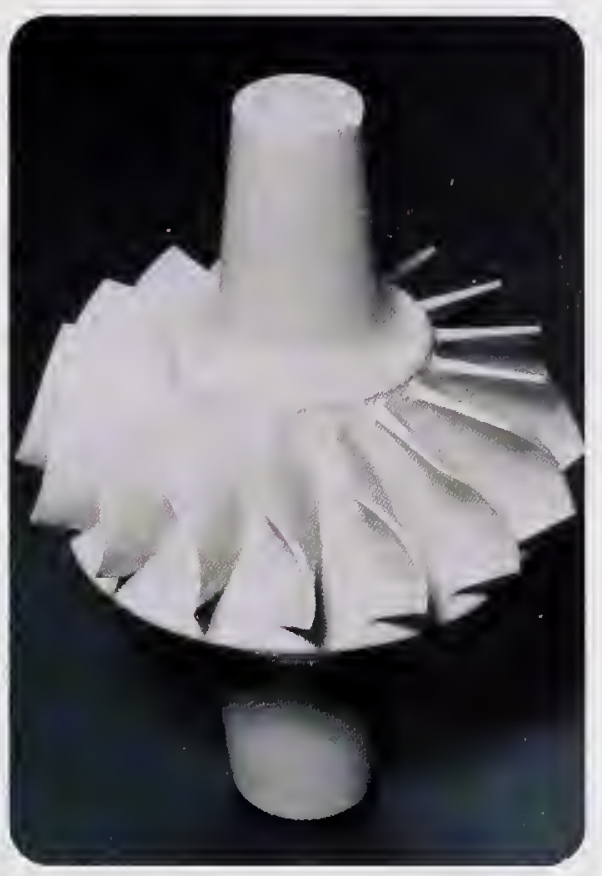
A 16-blade silicon nitride turbine wheel for use in small turbogenerators. much more limited in the shapes it can achieve than melt-processing or plastic deformation approaches.

This ATP project offered a novel approach to ceramics production via a relatively new process called gelcasting, a technology developed at Oak Ridge National Laboratory. In gelcasting, powdered ceramic precursors are mixed with a polymer precursor (monomer) and solvent (usually water) to make a slurry that is poured into a mold. The gel is then polymerized, locking the ceramic powder in a polymer matrix. The solvent is removed, and the part is heated 


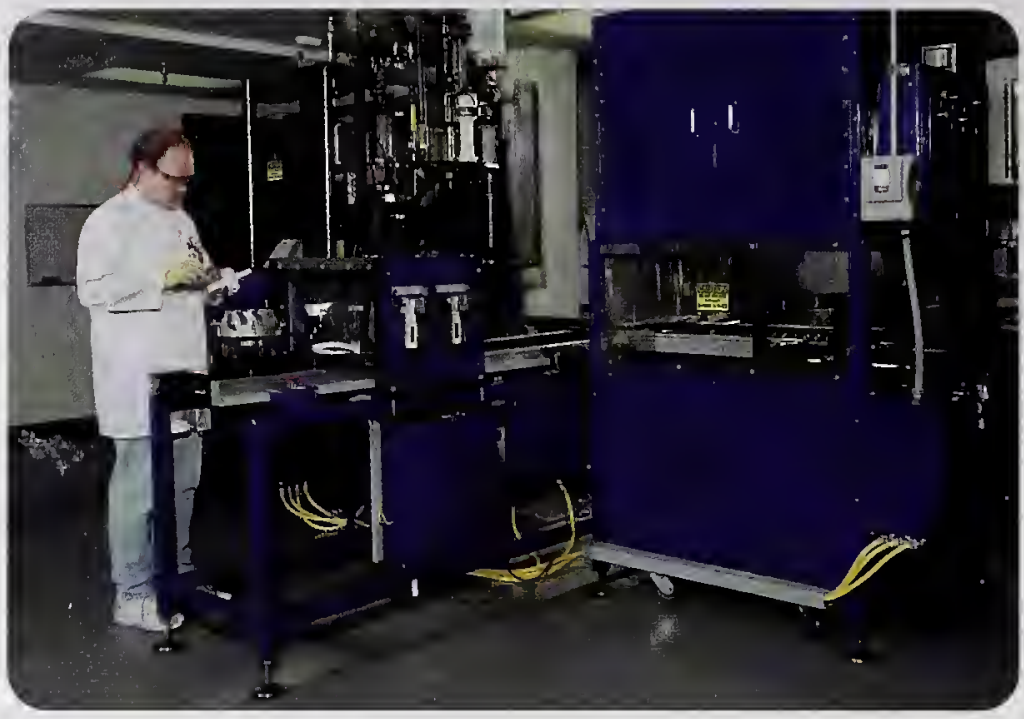

An automated gelcasting machine capable of forming

10,000 ceramic turbine wheels per year.

to burn out the polymer. At this point, if necessary, the "green" part can be machined to some degree. Finally, the part is fired to produce the ceramic. The process is capable of making very complex parts such as turbine wheels. Some shapes made with this technique cannot be made any other way.

\section{... potential applications in energy, chemicals, aerospace, electronics, advanced materials and telecommunications.}

A major drawback to the original gelcasting technology was its reliance on acrylamide as the gelling additive. Acrylamide is highly sensitive to oxygen, which inhibits polymerization. So the process must be done in an inert environment, which raises the cost. Acrylamide gel is also very difficult to remove if an inert environment is used, raising costs even more. Most important, however, acrylamide is a cumulative neurotoxin, and safety concerns had prevented the technology's widespread use.

AlliedSignal's innovation in this ATP project was to develop a low-cost, nontoxic alternative that retains acrylamide's excellent process characteristics. During the project, AlliedSignal researchers developed and demonstrated a novel near net-shape (requiring almost no machining) process for making high-performance ceramic parts for automobile and aircraft engines. In addition, the new gelcasting process has potential applications in energy, chemicals, aerospace, electronics, advanced materials, and telecommunications.

\section{Early Commercialization Expected}

Development of the technology is continuing. In 1995, under the "Partnership to Productionize and Commercialize a Manufacturing Process for Silicon Nitride Turbomachinery Components," AlliedSignal began receiving funds from the Defense Advanced Research Projects Agency for work that grew directly out of the ATP-funded gelcasting project. The company received additional funding for this effort from the Department of Energy in 1997, and it has made substantial progress toward a commercially viable manufacturing process. Marketable products have yet to be sold. But commercial production is expected to begin in the very near future, with annual sales projected to be several million dollars.

\section{. . acrylamide is a cumulative neurotoxin, and safety concerns had prevented the technology's widespread use.}

AlliedSignal has constructed a new plant for manufacturing ceramic parts, including those made with the gelcasting technology. Since the close of the ATP project in June 1995 , the company has invested $\$ 3$ million to further develop the technology for particular commercial applications. In addition, based explicitly on the successful completion of the ATP project, it received funding from the Department of Energy and the Defense Advanced Research Projects Agency to advance gelcasting technology into commercialization.

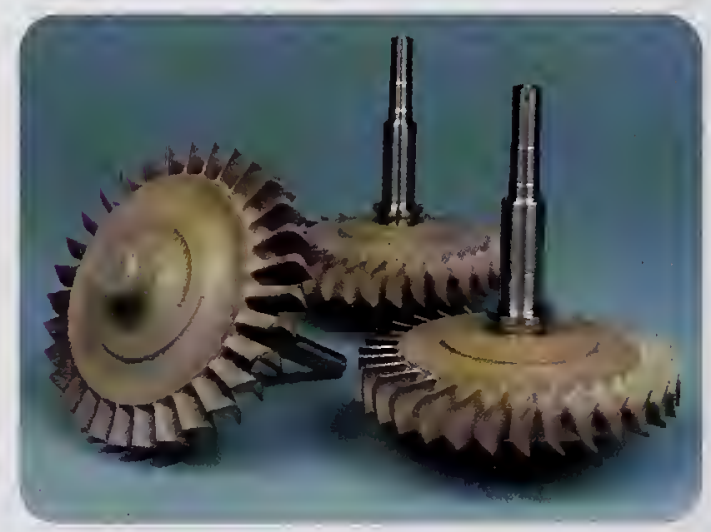

Near net-shape turbine wheels for use in commercial or military jet engine starters.

\section{Cost Reductions and Improved Performance}

Users of vehicles and other equipment using gelcast ceramic parts instead of metal ones will benefit from cost reduction and improved performance - in the case of some applications, to a considerable degree. Since Oak Ridge National Laboratory holds the underlying intellectual property for gelcasting, additional spillover benefits 


\section{PROJECT HIGHLIGHTS}

\section{PROJECT:}

To develop a low-cost, near-net-shape gelcasting process for making structural ceramics in a safer, less-costly way than conventional gelcasting based on acrylamide, a cumulative neurotoxin. Successful development of this process would open the door to commercial gelcasting production of these high-performance ceramics.

Duration: 7/1/1992 - 6/30/1995

ATP Number: 91-01-0187

\begin{tabular}{lrr}
\multicolumn{3}{l}{ FUNDING (in thousands): } \\
ATP & $\$ 1,136$ & $56 \%$ \\
Company & $\frac{884}{4}$ & $44 \%$ \\
Total & $\$ 2,020$ &
\end{tabular}

\section{ACCOMPLISHMENTS:}

AlliedSignal achieved its R\&D goal. The company also:

presented the new technology at several professional conferences;

invested after the ATP project another $\$ 3$ million of its own money on additional gelcasting $R \& D$ aimed at the development and installation in 1998 of an automated gelcasting system that can fabricate ceramic automotive turbogenerator wheels at a rate of 10,000 per year, and

received funding from the Department of Energy and the Defense Advanced Research Projects Agency to further advance gelcasting technology, with the specific goal of establishing viable manufacturing processes.

are likely to accrue. As a national laboratory, Oak Ridge offers its technologies to the public, and other companies are likely to realize considerable spillover benefits from the AlliedSignal/ATP-funded gelcasting technology. Oak Ridge has already licensed gelcasting technology to two other U.S. companies - a magnetic ferrite manufacturer and a small manufacturer of ceramics for automotive and fuel cell applications - and is working with a number of

\section{... invested . . . another $\$ 3$ million of its own money. . . aimed at the development and installation in 1998 of an automated gelcasting system . . .}

other companies evaluating the technology.

Future benefits are also expected to come from applications of the new gelcasting process in a number of sectors, including large aircraft engine parts. In addition, there may be applications in small parts for jet engines, small

\section{COMMERCIALIZATION STATUS:}

Commercialization is in progress, and the first gelcast parts made with the new technology are expected to reach the market very soon. Opportunities exist for commercialization in a variety of fields.

\section{OUTLOOK:}

The company is making excellent progress toward its commercialization goals and is expected to start producing gelcast parts in large volume in the near future. Users of vehicles or equipment made with gelcast ceramic parts will benefit from lower cost and better performance, with potentially huge benefits accruing in areas like auto engines, commercial aircraft and industrial applications such as stationary power generation.

\section{Composite Performance Score: $\star \star$}

\section{COMPANY:}

AlliedSignal, Inc., Ceramic Components (formerly Garrett Ceramic Components Division, AlliedSignal Aerospace)

2525 W. 190th St.

Torrance, CA 90504

Contact: John Pollinger

Phone: (310) 512-5654

Informal Collaborator: Oak Ridge National Laboratory

turbine generators for hybrid electric/fossil fuel cars and auxiliary power systems for aircraft.

\section{Progress Accelerated by Five Years}

Because of its success in developing the new gelcasting technology, AlliedSignal has also succeeded in developing the manufacturing technology and component fabrication projects that allow commercialization to progress. The company says that without the ATP funds, it would have needed another five years to reach this stage of development. And it would have been that much further behind its major competitor, Kyocera of Japan. Instead, AlliedSignal

$$
\text { ... made possible by the ATP }
$$

grant was the establishment of a technology-development relationship between AlliedSignal and Oak Ridge National Laboratory. 
believes that with the help of the ATP funds, it has now pulled even with Kyocera in most applications and is able to make superior-quality products in several areas.

Another clear benefit made possible by the ATP grant was the establishment of a technology-development relationship between AlliedSignal and Oak Ridge National Laboratory. Relations have continued through a scientific exchange agreement for an Oak Ridge scientist who coinvented the original gelcasting technology to work at AlliedSignal for two years. 


\section{Highly Sensitive Detectors for Biomedical and Environmental Diagnostics}

A

technology that can detect minute traces of biomolecules - pesticides, bacteria in water, organic toxins like botulin - much better than conventional detectors would be extremely useful in a number of fields. Medicine, for instance, has obvious need for highly sensitive methods of detecting viruses. Such a technology would also be applicable in a broad range of environmental areas, where early detection of chemicals or other substances could trigger corrective action early enough to head off disaster. Detecting traces of toxic materials in a municipal water supply, for example, might lead to the elimination of their source before they poison the city's population. A highly sensitive detection technology could also be useful for the optimized control of semiconductor fabrication.

COMPOSITE PERFORMANCE SCORE (Based on a four star rating.)

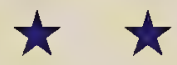

\section{Detecting Minute Amounts of Unwanted Molecules}

This ATP project created such a technology through the efforts of BioTraces, a small company founded in 1989 to develop, manufacture, and market instruments for detecting microtraces of various materials. During its ATP project, the company developed a highly sensitive biomolecule detection method based on an improved radioactive tracer detection system originally developed for cosmology. Instruments of this types use radioactive isotopes that are chemically bound to the target molecules or atoms. Photon or electron detectors that register radiation decay particles are used to spot the "tagged" targets. Sensitivity is limited by background radiation - 10 to 100 counts per minute for conventional commercial instruments in typical applications. BioTraces beats this limitation with a sophisticated multiphoton detector (MPD) that registers only counts that match the multiple-photon decay pattern of the isotopes used as tags. In contrast to conventional methods, background levels for BioTraces detectors are a few counts per day.

\section{Safer Analyses for Patients and the Environment}

The BioTraces technology uses different isotopes to tag different types of molecules in the sample. This allows several different molecule types to be measured simultaneously, greatly speeding complex analysis tasks such as those used in clinical screening (for example, to detect contaminants in blood supplies). Since background interference is so low, the minimum amount of isotope needed for an analysis can be as much as 1000 times less than that used in conventional radioisotope analysis, making the BioTraces system considerably safer for patients and the environment.

\section{Detecting traces of toxic materials in a} municipal water supply, for example, might lead to the elimination of their source before they poison the city's population.

The company met most of the project's technical goals. Its researchers developed prototype MPD instrumentation hardware and software that is much more sensitive than current state-of-the-art equipment. They also developed biomedical applications of the technology for enhanced immunoassay, chromatography and nucleic acid analysis.

\section{First Fruits of Commercialization}

At the start of the ATP project, BioTraces planned to do only the instrumentation work and to leave specific applications to partner companies. But lack of success in finding suitable partners led BioTraces to change its approach to commercialization. It is now finishing development work on the MPD technology and hopes to begin offering its own commercial products widely in the near future. 


\section{PROJECT:}

To develop instrumentation based on multiphoton detection (MPD), highspeed/high-sensitivity sensors and proprietary software, one that can detect minute concentrations of chemicals in gas, liquid or solid matrices - a technology that would be extremely useful in environmental monitoring and biomedical research.

Duration: 1/1/1994 - 12/31/1996

ATP Number: 93-01-0250

\begin{tabular}{|c|c|c|}
\hline \multicolumn{3}{|c|}{ FUNDING (in thousands): } \\
\hline ATP & $\$ 1,718$ & $69 \%$ \\
\hline Company & 773 & $31 \%$ \\
\hline Total & $\$ 2,491$ & \\
\hline
\end{tabular}

\section{ACCOMPLISHMENTS:}

BioTraces developed MPD instrumentation, both hardware and software, as well as biomedical applications of the technology for enhanced immunoassay, chromatography and nucleic acid analysis. The company:

applied for two patents on technology developed during the ATP project: "Enhanced Chromatography Using Multiphoton Detection" and "Ultralow Background Multiple Photon Detection;"

negotiated with the French company Pasteur-Merieux Connaught an agreement under which BioTraces developed an MPD-enhanced quantitative polymerase chain reaction assay for measuring tiny amounts of DNA and RNA;

negotiated a $\$ 1.78$ million agreement in July 1996 with a newly-formed company, PetroTraces, granting it an exclusive license for commercial applications of the new technology in the petroleum industry - a deal that so far has generated $\$ 585,000$ in revenues for PetroTraces and $\$ 560,000$ in license fees for BioTraces;

- arranged in June 1997 for Genetics Institute, Inc., to evaluate the MPD technology as a pharmaceutical R\&D tool; if successful, the test could lead to a license allowing Genetics Institute, Inc. to use the technology in its drug discovery program;

The company has made enough progress to license the technology exclusively to a new company, PetroTraces, for petrochemical applications. Petro Traces uses it to tag and trace different liquids and gases that are transported in pipelines so it can supply customers with data for auditing and other applications.

\section{BioTraces expects to launch wide-scale}

$$
\begin{gathered}
\text { sales of the SSMPD } \\
\text { or early } 1999 \ldots
\end{gathered}
$$

BioTraces' own initial commercial product, the ssMPD (sequential sample MPD) is used for super-sensitive measurement in extremely small samples - up to a created a clinical diagnostics device, the ssMPD ${ }^{\mathrm{TM}}$ (sequential sample MPD), which received market clearance from the U.S. Food and Drug Administration and entered the market on a limited basis in 1997;

$\square$ has received since the start of the ATP project $\$ 1$ million in equity investment to support commercialization of the new technology; and

- entered into discussions with two venture capital firms about securing an additional \$4 million in equiry funding in 1998 or 1999.

\section{COMMERCIALIZATION STATUS:}

Commercialization is in progress. Applications of the technology are underway in the petrochemical field via PetroTraces. BioTraces' first commercial product for medical applications, ssMPD ${ }^{\mathrm{TM}}$, has entered the market on a limited basis and is expected to be more widely available in 1998 or 1999 .

\section{OUTLOOK:}

Once BioTraces works out a strategy for protecting its intellectual property, the new technology is expected to be disseminated more aggressively. Given its potential use in detecting viruses, bacteria, toxins and pollutants, the ATP-funded technology stands to generate substantial benefits to the economy. If, for example, it were used to detect a toxin in a water supply, preventing a whole town or region from becoming ill, the benefits would be enormous.

\section{Composite Performance Score: $\star \star$ COMPANY:}

BioTraces, Inc. 10517-A West Drive

Fairfax, VA 22153

Contact: E. James Wadiak

Phone: (703) 273-6941

Number of Employees: 3 at project start, 14 at the end of 1997

few milliliters. The ssMPD received market clearance from the U.S. Food and Drug Administration for sale as a clinical diagnostics device and entered the market in 1997 on a limited basis for use in research. Bio Traces expects to launch wide-scale sales of the ssMPD in late 1998 or early 1999, after enhancing protection for its proprietary software and establishing a strategic alliance with a major clinical diagnostics company.

The new MPD technology has great potential as an advanced biomedical diagnostic tool and for other uses where detection of minute traces of biomolecules is critical. BioTraces entered an agreement with Pasteur-Merieux Connaught, a French company, under which it developed an MPD-enhanced quantitative polymerase chain reaction assay for measuring tiny amounts of deoxyribonucleic acid (DNA) and ribonucleic acid (RNA). And in June 1997, it arranged for Genetics Institute, Inc., to evaluate the MPD 
technology as a pharmaceutical research and development tool. If the test is successful, it could lead to a license allowing Genetics Institute, Inc., to use the technology in its drug discovery program.

\section{ATP Gives a Big Boost to a Small Startup}

BioTraces is a very small company, having only three employees when it started the ATP project. Since then, the company has received $\$ 1$ million in equity investment to support commercialization of the new technology. It has also entered into discussions with two venture capital firms about securing an additional $\$ 4$ million in equity funding in 1998.

Company officials report that the ATP award enabled Bio Traces to achieve its research results two to three years sooner than it otherwise would have been able to do.

The funds also helped it develop research alliances and improved its ability to raise investor capital. 



\section{Making Low-Cost, High-Quality Glass Microlenses at Low Temperature}

\section{$\int_{\text {iny }}$} systems, detector arrays, and fiberoptic data links. Tens of millions of these components are produced every year. Many are made of plastic, are of low quality, and cost little. Others made of silica glass are higher quality, but they cost much more than plastic lenses.

COMPOSITE PERFORMANCE SCORE (Based on a four star rating.)

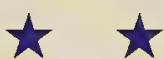

\section{Technology for Making Small, Complex Silica Micro-Optics}

This ATP project with Geltech, a small Florida company, developed a novel method for producing low-cost, highquality silica-glass microlenses based on "sol-gel" technology pioneered by the company. Geltech was founded in 1985 to commercialize micro-optics technology (dealing

\section{... the technology could not produce} refractive microlenses at a cost low enough to penetrate this market... with light wavelengths in the range of nanometers to hundreds of microns) discovered at the University of Florida, and it holds exclusive licenses for patents assigned to the university.

\section{Casting Silica at Room Temperature}

Silica cannot be used with traditional molding techniques because of its very high melting temperature. In addition, conventional grinding and polishing processes limit how small and complex the silica micro-optics can be. Geltech overcame these problems by developing methods to cast net-shape (no grinding necessary) silica-glass micro-optics at room temperature using sol-gel technology.

In the sol-gel process, silicon alkoxides are formed into larger molecules (polymerized) and combined with a liquid in a suspension, or sol, that is cast in a mold at room temperature to make a rigid, wet gel. The gel, in turn, is dried, strengthened and densified at high temperature into a pure, highly homogeneous, silica-glass structure. The ATP project demonstrated that fully dense silica glass - hard, transparent, nonporous glass with a density of two grams per cubic centimeter - can be produced by this process with a quality similar to that of the best fused silica glass.

\section{Signs of Initial Technical Success}

Near the end of the A'TP project, five of the company's prototype refractive lens devices were tested by a customer and found to perform satisfactorily. In addition, the Army recent-

\section{... used some of the ATP-funded technology to develop a porous-glass product, which has been introduced to the market as a component of a home sensor for toxic gases.}

ly gave Geltech a Small Business Technology Transfer Research Phase II award for research using technology partly developed with the ATP funding. Under the contract the company will build prototype windows molded in silica using the sol-gel process. The windows are designed to protect military personnel from intense laser pulses. 


\section{PROJECT HIGHLIGHTS}

\section{PROJECT:}

To develop a method of casting net-shape (no grinding necessary) pure silica glass micro-optics at room temperature.

Duration: $4 / 5 / 1993$ - 7/4/1995

ATP Number: 92-01-0074

$\begin{array}{lll}\text { FUNDING (in thousands): } \\ \text { ATP } & \$ 1,323 & 48 \% \\ \text { Company } & \frac{1,456}{2} & 52 \% \\ \text { Total } & \$ 2,779 & \end{array}$

\section{ACCOMPLISHMENTS:}

Geltech demonstrated that high quality, silica glass micro-optics can be produced by a manufacturing process that includes a room-temperature, net-shape casting method. Also, in activities related to the ATP project, the company:

had five prototype refractive lens devices tested by a customer and found to perform satisfactorily;

used the technology to develop diffraction gratings, for use in conjunction with lasers in optical systems, with market introduction just beginning;

used some of the ATP-funded technology (materials processing and mold fabrication methods) to develop a porous-glass product, which has been introduced to the market;

- used the procedures for making optical-quality molds, developed in the ATP project, as initial steps toward commercialization of plastic micro-optics;

increased revenues from less than a quarter million dollars in 1992 to $\$ 5$ million in 1995, with the new technology playing a significant role in the company's revenue growth; and

recently received a Small Business Technology Transfer Research Phase II award from the Army for research using technology developed in the ATP project.

\section{Secondary Products}

Although the ATP-project demonstrated that high-quality, silica-glass micro-optics can be produced by the sol-gel process at low temperature, the technology could not produce refractive microlenses at a cost low enough to penetrate this market. Therefore, the company has been as yet unable to commercialize microlenses produced by the new process.

The company, however, succeeded in using the new technology to produce diffraction gratings, its second major product, with acceptably high surface quality and at reasonable cost. A diffraction grating is a band of equidistant parallel lines (usually more than 5,000 per inch) ruled on a glass or polished metal surface and used to break a beam of light into components of different wave lengths. The company has just begun to offer parts to customers for use in conjunction with lasers in optical systems. It is too early to tell whether commercialization of its diffrac-

\section{COMMERCIALIZATION STATUS:}

Commercialization of refractive microlenses, one of the major products envisioned in the ATP project, has not occurred because the technology did not produce microlenses with a high enough surface quality to penetrate this market. Geltech began using the ATP-funded technology in 1994 to produce a porous-glass product for a home sensor application, with production reaching a peak of about 500,000 parts per week at the end of 1995 and sales achieving significant levels. Although today the sales of products derived from the ATP technology are relatively small, sales of diffraction gratings - the second major micro-optics product envisioned in the project - have just begun.

\section{OUTLOOK:}

Despite the successful commercialization of other products using the ATP technology, it is too early to tell when refractive microlenses will enter the commercial marketplace or whether commercialization of diffraction gratings will succeed. However, if the cost per piece of diffractive gratings continues to drop and Geltech succeeds in selling large volumes of them, producers and users of systems that contain optical components such as printers will benefit from parts that are smaller than their refractive counterparts or that perform functions not possible with refractive parts. Users of one device already on the market, a home sensor product for detecting toxic gases (details are still confidential), are already benefitting from the technology.

\section{Composite Performance Score: $\star \star$}

\section{COMPANY:}

Geltech Incorporated

3267 Progress Drive

Orlando, FL 32826

Contact: Jean-Luc Nogues

Phone: (407) 382-4003 ext. 302

Number of employees: 7 at project start, 65 at the end of 1997

tion gratings will succeed. Acceptance of this product in the marketplace has taken longer than anticipated.

Geltech also used some of the ATP-funded technology — materials processing and mold fabrication methods -

$$
\begin{gathered}
\text { The ATP project demonstrated that } \\
\text { fully dense silica glass . . . can be } \\
\text { produced by the sol-gel process with } \\
\text { a quality similar to that of the best } \\
\text { fused silica glass. }
\end{gathered}
$$

to develop a porous-glass product, which has been introduced to the market as a component of a home sensor for toxic gases. The details of this application are still confi- 
dential. The company is also using some of the technology to develop plastic micro-optics, which are lighter and less expensive than glass micro-optics, with hopes for commercialization in consumer products in the near future.

Geltech officials say the ATP funding helped the company form alliances with research partners and enabled it to conduct research it would otherwise have been unable to do. The funding was also critical in helping Geltech survive as a company. Geltech more than doubled its revenues over the ATP grant period, and the new technology played a significant role in boosting the company's revenues from less than a quarter million dollars in 1992 to about $\$ 5$ million three years later.

\section{Potential Broad Applications}

If the unit-cost of diffraction gratings continues to drop and Geltech succeeds in selling large volumes of them, producers and users of systems that contain optical components will benefit from components that are smaller, lighter and less expensive than their refractive (light-bending) counterparts. In addition, diffractive parts may perform functions not possible with refractive parts. Geltech's sales are small at this point, and specific applications are still in the testing stage, but the potential broad applications and benefits are there.

\section{. . . ATP funding helped the company form alliances with research partners ... enabled it to conduct research ... . critical in helping Geltech survive . . .}

The new gelcasting process technology can be used in manufacturing microlenses, microlens arrays, beam splitters and other micro-optics, and the company anticipates moving into these markets when it is economically feasible to do so. The technology has already been applied to refractive lenses, diffraction gratings, and porous glass optics. It might also be used for producing ceramic packages (casings for chips in computers and communications equipment) in electronics manufacturing and for applications in the global surveillance and communications fields. 



\section{Methods for Making New Optical Switches}

$\Gamma_{n f o r}$ e-mail, radio and TV broadcast, and data downloading. Several technologies are useful for each type of transmission, and in some instances, both electrical and optical methods can be used. Optical transmission has a signalquality advantage over electrical transmission in cable TV, telephone trunk lines, undersea cables and other cable applications.

COMPOSITE PERFORMANCE SCORE (Based on a four star rating.)

No Stars

\section{Faster, Cheaper Optical Transmission of Data}

Optical fiber is rapidly replacing metal wires in terrestrial and oceanic transmission, both for voice and data, because of cost savings and improved performance. Optical methods also have a potential advantage for transmitting information from component to component within computers. If optical signals could replace electrical signals in this context, bandwidth could be multiplied many fold, while heat generation and cross-talk - significant problems in computers - could be greatly reduced.

\section{New Optoelectronic Polymer and Prototype Switches}

IBM's ATP project aimed to develop optical switches to link the optical fibers running between components in computers. Current-generation switches convert data from an optical to an electrical signal, do the necessary switch-

\section{. . bandwidth could be multiplied}

many fold, while heat generation and cross-talk . . . could be greatly reduced.

ing, and then convert the data back to an optical signal, a process that involves expensive components and significantly limits the speed of the system. IBM's proposed technology would help achieve the technical advantages of optical signals over electrical signals in computers.

IBM researchers succeeded in developing high-speed, inexpensive optoelectronic switches using nonlinear optical polymeric waveguides suitable for use in the data com-

... this technology . . . may ...

be useful in telecommunications, rather than computers.

munications industry. Specifically, the project developed a general method for identifying and synthesizing particular dipolar molecules, known as chromophores, that are chemically stable at temperatures exceeding $300 \mathrm{C}$. Researchers were able to incorporate these molecules into thermally stable polymers, producing the desired optoelectronic polymer.

\section{Market Fails to Materialize as Expected}

Commercialization by IBM is not expected in the foreseeable future, even though IBM completed working prototypes of polymeric switches. The need for such switches in the envisioned application changed, and a broad market opportunity did not materialize. Technological change in this industry is rapid, and trends can suddenly switch directions. 


\section{PROJECT:}

To develop high-speed, inexpensive optoelectronic switches using nonlinear optical polymeric waveguides suitable for use in the data communications industry.

Duration: 8/1/1992 - 7/31/1995

ATP Number: 91-01-0017

FUNDING (in thousands):

ATP $\$ 1,787 \quad 44 \%$

Company $\quad 2,235 \quad 56 \%$

Total $\$ 4,022$

\section{ACCOMPLISHMENTS:}

Researchers reduced the size and cost and improved the speed and efficiency of switches for computers and communications systems. IBM produced working prototypes of polymeric switches. Technical progress is indicated by the fact that IBM:

received a patent for technology related to the ATP project: "Optical photorefractive article" (No. 5,607,799: filed 4/21/1994, granted 3/4/1997);

published more than 20 papers in professional journals in areas related to the project goals; and

presented technical results at several professional society meetings and conferences.

\section{New Opportunities Arising}

The rapid expansion of digital data transmission, however, is likely to open up opportunities for low-cost, high-speed optoelectronic switches in the future, and devices based on polymeric materials are viable candidates. Thus, chances are good that this technology will ultimately be used in important applications. Of the six key researchers on the project, five have left the company for other jobs. Knowledge spillover may occur elsewhere, as these researchers use their knowledge of the technology in new applications. They conjecture that the technology may be useful in the near future in telecommunications, rather than in computers. One potential application, according to project researchers, is in wavelength division multiplexing (sending light of more than one wavelength through a single optical fiber), where the technology might provide significant enhancements for high-speed, broadband telecommunications. Another possible application is in microprocessor chip-to-chip interconnects, but semiconductor industry experts suggest that the need for those interconnects may not become apparent for 10 or more years or might not ever arise.

No broad market benefits have emerged yet, because there are no commercial products incorporating the technology, either in the intended or other applications. It is likely, however, that the rapidly expanding use of digital
CITATIONS BY OTHERS OF PROJECT'S PATENTS: See Figure 2.1. COMMERCIALIZATION STATUS:

The technology has not yet been commercialized by IBM or others. The market opportunities for the polymer-based switches have yet to materialize.

\section{OUTLOOK:}

While predicting the future of this technology is difficult, it may possibly be useful in telecommunications, rather than computers. One potential application is in wavelength division multiplexing (sending light of more than one wavelength through a single optical fiber), where the technology may find cost-effective use in switches and other components.

Composite Performance Score: No Stars

COMPANY:

IBM Corporation, Almaden Research Center

650 Harry Road, K13/E1

San Jose, CA 95120-6099

Contact: Mike Ross

Phone: (408) 927-1283

Informal collaborator: University of Colorado

data communication will lead to opportunities for low-cost, high-speed optoelectronic switches in the future. The ATP-funded technology is a core technology for the polymeric materials and devices that IBM demonstrated, and these products have potential in a number of future applications.

The support enabled company researchers to publish more than 20 papers in professional journals, enabling the technology to be disseminated among other researchers.

Through its research under ATP funding, IBM was able to gain access to cutting-edge work being done on optoelectronic devices at the University of Colorado. The support enabled company researchers to publish more than 20 papers in professional journals, enabling the technology to be disseminated among other researchers. The knowledge gains are well documented. 
Figure 2.1 Patent Tree for Project Led by IBM Corporation: Citations by Others of IBM Corporation Patents

PATENT TREE KEY

Original Patent

Second Generation Patent

Third Generation Patent

Fourth Generation Patent

Fifth Generation Patent

1999

1998

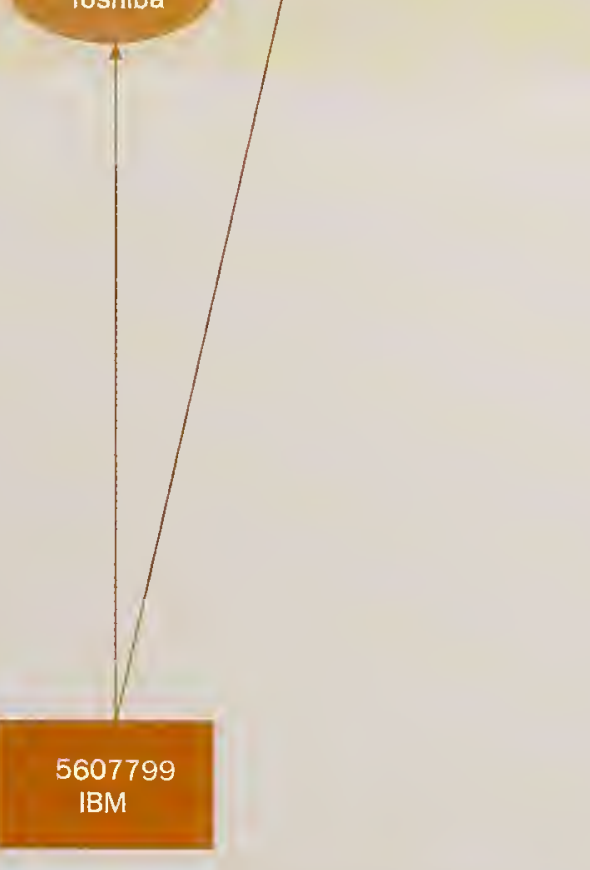

1997 



\section{Insulating Foams for Microelectronics}

人

ince the invention of the integrated circuit (IC) in 1958, chip designers have enhanced processing speeds by squeezing more and more transistors onto microchips. They have accomplished this by shrinking transistors, by shrinking the distance between them, and by increasing the number of layers in a chip. These improvements have reduced the time it takes for electrical signals to travel within integrated circuits by reducing the length of the connecting lines between transistors. Further development of more densely integrated semiconductor circuits depends critically on the availability of effective electrical insulators.

COMPOSITE PERFORMANCE SCORE (Based on a four star rating.)

No Stars

\section{The Challenge of Improving Electrical Insulation}

The electrical and material properties and its geometric shape determine an insulator's effectiveness. An insulating material must have a minimum geometric size, depending on its properties, to provide the desired electrical insulation. As integrated circuits shrink, the room avail-

\section{Further development of more densely} integrated semiconductor circuits depends critically on the availability of effective electrical insulators.

able for the material insulating the wires is reduced, and if insulation is inadequate, the current that carries signals on the chip "leaks," causing signal confusion or "cross-talk." This lowers the reliability of the logic, memory, or processing functions being executed by the integrated circuit.

A group of researchers at IBM recognized that progress toward more densely integrated circuits would be impeded by the material properties of the current industry standard for insulation, silicon dioxide. There are a number of materials with dielectric constants $(\mathrm{k})$-a measure of the ease with which electrons pass through a materiallower than that of silicon dioxide. The ideal insulator, in terms of its impermeability to electron flow and fields, is a vacuum. Air (e.g., air pockets in foam) is an excellent alternative: by creating pores filled with air in a material, its dielectric constant can be decreased. Thus, the researchers sought to figure out how to control the process of creating pores in a material (controlled porosity), with the goal of developing a method of providing new insulating materials to successive generations of IC devices.

\section{Research too Uncertain for Company Funding}

At the time IBM researchers submitted the proposal, few internal resources were available for hardware development due to a shift in priorities in favor of software development. In addition, IBM management considered the development of controlled porosity into a commercially viable practice to be too uncertain a prospect to justify the level of internal support necessary to mount the required research program.

At the time, company resources addressing electrical interconnection problems were focused on a research effort to substitute copper for aluminum in the fabrication of chip wires. IBM management believed that substituting copper for aluminum in the fabrication of wires might circumvent the need for improved insulators, copper being a much better conductor than aluminum. Some believed that the substitution of copper would allow for increases in signal speed sufficient to eliminate the need for the increased levels of integration that would make a new type of insulator necessary.

These factors combined to make the company unwilling to proceed with the research on controlled porosity without assistance. The researchers submitted their 
IBM researchers aimed to develop organic polymer nanofoams with dielectric constants ( $k$ ) as low as 2.0, almost twice as good as that of silicon dioxide, with its dielectric constant of 3.9 .

proposal in ATP's 1992 General Competition and received an award. The ATP award reduced the risk of the research to a level that IBM management was willing to provide the necessary internal support to pursue the research.

The ATP awarded IBM $\$ 1.8$ million for a three-year, $\$ 5.8$ million project to research and develop alternative methods for producing insulating foams using organic polymers. These foams were to make use of the insulation quality of air by creating tiny, nanometer-scale air pockets in a polymeric structure. IBM researchers aimed to develop organic polymer nanofoams with dielectric constants (k) as low as 2.0, almost twice as good as that of silicon dioxide, with its dielectric constant of 3.9.

\section{Some of the work was subcontracted to} researchers at Virginia Polytechnic Institute, Exfluor Research, and Sandia National Laboratories.

\section{The Project Team}

The project was led by researchers at IBM's Almaden Research Center in San Jose, California, and facilities in East Fishkill, New York. Some of the work was subcontracted to researchers at Virginia Polytechnic Institute, Exfluor Research, and Sandia National Laboratories. The composition of this team reflected an effort by IBM to harness the expertise of these institutions and to expose expert chemists to the specific needs of the microelectronics industry.

\section{Researchers Pursue Three Parallel Research Efforts}

Research on low-k dielectric foams was guided by a number of requirements. First, to be usable as insulators, foams must be produced with a specific horizontal and vertical thickness. Second, they must be structurally rigid to withstand the stresses of fabrication. Third, they must be able to withstand the high temperatures used in the deposition of metal wiring in the fabrication of integrated circuits. Aluminum wiring is deposited at temperatures of more than $450^{\circ} \mathrm{C}$.

The researchers pursued three different approaches to the development of low-k dielectric foams for insulation of microelectronics devices. One approach investigated closed-cell molecular foams. These foams incorporated a cage-like molecular structure inside a polymer, forming tiny pores in which the polymer would encapsulate air or other gaseous molecules. Given the lack of data on this technology, however, there was concern as to whether molecular foams with dielectric constants of less than two could be achieved while still meeting the other requirements for microelectronic applications. Researchers anticipated this approach might need to be combined with one of the other two processes.

The second approach to constructing polymer foams built on a method called induced phase separation, which had been developed by Sandia National Laboratories. The researchers sought to determine whether this process could produce extremely thin, heat-resistant foam structures suitable for microelectronic applications.

The third approach investigated the block copolymer method, considered the most promising by IBM. This approach combined two different polymers with different chemical and physical properties to create a structure that would provide the desired performance as an insulator while withstanding the heat employed in the process of fabricating aluminum circuitry.

\section{Achievements}

The first approach, which examined closed-cell molecular foams, was abandoned early in the project. The process did not produce foams that had low enough dielectric constants and that were uniform in their insulating properties.

The researchers carried out extensive experimentation with the second approach, which used induced phase separation. This technique developed extremely good electrical insulating foams, some of which had dielectric

\section{Using the block copolymer method, IBM} and its colleagues generated foams with the desired thermal characteristics, as well as foams with the desired electrical insulation, but could not produce foam that had both qualities at the desired levels. 


\section{PROJECT HIGHLIGHTS}

\section{PROJECT:}

To develop a method for creating insulators for integrated circuits by controlling porosity, with the goal of enabling multiple generations of ever faster and more densely integrated circuits.

Duration: 3/01/93 - 2/28/96

ATP Number: 92-01-0103

FUNDING (in thousands):

ATP $\quad \$ 1,602 \quad 29 \%$

Company $\quad \underline{3,940} \quad 71 \%$

Total $\$ 5,542$

\section{ACCOMPLISHMENTS:}

Research on low-k dielectric foams demonstrated the potential feasibility of polymer foams as insulators. Critical requirements and unpromising approaches were identified. Researchers pursued three approaches in the attempt to create effective foam insulators, and achieved the following: presented the new technology at several professional conferences;

identified two methods, involving molecular foams and induced phase separation, as technically infeasible;

found that one of the methods, involving block copolymers, offers promise for creating foam insulators suitable for microelectronics use;

published results in technical journal articles in the field of microelectronics, including "Templating Nanoporosity in Thin-Film Dielectric Insulators," Advanced Materials 1998; and "Nanoporous Polyimides," Advances in Polymer Science 1999, which laid out the state of the art in the development of block copolymers and the processes used to create nanofoams; and

stimulated further research on insulators for microelectronics.

\section{Researchers identified two methods,} involving molecular foams and induced phase separation, as technically infeasible

constants lower than two. The pores in these foams, however, were too large. It was not possible to use them in an insulating layer thin enough for an integrated circuit of the required density. Because the size of the air pockets could not be sufficiently reduced, the team chose not to pursue this approach further.

Using the block copolymer method, IBM and its colleagues generated foams with the desired thermal characteristics, as well as foams with the desired electrical insulation, but could not produce foam that had both qualities at the desired levels. The researchers did develop significantly better microelectronic insulators, but these insulators would only be usable in the future if copper

\section{COMMERCIALIZATION STATUS:}

IBM has continued its efforts to develop block copolymers for use as insulators. Much work, however, remains to develop a viable process for incorporating block-copclymer foams into microprocessors, and commercialization has not yet been achieved.

\section{OUTLOOK:}

The progress achieved by the ATP project, in combination with favorable market developments, has spurred additional industry efforts to develop insulating foams, and IBM's research results are guiding much of this effort. One initiative is a new ATP-funded joint venture project led by Dow Chemical Company and involving IBM, which aims to develop block copolymers from which to create nano-foam insulators with dielectric constants as low as 1.5. The participation of Dow, a major material supplier, may signal the creation of a base of suppliers capable of providing high-performance insulators for microelectronics. Thus, the outlook is positive for the more recent efforts that have grown out of this project, but not for this project directly.

\section{Composite Performance Score: No Stars}

\section{COMPANY:}

IBM Corporation, Almaden Research Center

650 Harry Road

MS K17-801

San Jose, CA 95120-6099

Contact: Dr. Robert D. Miller

Phone: (408) 927-1646

Subcontractors: Virginia Polytechnic Institute, Exfluor Research, and Sandia National Laboratories

wiring were to be substituted for aluminum, so that fabrication temperatures could be kept below $400^{\circ} \mathrm{C}$.

\section{Post-Project Developments}

Toward the end of the ATP project, IBM's other work on the substitution of copper for aluminum indicated that the move to copper alone would not be enough to speed up integrated circuits as much as desired. New insulating materials would, after all, be necessary to meet performance needs. Thus, work on block copolymers continued at IBM.

Since the end of the ATP project, IBM has made considerable progress in the development of improved block copolymer foams, but much work remains in the development of a viable process for incorporating these materials into the fabrication of microprocessors. Indeed, low dielectric constant insulators $(\mathrm{k}<2.5)$, including polymer foams, have yet to be fully developed or incorporated into integrated circuits. Separately, however, IBM's first series of integrated circuits with copper wiring (CMOS 7S) have 
been developed, lowering IC processing temperatures and increasing the possibility of lower-k polymer dielectrics being used in future circuits.

In the meantime, IBM also undertook R\&D on nonporous, lower-k dielectric materials that may serve in place of silicon dioxide. For instance, IBM researchers initiated a study of "toughened organosilicates," which have dielectric constants in the range of 2.6-3.0.

\section{ATP-supported Research Stimulates Industry-Wide R\&D Efforts}

Greater understanding of low-k dielectric polymer foams resulting from ATP-funded work at IBM has opened a new window for the study of porous dielectrics (including but not limited to polymer foams) as alternative insulators. At the same time, market conditions have become more favorable. The push toward network computing has also focused attention on the need to develop advanced materials for the high-end microprocessors required for network server functions.

As a result, many U.S. corporations, including Lucent Technologies, Texas Instruments, Motorola, Dow Corning, BF Goodrich, Allied Signal, Dow, Dow Chemical, and Du Pont, as well as IBM, are now reviving research into low-k dielectric materials. A number of key strategic alliances (Allied Signal-Nanopore, IBM-Siemens-'Toshiba, and IBM-Apple-Motorola) have been formed to pursue R\&D in advanced devices and materials. Low-k dielectric materials research has also been stimulated through industry consortia such as SEMATECH. ${ }^{1}$ Consequently, U.S. corporations remain major global players in the development of new low-k dielectric materials for on-chip applications.
The results of IBM's earlier research were substantial enough to attract the interest of a major materials supplier, Dow Chemical Company. Dow formed a joint venture involving IBM's Almaden Research Center and Yorktown Heights facilities, applied to the ATP, and, in October 1998, was awarded ATP funding. The new project aims to identify and develop polymers to produce nanofoams with a dielectric constant as low as 1.5 , and integrate them in common IC fabrication. If the Dow-IBM partnership proves successful, it could help establish a U.S. supplier base for high-performance insulating materials. ATP support in developing new ways to produce insulators for new generations of high-performance microelectronics has helped to secure an important technical option for the industry. It represents one of the efforts underway to sustain progress in integrated circuit technology and increase U.S. producers' share of the global microelectronics market.

\section{The results of IBM's earlier research}

were substantial enough to attract...

Dow Chemical Company.

\footnotetext{
${ }^{1}$ Companies and alliances cited are listed in ATP Final Report, "Low Dielectric Polymers for Microelectronic Applications," No. 70NANB3H1365,

February 12, 1997, p. 68.
} 


\section{$M \mid C H I G A N$ MOLECULAR INSTITUTE (MMI) \\ Recycling Mixed Plastics}

like turning swords into plowshares, the idea of turning waste plastics into fenceposts, park benches, building blocks, and other useful, long-lasting items holds tremendous promise for the welfare of society. Wood rots, iron rusts, and stones weather, but plastic endures. You can tear, bend, or break plastic. But words like "rot" or "rust" simply do not apply - a blessing when durability is at issue; a curse when plastics are dumped into landfills.

COMPOSITE PERFORMANCE SCORE

(Based on a four star rating.)

\section{Technology to Recycle Much More Waste Plastic}

The U.S. economy produces about 75 million pounds of plastic products each year, and the idea of recycling them is appealing. A problem with reusing plastics, though, is that the many kinds do not mix well in recycling processes. Recycling today requires sorting of plastics, many of which still get dumped because they are not compatible with the others. This ATP project with Michigan Molecular Institute (MMI) aimed to develop a technology that would dramatically increase the proportion of plastics that can be

\section{Wood rots, iron rusts, and stones weather, but plastic endures.}

recycled. The new technology would "compatibilize," or alter, various plastics so they mix well in recycling. They could then be formed into pellets with essentially the characteristics of virgin plastics. These pellets would be mixed into a slurry fed into a continuous flow process that puts out a mixed plastic strong enough for construction materials.

A key technical goal of the project was to develop the science and technology of polymer compatibilization, which would enable polymers in the commingled plastic-waste stream to be recycled into commercially useful products.
Collaborating researchers from Eastman Kodak, Eastman Chemical, and the University of Florida (UF) accomplished that goal by establishing the fundamentals of compatibilization of multiphase polymer blends, including new knowledge about the morphology - the shape and structure - of polymer blends. The team also prepared compatibilizers using a variety of chemical approaches and produced and tested prototype compatibilized materials. Researchers found effective methods to compatibilize commingled-plastic waste.

\section{New Recycled-Plastic Products}

Results of the ATP project are being used by Eagle Plastics Systems of Florida to produce compatibilized plastic panels for housing parts, in collaboration with UF researchers who were involved in the ATP project. Large four-inch-thick panels are fabricated by sandwiching fiber-

\section{... a curse when plastics are dumped into landfills.}

glass insulation between thin plastic sheets attached to galvanized steel studs. These wall units are then used for the construction of low cost, modular houses, many of which are used following a fire or other disaster, when temporary housing must be built quickly. The company 


\section{PROJECT HIGHLIGHTS}

\section{PROJECT:}

To develop methods for polymer compatibilization - adding small amounts of a substance to a blend of different plastics to make them chemically compatible so that the material fabricated from them has good mechanical and physical properties. This technology would greatly increase the amount of waste plastic that can be recycled.

Duration: 8/15/1992 - 8/14/1995

ATP Number: 91-01-0088

\begin{tabular}{|c|c|c|}
\hline \multicolumn{3}{|c|}{ FUNDING (in thousands): } \\
\hline ATP & $\$ 1,642$ & $30 \%$ \\
\hline Company & $\underline{3,808}$ & $70 \%$ \\
\hline Total & $\$ 5,450$ & \\
\hline
\end{tabular}

\section{ACCOMPLISHMENTS:}

MMI researchers and their collaborators established the fundamentals of polymer compatibilization, which enables polymers in a waste stream of different kinds of plastics to be recycled into commercially useful products. Indicators of this accomplishment are that MMI and its collaborators:

published more than 10 papers on the technology in professional journals; 1. made the technology available to Eagle Plastics Systems to develop and test materials for the housing construction industry; and

made the technology available through MMI to two ongoing R\&D projects in the automobile industry that focus on recycling plastics from auto parts such as dashboards, door panels and tail lights.

\section{COMMERCIALIZATION STATUS:}

One collaborating company has begun to use the technology in the construction of low-cost modular houses. Information on the technology generated by the project is now available to the plastics and recycling industries via published technical papers, and some of it is being used in additional research projects.

\section{OUTLOOK:}

Commercialization is underway and is expected to increase substantially in the construction of modular housing. The technical base developed in this project is also being used in two new projects that focus on recycling plastic auto parts.

\section{Composite Performance Score: $\star \star$ ORGANIZATION: \\ Michigan Molecular Institute (MMI) \\ 1910 W. St. Andrews Road \\ Midland, MI 48640-2696}

Contact: Conrad F. Balazs

Phone: (517) 832-3882 ext. 590

Informal collaborators: University of Florida; Eagle Plastics Systems; Eastman Kodak Company; Eastman Chemical Company; Inter Recycling, Inc. plans to construct full-scale compatibilized plastic-panel manufacturing plants in the near future.

Eagle constructed an assembly plant in Kentucky and began manufacturing modular houses there in late 1996. It uses recycled plastics brought from a pilot plant to the site by railroad cars that left the state loaded with coal.

\section{Results of the ATP project are being used by Eagle Plastics Systems of Florida to produce compatibilized plastic panels} for housing parts . . .

Because of the extremely low cost of the recycled plastics, the company can manufacture its houses for about $\$ 6$ per square foot, much lower than the cost of conventional housing, which runs as high as $\$ 50$ per square foot. During its first year producing the modular houses, Eagle generated more than $\$ 100$ million in contracts.

In addition, attempts to commercialize the technology are under way via the development of two new MMI research and development projects in the auto industry that focus on recycling plastics from auto parts such as dashboards and door panels. Both projects rely on the knowledge of polymer blend morphology discovered in the ATP project. If these projects generate applications in the auto industry, the ATP technology will be commercialized via that route, as well.

Commercialization efforts did not proceed as quickly as anticipated when the proposal was submitted. One obstacle to the speed of commercialization was a change in ownership and direction of Waste Alternatives, one of the initial collaborators on the project and the company that was planned to play a key role in commercializing the technology.

\section{ATP Funding Critical for Recycling Research}

Without the ATP award, MMI officials say, the project would not have been undertaken. The funding helped MMI forge relations with research partners at the University of Florida, Eagle, Eastman Kodak, and Eastman Chemical. Research on post-consumer plastics packaging recycling, based on the ATP-funded technology and substantial funding from Eagle, is continuing at the university. In addition, researchers there have extended the ATP technology to develop new virgin plastics alloys that are 
expected to lead to further commercialization. A 30 -acre plastics recycling industrial park is being constructed on land owned by the UF Foundation, and continuing support for research amounting to about $\$ 100$ million over the next 15 years is anticipated.

\section{One obstacle to}

\section{the speed of commercialization}

was a change in ownership .. .

In addition, the use of knowledge developed by the ATP project may have advanced the two succeeding studies at MMI for recycled plastics parts in the auto industry by as much as two years. The scientific information generated by the ATP project has also been made generally available, via published technical papers, to the plastics and recycling industries. 



\section{WESTINGHOUSE AND SGS TOOL \\ Plasma Technology for Production of Low-cost Diamond Film}

iamonds not only are beautiful and valuable as jewelry, they also have a number of unique characteristics that make them valuable in a range of commercial applications, including optics, acoustics, medicine, electronics, tooling and hard coatings, abrasives, and ceramics. Economic and technical constraints, however, limit their use. A low-cost method of depositing diamond film would open the way to the cost-effective use of diamond coatings for a wide range of industrial applications. ${ }^{1}$

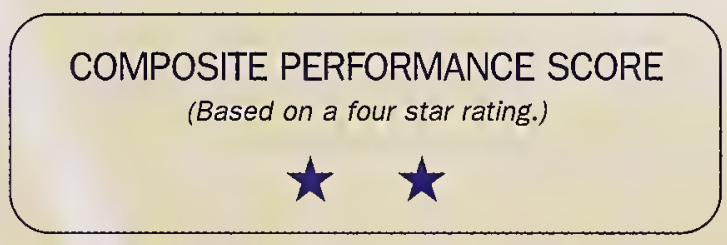

\section{Diamond Coated Tools Offer More Than Sparkle}

High-performance industrial cutting tools, such as drills, are used for machining demanding materials in the automobile, aerospace, and other industries. For example, in the aerospace industry, Boeing alone currently uses on the order of 11 million drill bits per year. There is opportunity for substantial productivity gains by extending the useful life of industrial cutting tools. Not only could the replacement costs of tools be reduced, but so too could the accompanying production downtime that results when tool replacement is required.

\section{There is opportunity for substantial productivity gains by extending the useful life of industrial cutting tools.}

Diamond coatings would harden the tools and extend their lives. The feasibility of utilizing diamond-coated tools, however, depends on the ability to apply diamond coatings at a lower cost. And, key to making diamond films cost effective for application to a broad range of industrial cutting tools is the ability to coat larger areas more quickly at a lower cost per carat than is currently feasible. Current limitations on the size of the area of

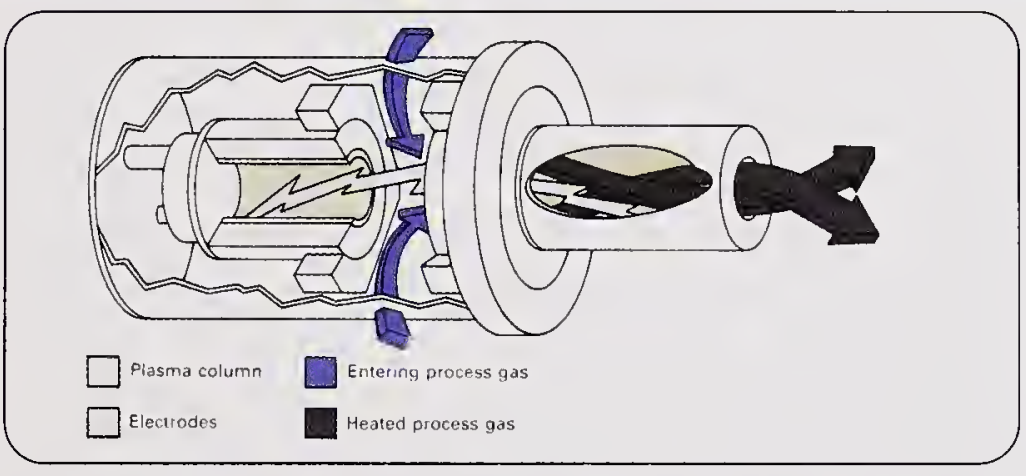

As shown in the above figure, the plasma torch consists of a closely spaced pair of tubular water-cooled electrodes within which an electric arc discharge is magnetically rotated at extremely high speeds. During operation, a process gas is injected into the heater through a space (approximately $1 \mathrm{~mm}$ ) between the electrodes.

deposition mean that costly process repetition is required to coat large cutting surfaces.

\section{Westinghouse Electric and SGS Tool Company Propose to Solve the Problem}

In 1992, Westinghouse Electric Corporation and SGS Tool Company teamed up to propose to the ATP a joint-venture project to develop a low-cost diamond film deposition process. The Westinghouse/SGS team proposed an approach for diamond film deposition based on arc plasma chemical vapor deposition (CVD) technology. The team's specific focus was diamond film coatings for high-performance rotary tools.

\footnotetext{
${ }^{1}$ Status and Applications of Diamond and Diamond-Like Materials: An Emerging Technology, National Material Advisory Board, NMAD-445, 1990.
} 
At the time of the project, several competing technologies were used to apply diamond coatings, including the basic CVD approach proposed for research by the Westinghouse/SGS team, but only in small areas and at high cost. ${ }^{2}$ Westinghouse researchers proposed to concentrate on the arc plasma chemical vapor deposition

\section{...they saw the potential of reducing the cost of diamond coating from over $\$ 30$ per carat to less than $\$ 5$ per carat.}

(arc plasma CVD) process because they judged it to offer the best potential for achieving the desired complex of features: high deposition rate, high quality, and acceptable (per carat) cost.

In 1992, ATP awarded the Westinghouse/SGS team $\$ 2.473$ million for a three-year project. Westinghouse and SGS together contributed $\$ 3.275$ million, for a total project budget of $\$ 5.748$ million.

Westinghouse aimed to increase the power of existing hot cathode plasma torch technology from 15 kilowatts $(\mathrm{kW})$ to a power level of $1,000 \mathrm{~kW}$, or 1 megawatt (MW). Westinghouse/SGS hoped thereby to increase the maximum coating area from roughly 80 to roughly 6,500 square centimeters, and the production rate from about 1 carat per hour to at least 100 carats per hour. By using this approach, they saw the potential of reducing the cost of diamond coating from over $\$ 30$ per carat to less than $\$ 5$ per carat. 'The team also aimed further to cut production costs and increase production rates through an integrated gas recycling process, which would reduce the need for expensive, time-consuming gas replacement.

The team sought to overcome an additional problem: the targeted high-performance rotary tools are made from a tungsten-carbide alloy. The material contains traces of cobalt, and diamonds do not adhere well to cobalt.

\section{The Arc Plasma Chemical Vapor Deposition Process}

In arc plasma CVD, gas that contains carbon passes through an arc chamber. 'This electrically charged chamber superheats and ionizes the gas, creating plasma. The plasma, rich in carbon ions, is projected through a plasma jet onto the substrate (or surface) to be coated. As the plasma cools, the carbon atoms deposit on the substrate as tiny diamond crystals (a particular type of carbon structure), which form a diamond film. This technology is also referred to as the hot cathode plasma torch process.

Increasing torch power was considered critical to success. It would allow for diamond coating to be deposited over a larger area with each run of the plasma torch, thereby increasing the production rate. Because the process would need to be repeated fewer times to coat the same amount of surface area with diamond film, the cost per carat of diamond film would be reduced.

\section{Complementary Know-how of Team Members}

Westinghouse Electric had experience in the development and production of high-power, commercial plasma torch systems. These units are based on cold cathode, nontransferred arc technology. The company had also developed a $15 \mathrm{~kW}$ hot cathode plasma torch that was capable of extremely low electrode contamination in the plasma plume. Furthermore, it also enjoyed a leading position in the development of diamond coatings for optics, as well as R\&D capabilities in the use of CVD for diamond coating.

\section{Westinghouse Electric had experience in the development and production of high-} power, commercial plasma torch systems.

SGS Tool, a leading supplier of precision cutting tools, had product research capabilities in materials testing, product geometry, and coatings. In addition to experience in developing and producing these tools, SGS brought an understanding of customer needs. SGS Tool was to provide an automated platform that would manipulate the tool surfaces to be coated as required by the CVD process. SGS also would test and evaluate tools featuring the diamond film coating.

$$
\begin{aligned}
& \text { SGS Tool, a leading supplier of precision } \\
& \text { cutting tools, had product research } \\
& \text { capabilities in materials testing, product } \\
& \text { geometry, and coatings. }
\end{aligned}
$$




\section{PROJECT HIGHLIGHTS}

\section{PROJECT:}

To promote the development of an arc plasma CVD process as a low-cost method of depositing diamond film coatings on high-performance rotary cutting tools, by increasing the power of hot cathode plasma torch technology from 15 to 1000 kilowatts, and developing an integrated gas recycling process to decrease production costs.

Duration: $1 / 15 / 1992-11 / 14 / 1995$

ATP Number: 91-01-0261

$\begin{array}{lll}\text { FUNDING (in thousands): } \\ \text { ATP } & \$ 2,473 & 43 \% \\ \text { Company } & \frac{3,275}{2} & 57 \% \\ \text { Total } & \$ 5,748 & \end{array}$

\section{ACCOMPLISHMENTS:}

Although the Westinghouse/SGA team failed to achieve its overall goal of developing a cost-effective process for coating high-performance rotary tools with diamond film, it achieved noteworthy technical advances. Specifically, the team:

increased the power of the hot cathode plasma torch from $15 \mathrm{~kW}$ to $100 \mathrm{~kW}$;

developed an integrated gas recycling process that eliminated the need for gas replacement, thus avoiding the need to interrupt the operation of the plasma torch;

disseminated technical accomplishments in a 1999 technical publication, as well as through the mobility of researchers who served on the team; and

set the stage for continued development of the technology by others.

\section{COMMERCIALIZATION STATUS:}

Westinghouse discontinued work on arc plasma CVD for diamond film deposition following the completion of the ATP project, mainly because it was unable to overcome the problem of adherence of diamond film to the tool surfaces being studied. Work on the development and application of the shot cathode plasma torch has continued elsewhere: Westinghouse Plasma Corporation was formed to acquire the plasma torch technology group from Westinghouse Electric Corporation. The new company is exploiting the commercial potential of the hot cathode plasma torch technology in testing thermal coatings for gas turbines.

\section{OUTLOOK:}

The outlook is brighter than might be expected, given the failure of the initial effort to achieve the overall project goal. The significant increase in torch power that was achieved in the project has enabled the newly formed Westinghouse Plasma Corporation to pursue applications of the hot cathode plasma torch technology to test the performance of alternative thermal coatings in the U.S. Department of Energy's Advanced Turbine Systems (ATS) program. The plasma torch achievements of the ATP project have greatly accelerated this effort and reduced its cost. In addition, the integrated gas recycling process that was developed in the project may prove useful in other applications.

\section{Composite Performance Score: \\ COMPANY: \\ Westinghouse Plasma Corporation \\ Waltz Mill Site, Plasma Center \\ P.O. Box 410 Madison, PA 15663-410 \\ Contact: Dr. S.V. Dighe \\ Phone: (724) 722-7050 \\ E-mail: dighesv@westinghouse-plasma.com}

Subcontractor: University of Minnesota

the design of the plasma torch for application to the CVD process.

\section{Some Success, Some Failure}

The project succeeded in substantially increasing the power of the hot-cathode plasma torch from $15 \mathrm{~kW}$ to 100 $\mathrm{kW}$, and this increase in torch power is proving useful. The project team also successfully developed an integrated gas recycling process that eliminated the need for gas replacement, one of the problems that drove up deposition costs by interrupting the operation of the plasma torch. Information on this process was disseminated by the researchers in a recent publication, and may prove useful in other applications. ${ }^{3}$

The team failed, however, in its overall goal to dcvelop a cost-effective process for coating rotary tools with dia-

\footnotetext{
${ }^{3}$ Martorell, et al., "Gas recycling and flow control for cost reduction of diamond films deposited by DG arc-jet," Diamond and Related Material, 8 (1999), pp. 29-36.
} 
A management group, including former

employees of the Westinghouse Science and Technology Center, bought the plasma torch technology and formed theWestinghouse Plasma Corporation (www.westinghouse-plasma.com) to exploit the commercial potential of the technology developed in the project.

mond film. The team was unable to develop a means of getting diamond coating to adhere to the surface of tungsten-carbide tools. It also failed to increase torch power to the target of $1,000 \mathrm{~kW}$, achieving $100 \mathrm{~kW}$ instead.

With these technical failures, the team could not proceed to scale up the arc plasma CVD process. As a result, Westinghouse discontinued its work on arc plasma CVD for diamond film deposition following completion of the ATP project, and subsequently sold off the divisions in which the work was carried out.

\section{Technological Advances Carried Forward by Others}

But the story does not end there. A management group, including former employees of the Westinghouse Science and Technology Center, bought the plasma torch technology and formed the Westinghouse Plasma Corporation (www.westinghouse-plasma.com) to exploit the commercial potential of the technology developed in the project. It has continued work on the development and application of the improved hot cathode plasma torch. The newly formed company is now applying this hot cathode plasma torch technology in a U. S. Department of Energy (DOE) Advanced Turbine Systems (ATS) program to develop thermal coatings for gas turbines. Hot cathode plasma torch technology is being used to test the performance of alternative thermal coatings, which would allow gas turbines to operate at higher temperatures and higher efficiencies.

According to a company member who was involved in the ATP project and the current DOE work, the accomplishments of the ATP project have accelerated the current ATS effort on the order of five years and have resulted in millions of dollars of savings by eliminating the need for a conventional high pressure test facility. ${ }^{4}$ Hence, the technology developed in the ATP project is having important consequences for electric power generation-an unplanned, but noteworthy, benefit.

\section{...the technology developed in the ATP} project is having important consequences for electric power generation-an unplanned, but noteworthy, benefit.

These developments-the original innovating firms ending their involvement with the technology and other organizations picking it up and carrying it forwarddemonstrate how the ATP's perspective of success can differ from a company's. The ATP views a proposing company as the mechanism by which accelerated application of the newly developed technology by one or more U.S. companies can be fostered. But that is not the only route to achieve benefits, as is demonstrated in this case. Project benefits that accrue to other U.S. organizations and individuals-spillover benefits-together with benefits that accrue directly to the innovating organizations, comprise the national benefits that the ATP was established to deliver. This case also demonstrates that technology development and implementation seldom proceed along a smooth path exactly according to preconceived plans. Rather, there are often twists and turns, and partial successes and failures, along the way.

\section{This case demonstrates that technology development and implementation seldom proceed along a smooth path...}

\footnotetext{
+'Telephone interview with Dr. S.V. Dighe, Nov. 21, 2000.
} 
ADVANCED TECHNOLOGY PROGRAM

CHAPTER 3

Biotechnology

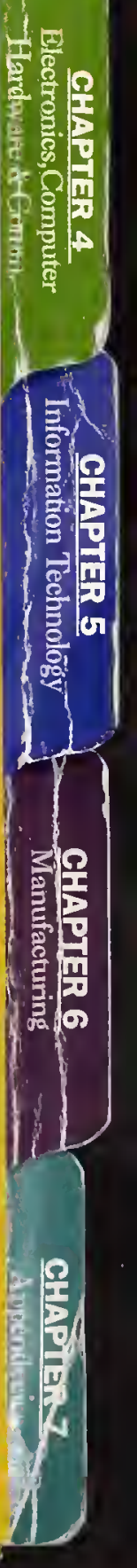





\section{A Patient-Friendly Approach to Human Cell Transplantation}

ne of the most important recent developments in cancer treatment has been the ability to harvest stem cells from bone marrow or blood to produce blood and immune system cells, and inject them into a cancer patient after drug or radiation therapy. These therapies kill cancer cells, but they also destroy life-protecting stem cells. Reinfusion of harvested stem cells enables the body to regenerate the blood and immune systems in the now cancer-free patient. Preferably, the stem cells come from the patient's own bone marrow. When that is not feasible, they may be taken from another donor.

\section{COMPOSITE PERFORMANCE SCORE} (Based on a four star rating.)

\section{Serious Drawbacks to Existing Methods}

Good as it is, stem cell harvesting has important drawbacks. Harvesting stem cells from bone marrow is painful, usually requiring 100 to 140 needle sticks - performed as major surgery under general anesthesia - to extract from the hip or other large bones enough marrow for successful

...the cell expansion system...could eventually mitigate most of the drawbacks associated with current harvesting techniques while reducing costs and increasing the number of patients who could use Aastrom's procedure.

transplantation. Some cancer patients are not strong enough to withstand so many extractions. A few are so ill they can't afford to postpone therapy while stem cells are being harvested. Still others suffer significant side effects (pneumonia, pulmonary embolism, bone marrow inflammation) from the extraction process itself. A typical procedure involves eight separate donor visits (one for the extraction, several for blood testing and other medical procedures, one for reinfusion of the stem cells), takes about 16 hours altogether and costs $\$ 10,000$ to $\$ 15,000$.

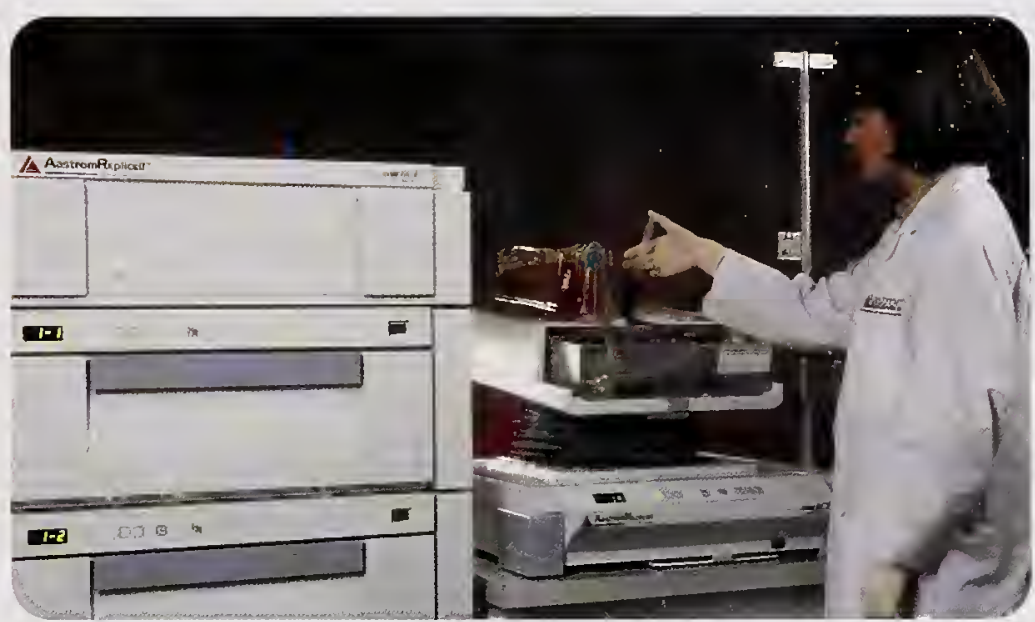

Ex Vivo cell expansion-from lab to the clinic.

Another harvesting method - peripheral blood progenitor cell (PBPC) collection - is in some ways an improvement over traditional bone marrow harvesting. PBPC involves injecting the donor (who might be the patient) with drugs to stimulate the movement of stem cells from the bone marrow into the blood stream. When it becomes enriched with stem cells, the blood is circulated through an apheresis machine, where stem cells are separated, and then back to the donor.

PBPC collection typically involves 21 donor visits (at least one for drug administration, three or four for apheresis, some for blood work, others for follow-up work related to the apheresis, one for reinfusion); takes an average of 39 total hours; requires about 22 needle sticks; and costs around $\$ 16,000$. It has gained popularity over bone marrow 
harvesting in recent years, the company reports. This is particularly true for collecting cells from cancer patients themselves, in part because some patients receiving PBPCbased treatment have less need for platelet transfusion.

The overall costs of cancer treatment where stem cell therapy is used may total $\$ 100,000$ or more. These costs include diagnosis, chemotherapy, radiation therapy, stem cell transplant therapy, and patient management. The costs of stem cell transplant therapy include the costs of cell collection, the costs of reinfusing the cells, and patient support during post-transplant recovery. The latter involves hospitalization, antibiotic treatment, infusions of platelets and red blood cells, and management of adverse reactions to large-volume cell infusions.

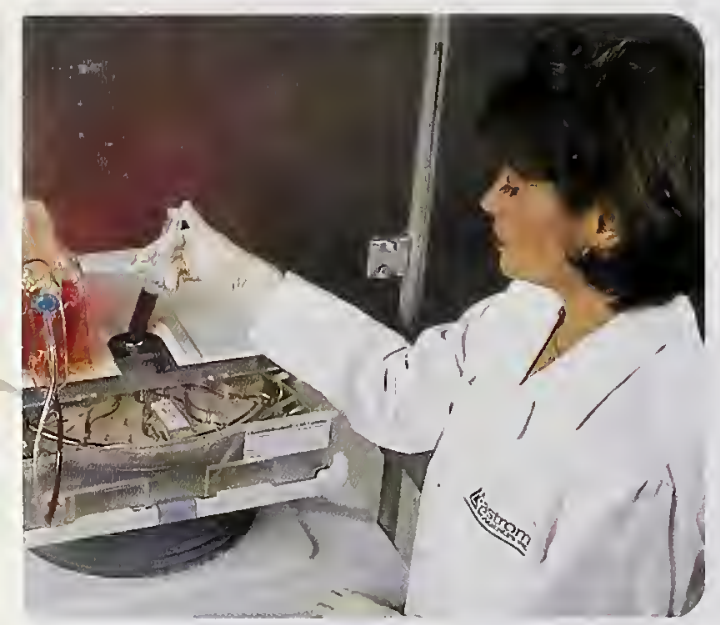

Injecting Into Processor.

\section{New Approach Promises Large Benefits}

A cell expansion system developed by Aastrom

Biosciences could potentially mitigate most of the drawbacks associated with current harvesting techniques while reducing costs and increasing the number of patients who could use Aastrom's procedure. The company was founded in 1989 and had only four persons on staff when it gained ATP support three years later. Wide-scale use of its system would produce large benefits across the economy via new therapies, reduced treatment costs and lower risks to patients undergoing cell harvesting and transplantation.

\section{Aastrom's policy is to disseminate its findings widely after establishing protections for its intellectual property.}

Aastrom expects cell harvesting via its AastromReplicell ${ }^{\mathrm{TM}}$ Cell Production System — which induces cells to rapidly multiply or expand - will be cost competitive. The typical patient/donor is likely to need just two clinic visits, one for harvesting a small amount of bone marrow and the other for reinfusing the expanded cells. An average of just seven needle sticks would be required during the initial visit.
The core technology of the system is a bioreactor that expands small amounts of bone marrow into a transplant product rich in stem cells and progenitor cells (stem cells that have started maturing into blood or immune cells). During a single 20-minute outpatient procedure, less

\section{Another clinical trial, completed in May 1997, reported excellent findings for six breast cancer patients...}

than 50 millimeters of bone marrow is extracted from the patient under local anesthesia. The marrow is injected into a disposable cassette - about the size of a large pizza - which is inserted like a video cassette into the automated bioreactor. A key aspect of the system is the creation of culture conditions that duplicate the human bone marrow environment. The cassette uses growth media, oxygen supplies, and proprietary processes within the bioreactor to stimulate the marrow to produce its own growth factors. Over 12 days, the cell population expands 5 to 10 times while stem and progenitor cells expand even more, producing enough cells for effective transplantation.

\section{Scale-Up and Clinical Trials}

Aastrom has successfully scaled up a small laboratory prototype of the cell expansion system to one large enough for clinical use. Clinical research has confirmed that cells produced by this device, called "the System," can safely be infused into patients.

In the first test of the System, a dose-ranging study with seven lymphoma patients at the University of Michigan Medical Center in 1993, Aastrom found that stem cells generated with its procedure were as safe as those collected by the direct bone-marrow harvesting technique. And in the first feasibility trial of the System - with 10 breast cancer patients at the University of Texas M.D. Anderson Cancer Center in Houston - standard clinical recoveries were seen following injection of the System-produced cells, showing that the System can be operated adequately by clinical personnel.

Another clinical trial, completed in May 1997, reported excellent findings for six breast cancer patients treated through the Bone Marrow Transplant Program at Loyola University Medical Center in Chicago. The study demonstrated that the System technique produced recovery results in line with outcomes for transplantation using other cell harvesting procedures.

Favorable results were also reported at the American Society of Hematology conference in December 1997. A Duke 


\section{PROJECT HIGHLIGHTS}

\section{PROJECT:}

To design and construct a desktop-size device that can expand small samples of stem cells, a process that would enable reductions in the risk, pain, time and cost of collecting these specialized blood-production cells for use in bone marrow transplantation for cancer patients.

Duration: 7/1/1992 — 6/30/1994

ATP Number: 91-01-0243

\begin{tabular}{|c|c|c|}
\hline \multicolumn{3}{|c|}{ FUNDING (in thousands) } \\
\hline ATP & $\$ 1,220$ & $45 \%$ \\
\hline Company & $\underline{1,514}$ & $55 \%$ \\
\hline Total & $\$ 2,734$ & \\
\hline
\end{tabular}

\section{ACCOMPLISHMENTS:}

Aastrom designed, constructed and validated a desktop-size bioreactor to produce large amounts of stem and other cells from bone marrow, umbilical cord blood and possibly other human tissues. A number of signs indicate the value of this accomplishment:

- Aastrom received a fundamental patent for its bioreactor: "Bioreactor for Mammalian Cell Growth and Maintenance" (No. 5,688,687: filed 6/7/1995, granted 11/18/1997).

It has applied for several additional patents for technologies related to the ATP project.

By the end of the ATP award period in June 1994, Aastrom staff had published or presented at professional conferences numerous technical papers on the company's Aastrom-ReplicellTM Cell Production System (System), which incorporates the Biochamber developed with ATP funds.

- In October 1995, Aastrom received $\$ 35$ million from Rhone-Poulenc Rorer for use of System technology worldwide for cell and gene therapies involving lymphoid blood cells.

- Aastrom raised $\$ 21$ million in new investment capital via an initial public stock offering in February 1997.

University Medical Center preclinical study showed that the System reduced the number of tumor cells during production. At the same conference, Aastrom announced completion of another Loyola clinical study, this one with 19 patients, that generated further evidence that bone marrow grown in the System retained stem and other key immune cells needed to restore vital tissues after drug and radiation therapy.

\section{Intellectual Property and Stock Market Reaction}

Protection of its intellectual property has always been important to Aastrom. The company was founded as a joint effort between the company's initial investors and the University of Michigan. The investors and the university agreed that inventions by the three principal researchers, all university professors, would be assigned to the university and licensed exclusively to Aastrom. In March 1992, prior to the ATP award, Aastrom and the university signed a detailed licensing and royalty agree-
In November 1997, when Aastrom received the patent listed above, the company's stock price jumped more than 60 percent in one day.

- By the end of 1997 , Aastrom had entered into agreements with SeaMED and Ethox Corporations and Anchor Advanced Products for the collaborative development and manufacture of certain components of the system.

To date, the System has been used in clinical trials at six U.S. and two foreign sites with more than 60 patients, and additional trials are underway.

\section{COMMERCIALIZATION STATUS:}

Clinical trials are in progress. The firm is also looking for partners with whom to develop a marketing relationship.

\section{OUTLOOK:}

There are high expectations that this new technology will be useful in a variety of medical treatments. Test results at various stages in the regulatory process have been promising. The stock market response to the initial public stock offering, patent-grant announcements and attention from investment analysts suggest that the private market believes the company and its technology have a good future. Also, a recent detailed economic study indicates this new technological approach could yield significant social benefits just in treating cancer patients with solid tumors.

\section{Composite Performance Score: $\star \star \star \star \star$ \\ COMPANY:}

Aastrom Biosciences, Inc.

Dominos Farms, Lobby L

24 Frank Lloyd Wright Drive

Ann Arbor, MI 48106

\section{Contact: Alan K. Smith}

Phone: (734) 930-5555

Number of employees: 4 at project start, 70 at the end of 1997

ment. Through the end of 1997,12 patents covered by the agreement had come out of the Aastrom/University of Michigan collaboration. Most of them underlay the ATPfunded technology. News reports about the granting of two of them in September 1997 were immediately followed by a substantial increase in the price of the company's stock.

The company is also pursuing patent protection for inventions not covered by the agreement with the university. In 1997, Aastrom received in its own name a fundamental patent - "Bioreactor for Mammalian Cell Growth and Maintenance" - for the System method and device. News that this patent had been granted was accompanied by a one-day increase of 60 percent in the company's stock price.

Aastrom's policy is to disseminate its findings widely after establishing protections for its intellectual property. This is true of the technical specifics of its discoveries, as 
well as the results of clinical trials. Company staff have produced numerous papers for presentation at professional conferences or publication in professional journals.

\section{Strategic Alliances for Commercialization}

In 1993, the company entered into a strategic alliance with COBE Laboratories and COBE BCT (collectively, $\mathrm{COBE}$ ) for the worldwide distribution of the System for stem cell therapy and related uses. COBE committed up to $\$ 20$ million in equity investment in Aastrom. In addition, Aastrom and COBE initiated a clinical trial in France in early 1997 to evaluate the use of System cells to promote the recovery of blood cell production in breast cancer patients undergoing aggressive marrow-damaging chemotherapy. Aastrom is seeking approval to market the System in Europe.

\section{Other possible applications include} immunotherapy, stem cell gene therapy and cells for solid tissue repair.

In September 1995, Aastrom entered into a research and development collaboration with Rhone-Poulenc Rorer (RPR), granting RPR a right to license the System for lymphoid cell applications. Under the agreement, RPR will invest $\$ 35$ million. In September 1997, Aastrom had received $\$ 3.5$ million in equity payments and $\$ 1.5$ million in revenues from $\mathrm{RPR}$.

\section{Initial Public Stock Offering}

In addition to financial support from strategic alliances, the company has secured funding in the public capital market. In February 1997, Aastrom conducted its initial public stock offering, which raised $\$ 21$ million, and conducted another offering in December 1997 that raised $\$ 11$ million.

All equity funding is invested in Aastrom's research and development (R\&D) efforts and administrative activities required to support that research - the only focus of the company's activities. Thus, as Aastrom succeeded in attracting more private capital, ATP funding constituted a declining proportion of its R\&D spending. ATP funds amounted to 23 percent of Aastrom's $\$ 2.6$ million R\&D budget in 1993 but only 11 percent of its $\$ 4.9$ million R\&D budget in 1994 .

Aastrom does not manufacture products, nor does it intend to. It arranges with third parties to manufacture its candidate products and has agreements with SeaMED and
Ethox Corporations and Anchor Advanced Products, Mid-State Plastics Division, for the collaborative development and manufacture of certain components of the AastromReplicell ${ }^{\mathrm{TM}}$ System.

\section{Large Potential Benefits}

Patients - the main beneficiaries of the new technology - are expected to gain from a less invasive procedure that is cost effective, provides greater procedural flexibility, and offers tumor purging benefits. In addition, because of fewer hospital or clinic visits, total costs are expected to be as much as 25 percent less $(\$ 12,000$ instead of $\$ 16,000)$ than costs for PBPC apheresis. Furthermore, if the Aastrom technology substantially decreases the cost of cell transplantation, others who could not have afforded the treatment will now be able to and will benefit. Their benefit may well be life itself, since bone marrow transplantation for cancer patients is frequently a life-saving therapy.

A study of tissue engineering projects, conducted by economists at Research Triangle Institute, Inc. (RTI), under contract to the ATP, noted that Aastrom achieved ATP-project results one to two years earlier than would have been possible without the ATP award. Having the ATP funds also helped the company attract additional equity capital and establish new strategic partnerships. These, in turn, helped accelerate the company's R\&D even more.

Wide-scale use of the System is expected to produce large benefits across the economy via reduced treatment costs and lower risks to patients undergoing cell harvesting and transplantation. The RTI study estimates that the present value of expected net benefits from using the System technology for just one type of application treating cancer patients with solid tumors - exceeds $\$ 100$ million. The study estimates that ATP's contribution of $\$ 1.5$ million to the project will generate nearly $\$ 50$ million of the expected benefits by speeding the technology's development by one to two years. The RTI study did not attempt to develop estimates based on characteristics of System-based stem cell transplantation that might yield better patient outcomes. It focused only on cost savings.

In addition, the study did not attempt to estimate the value of the effects that a number of other potential appli- 
cations might have. First use of the System technology is for expanding small amounts of stem cells from bone marrow. It has now been extended to the production of stem cells from umbilical cord blood. Other possible applications include immunotherapy, stem cell gene therapy and cells for solid tissue repair. More benefits can be expected to be generated as the company applies the technology to growing other types of cells - platelets and red blood cells, as well as liver, kidney and nerve tissue - outside the body. 



\section{Searching for New Enzymes in Deep-Sea Microorganisms}

Hound tions occurring in cells. Enzymes are responsible for many thousands of biochemical processes and are vital for cell growth and the production and use of energy within cells. Enzymes also play a vital role in industrial applications and microbiology research. By providing the foundation for many of the advances in biotechnology, enzymes are now revolutionizing health care and agriculture industries.

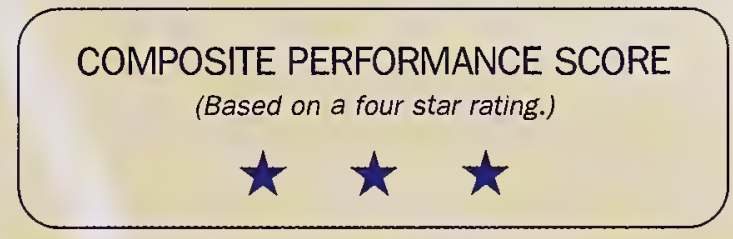

\section{Unlocking Genetic Information}

The current biotechnology revolution began only a few decades ago when scientists discovered they could use certain enzymes to unlock the genetic information contained in a cell's chromosomes. Found in the genes of DNA strands, a sequence of nucleotides provide cells with instructions on how to build the proteins and amino acids that are used to carry out biological functions. Study of this sequence information has already led to major advances in cloning, forensic identification, and cancer research. It may also lead to therapeutic treatment and custom drug design for other diseases currently without a cure.

\section{Thermally Stable Enzymes Needed for DNA Amplification}

The techniques used to obtain sequencing information involve a series of processes to tear apart a cell and break open its components to reveal the underlying genes. This is done with the help of an enzyme called DNA poly-

The enzymes initially used for sequencing and amplification were not thermally stable and tended to break down when subjected to the heat necessary to separate the DNA strands.

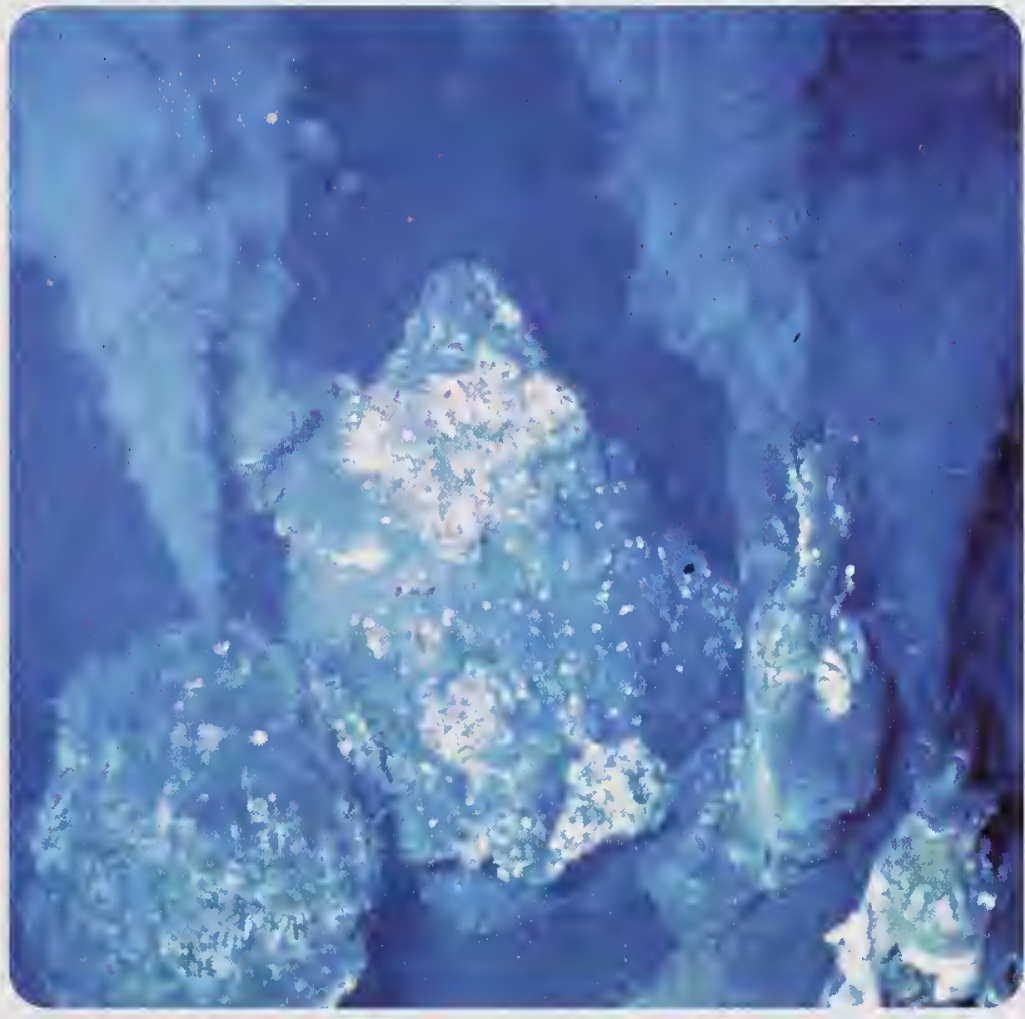

Deep Sea Vent “Black Smoker.”

merase. DNA polymerase also plays a critical role in another important genetic process that is used to create multiple copies of a known sample of DNA. This process, called amplification, works by placing an isolated sample of DNA in a solution of bases, primers, and DNA polymerase. The solution is then heated, which causes the double-stranded DNA to separate into two single strands. The mixture is then cooled so the primers can bind to 
pre-established sites along each of the separate DNA strands. When the mixture is reheated, the DNA polymerase moves along the single strands of DNA and attaches the bases to form two identical, double strands of DNA. Repeating the heating and cooling cycle doubles the strands, and after about 30 cycles, the single fragment of DNA is sufficiently amplified to provide enough material for sequencing and further research.

The enzymes initially used for sequencing and amplification were not thermally stable and tended to break down when subjected to the heat necessary to separate the DNA strands. As a result, the polymerization process required constant monitoring to insure that adequate enzyme amounts were present.

Scientists discovered that microbes inhabiting the hot springs of Yellowstone Park produce a heat tolerant DNA polymerase. Although this enzyme, commercially developed as "Taq," was thermally stable for amplification of DNA, it often proved inaccurate for DNA sequencing. As the problems with Taq became apparent, the search for superior enzymes became a major quest.

\section{ATP Supports the Search for a More Effective Enzyme}

In 1993, U.S. Biochemical Corporation (USB) applied to ATP to study the commercial potential of enzymes extracted from newly discovered microorganisms found living in the superheated waters of thermal vents on the deep ocean floor. Researchers hoped that microorganisms living in such extreme temperatures could be used to produce an enzyme that was both thermally stable and more accurate than Taq.

Working together with the University of Maryland's Center of Marine Biotechnology (COMB), Amersham's initial objective was to collect a large number of exotic hyperthermophiles from the superheated waters found in thermal vents along the ocean floor.

At the time, USB, a small company located in Cleveland, Ohio, was a recognized leader in the development of DNA sequencing products and had more than 20 years of experience in the biochemical industry. Shortly after originating this project, USB was purchased by U.K.based Amersham International. Amersham pledged full commitment to this project using USB's original plan and U.S.-based personnel and facilities. The ATP awarded $\$ 1.6$ million to USB, and determined that continuation of the project after the company was purchased by Amersham International would be in the U.S. economic interest.

Working together with the University of Maryland's Center of Marine Biotechnology (COMB), Amersham's initial objective was to collect a large number of exotic hyperthermophiles from the superheated waters found in

\section{As the work developed, researchers}

found that the DNA polymerases from deep-sea hyperthermophiles, like Pyrococcus furiosus, did not outperform Taq.

thermal vents along the ocean floor. Hyperthermophiles actually thrive in extremely high temperatures $\left(80^{\circ}-110^{\circ} \mathrm{C}\right)$, high pressures (@3300l bps), and highly caustic solutions made up of sulfur and other minerals.

The unusual properties that make hyperthermophiles so appealing also make them extremely difficult and expensive to work with. The researchers designed special equipment and improved methods to allow the tasks of isolating and purifying the new enzymes to be carried out in an environment that matches their deep-sea habitat. Once the new enzymes were available, researchers screened them to determine how their properties compare to Taq.

As the work developed, researchers found that the DNA polymerases from deep-sea hyperthermophiles, like Pyrococcus furiosus, did not outperform Taq. Indeed, none of the enzymes they produced was found to be superior to Taq. As researchers continued their study, they began to realize that the search for the Holy Grail of enzymes was not yielding results from the ocean depths.

\section{Scientific Discovery Leads Amersham To Redirect Research Efforts}

Two years after the project began, a discovery published in the Proceedings of the National Academy of Sciences by Tabor and Richardson showed how scientists could reengineer Taq to achieve greater fidelity and accuracy of sequence data. ${ }^{1}$ By creating a single amino acid change 


\section{PROJECT HIGHLIGHTS}

\section{PROJECT:}

To study deep-sea microorganisms in an effort to identify, isolate, and characterize their commercially important enzymes for use in life sciences research, including a suitable enzyme for DNA sequencing, and industrial applications.

Duration: $2 / 15 / 1994-2 / 14 / 1997$

ATP Number: 93-01-0113

\begin{tabular}{lll}
\multicolumn{3}{l}{ FUNDING (in thousands): } \\
ATP & $\$ 1,558$ & $65 \%$ \\
Company & $\frac{839}{32}$ & $35 \%$ \\
Total & $\$ 2,397$ &
\end{tabular}

\section{ACCOMPLISHMENTS:}

Recent advances in molecular biology and discoveries of exotic new life forms have created commercial opportunities in the fields of genomics and enzyme development. The ATP-funded projeect led by Amersham explored the properties of newly discovered, heat-loving microorganisms with the objective of advancing the scientific knowledge of their genetic makeup and identifying the commercial potential of their expressed enzymes.

Key accomplishments for this project include:

isolation and genomic characterization of hyperthermophiles obtained from deep-sea thermal vent fluids;

successful partial DNA sequencing of hyperthermophiles using directed cDNA cloning and other advanced sequencing techniques;

- successful cloning of genes encoding enzymes that have unique applications in life science research and are of significant commercial interest. These enzymes include DNA polymerases used in DNA cycle sequencing and several modifying enzymes used to improve the detection, selection and manipulation of DNA sequences;

publication of sequencing results as "A Survey of the Genome of the Hyperthermophilic Archaeon Pyrococcus F uriosus" in the first volume of Genome Science and Technology, one of 16 publications which helped to diffuse knowledge gained through the project;

applied for 7 patents and, by the time of this study, had been granted 5 patents:

"Thermostable alkaline phosphatase of thermus thermophilus" (No. 5,633,138: filed 5/30/1995, granted 5/27/97);

"Thermostable DNA polymerase from thermoanaerobacter thermohydrosulfuricus" (No. 5,744,312: filed 12/13/1996, granted 4/28/1998);

"Thermostable DNA polymerases"

(No. 5,885,813: filed 5/14/1996, granted 5/23/1999);

"Modified Pol-II type DNA polymerases"

(No. 5,827,716: filed 7/30/1996, granted 10/27/1998);

"Proteins from pyrococcus furiosus"

(No. 5,719,056: filed 4/26/1996, granted 2/17/1998).

in a polymerase, Tabor and Richardson showed that they could affect the enzyme's ability to discriminate among nucleotides, and thereby produce uniform sequence signals. This important discovery meant that the structure of an enzyme such as Taq could be reengineered to provide the discrimination functions that lead to accurate,

\section{CITATIONS BY OTHERS OF PROJECT'S PATENTS:}

\author{
See Figure 3.1.
}

\section{COMMERCIALIZATION STATUS:}

From its research on hyperthermophiles, Amersham developed a thermally stable alkaline phosphatase with applications in the detection of genetic diseases. This product has reached sales of $\$ 1.2$ million per year. With the application of newly discovered enzyme reengineering techniques, Amersham accelerated development of ThermoSequenase, a DNA polymerase that is both thermostable and accurate for DNA sequencing. Sales of ThermoSequenase are $\$ 15$ million per year and are expected to reach $\$ 60$ million by 2000 . Enzymes to replace chemical catalysts in large-scale industrial applications have yet to be developed.

\section{OUTLOOK:}

Amersham completed many of the technical objectives of this project and accelerated research and development of new enzymes for use in DNA diagnostics. Although it successfully isolated at least one commercially useful enzyme, it did not achieve the ultimate goal of finding a superior hyperthermophilic enzyme. Nevertheless, the project is at least partially responsible for accelerated development of a thermally stable DNA polymerase,

ThermoSequenase. This enzyme has helped to revolutionize automated DNA cycle sequencing by providing improved accuracy in fluorescent readouts of sequence information. Benefits are accruing from a growing number of health care and diagnostic applications that rely on accurate and timely DNA sequence information. The potential application areas are numerous, including medical diagnostics, gene therapy, drug discovery, human therapeutics, cell cloning, cancer genetics, agricultural biotechnology, forensic identification, toxicology, and environmental monitoring.

The development of competing enzymes is underway and there is substantial market competition in this area. The outlook is promising that the considerable knowledge gained from this project may yet lead to the development of new classes of industrial enzymes.

\section{Composite Performance Score: $\star \star \star \star$}

\section{COMPANY:}

Amersham Pharmacia Biotech

(Formerly U.S. Biochemical Corporation, then Amersham International) 800 Centennial Avenue

Piscataway, NJ 08855

Contact: Carl W. Fuller

Phone: (732) 457-8000

Informal Collaborator: University of Maryland's Center of Marine Biotechnology

uniform sequence signal intensity. It wasn't the Holy Grail, but it was very close.

So profound was this discovery that Amersham immediately stopped its effort to screen deep-sea hyperthermophilic enzymes and set about to reproduce the work of Tabor and Richardson. They soon discovered that these 
Figure 3.1 Patent Tree for Project Led

by Amersham: Citations by Others of

\section{Amersham Patents}

\section{PATENT TREE KET}

Original Patent

Second Generation Patent

Third Generation Patent

Fourth Generation Patent

Fifth Generation Patent
5885813

Amersham

1999 results could not be replicated with hyperthermophilic enzymes, but they could reengineer other thermophilic enzymes to produce properties superior to Taq.

\section{Faster Development of ThermoSequenase}

With the knowledge that naturally occurring hyperthermophilic enzymes were not viable alternatives to reengineered thermophilic enzymes, Amersham licensed Tabor and Richardson's technique and produced ThermoSequenase, a DNA polymerase that is both thermostable and produces amplified DNA sequences of uniform signal intensity. ${ }^{2}$ With ATP's support, the development

\section{With ATP's support, the development of} ThermoSequenase was advanced by at least six months. Former director of the Human Genome Project, Dr. David Smith of the Department of Energy, singles out the timely development of ThermoSequenase in 1995 as being critical to the Human Genome Project...

of ThermoSequenase was advanced by at least six months. Former director of the Human Genome Project, Dr. David Smith of the Department of Energy, singles out the timely development of ThermoSequenase in 1995 as being critical to the Human Genome Project, stating, "We would be in deep trouble if [such technologies] were at a less mature stage of development." ${ }^{3}$

ThermoSequenase is now incorporated into Amersham's leading line of sequencing reagent kits. Currently, these kits account for sales of over $\$ 15$ million per year and are expected to reach sales of $\$ 60$ million in 2000.

Researchers using ThermoSequenase for DNA sequencing now obtain 10 to 25 percent more information from each sequencing experiment. The availability of ThermoSequenase has effectively reduced the cost of sequencing substantially. It has also enabled greater use of advanced automated sequencing machines that can

${ }^{2}$ At the start of the project, Amersham was producing and marketing a DNA polymerase known as Sequenase that could produce accurate, uniform sequencing. However, this product was not thermally stable and could not compete with Taq when used in cycle sequencing machines.

${ }^{3}$ The Seventh International Genome Sequencing and Analysis Conference, September 1995, available on the Internet < www.olnl.cov/TecllResources/Hulllall Genome/publicat/97pr/evolve.html>. 
Researchers using ThermoSequenase

for DNA sequencing now obtain 10 to 25

percent more information from each

sequencing experiment.

now operate without the need for constant monitoring of enzyme amounts. Customers of services using ThermoSequenase benefit from more accurate and more efficient sequencing. Development of ThermoSequenase also has stimulated competition in the enzyme market and has improved the quality of enzymes in biotechnology applications.

\section{A New Field of Research Bears Fruit in Unexpected Ways}

ATP's cofunded project with Amersham has been praised as one of the first federally supported efforts to explore the potential of newly discovered deep-sea life. This has opened up a new field of research that was completely unknown two decades ago. ${ }^{4}$

\section{... as one of the first federally supported efforts to explore the potential of newly discovered deep-sea life.}

The Amersham researchers developed methods and applied them to search deep-sea life for an enzyme that offered a thermally stable and more accurate means of DNA sequencing. It did not find the hoped-for sequencing enzyme in the deep sea; in fact, during the course of the project, Amersham was able to conclude that hyperthermophiles were not the answer to the search for a better polymerase enzyme for DNA sequencing. The company quickly took a different approach to solving the problem. The project helped to position Amersham and its academic collaborators so that they could take advantage of new emerging techniques in enzyme reengineering.

Pioneering use of these techniques led to accelerated development of ThermoSequenase. Hence, the project achieved its goal, but not in the expected way. And, it did find a useful enzyme in the deep sea, though not the one of central focus.

\section{...it did find a useful enzyme in the deep sea, though not the one of central focus.}

Amersham has effectively diffused knowledge gained through the project by issuing 16 journal publications and a number of patents. The company filed for seven U.S. patents, five of which had been granted at the time of this study. In turn, the development of ThermoSequenase, and the release of information about it, have led to greater market competition, and encouraged the development of competing enzymes.

\footnotetext{
${ }^{4}$ William J. Brode, The Universe Below: Discovering the Secrets of the Deep Sea, Touchstone: Simon \& Schuster, 1997, p. 283.
} 



\section{APHIOS CORPORATION \\ (formerly BioEng, Inc.) \\ Reducing Viral Contamination in Donated Blood}

\section{$T$} oped technology to improve the quality of donated blood in the United States. If the technology is fully developed and widely applied, substantial benefits would accrue to patients. The transfused blood or other therapeutic substances they receive would essentially be free of hepatitis virus, human immunodeficien cy virus (HIV, which causes acquired immunodeficiency syndrome, or AIDS), and other viruses that may contaminate vaccines, donated blood, blood-related products, medical instruments, and recombinant-DNA proteins.

COMPOSITE PERFORMANCE SCORE (Based on a four star rating.)

No Stars

\section{Solving the Problem of Contaminated Blood}

Several sterilization procedures using heat, a chemical, or ultraviolet radiation are already in use, but each method has drawbacks: it may leave unsafe levels of some viruses,

\section{...commercial deployment... \\ will be much easier if the company can demonstrate that its technology \\ can inactivate parvovirus to an acceptable degree.}

be very costly, or damage the blood or plasma. The Aphios sterilization technology, called critical-fluid inactivation (CFI), uses a fluid such as carbon dioxide that is raised above its critical temperature and pressure. Above these levels, the substance cannot be liquefied. In laboratory tests, such fluids exhibit a combination of liquid and gaseous properties, and they have been found to effectively inactivate prototypical viruses. Critical-fluid viral inactivation uses low temperatures and short process times, so it has a minimal impact on blood and blood-related products. And, at an estimated cost of about $\$ 1$ per liter, it is much less expensive than existing technology.

\section{Overcoming Parvovirus}

The procedure Aphios developed during the ATP project has been able to achieve 99.9999 percent inactivation or more for most viruses in 20 seconds $(99.99$ percent inactivation by an individual viral inactivation technique is considered acceptable). The most difficult challenge has been parvovirus.

Parvovirus B19 in blood and blood products has proven difficult to inactivate, not only by the CFI process but by others as well. The virus is relatively benign for patients with healthy immune systems. But it can have serious consequences for those with weakened immune systems, as well as for pregnant women and persons with sickle cell anemia. 'The current Aphios procedure has achieved 90 percent inactivation of this virus. The compa-

$$
\text { ...signed a letter }
$$

of intent with the Northeast Region of the American Red Cross to develop and fieldtest a viral inactivation prototype...

ny is working on a five-step procedure that is expected to achieve better than 99.99 percent inactivation.

The blood industry has established an extremely high standard for new technologies. Therefore, commercial 


\section{PROJECT HIGHLIGHTS}

\section{PROJECT:}

To develop a critical-fluid viral inactivation process to protect the nation's supply of donated blood and blood-related products from contamination by AIDS, hepatitis, and other viral diseases.

Duration: 7/1/1992 - 6/30/1995

ATP Number: $91-01-0135$

\begin{tabular}{lll} 
FUNDING (in thousands): & \multicolumn{3}{c}{ ATP } & $\$ 2,000$ & $67 \%$ \\
Company & 1,000 & $33 \%$ \\
Total & $\$ 3,000$ &
\end{tabular}

\section{ACCOMPLISHMENTS:}

Aphios developed a procedure using critical fluids to inactivate viruses in blood and established that the process is applicable to a large number of viruses, al though with different levels of effectiveness. The following achievements indicate technical progress by the company, which:

applied for a patent ("Viral Inactivation Method and Apparatus") on technology related to the ATP project;

presented two papers at conferences on blood-safety issues;

executed a letter of intent with the Northeast Region of the American Red Cross to develop and field-test a virus inactivation prototype for individual units of blood; and

submitted a proposal to a consortium of companies to evaluate the viral inactivation technology for use in developing products and processes.

deployment of the Aphios technology will be much easier if the company can demonstrate that its technology can inactivate parvovirus to an acceptable degree. If it succeeds with this task, Aphios will seek to join a larger pharmaceutical company or consortium to further develop and commercialize the process, with substantial investment coming from these sources. In 1998, Aphios sought an arrangement with a consortium of five pharmaceutical

\section{Without the ATP funds, Aphios officials say, the company would not have conducted the project.}

companies to complete development of the CFI process.

If a company wishes to commercialize a product for use with donated human blood, it must deal with the American Red Cross (ARC), the source of most blood products used in clinics and hospitals in the United States. Aphios has signed a letter of intent with the Northeast Region of the ARC to develop and field-test a viral inactivation prototype for individual units of blood and is seeking funding for the project.

\section{COMMERCIALIZATION STATUS:}

Aphios has not commercialized the process yet. The firm has been negotiating with a health care company interested in sponsoring further development and commercialization of the technology. Some early knowledge benefits have emerged from the project via patent disclosures and scientific papers.

\section{OUTLOOK:}

Commercialization may occur after more R\&D work, primarily on the inactivation of parvovirus. There has been evidence of interest in the technology by the health-care community in general and by the American Red Cross in particular. Benefits are expected to accrue to society if the development of the technology can be completed successfully. However, given the company's financial difficulties, the outlook at this time is uncertain.

\section{Composite Performance Score: No Stars}

\section{COMPANY:}

Aphios Corporation

(formerly BioEng, Inc.)

3-E Gill St.

Woburn, MA 01801

Contact: Trevor P. Castor

Phone: (781) 932-6933

Number of employees: 3 at project start, 17 at the end of 1997

\section{Health Benefits to Patients and Those Close to Them}

If the technology is fully developed and commercialized, benefits are expected to accrue to users of blood and blood-derived products that can be made virus-free with the Aphios technology. Reducing the spread of viral disease is expected to generate large health-cost savings and related benefits to the United States. Users will also benefit if the process based on the new technology is, as expected, less costly than current decontamination procedures. Economic benefits might also extend to people who avoid viral disease because users of blood or blood-derived products decontaminated with the Aphios technology do not become infected and spread the disease.

Without the ATP funds, Aphios officials say, the company would not have conducted the project. Moreover, it would have been impossible for this small company to attract the interest of the health care company or the American Red Cross.

As this report was going to press in late 1998, it was learned that the company had reduced staff and was experiencing financial distress. 


\section{A New Bioabsorable Polymer: An Ideal Material for Medical Implants?}

Formor

fractures with screws, pins, and other fixation-type devices. Early on, these devices were often made from

common metals such as iron or steel. Later on, they were made of highly sophisticated metal alloys of titanium, zirconium, niobium, and tantalum. Still the search continued for materials that would be more compatible with the human body, and that search led researchers to consider bioabsorbable polymers.

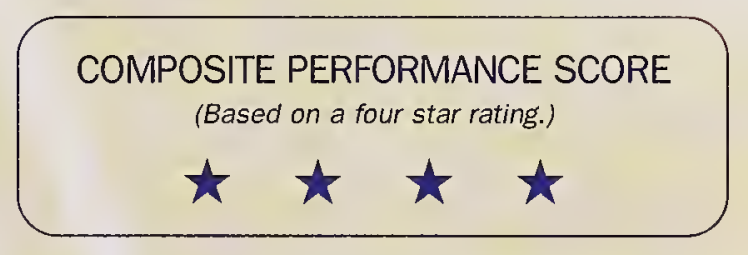

\section{Problems with Existing Materials}

While effective in binding the fractured bone, the devices made of common metal corroded when they were implanted in the body and released toxins that could cause inflammation, infection, and even life-threatening injury to the patient. The metal alloys offer major improvements because they do not corrode when exposed to body fluids and therefore can be left inside the body for long periods

\section{Many patients with metal alloy implants must undergo follow-up surgery, with its associated cost, risk, and trauma, to remove the implant once the healing process has occurred.}

of time without releasing harmful toxins. They, too, however, have serious drawbacks. Metal alloys are much harder and stiffer than the bone they replace or support, and can interfere with the regrowth of the bone.

Many patients with metal alloy implants must undergo follow-up surgery, with its associated cost, risk, and trauma, to remove the implant once the healing process has occurred. According to a recent study, the cost of a second surgery can range from $\$ 850$ for devices located in the shoulder to $\$ 2,200$ for devices located in the knee. More than 34,000 of these follow-up surgeries are performed in the United States each year, resulting in costs of $\$ 30-75$ million. ${ }^{1}$

\section{Bioabsorbable Polymers Offered Promise- and Potentially Dangerous Toxins}

Polymers offer great potential as a substitute for alloys for use in orthopedic implant devices. Polymers can be made to be biocompatible and designed to exhibit more bonelike properties. Their mechanical properties can be strong enough to withstand weight-bearing applications, yet they still retain a degree of elasticity not available with metal alloys. Most important, polymers can be made to be bioabsorbable, that is, they can be made to dissolve and slowly be absorbed by the body. Further, the rate of dissolving can be engineered so that it is consistent with the rate of new bone growth. Under ideal conditions, a bioabsorbable polymer could encourage bone healing while the body slowly metabolizes it. This eliminates the need for a second surgery that may be required when an unyielding - metal alloy is implanted.

A serious problem existed, however, with available bioabsorbable polymers-polylactic acid, polyglycolic acid, and polydioxanone. When they dissolve or degrade inside the body, they tend to release acids and other toxins that

\footnotetext{
1"A Framework for Estimating the National Economic Benefits of ATP Funding of Medical Technologies," The Research Triangle Institute Center for Economics Research, Project number 6715-01 FR, NIST GCR 97-737, April 1998, section 3.
} 
are harmful. For sutures and small staple devices this is not a serious problem because the quantity of harmful substances released is small. But for larger devices, such as weight-bearing screws, the release of harmful products can be significant and can cause inflammation problems, similar to the problems that occurred with the crude metal devices of the past.

\section{A serious problem existed with available bioab-} sorbable polymers. When they dissolve or degrade inside the body, they tend to release acids and other toxins that are harmful.

Over the past two decades, scientists have attempted to reengineer these polymers to minimize the release of harmful substances and reduce the resulting inflammation. This research has had some success but apprehensions remain over problems of bio-incompatibility. Market experts suggest that unless a major breakthrough occurs that solves this problem, the market for bioabsorbable polymer implants will not fully develop and patients will have to continue to undergo secondary surgeries with their associated costs and risks.

\section{ATP Funds Research for an Improved, Toxin-free Bioabsorbable Polymer}

In the early 1990s, Dr. Joachim Kohn, a professor of chemistry at Rutgers University, invented new "pseudopolyamino acids" based on tyrosine, a naturally occurring amino acid. The polymer's physical properties are similar to existing, FDA-approved bioabsorbable polymers, but because it is derived from tyrosine, any acids or toxins it releases are done so at significantly slower rates.

Several implant device manufacturers showed an early interest in Dr. Kohn's invention, but none were willing to make a commitment to develop the material because the technical risk of doing so was very high. Development of the polymer required the creation of a manufacturing process that guaranteed the material's purity and uniform characteristics on an industrial scale. In addition, quantities of the new polymer had to undergo a series of rigorous tests to show that the material was indeed capable of being used safely and effectively in implant devices. All of this had to be accomplished before additional funds would be committed to run the additional clinical trials mandated by the FDA approval process.
Integra LifeSciences Corporation, a small biomaterials company in New Jersey, approached Dr. Kohn with a plan to accelerate the development of this new polymer. Integra, in research led by Dr. George L. Brode (principal investigator for the ATP project) and Dr. John Kemnitzer, would develop a scaleable manufacturing process for the tyrosine polycarbonate and then perform tests to assess the new material's potential for use in implant devices. Once the difficult technical problems were overcome and the polymer's potential was demonstrated, it was expected that private investors in the new implant technology could be attracted.

To offset the high technical risks of this endeavor, Integra submitted a single-company proposal to the Advanced Technology Program's 1993 General Competition. Potential economic benefits looked strong, the research plan solid, and Integra received a $\$ 2$ million, three-year award from the ATP that began in January 1994.

\section{Integra Overcomes Technical Obstacles}

The first major task of the project was to design and develop a scaleable process technology that allows for flexible control of several key physical properties during manufacturing and ensures that the polymer can be produced with a high degree of purity. This work led to the development of the successful "Biphasic Process." Integra filed a patent on this process, and showed that it was capable of producing commercial quantities of the new polymer. Having developed the manufacturing process technology, Integra's next task was to assess the physical properties of the new material and prepare prototype devices for in vitro and in vivo testing.

\section{Working with Rutgers University and New York's Hospital for Joint Diseases, Integra conducted a series of tests to study how well the new polymer material interacts with living cells.}

Working with Rutgers University and New York's Hospital for Joint Diseases, Integra conducted a series of tests to study how well the new polymer material interacts with living cells. Toxicity and sensitization studies were performed to assess such issues as tissue compatibility, inflammatory response, bone growth, and hard tissue response. The results confirmed that the new polymer 


\section{PROJECT HIGHLIGHTS}

\section{PROJECT:}

To develop a new polymer material for making implantable surgical devices such as screws, plates, pins, wedges, and nails for repairing fractured bones; to design and develop a scaleable process for making it; and to assess the polymer's suitability as an effective inplant material.

Duration: 1/1/94 - 12/31/96

ATP Number: $93-01-0085$

FUNDING (in thousands):

$\begin{array}{lrr}\text { ATP } & \$ 1,999 & 81 \% \\ \text { Company } & 467 & 19 \% \\ \text { Total } & \$ 2,466 & \end{array}$

\section{ACCOMPLISHMENTS:}

Development of a new class of bioabsorbable polymers based on tyrosine, a naturally occurring amino acid, was greatly accelerated. This new polymer can be used to create implants for surgical devices, such as pins and screws for repairing fractured bones. Implants made from this polymer do not exhibit the problems of brittleness, release of toxins on absorption, or the need for surgical removal- all characteristics of implants made with existing materials. The material and process for making it were brought to the stage where prototype devices could be produced for testing and demonstration, and commercial development partners, in collaboration with Integra LifeSciences Corporation, could file for FDA approval. The project's accomplishments include:

development of a process to produce commercial quantities of tyrosinebased polymers, for which Integra filed a patent in 1997;

- synthesis and characterization of bioabsorbable tyrosine polycarbonates and creation of a variety of prototype fixation devices;

evaluation of the bioabsorbable polymer through studies of toxicity and sensitization, which indicate that the new polymer is comparable to existing biopolymers in terms of its mechanical and resorbtion properties, and superior in terms of its biocompatible properties;

diffusion of new technical knowledge through numerous presentations and 15 publications;

licensing of the technology to two commercial partners; and

does not emit toxic by-products when it degrades and does not have an adverse affect on tissue or bone. Other tests evaluated the polymer's resorption properties, i.e., how the process of bone re-growth interacts with the degrading polymer. Although the tests were not yet complete at the time of this study, early results suggest that the new polymer has resorption rates similar to existing FDA-approved polymers, but does not cause the adverse secondary reactions due to release of harmful materials.

The polymer's mechanical properties were tested and optimized. The results of these tests indicate that the new polymer can be used in a number of orthopedic devices, including weight-bearing devices such as large surgical screws. Integra is also evaluating various composite materials that could be used with the new polymer to produce materials with a wide range of physical and mechanical recognition of the technology by the New Jersey Research and Development Council who presented the Thomas Alvin Edison Award to Dr. Kohn of Rutgers University for project-related research.

\section{COMMERCIALIZATION STATUS:}

On September 18, 1998, Integra announced that it had formed two strategic commercial alliances for the commercial development of its tyrosine-based polymer. An alliance with Bionx Corporation is pursuing use of the new polymer to develop surgical screws, plates, pins, wedges, and nails to be used for the fixation or alignment of musculoskeletal fractures. An alliance with Linvatec, a subsidiary of CONMED Corporation, is pursuing use of the polymer to develop arthroscopic fixation devices such as surgical screws, tacks, and other anchoring devices to attach soft tissue to bone in the knee and shoulder. The partners have filed with the FDA for approval, and forecast their first products will be launched shortly after approval.

\section{OUTLOOK:}

The tyrosine-based polymer technology is a platform technology with broad applications in orthopedics (fracture fixation), cartilage and ligament repair, wound care, cardiovascular repair, drug delivery, and other uses. In the near term, economic benefits are expected to accrue from the development of a wide range of orthopedic fixation devices by Integra and its established commercial partners. The outlook for continued development and commercialization of the technology is excellent.

\section{Composite Performance Score:}

\section{COMPANY:}

Integra LifeSciences Corporation

105 Morgan Lane

Plainsboro, New Jersey 08536

Contact: George L. Brode, Ph.D.

Phone: (800) 762-1574

Number of employees: at project start 32; number of employees at project end: 129

properties. Additional patent applications in this area are also planned.

Integra forms alliances with Bionx and Linvatec With ATP's support, Integra and Dr. Kohn successfully accelerated the development of this new polymer to the

Integra's new commercial partners have agreed to undertake and fund the studies necessary for FDA approval, a commitment neither Bionx nor Linvatec would have made were it not for the accomplishments of the ATP project. 
point that implant device manufacturers could evaluate the risk associated with commercialization. Two years after completion of the project, Integra formed two strategic commercial alliances committed to the development of new orthopedic implant devices using the new material.

Integra formed an alliance with Bionx Corporation to develop surgical screws, plates, pins, wedges, and nails for the fixation and alignment of fractures and for other musculoskeletal surgical applications. An alliance with Linvatec, a subsidiary of CONMED Corporation, will develop smaller screws, tacks, and other arthroscopic fixation devices that will be used to attach soft tissue to bone in the knee and shoulder. In each case, Integra's new commercial partners have agreed to undertake and fund the studies necessary for FDA approval, a commitment neither Bionx nor Linvatec would have made were it not for the accomplishments of the ATP project. Both partners expressed the expectation that their first products would be launched soon, but the various filings and approvals through the Food and Drug Administration take time, and it is difficult to predict timing with accuracy.

According to Dr. Brode, "without ATP, I don't know that we could have proceeded. We would be at least five years or more behind where we are." 2

\section{Active Diffusion of Knowledge}

In addition to signing licensing deals, Integra has actively promoted the diffusion of knowledge developed from the project's technical accomplishments. Company scientists and other personnel have made numerous industry and academic presentations on the characteristics of the new polymer and on the tests of its mechanical properties and biocompatibility. Two scientists from Integra were invited to speak at an International Symposium on Polymeric Drugs and Drug Delivery Systems in Boston, August 1998, sponsored by the American Chemical Society. Currently, Dr. Kohn and Integra's other personnel have published 15 peer-reviewed articles dealing with this new polymer, including those for the American Chemical Society and the Materials Research Society.

\section{A Platform Technology with Multiple Uses}

The new bioabsorbable polymer is a platform technology with the potential to answer many challenging clinical and commercial needs. Integra has begun to adapt the technology, which recently won the Thomas Alvin Edison Award, to new applications including cartilage repair, wound care, cardiovascular repair, and drug delivery.

The new bioabsorbable polymer is a platform technology with the potential to answer many challenging clinical and commercial needs.

\footnotetext{
${ }^{2}$ Telephone interview with Dr. Brode of Integra, Nov. 27, 2000.
} 


\section{Powerful Software for Designing New Molecules and Therapeutic Drugs}

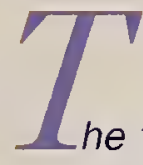

"semiautomated serendipity." In the search for new drugs, hundreds of synthetic chemicals and natural substances are put through a long series of trials, starting with effectiveness tests in cell-based assays and concluding with toxicity and effectiveness trials in laboratory animals and, finally, humans. At each stage, the vast majority of substances fail the test and are discarded.

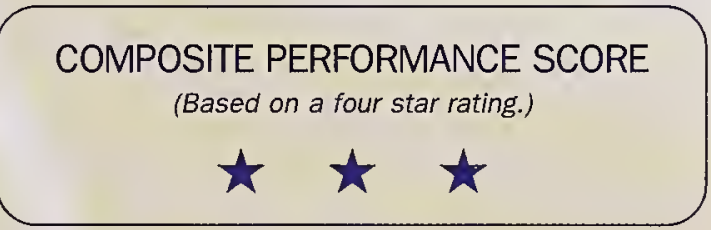

\section{Using Mathematics to Find New Drugs}

This ATP project with Molecular Simulations, Inc. (MSI), a small San Diego company that had 170 employees when the project began, combined applied mathematics and computer programming to develop new methods for simu-

\section{Density functional theory (DFT) proved} as accurate as other approaches, yet much less expensive.

lating molecular structures and reactions. The technology is more efficient than conventional molecule-design techniques, a quality that translates into speedier product development and lower costs.

The ATP-funded effort led to new understanding of density functional theory (DFT), a quantum mechanics method. Most work to understand molecules is mathematical, and DFT is a relatively new form of applied mathematics previously not widely used to simulate molecules. Researchers successfully demonstrated the applicability of DFT to the study of biochemical systems, the backbone of drug research, showing that DFT is as accurate as other approaches and considerably less expensive.

\section{Applications in New Drugs and Petrochemicals}

Prior to its ATP award, MSI was already developing, marketing and supporting a suite of software tools suitable for

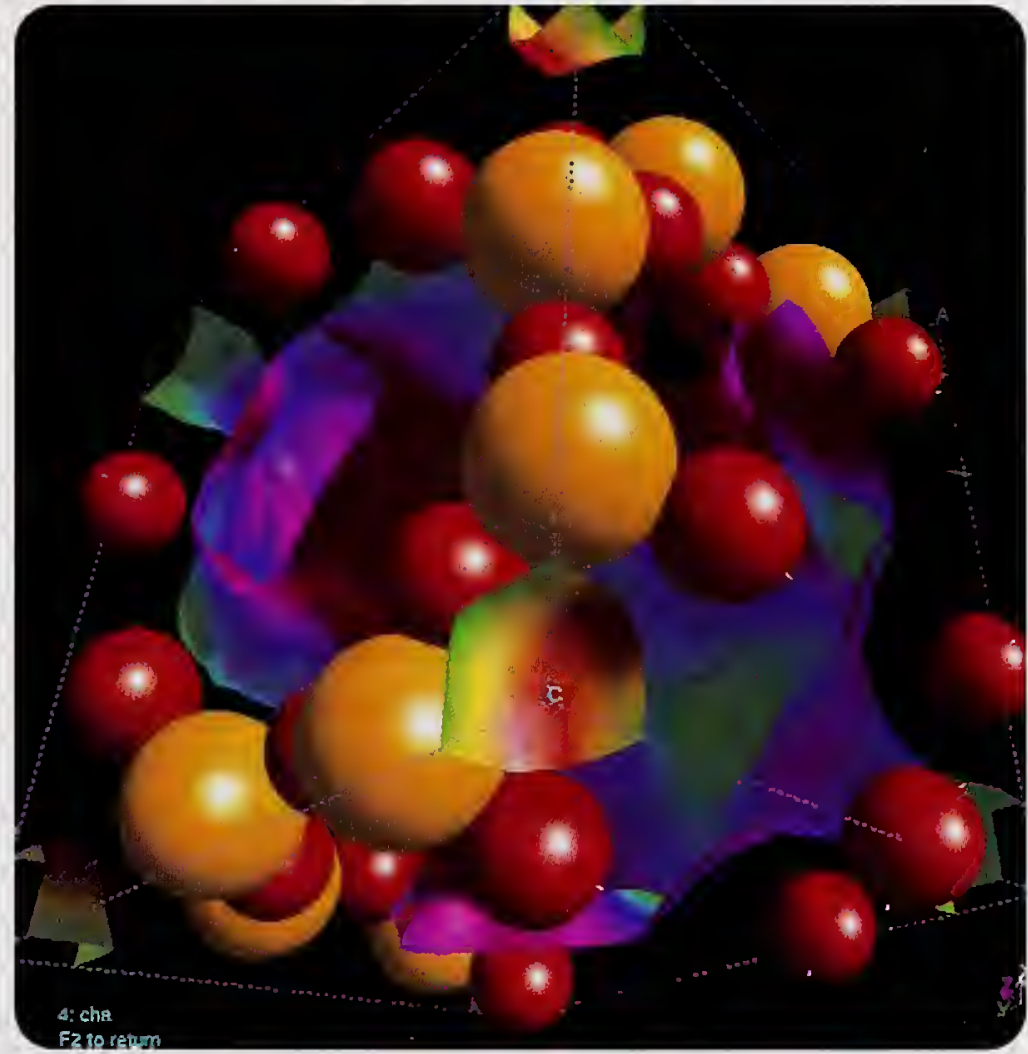

The geometrical and electron structure of a siliceous CHA-framework material isotopological with the mineral chabazite. Zeolites and related crystalline microporous solids such as chabazite have industrially useful separative and catalytic properties that are determined by both the micropore architecture and the nature of active sites.

computing the behavior and properties of molecules. The suite includes tools for bioinformatics, combinatorial library optimization, determination of protein structures 


\section{PROJECT HIGHLIGHTS}

\section{PROJECT:}

To develop density functional theory (DFT), a type of first principles quantum mechanics, for use in the development of new therapeutic drugs and other substances, an application that is expected to achieve substantial time and cost savings.

Duration: 6/1/1992 - 5/31/1995

ATP Number: 91-01-0224

\begin{tabular}{|c|c|c|}
\hline \multicolumn{3}{|c|}{ FUNDING (in thousands): } \\
\hline ATP & $\$ 1,442$ & $44 \%$ \\
\hline Company & 1,867 & $56 \%$ \\
\hline Total & $\$ 3,309$ & \\
\hline
\end{tabular}

\section{ACCOMPLISHMENTS:}

MSI successfully demonstrated the applicability of DFT to the study of biochemical systems and developed software that employs DFT to efficiently calculate molecular structures and energies. The software was used to study biochemically relevant systems. It proved as accurate as other approaches, yet much less expensive. Also, the company:

- prepared more than 30 technical papers on the ATP-funded technology for publication in professional journals or presentation at conferences;

implemented a highly accurate way of applying DFT in the company's Turbomole computer software product;

- expanded its physical plant to accommodate larger $R \& D$ and production facilities;

was a finalist for a Computerworld Smithsonian Award, the 1996 Innovator Medal; and

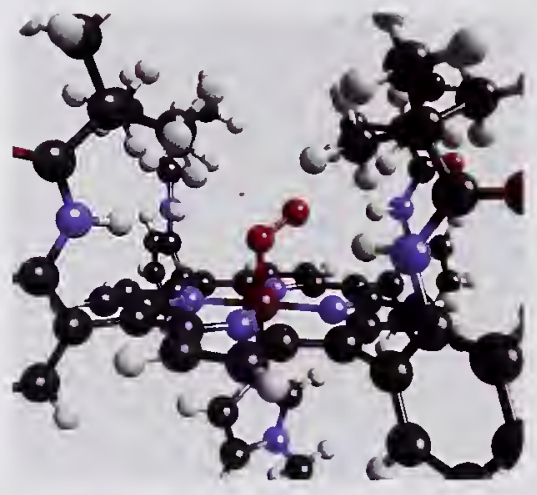

from amino acid sequences, and structureand analog-based rational drug design. The ATP project enabled MSI researchers to incorporate the new DF'T knowledge into several of these tools. Most MSI software users

The geometry of a heme complex, optimized by first principles density functional methods implemented in the program DMol, using technology developed under ATP sponsorship. In this molecule, which con tains more than 150 atoms, the central iron atom (central, dark red) is coordinated by four nitrogen atoms (blue) of the heme group, and a dioxygen molecule (red). benefit from access to several different tools and will use more than one of them in a given study.

One of the first MSI tools to be enhanced with the DFT technology was Turbomole, a computer software application that integrates a database of atomic functions, a modern user-interface, and mathematical tools like DF'T. The computer program calculates tables of molecular characteristics and generates a has grown at a cumulative annual rate of about 20 percent since the end of the ATP project in May 1995.

\section{COMMERCIALIZATION STATUS:}

Commercialization is in progress. MSI incorporated the ATP-funded technology into the company's existing Turbomole software package, which has been distributed to more than 100 sites. The ATP-funded technology has also been incorporated into MSI's quantum chemistry workbench software. Benefits from the ATP-funded technology are already accruing to users of MSI software, as well as to users of products developed with the software.

\section{OUTLOOK:}

Expectations for this technology and the company are strong. The technology has been incorporated into commercially distributed products that are being used extensively by a relatively small, yet global, community of scientists in academic, industrial, and governmental laboratories for rational drug design and petrochemical research. It has potential applications in biotechnology, microelectronics, and industrial fine chemicals research.

\section{Composite Performance Score: $\star \star \star$ \\ COMPANY: \\ Molecular Simulations, Inc. \\ (MSI; formerly Biosym Technologies, Inc.) \\ 9685 Scranton Road \\ San Diego, CA 92121}

Contact: John M. Newsam,

Phone: (619) 546-5391

Number of employees: 170 at project start, 292 at the end of 1997

three-dimensional structure of the molecule that can be viewed by molecular graphics.

Another tool upgraded with the new technology is DMol, a quantum chemistry program that enables users to make reliable, quantitative predictions about molecular systems. The ATP-funded technology-a DF' I-based component of the program-decreases the cost of these

\section{Researchers successfully demonstrated the applicability of DFT to the study of biochemical systems, the backbone of drug research ...}

types of computation, potentially reducing the cost of designing new molecules. The ATP-funded technology is being used experimentally in petrochemical research, and it has potential applications in biotechnology, rational drug design, microelectronics, and industrial fine chemicals research. 


\section{Benefits to Companies and Consumers}

Because the MSI software is relatively low-cost, enters the discovery and development cycle close to its beginning, and is used by research and development personnel in large organizations, the benefits to the users of the soft-

\section{. . . prepared more than 30 technical papers ... for publication ...}

ware can be large relative to what MSI earns through software licenses. Such benefits will accrue to chemical, petrochemical, pharmaceutical, and biotechnology companies, as well as to companies in other industries that use MSI software incorporating the ATP-funded technology. Benefits will also accrue to people who use therapeutic drugs and other products made by companies using the new technology. In addition, scientists worldwide might benefit from a database of molecular structures developed under the ATP award - MSI is considering making the

\section{... potential applications in biotechnology,} rational drug design, microelectronics, and industrial fine chemicals research.

database available on the Internet.

MSI reports that the ATP funds enabled it to complete research on the DF' $T$ technology and incorporate the results into its software products some 18 months earlier than it would otherwise have been able to do. The company, its customers in the pharmaceutical and materials industries, and their customers have all benefited. The project also facilitated the dissemination of new knowledge, particularly via the many scientific papers that were published about the ATP-funded technology.

\section{... scientists worldwide might benefit}

from a database of molecular structures

$$
\text { developed under the ATP award - }
$$

$\mathrm{MSI}$ is considering making the database available on the Internet.

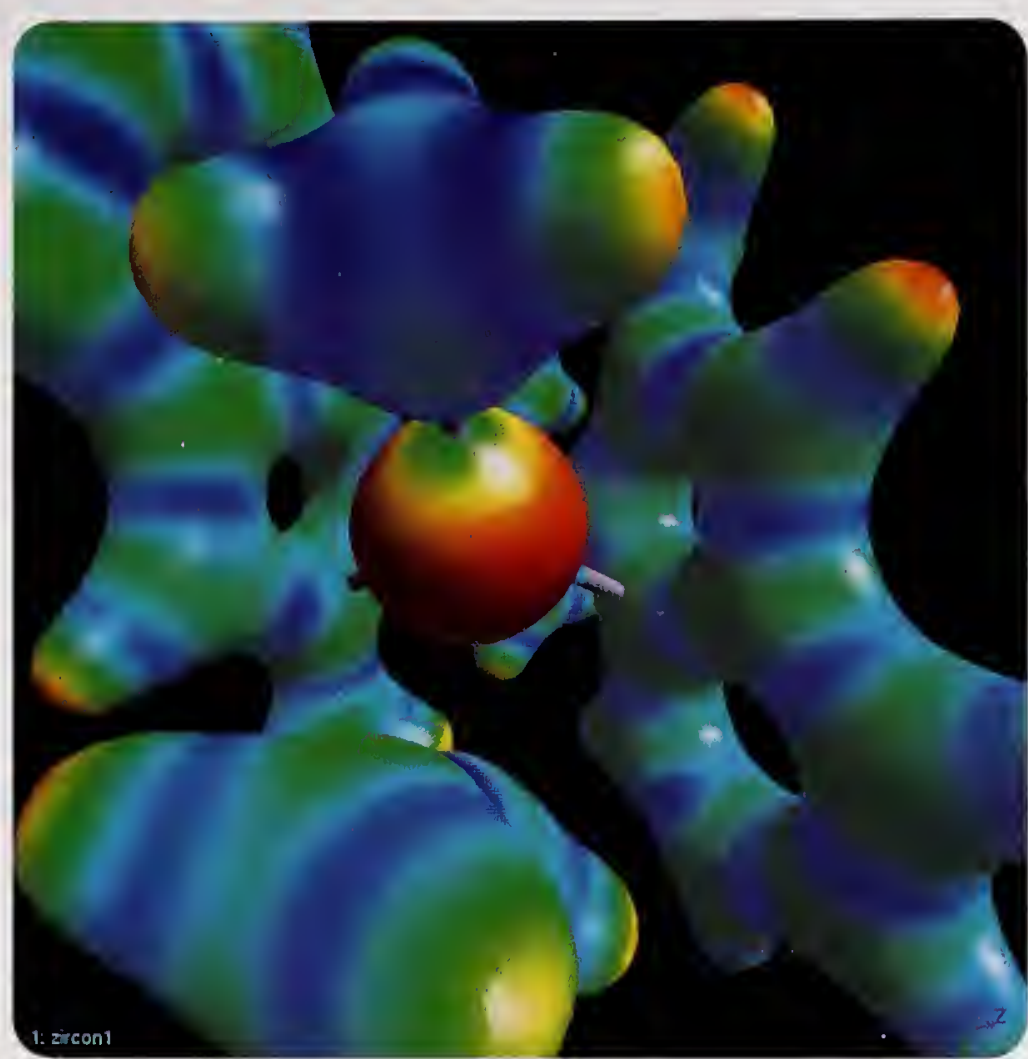

Electron density isosurface of a zirconocene complex, color-coded by electrostatic potential, as computed by the DMol program. The geometrical and electronic structures in metallocene complexes govern the nature of the polyolefin products produced when single site catalysts of this type are used to catalyze olefin polymerization.

\section{Company Grows, Announces IPO, is Acquired at a Large Premium}

Since the end of the A'TP project in May 1995, the company has grown at a cumulative annual rate of about 20 percent. In February 1997, it filed a Form S1 with the Securities and Exchange Commission announcing its intention to conduct an Initial Public Offering of stock, and noted that it expected to raise about $\$ 35$ million by selling about half of the stock in the company. In February 1998, the company and Pharmacopeia, Inc., announced that Pharmacopeia would acquire MSI. The acquisition was finalized in June 1998 in a transaction valued at approximately $\$ 140$ million. 



\section{THERMO TRILOGY CORPORATION \\ (original awardee: AgriDyne Technologies, Inc.) \\ Bioengineering of a Safe, Organic/Chemical Insecticide}

E

very year millions of tons of chemical pesticides are sprayed or irrigated onto plants in fields and gardens throughout the United States. Protected from weeds and insects, these plants flourish and grow to provide food and visual delight for us all. Chemicals used for pest control, however, sometime turn out to be poisonous for humans, and the results are often tragic. Consequently, efforts are under way to reduce the need for toxic chemical pesticides and, in the process, to eliminate the adverse side effects they can bring.

\section{Reducing the Risk of Toxic Pesticides}

One promising approach to reducing the hazards of pesticides is to use genetically engineered organic compounds based on naturally occurring pesticides that are harmless to humans. The ATP project with AgriDyne Technologies offered a novel way to do this by taking advantage of largescale biochemical production. AgriDyne, founded in Utah

\section{Scientific knowledge generated by the} ATP project . . . is disclosed in two patents and may be important to the genetic engineering of other plant extracts.

in the early 1980 s as Native Plants, was a small company that would have been unable to pursue this research without the ATP award.

\section{A Nontoxic, Chrysanthemum-Based Pesticide}

The technology AgriDyne developed during its ATP project is based on the chemistry of pyrethrins, a group of six closely related natural insecticides derived from pyrethrum, a type of chrysanthemum. Pyrethrins kill insects on contact, have low toxicity for mammals, degrade shortly after application, and produce no harmful residues. The only current source for natural pyrethrins is chrysanthemum from east Africa. But, according to AgriDyne's proposal to ATP, supplies were neither stable nor sufficient to meet the worldwide demand.

Although pyrethrins can be synthesized in the laboratory, production via traditional chemical processes is difficult and expensive. AgriDyne's alternative was to genetically engineer yeast cells to produce chrysanthemyl alcohol, a precursor that is then chemically converted to chrysanthemic acid. This, in turn, can be used to produce commercial quantities of pyrethrin.

\section{Business Upheavals Stall Technology}

AgriDyne achieved most of the technical goals of the project, but production costs were higher than predicted. The company encountered financial problems that forced it to close in 1995, just as the project was ending. AgriDyne apparently did not have enough management resources to

\section{The company encountered financial} problems that forced it to close in 1995 , just as the project was ending.

handle the challenges of both developing the technology and commercializing a product. The firm was acquired by Biosys of Columbia, Md., another biopesticides company, which decided not to make the investment required to commercialize the ATP-funded AgriDyne technology.

Biosys, in turn, declared bankruptcy in 1996. Its 


\section{PROJECT HIGHLIGHTS}

\section{PROJECT:}

To develop a genetic engineering process for producing pyrethrin, a natural insecticide from chrysanthemums that is nontoxic to mammals but was available only from Africa in limited, unstable supplies. The technology would provide a less-costly, stable domestic source of supply.

Duration: 6/1/1992 - 5/31/1995

ATP Number: 91-01-0071

\begin{tabular}{|c|c|c|}
\hline \multicolumn{3}{|c|}{ FUNDING (in thousands): } \\
\hline ATP & $\$ 1,200$ & $37 \%$ \\
\hline Company & 2.012 & $63 \%$ \\
\hline Total & $\$ 3,212$ & \\
\hline
\end{tabular}

\section{ACCOMPLISHMENTS:}

AgriDyne achieved most of its technical goals and received two projectrelated patents:

"Storage Stable Pesticide Compositions Comprising Azadirachtin and Epoxide" (No. 5,352,697: filed 7/28/1992, granted 10/4/1994) and

- "Chrysanthemyl Diphosphate Synthase, Corresponding Genes and Use in Pyrethrin Synthesis" (No. 5,443,978: filed 6/25/1993, granted 8/22/1995).

CITATIONS BY OTHERS OF PROJECT'S PATENTS: See Figure 3.2.

\section{COMMERCIALIZATION STATUS:}

No commercial product has yet been produced.

\section{OUTLOOK:}

Commercialization is uncertain, owing to the dissolution of AgriDyne, current market conditions that make the new production approach too costly to compete with natural sources of supply, and lack of plans, at this writing, by Thermo Technology (which now owns the intellectual property) to pursue further development. Scientific knowledge generated by the ATP project, however, is disclosed in two patents and may be important to the genetic engineering of other plant extracts. The knowledge has potential applications in pharmaceuticals and specialized materials and chemicals, as well as in pesticides.

\section{Composite Performance Score: No Stars}

\section{COMPANY:}

AgriDyne Technologies, Inc. (acquired by Biosys, Inc. in 1995; Biosys assets acquired by Thermo Trilogy in 1996)

Thermo Trilogy Corporation

7500 Grace Drive

Columbia, MD 21044

Contact: Ramon Georgis

Phone: (410) 531-4711

\section{Gains in Bioengineering Knowledge}

Although no commercial product has yet resulted from the ATP-funded technology, new bioengineering knowledge has. Some of it has been disclosed through two patents. But AgriDyne's manufacturing know-how was apparently not passed on to the company's successors. Should events in Africa decrease the supply or increase the cost of natural pyrethrin, the AgriDyne approach may be resurrected by funding development of the needed manufacturing skills.

\section{Although no commercial product has yet resulted from the ATP-funded technology, new bioengineering knowledge has.}

edge of the scale-up process for the technology (requirements for physical plant investment, as well as information on the predictability of a viable, consistent production yield) was unknown to them and their counterparts at Biosys, and they found it difficult to assess AgriDyne's A'TP project. Both companies considered further pursuit of the technology too risky for them. 
Figure 3.2 Patent Tree for Project Led by AgriDyne Technologies, Inc.: Citations by Others of AgriDyne Patents

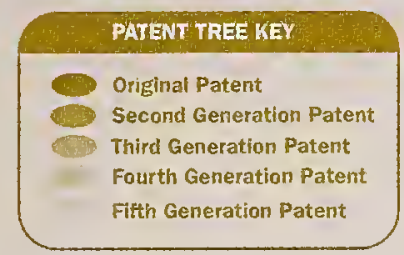

1999

1998

1997

1996

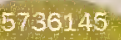

Balmia Centr

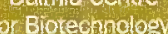

5928924

Human Genom

Sciences

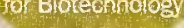

5786193

Humar Genome

Sciences

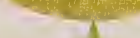

A

1995

5448978

Agridyne 



\section{Prostheses Made of Biomaterials That Regenerate Body Parts}

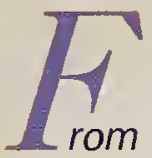

rom its beginning, the field of bioengineering has focused on providing the best artificial devices - hearing aids, artificial limbs and other prostheses - to replace body parts that are missing, broken, or dysfunctional. This ATP project with Tissue Engineering (TE), a biotechnology start-up company, takes bioengineering far beyond artificial replacements to a technology that regenerates, rather than replaces, lost or damaged tissues. Although this claim sounds like science fiction, it is in fact quite real. And it promises to produce real medical benefits in the very near future.

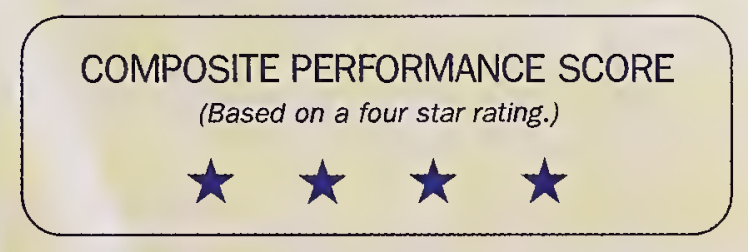

\section{Technology to Regenerate Lost or Damaged Body Parts}

TE is pioneering a new class of biomaterials called ADMAT (animal-derived extracellular matrix). The idea behind the company's ATP project is to use ADMA'T materials in collagen-scaffold prostheses to replace damaged or dysfunctional tissues and organs. The prostheses are designed to provide templates that mobilize the body's

This ATP project . . . takes bioengineering far beyond artificial replacements to a technology that regenerates, rather than replaces, lost or damaged tissues.

own cells and induce them to rebuild the lost tissue, gradually replacing the prosthesis itself. Regeneration of body parts requires a biomaterial with a structure, components and chemical signals that allow the body's tissue cells to recognize, respond to, and remodel the material without rejecting it as foreign.

\section{Demand for ADMAT Materials}

ADMAT materials are derived from the byproducts of land and marine animals processed for food. The material can be spun into fibers and woven into fabrics using tech-

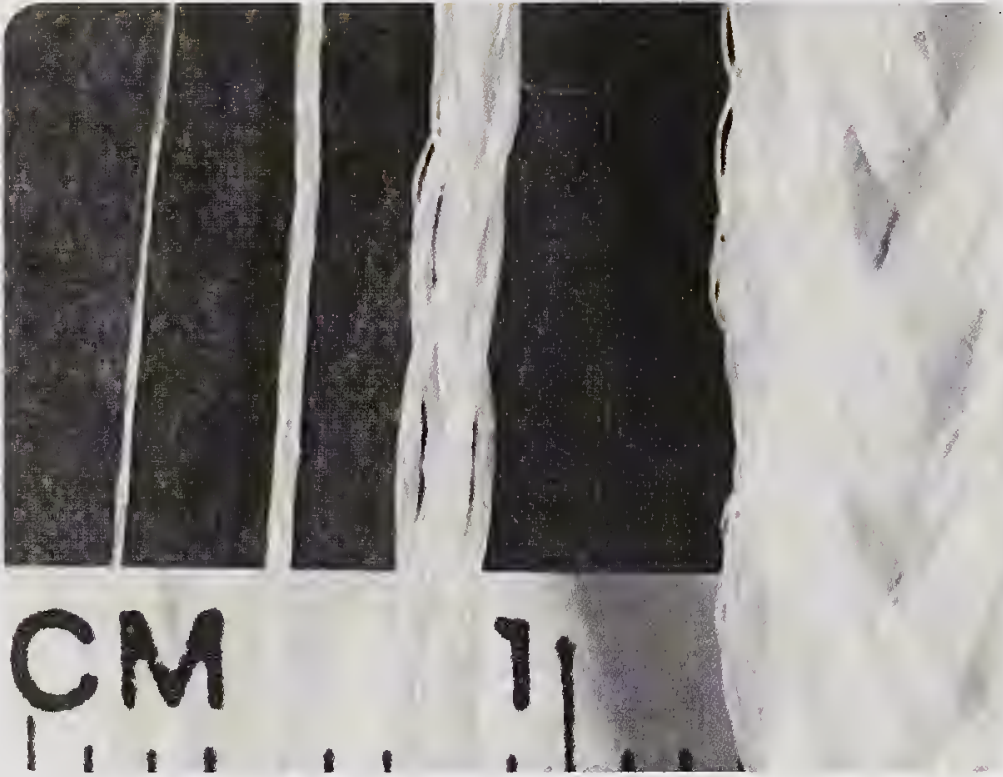

Collagen fiber and braided structures from collagen fiber: (a) single collagen fiber, (b) 8-ply collagen fiber braid, (c) 64-ply collagen fiber braid, (d) 512-ply collagen fiber braid.

niques borrowed from the textile industry, or it can be formed into foams, sheets, and films. ADMAT can be used to enhance collagen scaffolds for vascular grafts, ligaments, tendons, periodontal tissue, and similar reconstructions.

During the ATP project, TE successfully developed techniques and procedures for extracting and storing a mixture of collagens and for preserving the desired characteristics of the extracellular matrix. The company developed new materials for hosting the matrix and a process for adding the matrix to collagen fibers in the course of spinning. 


\section{PROJECT HIGHLIGHTS}

\section{PROJECT:}

To develop rechniques and procedures for processing tissue, extracting and storing collagen, and spinning and weaving collagen fibers into fabrics and other forms suitable for human prostheses that could induce the body's own cells to rebuild lost tissue while gradually replacing the prosthesis.

Duration: 3/1/1993 - 2/28/1996

ATP Number: $92-01-0133$

\begin{tabular}{llc}
\multicolumn{3}{c}{ FUNDING (in thousands): } \\
ATP & $\$ 1,999$ & $48 \%$ \\
Company & 2,128 & $52 \%$ \\
Total & $\$ 4,127$ &
\end{tabular}

\section{ACCOMPLISHMENTS:}

TE accomplished its technical goals. The company developed procedures for processing a tissue-specific extracellular matrix rich in cytokines (cell-generated proteins), extracting and storing type I collagen (a material present in all tissues), and spinning collagen into fibers that can be woven into prosthetic fabrics. The company:

received two patents for technologies related to the ATP project: "Apparatus and Method for Spinning and Processing Collagen Fiber" (No. 5,562,946: filed 11/2/1994, granted 10/8/1996) and

"Bipolymer Foams Having Extracellular Matrix Particulates" (No. 5,709,934: filed 11/22/1994, granted 1/20/1998);

applied for three other patents related to the technology;

made several presentations at conferences and workshops; and

The demand for products the company plans to offer clearly exists. The lag time, however, between technology conception and market availability - particularly for medical treatments - is long. Tissue-engineered products face clinical trials and other regulatory hurdles, in addition to technical and market-introduction barriers. The company is making good progress in navigating these barriers in accord with its technical and business plans.

Commercialization is in progress. TE has placed periodontal prosthesis prototypes with potential customers for testing. It has created other products for research, testing and diagnostic applications. These activities are not regulated, so commercialization can happen more speedily. In addition, it has formed a venture with Wright Medical Technology for commercialization of orthopedic applications. TE is also in discussions with several other companies to commercialize other applications, such as a line of skin and wound-healing products.

\section{Large Potential Benefits for Society}

The eventual successful commercial introduction of the ATP-funded technologies will bring large health gains to patients with many forms of medical problems, ranging from dental to cardiovascular. Procedures and materials formed a joint venture with Wright Medical Technology, Arlington, Tenn., to develop and distribute products based on the ATP-funded technology for applications involving ligaments, tendons, cartilage, and other musculoskeletal parts.

CITATIONS BY OTHERS OF PROJECT'S PATENTS: See Figure 3.3.

\section{COMMERCIALIZATION STATUS:}

A commercialization venture has been formed for orthopedic applications. Prototypes are in testing, although no product has yet entered the market. Patent disclosures and a joint venture to commercialize the technology may be providing useful knowledge to other researchers in the field.

\section{OUTLOOK:}

This project is on track for market entry in the very near future. The technology is scheduled to be used first in the fabrication of periodontal prostheses and orthopedic applications. Ideas for skin and wound-healing products are also being explored by the company with potential customers.

\section{COMPANY: \\ Tissue Engineering, Inc. (TE) \\ 451 D St., Suite 807 \\ Boston, MA 02210}

Composite Performance Score:

Contact: Eugene Bell

Phone: (617) 946-0520

Number of Employees: 1 at project start, 18 at the end of 1997

that would enable the regrowth of ligaments and cartilage in knees and enable dental tissue to regenerate with a single surgery - at costs lower than those offered by alternative medical approaches today, and that one day may even facilitate organ regeneration - would have great benefits for society.

\section{TE has placed periodontal prosthesis prototypes with potential customers for testing.}

These potential benefits are likely to be huge because of the large number of patients who could use these prostheses, the advantages the TE approach has over currently available alternatives, and improvements in the ability of patients to function as a result of using the new technology. The ATP award is playing an important role in bringing these benefits to society, because applications of the new technology are about two years ahead of where they would have been without ATP funding.

A recent detailed case study by the Research Triangle 
Figure 3.3 Patent Tree for Project Led by Tissue Engineering, Inc.: Citations by Others of Tissue Engineering, Inc. Patents PATENT TREE KEY

Original Patent

Second Generation Patent

Third Generatlon Patent

Fourth Generation Patent

Fifth Generation Patent

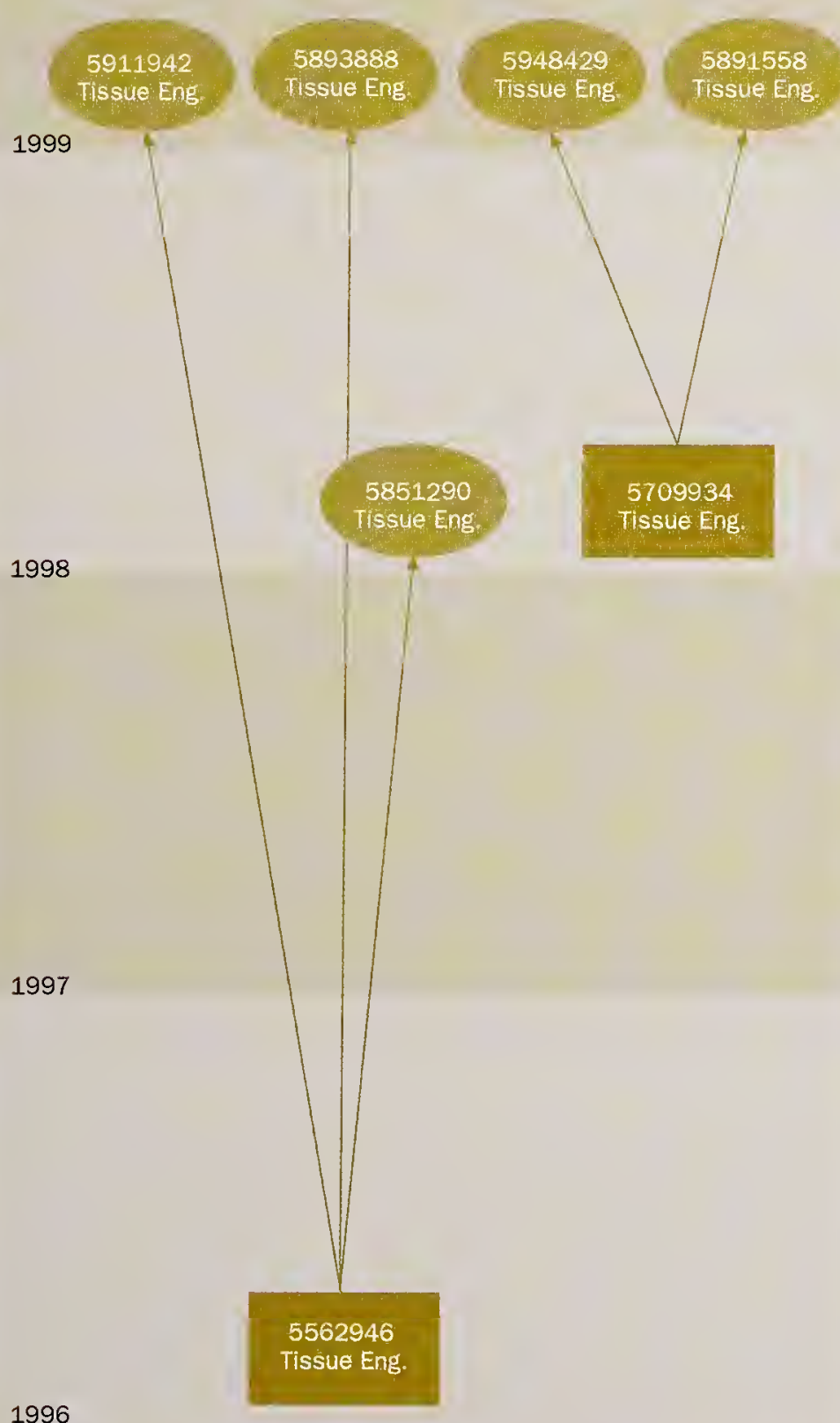

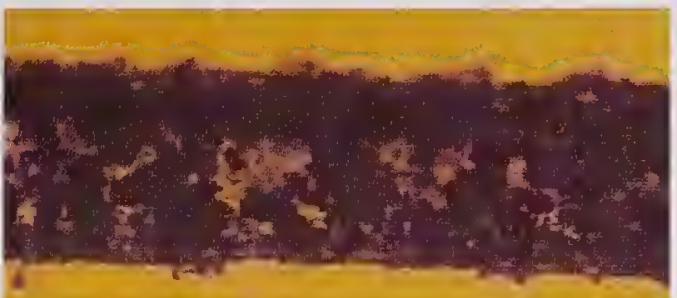

Collagen fiber decorated with ADMAT microparticulates via ATP-funded patented process.

Institute estimated that TE's ADMAT technology could be expected to generate about $\$ 33$ billion (in present value dollars) in net benefits for society in a single medical application area: anterior cruciate ligament repair.

The study estimated that about 100,000 patients per year with ligament damage would be eligible for the new treatment, that the number using the Tissue Engineering technology would start at 9,000 in the first year of availability and grow to 72,000 ten years later, supplanting an increasing percentage of alternative technologies currently

\section{. . formed a venture with Wright Medical Technology for commercialization of orthopedic applications.}

in use. The study incorporated estimated benefits from quality-of-life improvements, using a "quality-adjustedlife-years" index value. It estimated that about $\$ 15$ billion of the expected benefits would be attributable to ATP's accelerating the technology development by two years 

ADVANGED TECHNOLOGY PROGRAM

CHAPTER 4

Electronics,

Computer Hardware

\& Communications

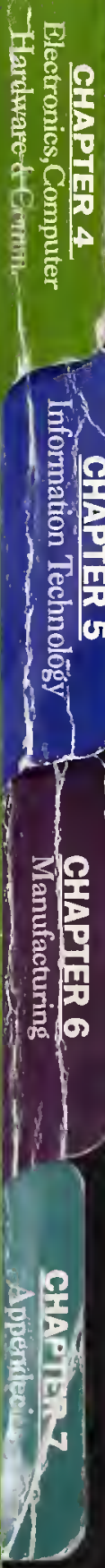





\section{ACCUWAVE CORPORATION \\ Expanding the Number of Light Signals in an Optical Fiber}

ver the last two decades, the use of optical fiber as an alternative to metal wire and cable has exploded. Optical fiber is now the technology of choice for use undersea and for most terrestrial applications of more than the shortest distances.

COMPOSITE PERFORMANCE SCORE

(Based on a four star rating.)

No Stars

\section{More Light Signals Per Optical Fiber}

This ATP project with Accuwave Corporation, a small California company specializing in the development of holographic communications systems, created a way to

... multiwavelength light enters one end of the crystal and encounters a series of holographic gratings

. . . that separate the light signals of different wavelengths.

substantially increase the number of signals that can be transmitted in a single strand of fiber-optic cable. The new technology is designed to enable the transmission of 80 or more channels per fiber. If adopted, it could eventually reduce the cost per transmission and save hundreds of millions of dollars over a period of just a few years.

\section{A Unique Holography-Based Approach}

The new technology is based on the concept of wavelength division multiplexing (WDM), which transmits light of more than one wavelength through a single optical fiber, separating the individual wavelengths at the receiver. Such systems must discriminate among the different wavelengths and so are limited by the accuracy of the multiplexing and demultiplexing optics.
Accuwave had previously developed a unique approach to WDM using volume holography: holograms "written" in the interior of thick crystals of photorefractive (light-bending) materials. In the demultiplexer crystal, for example, multiwavelength light enters one end of the crystal and encounters a series of holographic gratings each tuned to deflect a specific wavelength of light that separate the light signals of different wavelengths. Accuwave had demonstrated the individual elements of a system that could multiplex wavelengths more than 10 times better than the current state of the art at visible wavelengths. With its ATP funding, Accuwave extended its technology to the infrared wavelengths used for longdistance telecommunications, and designed a prototype WDM system.

. . another company beat it to market with a competing system operating in the same infrared wavelengths.

Accuwave officials report that ATP funding enabled it to develop WDM for signal transmission, a task it would otherwise have been unable to do. In addition, receiving the ATP award helped the company form important alliances with research partners during the ATP project (not identified here for confidentiality reasons). 


\section{PROJECT:}

To develop holographic-optics technology that will increase (by more than 10 times) the number of signals that can be transmitted through a single optical fiber.

Duration: 3/1/1993 - 3/14/1995

ATP Number: 92-01-0055

\begin{tabular}{|c|c|c|}
\hline \multicolumn{3}{|c|}{ FUNDING (in thousands): } \\
\hline ATP & $\$ 1,987$ & $69 \%$ \\
\hline Company & 898 & $31 \%$ \\
\hline Total & $\$ 2,885$ & \\
\hline
\end{tabular}

\section{ACCOMPLISHMENTS:}

Accuwave developed a process for producing photorefractive materials suitable for fiber optics telecommunications applications. The company also:

received two patents for technologies related to the ATP project:

"Photorefractive Systems and Methods (Divisional)"

(No. 5,684,611: filed 6/6/1995, granted 11/4/1997) and

"Wavelength Stabilized Laser Sources

Using Feedback From Volume Holograms"

(No. 5,691,989: filed 9/14/1993, granted 11/25/1997);

applied for two additional patents for technologies related to the ATP project;

completed pilot production of wavelength division multiplexing (IVDM) components designed for incorporation into equipment manufactured by other companies, and introduced the components in 1996;

signed a purchase agreement with a major telecommunications equipment manufacturer;

raised \$4 million from venture capitalists and other investors since 1990; and built a plant and ramped up volume production in 1998.

CITATIONS BY OTHERS OF PROJECT'S PATENTS: See Figure 4.1. COMMERCIALIZATION STATUS:

In 1996 and 1997, Accuwave introduced three WDM system components: wavelength controllers, wavelength lockers and fiber-optic collimators. The company continued to pursue its original goal of selling WDM products for fiber optics telecommunications applications.

\section{OUTLOOK:}

Despite the heretofore promising prospects for growing applications of this technology in the telecommunications sectors, the commercialization outlook at this time is bleak. As this report was going to press in late 1998, it was learned that the company had ceased operations and was in the process of declaring bankruptcy. While it is possible that the technology will be picked up by other companies and carried forward in the future, at this point there is insufficient information about the likelihood of this to comment further on the outlook.

Composite Performance Score: No Stars

COMPANY:

Accuwave Corporation

1651 19th St.

Santa Monica, CA 90404

Contact: Neven Karlovac

Number of Employees: 5 at project start, 16 at the end of 1997

commercialization plans for sale of a WDM system in the bulk-signal-transmission market, it launched several component products based on the ATP-funded technology. These include wavelength controllers, wavelength lockers, and fiber-optic collimators, all of which are being sold to producers of WDM systems. The company developed contacts with potential telecommunications clients in Europe, Japan, and Brazil, as well as the United States, and it planned to introduce its own wavelength multiplexers in the near future.

\section{Potential Big Savings in Telecommunications}

With its potential to increase the number of signals that a single optical fiber can carry, the Accuwave technology could significantly affect the cost of communications via fiber-optic cables, particularly if used for undersea applications. Because of the volume of messages transmitted via this medium, cost savings would be great, even if the number of signals per fiber were doubled. The Accuwave technology has the potential to double and redouble the number of signals per fiber many times over, with the count possibly reaching as many as 80 signals per fiber. 
Figure 4.1 Patent Tree for Project Led by Accuwave Corporation: Citations by Others of Accuwave Corporation Patents

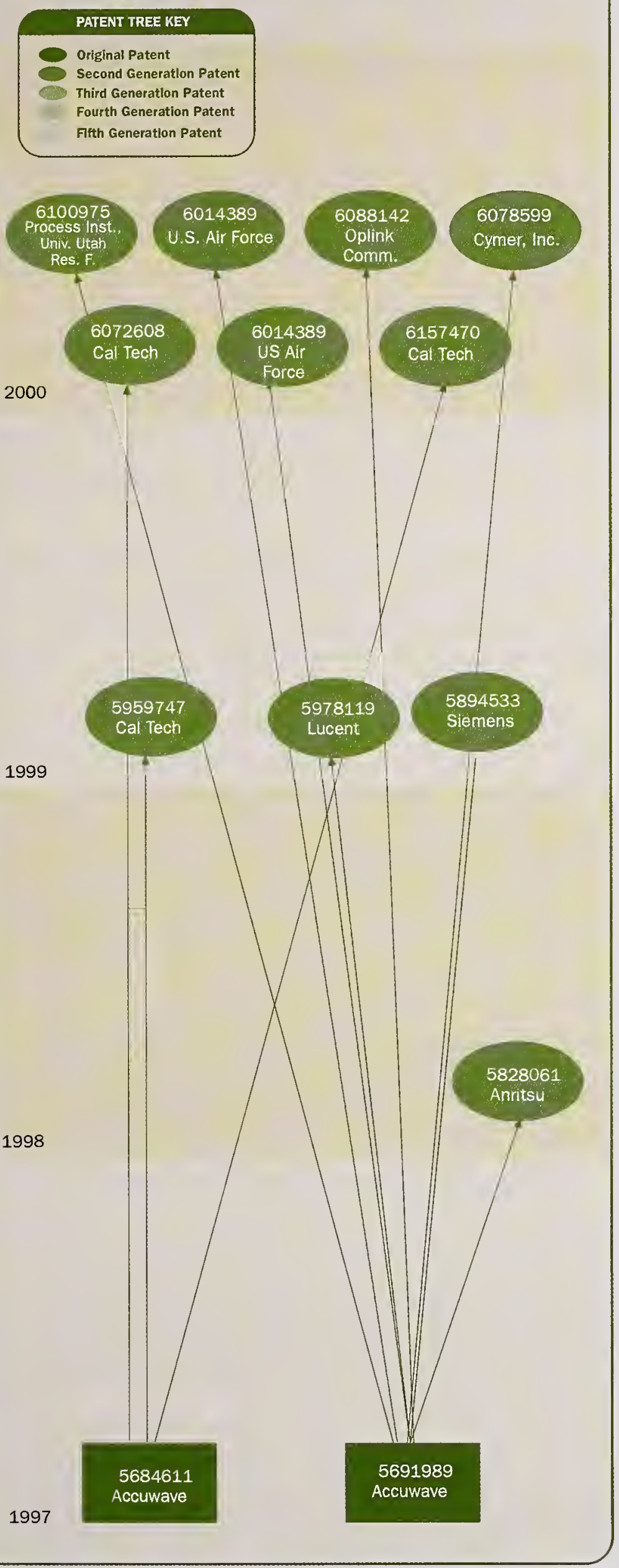

In addition to applications in the bulk-signaltransmission market, the ATP-funded technology has the potential of providing greater cable bandwidth to homes and offices for use with high-definition TV and to the closed-circuit TV market, particularly for security

\section{. . . in late 1998 it was learned that the company had ceased operations and was in the process of declaring bankruptcy.}

uses. The company was interested in pursuing these potential applications, but instead used its resources to develop the WDM system for telecommunications applications. The technology also has potential applications in ultranarrow band filters, spectrometers and optical disk memories.

As this report was going to press in late 1998, it was learned that the company had ceased operations and was in the process of declaring bankruptcy. It is possible that the technology will be picked up by other companies and carried forward in the future. 



\section{AMERICAN DISPLAY CONSORTIUM \\ A Technology Boost for U.S. Manufacturers of Flat Panel Displays}

lonsumers are always hungry for the latest and greatest, especially in computers and televisions. Demand is high for the development of larger, higher-resolution displays. Flat-panel displays offer larger viewing areas, higher resolution, lighter weight, and require less space than traditional cathode-ray tube (CRT) technology. Applications range from laptop computer screens to high-definition television to signs. As new digital HDTV is adopted in the United States, flat-panel displays are likely to increase in economic importance. The 1998 global market for flatCOMPOSITE PERFORMANCE SCORE (Based on a four star rating.) panel displays totaled $\$ 11.8$ billion, and is growing approximately 9 percent per year, with 12 percent expected by $2003 .^{1}$

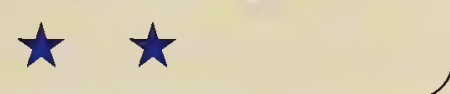

\section{Common Problems Impeding U.S. Producers}

A flat panel display (FPD) consists of two glass plates with an electro-optical material compressed between them that responds to an electrical signal by emitting light or modulating backlighting. On the glass plates are rows and columns of electrical conductors that form a grid pattern. It is the intersection of these rows and columns that define picture elements, called pixels. The modulation of light by each pixel creates the images on the screen. There are three broad types of commercially available FPDs: liquid crystal displays, electroluminescent (EL) displays, and plasma display panels.

\section{A problem confronting all of the producers of} FPDs has been the cost of undetected defects on a panel, which can result in costly repairs, or scrap if repairs cannot be made.

A problem confronting all of the producers of FPDs has been the cost of undetected defects on a panel, which can result in costly repairs, or scrap if repairs cannot be made. Because of the complexity and size of flat panel displays, flaws such as "opens" (spaces where there should be wires) or "shorts" (wires where there should be spaces) are quite common. According to some estimates, manual inspections and repairs have accounted for as much as 40 percent of the total cost of flat panel production. By finding solutions to problems causing defects, U.S. flat-panel display companies saw an opportunity to fight their way into the Japanese-dominated world market.

\section{...U.S. flat-panel display companies saw} an opportunity to fight their way into the Japanese-dominated world market.

\section{An Industry-led Collaborative Research Initiative}

In the early 1990s, Japanese producers emerged as market leaders in flat panel display technologies. By 1993, Japan held 92 percent of the world market share for liquid crystal displays, 68 percent for plasma displays, and 47 percent for electroluminescent (EL) displays.

In an attempt to change this unfavorable world market

${ }^{1}$ SRI Consulting, Tech Monitoring, Flat-Panel Displays, 1999.

${ }^{2}$ Kala Krishna and Marie Thursby, Whither Flat Panel Displays? NBER Working Paper 5415, January 1996, cited in Albert Link, Eronomic Analysis of the Advanced Manufacturing Technology for Flat Panel Display Joint Venture at Project End, Draft Report to ATP, April 1997: 23 (unpublished). 


\section{PROJECT HIGHLIGHTS}

\section{PROJECT:}

To improve the ability of U.S. firms to manufacture flat panel displays efficiently, by developing equipment to inspect and repair displays automatically, and by developing improved methods of mounting integrated circuits to increase resolution.

Duration: 8/15/1991 -8/14/1996

ATP Number: 90-01-0060

\section{FUNDING (in thousands):}

ATP $\$ 7,306 \quad 49 \%$

Company $\quad \mathbf{7 , 6 0 4} \quad 51 \%$

Total $\$ 14,910$

\section{ACCOMPLISHMENTS:}

A group of U.S. producers of flat panel displays cooperated to address common problems that were plaguing the industry. They made a number of advances that should improve their ability to compete in world markets, currently dominated by foreign producers. Specifically, they:

developed a process of tape automated bonding (TAB), a technique for mounting integrated circuits on a display surface, for which a patent was received by Planar;

- introduced the TAB process into commercial production;

developed prototype equipment for automatically inspecting flat panel displays for flaws and automatically repairing these flaws;

- explored other approaches for the fabrication of driver circuitry for displays, including flip-chip-on-glass and Silicon-on-Glass technologies;

- presented papers at industry meetings; and

- filed a patent application which was granted:

"Die Bonding Connector and Method"

(No. 5,426,266: filed 11/8/1993, granted 6/20/1995).

situation, a group of U.S. flat panel display manufacturers, organized as the Advanced Display Manufacturers of America Research Consortium (ADMARC), applied to the Advanced Technology Program for research funding. In 1991, ADMARC companies received an ATP jointventure award of $\$ 7.3$ million for a five-year project to develop technology that would improve the ability of U.S. firms to manufacture flat panel displays efficiently and with improved performance and quality. Consortium companies matched the ATP award with $\$ 7.6$ million, for total project funding of $\$ 14.9$ million. After receiving funding from ATP, the consortium changed its name to the American Display Consortium (ADC). ${ }^{+}$

Initially, the American Display Consortium was made up of three members: Photonics, Planar Systems, and
CITATIONS BY OTHERS OF PROJECT'S PATENTS: See Figure 4.2.

\section{COMMERCIALIZATION STATUS:}

The tape automated bonding process developed by Planar has been introduced into commercial production.

\section{OUTLOOK:}

Project accomplishments, particularly the work on TAB which enabled substantial improvements in the resolution level of flat panel displays, have increased the competitiveness of U.S. FPD producers. Yet the challenges faced by U.S. producers are large, and the results of the project alone appear insufficient to meet those challenges. The general outlook for the U.S. industry remains uncertain at this time. ${ }^{3}$

\section{Composite Performance Score: $\star \star$ \\ COMPANIES:}

American Display Consortium

6975 Wales Rd.

Northwood, OH 43169

Contact: Dr. Peter Friedman

Phone: (419) 666-1024

Joint Venture Members at Project End: Photonics Imaging, Inc., Electro-Plasma, Inc., Kent Display, Inc., Westinghouse Norden Systems, Inc., and Planar Systems, Inc.

Subcontractors: Florod and Micron Corporation

Collaborator: University of Michigan

Spin-off Company: Ward Synthesis.

Optical Imaging Systems (OIS). OIS was later bought by another firm and left the consortium. Following the departure of OIS, several additional companies joined the consortium, including Electro-Plasma, Inc., Northrop Grumman, Norden Systems, Plasmạco, Inc., and Kent Display Systems. By the end of the project, the ADC had grown to include 14 member companies, but Photonics and Planar remained the leaders of the ATP project.

Approximately half of the participating companies shared the costs of the tasks that were undertaken. All of the companies had access to periodic reviews of technical progress as well as the intellectual property created by the project. But those companies that did not participate in sharing the project's costs were not allowed to help set the research agenda for the project.

\footnotetext{
${ }^{3}$ Substantial additional technical assistance to the industry has been provided by DARPA and that assistance may further improve the outlook for U.S producers.

${ }^{4}$ This is not the same organization as the U.S. Display Consortium, which later formed and received money from the Defense Advanced Research Projects Agency (DARPA) to research flat panel displays. ADC later became a member of the U.S. Display Consortium.
} 


\section{A Shared Motivation for Improvement Among Head-to-Head Competitors}

At the outset of the project, all three of the participating companies were struggling financially, and were preoccupied with their individual business and production problems. Although the participating companies' businesses were based on different technologies (i.e., liquid crystal, electroluminescent, and plasma displays), the companies shared common problems and goals. They all wanted to be able to increase the density of driver circuitry and interconnections in order to improve display resolution, and they wanted automated testing to decrease production costs. By improving quality and lowering costs, they could better compete with foreign manufacturers and regain market share. At the same time, they were among the community of U.S. flat-panel display producers who were also competing among themselves for market share.

The resulting project structure was a horizontal joint venture of competitors who were all operating in a difficult market situation. Maintaining a climate of openness, with a high degree of sharing of information appeared to be much more challenging to achieve in this joint venture project than in many of the others that ATP has funded. It is perhaps not surprising that each member tended to have its own area of focus and major issues of concern, and that the project tasks were primarily divided along individual company lines. This division of research is in contrast to the cross-company research teams, used, for example, in the Printed Wiring Board Joint Venture led bt NCMS described in this chapter.

\section{Technology for Automatic Inspection and Repair}

The consorrium took several major approaches and areas of focus: Photonics sought to automate systems for inspection and repair on the manufacturing line in order to decrease the costs associated with quality assurance.

The company sought to develop an automated system that could inspect displays quickly and reliably, allowing engineers to modify the production equipment before more flawed displays were produced. An additional goal was to develop an automatic repair system that could add or remove conductive material on a display to repair opens or shorts. Both steps toward automatic repair could decrease production costs, allowing U.S. companies to compete more effectively with their foreign competitors.

Photonics worked with Florod, a subcontractor, to develop prototype automatic inspection equipment. The first resulting prototype, AIM-1, had substantial per- formance problems. To fix these problems, Photonics worked with consultants from the University of Michigan to design the second prototype, AIM-2. Photonics then issued a contract to a spin-off company, Ward Synthesis, to construct the new device. The AIM-2 can successfully detect a number of different defects on various types of flat panel displays.

Photonics also developed a prototype automatic repair station with the help of another subcontractor, Micron Corporation, who delivered the prototype to Photonics in December 1995. Demonstrations have shown that the repair equipment can successfully repair defects in active and passive liquid crystal displays.

\section{Technology for Improved Resolution}

The other goal of the project was to improve the degree of resolution, a key performance criterion for FPDs. The higher the resolution of images on the screen the better, and higher resolution requires more pixels. Pixels are controlled by integrated circuits (ICs), or driver chips, mounted on the glass. More pixels require additional driver chips, each of which must be connected with the display. More pixels and more driver chips present other manufacturing challenges that the consortium sought to address.

To increase resolution for a given screen size requires increasing the density of circuit integration and the density of connections between chips and display. To achieve a higher level of integration, Optical Imaging Systems (OIS) sought to stack and interconnect memory and/or logic elements on the driver chips that control the pixels. It did this by using polysilicon-on-glass (PSOG) transistors. These thin-film transistors serve as electrical switches on many large-area displays, and are especially important to the manufacturers of active matrix LCD.

The PSOG task was redefined after OIS was bought by another company and could not pursue its part of the research on the project. The consortium's new effort, called the silicon-on-glass (SOG) task, directed by Photonics, was intended to investigate a version of this technology that would be applicable to driver chips for all FPD technologies, not just active matrix liquid crystal displays (AMLCDs). A prototype was developed using SOG technology, but testing found that some of the chips could not handle high voltages. As a result, the SOG task was terminated in the project. Reportedly, several large semiconductor firms subsequently undertook further development of the silicon-on-glass approach to increasing integration of driver chips. ${ }^{5}$

\footnotetext{
${ }^{5}$ Link, 1997, p. 25. Substantial additional technical assistance to the industry has been provided by DARPA and that assistance may further improve the outlook for U.S. producers. 25.
} 
Driver circuitry for active-matrix LCDs (AMLCDs) is fabricated directly on the display area itself with the individual pixels that the drivers control, while driver chips for plasma and electro-luminescent displays, as well as some driver chips for AMLCDs, are mounted on the edge of the display area.

Planar explored another approach to fabricating driver circuitry on the edges of displays. Planar sought to develop flip-chip-on-glass (FCOG) technology, which would allow for the ICs controlling pixels to be fabricated directly onto the glass. Planar demonstrated the technical feasibility of FCOG technology. The cost of the technology, however, led company participants to conclude that the technology was "not economical at this time." The FCOG task was therefore concluded ahead of schedule, and instead, Planar began working on a technology called tape automated bonding (TAB).

$\mathrm{TAB}$ was and is the primary approach to attaching driver chips to the edges of flat panel displays. This technology works by mounting integrated circuits on tape and then attaching this tape to the display glass. Planar researched and successfully developed techniques to attach adhesive to the display glass, align the tape on the glass, and then bond the tape to the glass. Planar subsequently introduced the TAB process into commercial production.

\section{Tape Automated Bonding (TAB) Technology: a Central Achievement}

In the opinion of those closely associated with the project, its central achievement was the improvement of the TAB technology, the primary approach for mounting driver circuitry on the edges of flat panel displays. Planar's work on the $\mathrm{TAB}$ technology resulted in the capability to triple the resolution of flat panel displays. ${ }^{6}$ Not only does the manufacturer benefit, but so do the customers of improved displays. And, the ability to improve resolution will make these U.S. companies more competitive internationally.

\section{...the TAB technology resulted in \\ the capability to triple the \\ resolution of flat panel displays.}

Project-related advancements in TAB were disclosed in a patent issued to Planar in June 1995. The advancements in technical knowledge were also disseminated in a series of presentations at professional gatherings: at the Symposium on Electronic Imaging-Science and Technology; at the annual meeting of the Society of Imaging Science and Technology; and at the Electronics Display Forum 95.

\footnotetext{
${ }^{6}$ Chris King, phone interview, May 13, 1999.
} 
Figure 4.2 Patent Tree for Project Led by American Display Consortium: Citations by Others of Planar Systems Patents

\section{PATENT TREE KEY}

Original Patent

Second Generation Patent

Third Generation Patent

Fourth Generation Patent

Fifth Generation Patent

1999

1998

1997

1996 


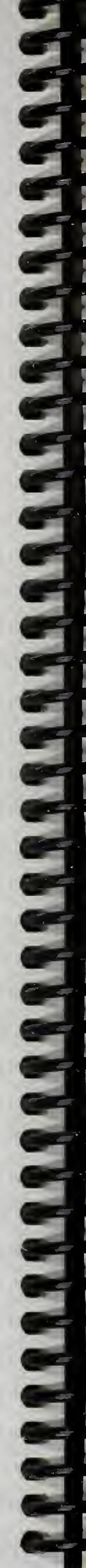




\section{Manufacturing Technology for High-Performance Optoelectronic Devices}

ptoelectronic devices - from light-emitting diodes (LEDS) and solar cells to lasers and detectors - are abundant in everyday life. Millions of LEDs are used in automobile dashboards and consumer electronic products (clocks, radios, VCRs, CD players, coffee brewers, and microwave ovens), as well as in commercial and industrial products such as fax machines, copiers, and printers.

COMPOSITE PERFORMANCE SCORE

(Based on a four star rating.)

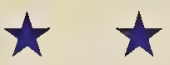

\section{LEDs That are Four Times as Bright}

Although LEDs are used in many applications where digital readout is needed, they have limitations. They do not emit much light, so they cannot be seen at a distance. If they produced really bright light, LEDs would be even more widely used than they are already. This ATP project with AstroPower, a small Delaware company incorporated in 1989, developed a new approach to production-scale liquid-phase epitaxy (LPE). The company has fabricated LEDs in a way that significantly increases, by a factor of four, the brightness of the light they emit.

\section{A New Approach}

LPE is a widely used technique that involves melting a semiconductor material and letting it crystallize on a substrate. AstroPower's novel enhancement, the first technical goal of the project, involved the use of a thermal gradient

\section{.. . made significant advances in} understanding growth processes for compound semiconductor materials . . .

that promotes the growth of the epitaxial layer laterally much faster than vertically from the substrate. Company researchers made significant advances in understanding growth processes for compound semiconductor materials

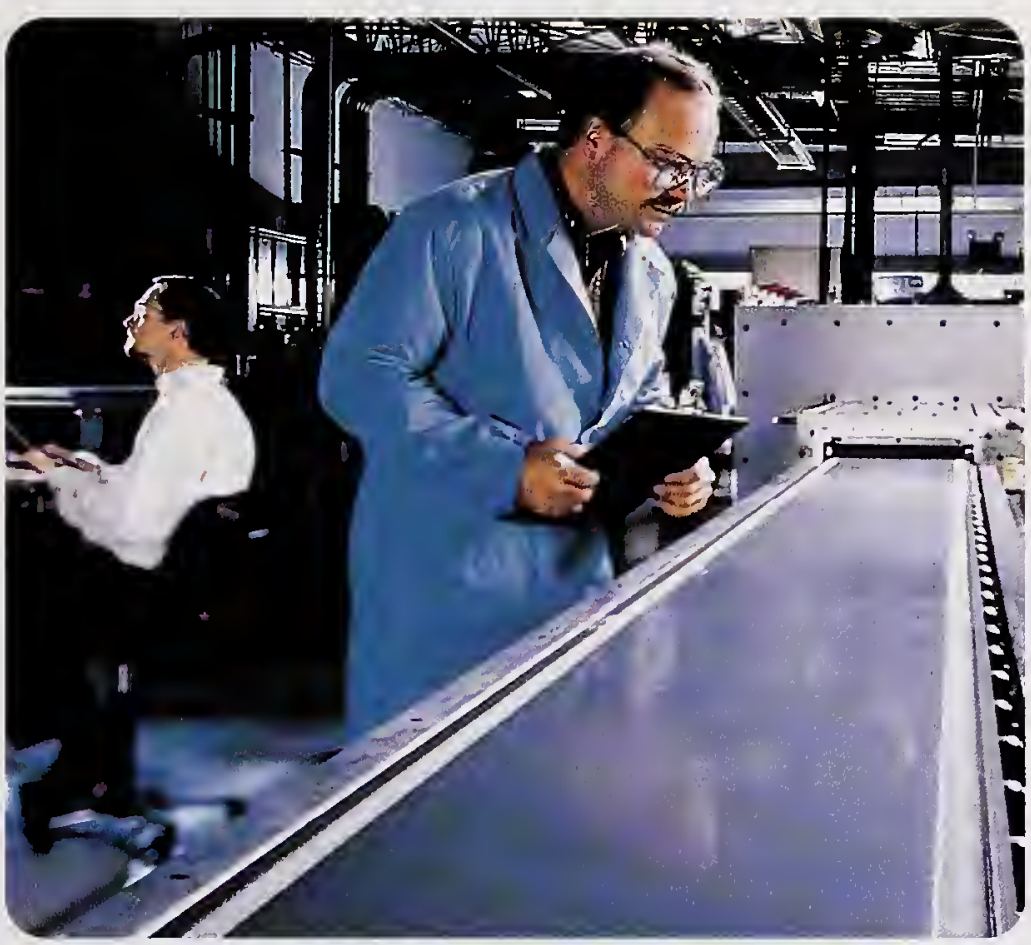

A large area solar grade silicon sheet emerging from a silicon growth reactor which incorporates new ATP-funded technology.

and in applying LPE to lateral growth over buried reflectors and other components. The technology can be used for volume production of low-cost compound semiconductor devices - those made from a compound of elements, such as gallium arsenide, rather than a single element.

AstroPower's second technical goal was to develop the technology to automate the new LPE growth process in integrated factory-scale fabrication equipment. Company researchers succeeded in designing and assembling a modular prototype production growth system that has 


\section{PROJECT:}

To develop new crystal growth methods and high-throughput manufacturing technology for fabricating light detectors and emitters with integrated reflecting mirrors.

Duration: 7/15/1992 to 7/14/1995

ATP Number: 91-01-0142

FUNDING (in thousands):

$\begin{array}{lrr}\text { ATP } & \$ 1,423 & 47 \% \\ \text { Company } & 1,580 & 53 \% \\ \text { Total } & \$ 3,003 & \end{array}$

\section{ACCOMPLISHMENTS:}

The company achieved the goals of the ATP project: developing new epitaxial growth methods, as well as new processes for plant-scale industrial production operations. Evidence of the company's achievements are that it:

received four patents related to the ATP project technology; "ColumnarGrained Polycrystalline Solar Cell and Process of Manufacture" (No. 5,336,335: filed 10/9/1992, granted 8/9/1994)

"Hetero-Epitaxial Growth of Non-Lattice Matched Semiconductors" (No. 5,356,509: filed 10/16/1992, granted 10/18/1994)

"Columnar-Grained Polycrystalline Solar Cell and Process of Manufacture" (No. 5,496,416: filed 8/5/1994, granted 3/5/1996)

"Semiconductor Device Structures Incorporating "Buried" Mirrors and/or "Buried" Metal Electrodes"(No. 5,828,088: filed 9/5/1996, granted 10/27/1998);

demonstrated the application of the new epitaxial production technology to optoelectronic device structures that have integrated reflecting mirrors for enhancing light output (an ultrabright light-emitting diode (LED) with buried reflectors), achieving a fourfold increase in brightness;

completed scale-up of liquid-phase epitaxy (LPE)-growth technology to a high-throughput, production-scale process;

significantly shortened production scale-up times for specific products,

already significantly shortened production scale-up times for currently fabricated products, as well as for potential products under consideration by customers.

\section{Market Developments Upset Initial Commercialization Plans}

Commercialization of the enhanced compound semiconductor devices in high volumes has not yet happened. An initial goal, to produce high volumes of red LEDs, has been stymied by market developments. The Japanese have come to dominate the market for red LEDs, which have become a commodity product. Although AstroPower has a technical advantage in producing the devices, the value of this market to the company is quite small, since the cost of entering the market is too high to make such a venture profitable. compared with previous manufacturing processes;

a constructed a demonstration production facility to implement the technology; and

E conducted an initial public offering of stock in February 1998, raising $\$ 16.7$ million.

CITATIONS BY OTHERS OF PROJECT'S PATENTS: See Figure 4.3.

\section{COMMERCIALIZATION STATUS:}

Direct commercialization of ultrabright red LEDs, a proposed initial goal of the project, did not occur, mainly due to economic and market developments. Knowledge of new crystal growth methods acquired during this project contributed, however, to the enhancement of fabrication methods for the company's Silicon-Film ${ }^{\mathrm{TM}}$ solar cell and for other compound semiconductor devices.

\section{OUTLOOK:}

AstroPower has applied the ATP-funded crystal growth technology to its current manufacturing processes, improving productivity and lowering costs. It also plans to use the technology for several breakthrough devices when appropriate market size has been achieved; if such markets develop substantially, the outlook is promising. Two significant products that are nearing introduction are combustion sensors based on gallium-phosphorus compounds, and avalanche photodiodes and detectors based on indium-gallium-arsenic-antimony compounds.

\section{Composite Performance Score: $\star \star$}

\section{COMPANY:}

AstroPower, Inc.

Solar Park, 461 Wyoming Road

Newark, DE 19716-2000

Contact: James B. McNeely

Phone: (302) 366-0400

Number of Employees: 86 at project start; 160 at the end of 1997

\section{Use of the Technology for Current Product Lines}

Knowledge developed in the ATP-funded project, especially advances in understanding epitaxy technology, has proven useful across all company production activities, AstroPower officials say. They report that the company's

\section{... succeeded in designing and assembling a modular prototype production growth system ...}

product lines have all grown rapidly in recent years, and they attribute much of the growth to the ATP project. All of AstroPower's compound semiconductor-based products incorporate epitaxial growth in their fabrication. This includes their flagship product, the Silicon-Film ${ }^{\mathrm{TM}}$ solar cell. Silicon-Film ${ }^{\mathrm{TM}}$ is a continuous production process to manufacture crystalline silicon sheets and layers. 


\section{Shortened Production Scale-Up Times}

The success of the ATP-funded project ensures that new and innovative optoelectronic devices will have significantly shorter production scale-up times than were possi-

\section{. . . the company's product lines have all} grown rapidly in recent years, with much of the growth attributed to knowledge developed in the ATP-funded project.

ble before the project. The establishment of a technology that permits low-cost, high-throughput synthesis of compound semiconductor structures is potentially useful for many optoelectronic device products. It can be used, for example, in making specialty devices on a job-order basis using gallium arsenide, gallium arsenide-on-silicon, indium phosphorus, and a host of other unexplored alloys.

These devices are used in the fabrication of common products like detectors, solar cells, sensors and light-emitting products. The new technology can also be used in the production of highly sophisticated devices such as vertical cavity surface emitting lasers and resonant optical cavity detectors with back reflectors.

\section{An initial goal, to produce high volumes of red LEDs, has been stymied by market developments ... red LEDs have become a commodity product.}

AstroPower intends to incorporate this technology in a number of breakthrough devices that it can produce in sufficiently large quantities when appropriate market size has been achieved. Two significant applications are nearing product introduction. The first is combustion sensors, based on gallium phosphorus compounds, that can be used for flame control in internal combustion engines and utility burners. The second is avalanche photodiodes and detectors, based on indium-gallium-arsenic-antimony and indium-arsenic-antimony-phosphide compounds, that can be used for light direction and range instruments, collision avoidance, atmospheric gas measurements, weather prediction, spectroscopy, blood gas analysis, and noninvasive medical analysis. These two products are currently in pilot production and are being tested by NASA, the Air Force, and industrial companies.

\section{Company Growth}

At the beginning of the ATP project in 1992, AstroPower had annual product sales of $\$ 1$ million. By 1997, sales had grown to $\$ 16$ million. And in February 1998, AstroPower successfully conducted an initial public offering of stock, raising $\$ 16.7$ million.

AstroPower is convinced that had it not conducted the ATP-funded project, its growth experience (as measured by product sales) would have been set back by three years, the length of the ATP project. This belief is based on the use of improved epitaxial growth technology across all of its product lines, its application of manufacturing automa-

\section{... had it not conducted the ATP-funded project, its growth experience... . would have been set back by three years.}

tion processes to all of its manufacturing operations, and to the overgrowth of semiconductor materials on dissimilar substrates as well as on mirrors, insulators, and conducting planes. Without the ATP funds, AstroPower says it would not have carried out the project.

\section{Potential Large Economywide Benefits}

AstroPower noted at the beginning of its ATP project in 1992 that it expected in a project like this that products might take as long as 10 years to move from initial technology development to new product sales. The demonstration production facility AstroPower developed is capable of producing millions of LEDs or other LPE-based optoelectronic devices per month. When sufficient demand for the new products emerges, AstroPower plans to construct an optoelectronic semiconductor chip-manufacturing facility for new products made possible by the innovative LPE-growth technology.

Benefits are already accruing to purchasers of the company's solar cells, which have higher quality and cost less than they did before the ATP project. 
Original Patent

Second Generation Patent

Thlrd Generatlon Patent

Fourth Generation Patent

Fifth Generation Patent
Figure 4.3 Patent Tree for Project Led by AstroPower, Inc.: Citations by Others of AstroPower, Inc. Patents

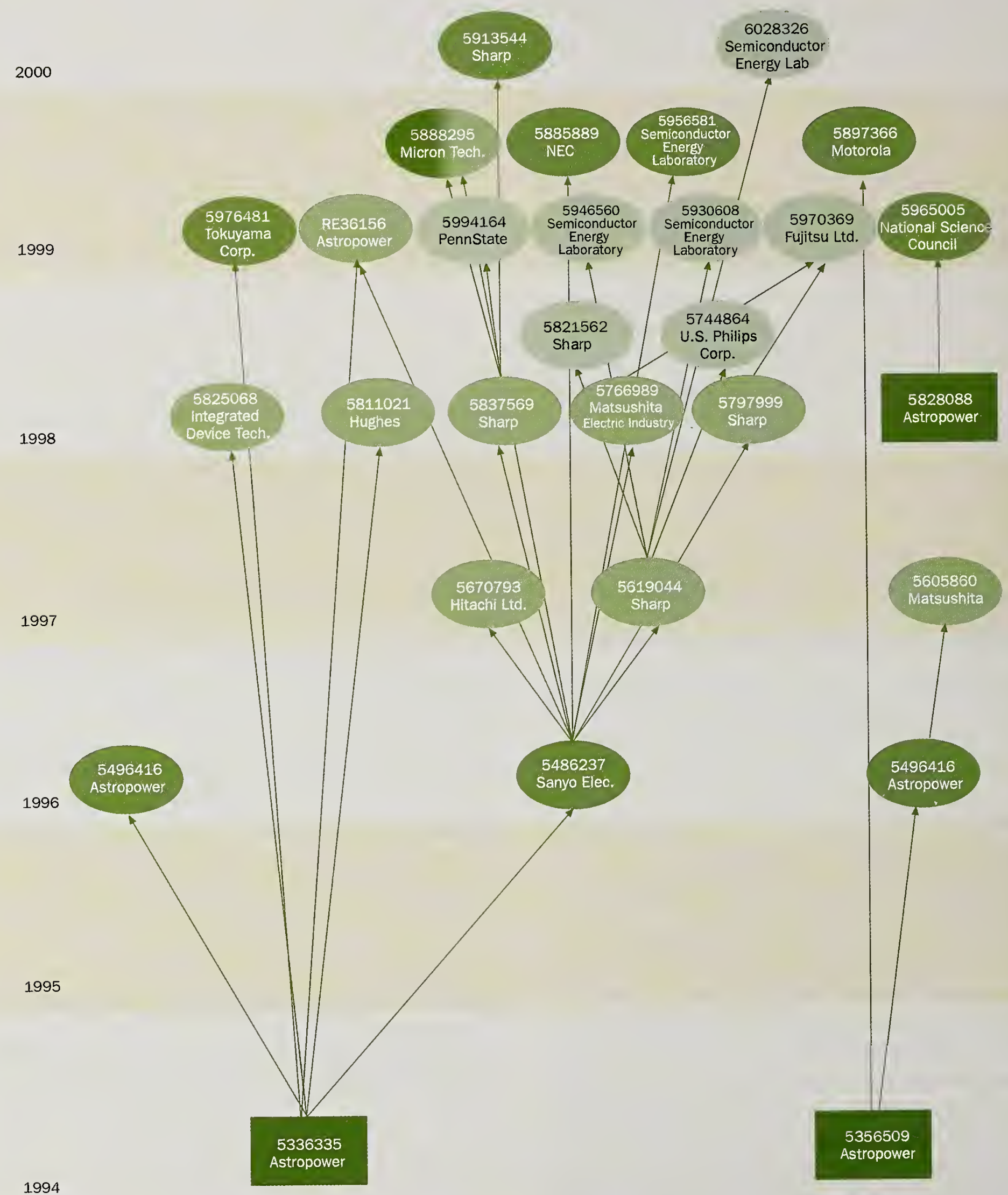




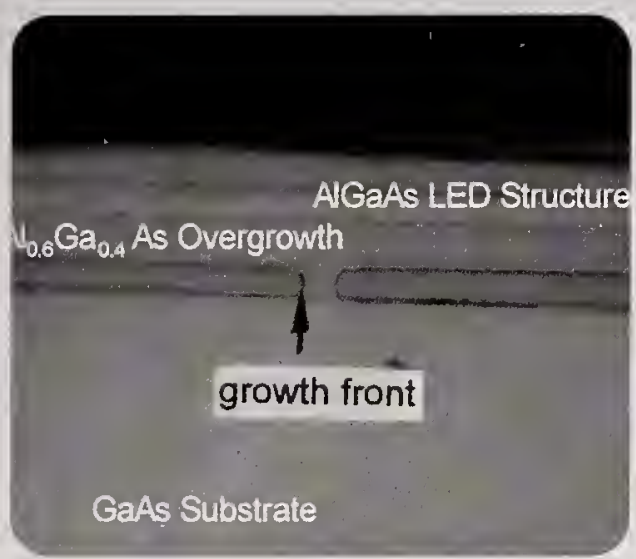

Cross-sectional

photomicrograph of a

light emitting diode

showing device active

layers and buried

mirror overgrowth.

Benefits are already accruing to purchasers of the company's solar cells, which have higher quality and cost less than they did before the A'TP project. If the company succeeds in bringing to market additional products that use the new technology, even more benefits will accrue to its customers. Because of substantial uncertainty about these events, it is too speculative at this time to try to predict the magnitude of these future benefits. 



\title{
Pit Depth Modulation: Multiplying the Capacity and Speed of CDs and DVDs
}

\begin{abstract}
$I_{1}$ latest in optical storage disc trends by offering a larger storage capacity and faster reading speed than prior $C D$ formats. In this rapidly changing digital revolution, however, the need for the still larger storage in the next generation disc has already become apparent.
\end{abstract}

1983, the compact disc (CD) became the hottest product on the consumer electronics market with the ability to encode over an hour of high-quality audio on each of the silvery discs. A few years later, computer users were equally enthusiastic when CD-ROMs, each with the data capacity to hold entire encyclopedias or the complete works of Shakespeare, first appeared on store shelves. In 1997, the digital video disc (DVD) ${ }^{1}$ became the

COMPOSITE PERFORMANCE SCORE (Based on a four star rating.)

\section{Ever-Increasing Demands for More Storage Capacity} Demand for DVDs continues to grow; DVD system sales are estimated to increase from 95 million units sold in 1998 to over 175 million units in $2001 .^{2}$ This popularity is not surprising given that a DVD can hold enough data (up to 8.5 gigabytes on a dual layer disc) to play back an entire motion picture on a standard television with far greater clarity than a standard VHS videotape. ${ }^{3}$

A single-sided DVD, however, does not have sufficient capacity to store the same movie at the much greater level of resolution required for high-definition television (HDTV)—which requires 15-20 gigabytes (GB) per disc. The shortfall of storage capacity for HDTV applications represents a large challenge. The recent proliferation of digital technology for other uses, such as audio recordings and computer storage, has created a voracious worldwide appetite for ways to store huge amounts of data.

The fast-moving computer and consumer electronics sectors are highly competitive, promoting widespread demand for digital media and driving the need for more storage capacity. Digital storage is vitally important for delivering telecommunication and entertainment services, as well as computer programs to households.

Given the high stakes, competition among datastorage companies in the United States, Japan, Europe, Australia, and elsewhere is intense. Hundreds of millions of dollars have been spent researching a variety of methods to increase data storage speed and capacity.

\section{Turtle Ears Lead to Proposed Method}

During his doctoral studies at the University of California at Berkeley, from 1988-1993, Mike O'Neill was working on the development of a laser feedback microscope to study the inner ear function in turtles (a turtle's inner ear is very similar to a human's). During this time, O'Neill met Terry Wong, another graduate student interested in the laser feedback microscope. Working in the same lab, the two began to see a very different potential application of the laser technology they were developing: to increase data storage.

The following year, O'Neill and Wong, along with Tom Burke, a former McKinsey \& Company consultant, founded Calimetrics. The company's mission was to develop their "pit depth modulation" (PDM) technology to increase the storage capacity and access speed of CDs.

\footnotetext{
' Since the introduction of computer DVD-ROMs, DVD has become "Digital Versatile Disc."

2 Source: IDC, Strategic Marketing Decisions, Disc/Trend, Wall Street Journal. <www.calimetrics.com>.

${ }^{3}$ The $8.5 \mathrm{~GB}$ on a dual layer DVD disc is doubled to $17 \mathrm{~GB}$ for a dual layer double-sided DVD disc. Although PDM increases capacities to the range needed for HDTV quality content, $17 \mathrm{~GB}$ can handle this. ML reduces the cost of media manufacture as compared to the DVD solution, and eliminates the need of turning the disc over in the middle of the movie.
}

+ "Optical Storage Technologies," TechMonitoring, 1998 (SRI Consulting). 


\section{PROJECT HIGHLIGHTS}

\section{PROJECT:}

To develop pit depth modulation (PDM) technology to triple the storage capacity and reading speeds of existing CDs and DVDs by using multilevel pit depths rather than binary pit depths.

Duration: 2/1/95-3/31/97

ATP Number: 94-01-0115

\begin{tabular}{|c|c|c|}
\hline \multicolumn{3}{|c|}{ FUNDING (in thousands): } \\
\hline ATP & $\$ 1,808$ & $66 \%$ \\
\hline Company & $\mathbf{9 4 5}$ & $34 \%$ \\
\hline Total & $\$ 2,753$ & \\
\hline
\end{tabular}

\section{ACCOMPLISHMENTS:}

Calimetrics developed data storage enhancement technologies using patented pit depth modulation (PDM) technology and is poised for commercial development. The company:

developed microchips for existing laser $\mathrm{CD}$ readers that can evaluate the intensity of the laser light reflected from the disc, making PDM compatible with existing products on the market;

developed integrated circuits that can be used in current CD and DVD manufacturing systems to make drives that can read at multiple depths and which add very little to the cost of disc mastering while producing the dramatically improved storage benefits of PDM;

improved the precise control of the laser depth for the mastering process, by reducing power fluctuations and improving the electronics that turn the beam on and off;

investigated different materials to sharpen the differences in the pit depths (but did not use them due to market resistance);

developed new decoding software to interpret optically-stored data and correct errors;

presented a paper on PDM at the 1997 Optical Data Storage Conference and published articles in multiple periodicals;

received two patents for project research:

"Optical disc reader for reading multiple levels of pits on an optical disc"

(No. 5,854,779: filed 1/5/1996, 12/29/1998)

"Method and apparatus for providing equalization for the reading of marks on optical data storage media" (No. 5,818,806: filed 5/6/1997, granted 10/6/1998);

licensed suite of optical storage technologies to Texas Instruments in August 1999.

When first starting out, O'Neill and Wong had confidence in PDM's technological potential, but the fledgling company did not have the means for sustained research. With a kick-start of $\$ 25,000$ from family and friends, the company sought funding from venture capitalists and other private sources. All, however, rejected investment in PDM development, deeming the technical and market risk too high. The company faced the classic catch-22 situation of innovation financing: funding was not available because the technology was unproven, yet it could only be proven if substantial financial resources were brought to bear on the problem. finalized $\$ 12$ million in venture capital funding from Walden International Investment Group, JAFCO America Ventures, and others, and two industry veterans, William J. Schroeder (CEO of Diamond Multimedia Systems) and James A. Malcolm (founder and former CEO of Accumap Corporation) joined the Calimetrics Board of Directors; and

formed strategic agreements with TDK Electronics and other industry leaders for joint development of new products that implement Calimetrics' advanced multilevel optical storage capabilities.

CITATIONS BY OTHERS OF PROJECT'S PATENTS: See Figure 4.4.

\section{COMMERCIALIZATION STATUS:}

Calimetrics has licensed its technology for commercial use and formed alliances with TDK and other companies for new product development.

\section{OUTLOOK:}

Optical data storage markets are expanding. Annual shipments of DVD systems worldwide are expected to increase from 95 million units in 1998 to 175 million units by the end of 2001. Calimetrics is positioned to take advantage of this expanding market through strategic alliances with leading disc drive, disc media, and integrated circuit manufacturers. The company's alliances with Texas Instruments and TDK Electronics for joint new product development are important steps towards commercializing the new storage capabilities. At the same time, the technology has disseminated to others through publications and patents.

The advantages of larger storage capacity and faster read speeds offered by PDM technology will be available to those in the data storage industry for a relatively low incremental cost. Calimetrics has designed this technology to be both backward and forward compatible. It will work with existing CD and DVD systems, while also supporting the latest (and anticipated) laser technologies. With commercialization plans for the near future and strategic partnerships established, Calimetrics' PDM technology appears poised to make a strong impact in the expanding optical data storage market.

\section{Composite Performance Score: $\star \star \star \star$}

\section{COMPANY:}

Calimetrics, Inc.

815 Atlantic Avenue

Suit 105 Alameda, CA 94501-2274

Contact: Tom Burke

Phone: (510) 864-4100

Number of Employees: 3 at project start; 10 at project end; 35 as of January 2000

In 1994, Calimetrics became aware of ATP, submitted a project proposal to develop PDM technology, and won. With a $\$ 1.8$ million award from ATP, and a smaller grant from the state of California's Trade and Commerce Agency, Calimetrics took on the challenge of developing the technology born of the earlier laboratory experiments of the two graduate students.

\section{Achieving Compatibility with Industry Standard Production Methods}

O'Neill, Wong, and Burke knew that attempting to redirect the entire $\mathrm{CD}$ market toward a new technology would 
be a formidable task for a small company, even if they could raise research funding. They, therefore, made the decision to pursue applications of the technology that would be compatible with existing CD manufacturing processes and usable with existing CD readers.

Standard compact discs are manufactured by spinning a fine layer of light-sensitive material (photoresist) onto a clean glass disc. The disc is then baked to remove the solvent. Next, the coated glass disc is engraved by a laser, creating pits in a binary (pit or no pit) pattern, thus encoding information onto the disc. In the next step, the exposed photoresist is developed and washed away, and a thin layer of metal is sputtered over the master. The final stage involves growing a thicker metal layer through galvanic action on the master disc that ultimately forms the teeth of the die used to replicate or stamp out the pits on CD copies. ${ }^{5}$ The lasers in disc systems read the lack of a pit

\section{The company faced the classic catch-22}

\section{situation of innovation financing: funding} was not available because the technology

was unproven, yet it could only be proven

\section{if substantial financial resources were brought to bear on the problem.}

edge as a " 0 " and the presence of a pit edge as a " 1 ," making music or pictures from encoded streams of these numbers.

Building on this technique, DVDs have increased optical storage capacity over CDs because they have smaller, more densely packed pits on each disc. A CD-ROM holds only 650 megabytes $(\mathrm{MB})$ of data that can be read at a speed of $3 \mathrm{MB}$ per second (on a $20 \mathrm{X}$ drive). A dual-layer DVD-ROM holds $8.5 \mathrm{~GB}$ of data. ${ }^{6}$

PDM technology expands and extends on the DVD advances by creating multiple-level pits that have eight possible depths, rather than just two. This increase multiplies the disc's storage capacity and the rate at which the data is read. Using advanced circuits, PDM pits are engraved by adjusting the intensity of the laser to generate a desired pit depth: the greater the intensity, the greater the pit depth. By increasing the number of pit depths from one to eight, PDM triples the storage capacity, as each PDM pit provides the same amount of information as three traditional binary pits. It also enables the retrieval of information at three times the speed of traditional CDs since the laser scans the PDM-enhanced pits at the same speed, with three times the data content. ${ }^{7}$ PDM technology increases the standard CD-ROM storage space and retrieval time from $650 \mathrm{MB}$ at $3 \mathrm{MB}$ per second to $2 \mathrm{~GB}$ of data at $9 \mathrm{MB}$ per second. ${ }^{8}$ Similar improvements are also possible with DVD: storage capacity can be increased from $8.5 \mathrm{~GB}$ to $18 \mathrm{~GB}$ per side on a dual-layer disc, and read up to two times faster. ${ }^{9}$ The increase in storage capacity and read time provided by PDM technology will help keep optical storage discs up to pace with software innovations and HDTV advances.

To achieve compatibility with existing products in the optical storage industry, Calimetrics created new microchips that can be incorporated into current CD and DVD readers and manufacturing systems to enable them to work with PDM technology. Drive designs were modified to be able to evaluate the intensity of laser light reflected from the discs and, therefore, read multiple depths. This strategy of making their new disc technology work with existing readers and manufacturing systems was key for a small company like Calimetrics to be able to enter into the marketplace effectively.

Other core innovations included increasing the precision of laser depth control during the disc mastering process by reducing power fluctuations and improving the electronics that turn the beam on and off. Coupled with better lasers, new decoding software was also developed to interpret data and correct errors. Additionally, Calimetrics investigated various materials for sharpening the differences in pit depths. They discovered, however, that market acceptance required standardization of materials to those already in use.

The related group of supporting technologies developed by Calimetrics is expected to allow PDM to stay compatible with expected future technologies such as shorter wavelength lasers, faster spindle speeds, dual lasers, and multi-layer discs. In contrast, the research being done by other data storage companies has focused more on the development of completely new types of lasers to read discs. PDM and its laser-reading software represent a cost-effective solution that can be produced

\footnotetext{
${ }^{5}$ Description by the company at <www.calimetrics.com>.

${ }^{6}$ A single-layer DVD holds $4.7 \mathrm{GBs}$ of optical data.

${ }^{7}$ Design Engineering, September 1997, p. 11.

8 "3-D Pits Boost Optical Storage," Photonics Spectra, July 1997, <www.PhotonicsNet.com>, updated by Calimetrics, December 1999. (For Calimetrics' first product, the increase in read speed will be limited to $5.4 \mathrm{MBs}$ because of electronic limitations.)

9 Matthias Henneberg, "Optical Storage Technologies," Tech Link, July 1997 (SRI Consulting).
} 
and marketed by major DVD-drive manufacturers without major equipment changes. The PDM-related modifications increase the capital cost of a disc mastering machine by only about 1 or 2 percent, while creating a 300 hundred percent improvement in storage capacity and read time.

\section{ATP Funding Nurtures PDM in A Rapidly Changing Market}

While Calimetrics was developing PDM, concurrent technological changes were occurring in the optical storage industry. Researchers developed phase-change technology, a process that takes advantage of the changes in reflectivity of a new optical disc surface as it changes between an amorphous and a crystalline state. Information is read from the phase-change discs by discriminating between the dark amorphous zones and the bright crystalline zones. Phasechange technology has been embraced by industry as a low cost, marketable technology for rewritable DVDs and CDs.

In October 1997, demonstrating both its nimbleness and the broad applicability of the technology, Calimetrics combined phase-change technology with the ATP-funded PDM technology to produce a new multilevel (ML) technology. ML enables PDM encoding on rewritable and write-once optical storage systems. The ML technology enabled Calimetrics to keep up with the movement within the DVDCD industry for rewritable and write-once CDs and DVDs.

\section{Industry-wide Recognition for PDM}

Calimetrics publicized its PDM work soon after the fruits of research were demonstrated. The company received two patents for its PDM research conducted with ATP funding, which complement the two original patents that the company licenses on an exclusive basis from University of California, Berkeley, and the multiple patents that it has received after its ATP project.

Presentations by Calimetrics have contributed industrywide knowledge of PDM technology. Company researchers made presentations at the 1997 Optical Data Storage Conference in Tucson, Arizona. In addition, PDM technology has been featured in articles in various publications including Data Storage magazine, Popular Science, and the Wall Street Journal. Further impact will be gained through Calimetrics' membership in the National Storage Industry Consortium (NSIC), a group of 60 of the nation's leading firms, research organizations, and universities dedicated to the advancement of U.S. data-storage technologies.

\section{Technology Alliances to Commercialize PDM Technology}

Texas Instruments (TI) licensed PDM and ML technology from Calimetrics in August 1999. Calimetrics has also formed strategic partnerships with leaders in the disc drive and media industry. It has successfully attracted new venture capital and corporate investment.

On October 30, 2000, TDK Electronics Corporation, a Japanese-owned company, announced the creation of a technology alliance with Calimetrics, Inc., to apply Calimetrics' ML technology to create a new recordable and rewritable optical disc format with three times the capacity and three times the speed of conventional CD$\mathrm{R} / \mathrm{RW}$ recording. It was announced that the first products to incorporate the new multilevel recording technology will be a new generation of computer drives. The company president commented, "The dramatic gains in capacity and speed offered by the new ML format make it the ideal bridge to the future... to the era of inexpensive recordable DVD." At an upcoming Comdex Show in Las Vegas, TDK and Calimetrics will demonstrate the ML recording system for interested drive and media manufacturers, IC manufacturers, OEM suppliers and software developers. ${ }^{10}$

\section{Figure 4.4 Patent Tree for Project Led by Calimetrics: Citations by Others of Calimetrics Patents}

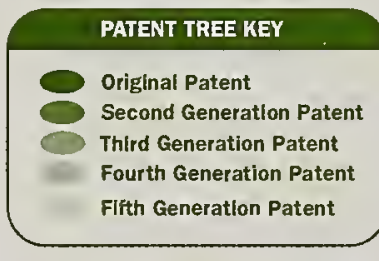

000

6148428

Calimetrios

2000

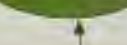

1999 


\author{
CREE RESEARCH, INC.
}

\title{
Processes for Growing Large, Single Silicon Carbide Crystals
}

M crystal. As many as five million discrete components can be placed on a piece of crystal less than two inches square. Silicon crystal chips, however, are quite sensitive to heat. Electricity passing through a chip's superthin connecting wires creates heat, just as it does in the heating element of a toaster. If too much heat builds up, the chip loses its functionality.

COMPOSITE PERFORMANCE SCORE (Based on a four star rating.)

\section{Beating the Heat in Electronic Devices}

This ATP project with Cree Research, a small company in North Carolina's Research Triangle Park, made significant progress in the development of an alternative raw material for making crystal slices - silicon carbide. This material belongs to a class of semiconductors having wide bandgap, which means they are relatively insensitive to increased temperatures. Silicon carbide's thermal conductivity is greater than that of copper, so it rapidly dissipates heat. It is impervious to most chemicals and highly resistant to radiation. Silicon carbide is extremely hard - it is used as grit in common sandpaper - indicating that devices made with the substance can operate under extreme pressure. It also possesses high field strength and high saturation drift velocity, characteristics suggesting that devices made of it can be smaller and more efficient than those made of silicon.

\section{... full-color LED displays become possible} with the existence of blue LEDs, as blue was a missing primary color.

Cree and others have shown that, even at red-hot temperatures, silicon carbide devices maintain functionality. Some of them, in fact, have continued to operate at 650 degrees Celsius. The wide bandgap also allows silicon carbide devices to operate at shorter wavelengths, enabling

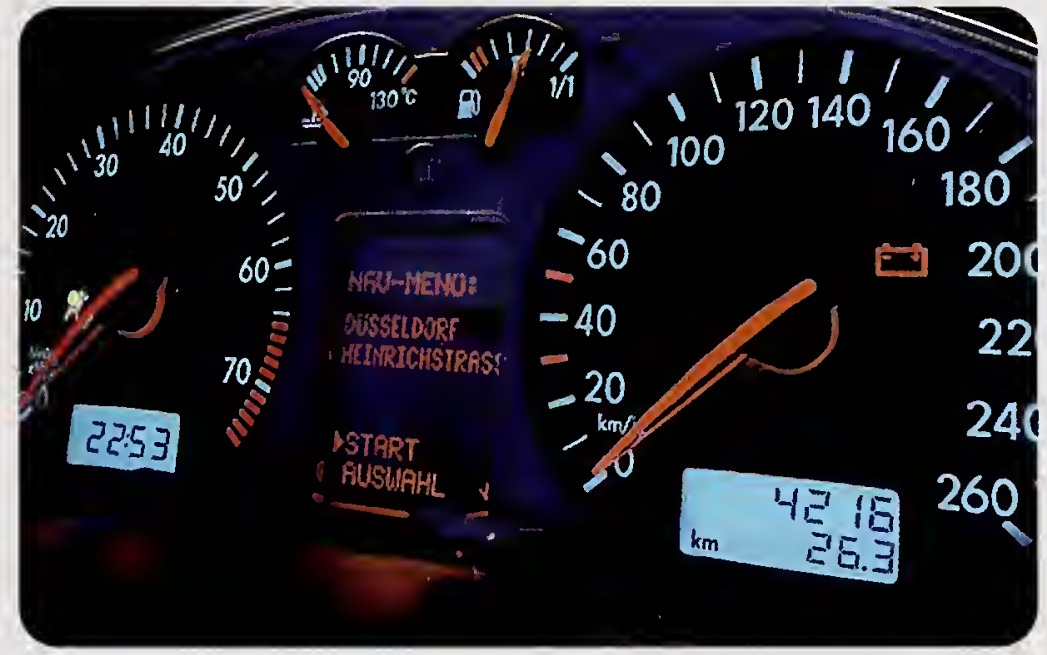

Cree's LED chips are used by Siemens A.G. for back

lighting for this dashboard.

the creation of blue light-emitting diodes (LEDs) that could not be made from silicon. Moreover, full-color LED displays become possible with the existence of blue LEDs, as blue was a missing primary color.

\section{Growing Large Crystals to Reduce Costs}

Cree was founded in 1987 to commercialize silicon carbide and began by making LEDs on a silicon carbide substrate. Prior to its ATP project, Cree was already the world leader in silicon carbide technology and had been making oneinch-diameter silicon carbide crystals. But progress in the development of devices based on silicon carbide had been stymied by difficulties in growing large, high-quality single crystals, a bottleneck that led Cree to pursue more research. 


\section{PROJECT:}

To substantially reduce the cost and improve the durability of light-emitting diodes (LEDs) and other electronic and optoelectronic devices by increasing the quality and size (to 2 inches or more) of silicon carbide ( $\mathrm{SiC}$ ) single crystals.

Duration: 6/15/1992 - 6/14/1994

ATP Number: 91-01-0256

FUNDING (in thousands):

$\begin{array}{lrr}\text { ATP } & \$ 1,957 & 82 \% \\ \text { Company } & \frac{435}{2} & 18 \% \\ \text { Total } & \$ 2,392 & \end{array}$

\section{ACCOMPLISHMENTS:}

Cree essentially met or exceeded all of the technical milestones. Successful development of the technology is indicated by the fact that the company:

applied for one patent on technology related to the ATP project;

presented several papers at professional conferences;

raised $\$ 13.2$ million via an initial public stock offering in February 1993;

made high-quality, two-inch $\mathrm{SiC}$ wafers, greatly opening up the blue LED and SiC wafer markets;

raised approximately $\$ 17.5$ million in a private stock offering in September 1995;

increased annual revenues from $\$ 3$ million at the start of the ATP project in 1992 to $\$ 7.5$ million at the end of the ATP award period in 1994;

received $\$ 5.8$ million from the Defense Advanced Research Projects Agency in May 1995 for further development of silicon carbide growth processes to support production of three-inch wafers;

a formed Real Color Displays, a wholly owned subsidiary, to exploit this technology for full-color LED displays;

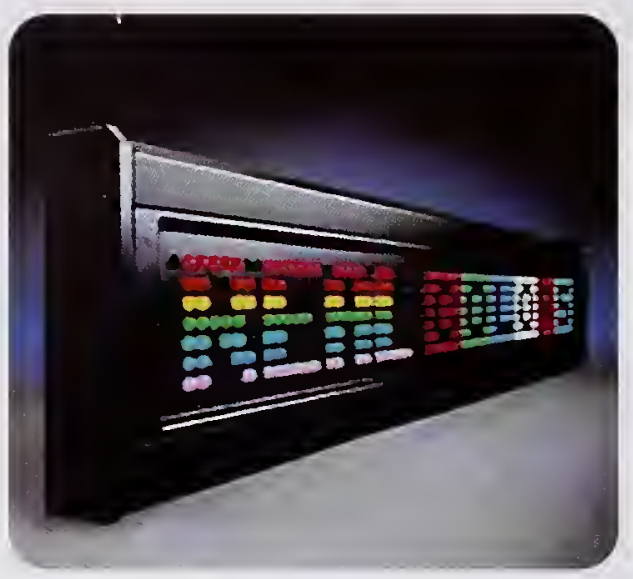

The Real Color Display'm, a moving sign which is capable of displaying the full range of colors, made possible by the use of blue LEDs.

During the ATP project, Cree advanced silicon carbide technology by developing methods to greatly reduce the amount of imperfections in crystals and to increase their size to two inches or greater in diameter. Larger diameter crystals result in lower production costs, which are crucial to opening markets for silicon carbide devices. The company also developed ways to significantly improve the doping (adding impurities to achieve desired properties) and epitaxial deposition (growing one crystal layer on another) processes for silicon carbide. Improving doping received a $\$ 6$ million order in September 1996 from Siemens for blue LEDs; and

supplied the $\mathrm{SiC}$ wafers for components in the $\mathrm{SiC}$ solid-state transmitter used by Westinghouse Electric to make the first U.S. commercial-scale high-definition TV (HDTV) broadcast in April 1996.

\section{COMMERCIALIZATION STATUS:}

The larger SiC wafers, made with the ATP-funded technology, are being used in the fabrication of blue LEDs sold to many industrial customers. The wafers are also being provided in limited quantities for development projects in government and industry research laboratories.

\section{OUTLOOK:}

The improved processing technology makes the outlook for the commercial use of SiC crystals highly promising. The cost of producing blue LEDs has already been reduced substantially, and the expected widespread commercial availability of larger diameter $\mathrm{SiC}$ wafers promises a new range of applications, including HDTV transmitters. Benefits in the form of lower costs and higher quality will accrue to industrial users of blue LEDs and SiC wafers, as well as to consumers who use devices containing these two Cree products.

\section{Composite Performance Score: $\star \star \star \star \star$}

\section{COMPANY:}

Gree Research, Inc.

2810 Meridian Parkway, Suite 176

Durham, NC 27713

Contact: Calvin Carter

Phone: (919) 361-5709

Number of Employees: 41 at project start, 210 at the end of 1997

uniformity directly increases production yield and thus reduces costs.

Cree's success with the ATP project enables the fabrication of electronic devices that can operate at much higher temperatures and withstand high power levels. Silicon carbide components used in experimental high-definition television (HDTV) transmission, for instance, delivered

\section{... devices that were impractical to make with pure silicon can be made with silicon carbide.}

more power, lasted longer and cost less to produce than conventional silicon-based components. Now equipment that was costly to manufacture (owing to the need for heat-dissipation systems) can be produced less expensively, and devices that were impractical to make with pure silicon can be made with silicon carbide. 
Cree's success with

the ATP project enables the fabrication

of electronic devices that can operate

at much higher temperatures and

withstand high power levels.

\section{New Products: Blue LEDs and Silicon Carbide Wafers}

The ATP project has been highly productive for Cree and the economy at large. The company has used the new technology to produce larger silicon carbide wafers to use in its fabrication process for blue LEDs. It is also offering the larger silicon carbide wafers for sale to other companies.

Cree is using the ATP-funded technology to reduce the cost of producing blue LEDs, and their sales have increased substantially. Production cost is primarily a function of the number of wafers processed. If wafer size can be increased dramatically, the cost per device will decrease dramatically because so many more devices can be made on a wafer. The silicon carbide wafer technology is also aimed at markets for other blue light-emitting optoelectronic devices, optical disk storage, microwave communications, and blue and ultraviolet laser diodes, as well as high-temperature, high-power, and high-frequency semiconductors.

\section{Benefits for the Economy}

Benefits from the new silicon carbide technology are already accruing to customers who have bought large volumes of blue LEDs or silicon carbide wafers to use in their own production. Performance measures (resistance, power output, sensitivity to light, operating temperature) for silicon carbide devices are frequently large, relative to available alternatives. Economic benefits from these performance improvements spill over to other producers involved in fabrication and assembly before a wafer-based product reaches the end user. The total of these incremental benefits is expected to be much larger than the profits Cree receives for selling the silicon carbide wafers.

Cree's private success has led to public benefit, which is expected to grow as the number of applications for larger silicon carbide wafers increases. Westinghouse, for example, used Cree's silicon carbide wafers in fabricating components for the transmitter it used in the first commercial-level HDTV broadcast in the United States, in 1996. Westinghouse said its transmitter can deliver three times more power, has longer life and costs less to produce than conventional silicon-based transmitters. Although the

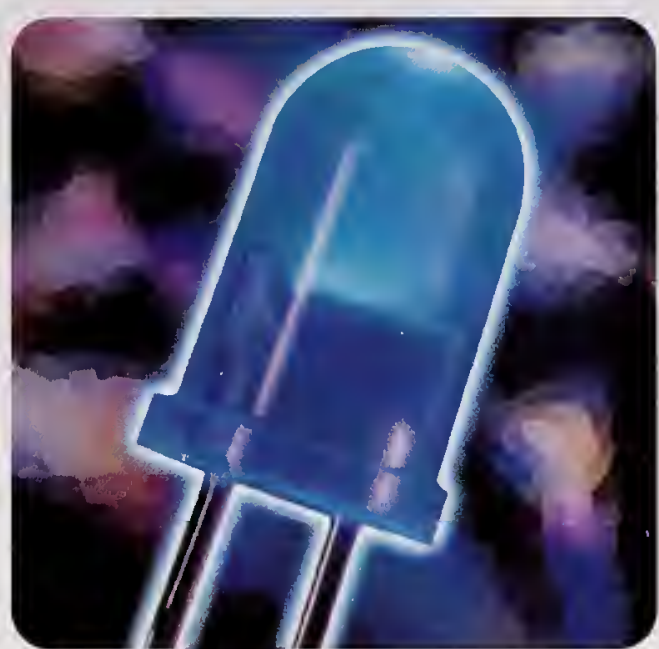

The low-cost blue light emitting diode (LED) produced with new silicon carbide crystal technology.

number of HDTV transmitters that will use silicon carbide wafers is unknown at this time, widespread use of this technology in HDTV broadcasting could produce large general economic benefits if it speeds commercialization of HDTV.

\section{ATP Advantages}

Cree reports it was attracted to the ATP as a funding source for the development of the bulk crystal and epitaxial growth technologies because the company could retain its process technology knowledge. The ATP award also helped Cree form alliances with research partners and speed the development work, enabling the company to get results about 18 months sooner than it would otherwise have been able to do. During the course of its twoyear ATP project, Cree also grew significantly.

\section{... silicon carbide wafers . . . used in the first commercial-level HDTV broadcast in the United States...}

Company officials say the success of the ATP-funded project was primarily responsible for a subsequent award of $\$ 5.8$ million from the Defense Advanced Research Projects Agency (DARPA) to further develop silicon carbide growth processes to produce three-inch wafers. If wafer size can be increased to three inches, the cost per device will drop even further. This DARPA project got under way in May 1995. 


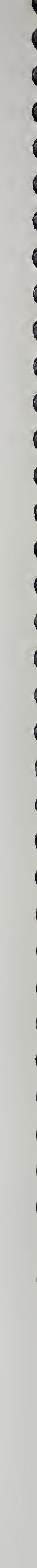




\section{Harnessing Cheap Diode Lasers to Power a Low-Cost Surgical Laser}

人 urgery is performed tens of millions of times a year in the United States, and it is usually a painful, risky procedure for the patient. It is also risky for the surgeon in terms of malpractice liability. Patients, surgeons, and health insurance companies are constantly looking for new, less invasive procedures to replace conventional surgery. Laser surgery is a prime candidate. One problem that limits this approach, however, is the price of equipment. A typical 100-watt surgical laser costs about $\$ 700$ to $\$ 1,000$ per watt of laser output, or about $\$ 70,000$ to $\$ 100,000$.

COMPOSITE PERFORMANCE SCORE (Based on a four star rating.)

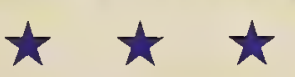

\section{A Laser for Lower Cost, Less Invasive Surgery}

This ATP project with Cynosure, founded in 1991, was designed to develop a smaller, less expensive laser source for surgery and other applications. The idea behind the Cynosure laser system - which was expected to sell for about $\$ 150$ to $\$ 200$ per watt of laser light delivered at the end of a surgical optical fiber - is based on harnessing the light from an array of 200 semiconductor, or diode, lasers. The problem with this approach in the past has been the difficulty of exactly aligning all 200 beams before they go into the diffractive optics transformer that collimates them into one tight, powerful beam. Minor inaccuracies in the alignment of the individual lasers can greatly degrade the performance of the system.

Cynosure's innovation was to develop an automated system to custom-mill arrays of 200 corrective lenses to match arrays of 200 diode lasers. In such a system, diagnostic equipment measures the alignment error of each laser beam and feeds the results to a computer, which drives a powerful laser that mills the lens array in less than 10 minutes. The result is a customized lenslet array that corrects the beams before they enter the transformer.

\section{Barriers to Commercialization}

Cynosure successfully designed and built a customized lenslet array to correct the beams from an array of 200 diode lasers. The researchers, however, failed to build a system that could generate the target power level -20 watts of laser light from a medical optical fiber - because the company was unable to secure an adequate, low-cost supply of

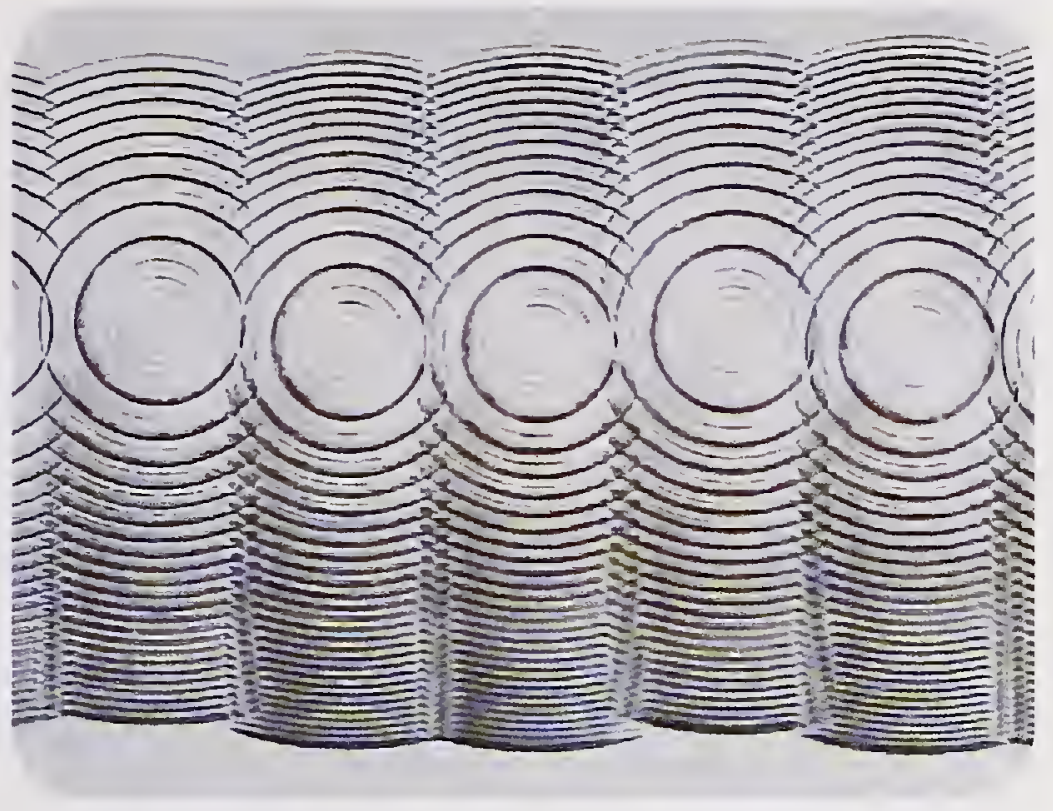

Photomicrograph of an array of multilevel diffractive lenses, fabricated with a 193 nanometer excimer laser.

a low-tech component: a collimating array. The intended supplier, which was the sole source of the collimating array, stopped making the device and sold its production division. The new owner also chose not to produce the array.

To make use of some of the technology developed in the ATP project, Cynosure is collaborating with the Lincoln Laboratory at Massachusetts Institute of Technology and using about $\$ 100,000$ from the Small Business Technology Transfer Program to develop a low-cost diode-laser system for treatment of arrhythmia for the National Heart, Lung, and Blood Institute. The com- 


\section{PROJECT:}

To design an optical system for collecting, aligning, and combining beams from an array of semiconductor lasers into one powerful beam, an achievement that will lead to the development of smaller, cheaper lasers for surgery and other applications.

Duration: 5/1/1993 - 4/30/1995

ATP Number: 92-01-0136

\begin{tabular}{|c|c|c|}
\hline \multicolumn{3}{|c|}{ FUNDING (in thousands): } \\
\hline ATP & $\$ 1,965$ & $49 \%$ \\
\hline Company & 2.067 & $51 \%$ \\
\hline Total & $\$ 4,032$ & \\
\hline
\end{tabular}

\section{ACCOMPLISHMENTS:}

Cynosure designed and built a fault-tolerant optical system for a diode-laser array but was unable during the project to obtain a laser beam with the targeted 20 watts of output from a medical optical fiber. Later, the company achieved this goal with an alternative approach built, in part, on the knowledge developed during the ATP project. The company:

received one patent for technology related to the ATP project: "Fault-Tolerant Optical System Using Diode Laser Array"

(No. 5,369,659: filed 12/7/1993, granted 11/29/1994);

- published a paper on its research findings;

was ranked number 112 in the 1996 Inc. magazine list of the 500 fastest-growing private companies in America;

increased its sales from $\$ 626.000$ in 1991 to more than $\$ 23$ million in 1997; and

is collaborating with Lincoln Laboratory and using funds from the

\section{The researchers, however, failed to} build a system that could generate the target power level...

pany is proposing to extend the scope of the project to include other conditions, besides arrhythmia, that can be treated with minimally invasive surgery. This new project is based in part on the demonstration that the A'TP-funded technology, as modified by the company, is capable of delivering 10 watts of power into a 100 -micron fiber-optic tube.

\section{Alternative Approach}

After the ATP project, Cynosure investigated alternative techniques, based on commercially available components, to channel the many beams from diode-laser arrays into a surgical optical fiber. The company found this can be done by grinding a hyperbolic lens onto the end of a small optical fiber, fitting one such fiber to each diode and stacking
Small Business Technology Transfer Program to develop a low-cost diode-laser system for treatment of arrhythmia, based on the ATP technology, for the National Heart, Lung, and Blood Institute.

CITATIONS BY OTHERS OF PROJECT'S PATENTS: See Figure 4.5.

\section{COMMERCIALIZATION STATUS:}

Commercialization was stymied by Cynosure's inability to secure the supply of a critical part at an affordable price. Since the ATP project ended, the company has taken a different, less-sophisticated approach to building a commercializable medical laser, using its own funds. That device has achieved the 20-watt ATP goal, and the company is scaling it to achieve 200 watts output. Commercial lasers are scheduled for market introduction in the near future.

\section{OUTLOOK:}

The benefits originally expected from commercialization of the ATP-funded technology should be realized via commercialization of the alternative technology that built on the technical knowledge developed in the ATP project.

\section{Composite Performance Score:}

\section{COMPANY:}

Cynosure, Inc.

10 Elizabeth Drive

Chelmsford, MA 01824

Contact: Horace Furumoto

Phone: (978) 256-4200

Number of Employees: 30 at project start, 120 at the end of 1997 Informal collaborator: Massachusetts Institute of Technology, Lincoln Laboratory

the fiber-coupled diodes into a two-dimensional array, as the ATP proposal had suggested. The fibers take the place of the diffractive optics in the proposed ATP laser system, with the tiny lenses directing the output from the diode array into a single fiber.

The company's switch to a different technological approach using readily available parts to concentrate the laser beams allowed commercialization to resume. Commercial lasers are now scheduled to be available in the near future.

\section{Mission Accomplished}

Lower-cost, higher-power medical diode lasers are a necessity for minimally invasive surgery, and it is said that necessity is the mother of invention. Cynosure invented the approach using fiber-coupled lasers, which are manufactured using standard optical fabrication methods and readily available components. The company expects this approach will not only reduce the cost of medical lasers but will also cost less than the diffractive optics-combiner approach envisioned by the ATP project.

By significantly reducing the cost of surgical lasers, 
Figure 4.5 Patent Tree for Project Led by Cynosure, Inc.: Citations by Others of Cynosure, inc. Patents
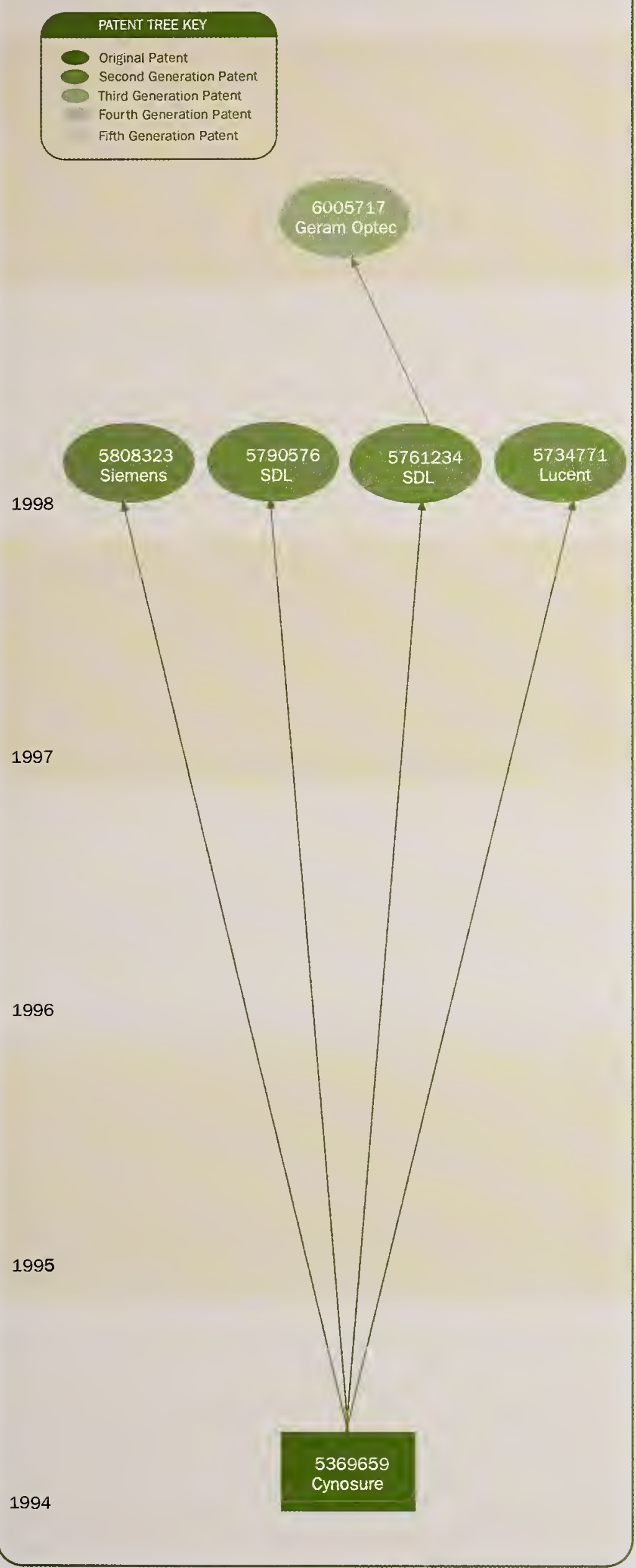

the Cynosure technology would enable wider use of minimally invasive surgery, reducing hospitalization times and lowering health-care costs. For example, gall bladder removal by conventional surgery requires a four-to-six-inch incision that results in four to seven days of hospitalization and a month of recovery time. When the removal is done by laser via a fiberoptic scope inserted through a small

\section{The company's switch}

to a different technological approach using readily available parts to concentrate the laser beams allowed commercialization to resume.

incision (a procedure already in widespread use), the patient is hospitalized for only two or three days and recovers much faster. Less costly medical lasers would likely increase gall bladder removal by laser.

Funding from the A'TP allowed Cynosure to perform research and development work it would otherwise have been unable to do. The award enabled it to hire highly qualified optical physicists to conduct the research on diffractive optics, and to develop the technical capability needed for future manufacture of diffractive optics devices. Cynosure is currently considering licensing this technology to a company whose core business is diffractive optics. In addition, the availability of highly sophisticated optical diagnostic equipment allowed Cynosure to better understand and test the fiber-coupled equipment it is developing for the commercial sector. 

DIAMOND SEMICONDUCTOR GROUP, LLC (DSG)

\section{Lowering the Cost and Improving the Quality of Computer Chips}

B

illions of integrated circuits - the tiny chips that run personal computers and thousands of other electronic devices - are fabricated every year in the United States through ion beam implantation, a technique for introducing carefully controlled impurities, or dopants, into specific locations on the semiconductor wafers from which chips are cut. Dopants control the electrical properties of the semiconductor, forming the transistors and other microscopic components of each chip.

\section{COMPOSITE PERFORMANCE SCORE (Based on a four star rating.)}

\section{Ion Beam Implantation for 300-mm Wafers}

With chip components getting smaller and denser, the need for more accurate control of dopant implantation has risen. At the same time, competitive manufacturing has driven the size of production wafers up, making increased accuracy problematic because of the difficulty in precisely scanning the implantation beam across the wafer.

\section{... the new approach enables the} production of about 2.5 times as many chips from a single wafer as the 200-mm technology can make.

This ATP project allowed Diamond Semiconductor Group (DSG), a two-person start-up company when it applied to the ATP, to develop a new and better way to implant dopants on large silicon crystal wafers measuring $300 \mathrm{~mm}$ or more in diameter, compared with the previous industry standard of $200 \mathrm{~mm}$. Because the area of a 300$\mathrm{mm}$ wafer is 2.25 times that of a $200-\mathrm{mm}$ wafer and some waste always occurs at wafer edges, the new approach enables the production of about 2.5 times as many chips from a single wafer as the $200-\mathrm{mm}$ technology can make. The use of DSG's new technology in production equipment makes it possible to lower the cost and improve the quality of computer chips and other integrated circuits.

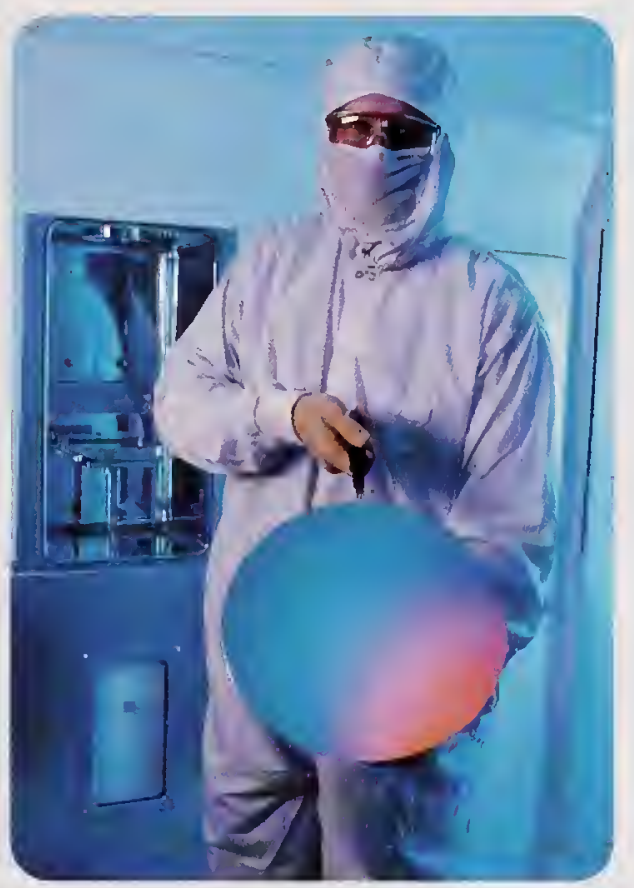

Worker holding the world's first 300 millimeter silicon wafer populated with electronic components using the wide beam ion implantation technology.

\section{Multiple Advantages of Wide-Beam Technology}

A key innovation in the new technology is passing the wafer under a 350 -mm-wide ion beam for implantation, rather than scanning the ion beam across the wafer. The broad beam is very stable and therefore highly accurate. The new equipment incorporating this technology is also significantly simpler than earlier machines and so is cheaper to build and maintain and is more reliable. Use of the DSG technology has already improved fabrication quality substantially relative to the existing industrywide standard. It doubled the mean time between failures, which means that on average, failures occur only half as often as with current equipment. 


\section{PROJECT HIGHLIGHTS}

\section{PROJECT:}

To develop a novel approach for introducing dopants - substances that alter the electrical properties of semiconductor materials - into large semiconductor wafers to enable faster, less costly fabrication of larger wafers with smaller. more-densely packed components.

Duration: $3 / 1 / 1993-6 / 30 / 1994$

ATP Number: 92-01-0115

\section{FUNDING (in thousands):}

$\begin{array}{lrr}\text { ATP } & \$ 1,326 & 77 \% \\ \text { Company } & \frac{393}{23} & 23 \% \\ \text { Total } & \$ 1,719 & \end{array}$

\section{ACCOMPLISHMENTS:}

DSG developed broad-beam ion-implantation technology (now embodied in Varian's SHC80 Serial High-Current Implanter) that successfully implanted the first commercially viable $300-\mathrm{mm}$ semiconductor wafer. The new technology doubled the existing industrywide mean time between failures and provided additional ways to increase the quality and reduce the cost of chip fabrication. The company:

received two patents for technology relared to the ATP project: "Compact High-Current Broad-Beam Ion Implanter"

(No. 5,350,926: filed 3/11/1993, granted 9/27/1994) and

"High Speed Mlovement of Workpieces in Vacuum Processing" (No. 5,486,080: filed 6/30/1994, granted 1/23/1996);

applied for two additional patents for technologies related to the ATP project;

licensed the technology developed during the ATP project to Varian, which incorporated it in its SHC80 implant system and is actively selling the equipment to commercial customers; and

licensed its technology to Mitsui Electronics and Shipbuilding for a flat- panel display application, after U.S. companies declined the licensing opportunity. DSG used \$6.1 million from Mitsui to develop a $650-\mathrm{mm}$ flat-panel component for displays. In 1997, Mitsui signed its first contract to supply the displays to a customer.

CITATIONS BY OTHERS OF PROJECT'S PATENTS: See Figure 4.6.

\section{COMMERCIALIZATION STATUS:}

The technology has been commercialized in one application and is very near commercialization for a second application. Chip manufacturers using the Varian SHC80 implant system (which incorporates the technology) are producing larger $(300-\mathrm{mm})$ wafers than before $(200-\mathrm{mm})$ and making them faster, with higher quality and at lower cost.

\section{OUTLOOK:}

The outlook is exccllent. Varian is already selling semiconductor fabrication equipment that incorporates the new technology, and a flat-panel display application is under way. The technology generates cost savings not only for companics using it to make computer chips but also for those who ultimately buy the chips and the products containing them. The benefits directly captured by DSG will likely be only a small fraction of the total net benefits the technology generates for the economy.

\section{Composite Performance Score: $\star \star \star$}

COMPANY:

Diamond Semiconductor Group, LLC (DSG)

30 Blackburn Center

Gloucester, MA 01930

Contact: Manny Sicradzki

Phone: (978) 281-4223

Number of Employees: 9 at project start, 25 at the end of 1997

Informal collaborator: Varian Associates Inc.

$\$ 1.2$ billion per year, and Varian has 40 percent to 50 percent of the market. Most of the equipment currently sold is for 200-mm wafers, and Varian was the first to market equipment that handles $300-\mathrm{mm}$ wafers. Over the next five years, industry analysts say, the majority of implanters sold will be for $300-\mathrm{mm}$ wafers. All $300-\mathrm{mm}$-wafer ion implanters currently manufactured by Varian include the DSG technology, and those produced in the future are expected to, as well.

DSG is also developing the technology for another application: flat-panel displays, such as those used in notebook computers. The company has completed the development work through a licensing agreement with Mitsui Electronics and Shipbuilding, which invested $\$ 6.1$ million in the effort. In late 1997, Mitsui announced it had already won a contract to supply the panels to a customer. Prior to licensing the technology to Mitsui, DSG attempted to interest U.S. flat-panel display companies in it. But most of this industry is off shore, and there were no interested parties in the United States. 
PATENT TREE KSY

Original Patent

Second Generation Patent

Third Generation Patent

Fourth Generation Patent

Fifth Generation Patent
Figure 4.6 Patent Tree for Project Led by Diamond Semiconductor Group, LLC: Citations by Others of Diamond Semiconductor Group,

\section{LLC Patents}

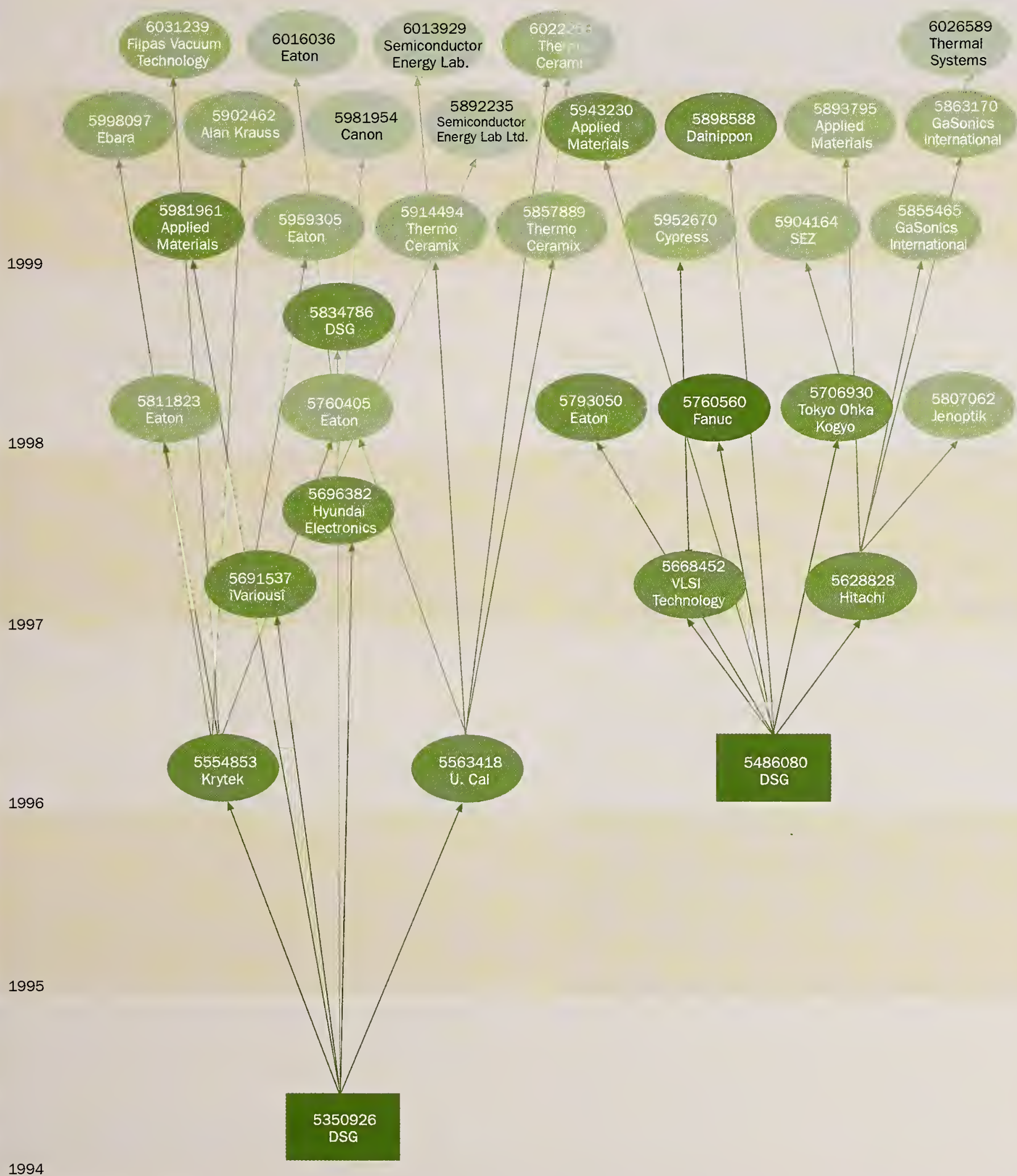

1994 


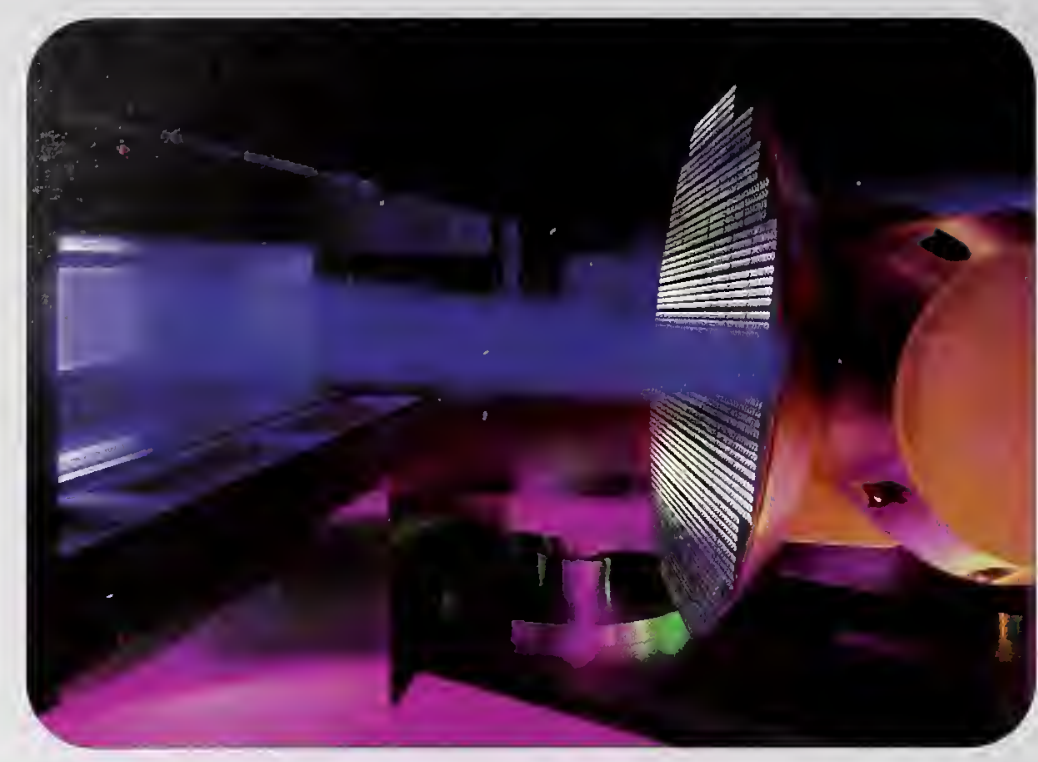

The uniform ribbon beam vertically scanning a wafer, in an ion implanter manufactured by Varian Associates.

\section{Benefits All Along the Supply Chain}

DSG's broad-beam technology enables the generation of substantial economic benefits. Varian sells its ion implanters to chip-fabrication companies such as Intel, Motorola, and Texas Instruments. These companies, in turn, sell their chips to manufacturers that use computer chips in their products - computer companies like Apple, Gateway, Hewlett-Packard, and IBM, as well as firms that make automobiles, appliances, consumer electronics, and

\section{The new equipment . . . is cheaper to build and maintain and is more reliable.}

communications equipment. All along this chain of production, the new technology is saving costs and improving quality.

End users of these products can also expect to benefit from the new technology. Businesses that use desk-top computers containing chips made with this technology, for example, will get lower-cost, higher-quality machines. These will enable better services at lower costs, producing economic benefits for the businesses and their customers. Ultimately, company officials say, the profit DSG earns from its new technology will likely be only one percent to two percent or less of the total incremental economic benefits the technology is apt to generate across the economy, that is, the spillover benefits are likely to be large.

\section{ATP Award Invigorates Small U.S. Company}

DSG reports that without the ATP award, it would probably have been unable to do the research or survive as a company. Its only other alternative then was to become part of a foreign company. All the high-risk research and development work on DSG's broad-beam technology was done during the ATP project, and there was a high likelihood of failure. In addition, the company's status as an ATP participant facilitated the agreement it negotiated with Varian to help DSG meet its cost share for the project and, later, to include the technology in Varian's wafer implantation equipment.

\section{. . . the company's status as an ATP participant facilitated the agreement it negotiated with Varian ...}




\section{ETOM TECHNOLOGIES, INC. \\ (formerly Optex Communications, Inc.) \\ Packing More Data Into Optical Data-Storage Disks}

ptical data-storage devices, typically CD-ROMs (compact disk, read-only memory), have taken the desktop computer market by storm, becoming a standard part of almost every computer sold. Just five years ago they were included in such equipment only by special order. Now, millions of these devices are manufactured and installed every year.

COMPOSITE PERFORMANCE SCORE (Based on a four star rating.)

No Stars

\section{A Rewritable, Higher-Capacity Compact Disk}

Optical disks hold much more data than conventional magnetic hard or floppy disks, the alternative data-storage technology. The optical devices employ the same technology used with music CDs: a laser stores the data by pitting the disk surface in a pattern that can be read by another laser. When it was introduced, a conventional plastic CD-ROM could hold 650 megabytes of data, whereas typical hard disks then held fewer than 50 megabytes. Optical disks, however, could be written only once, and the drive mechanism was much slower than magnetic hard disk drives.

\section{. . barriers arose that made it impossible to offer a cost-effective video CD-ROM.}

New technology is addressing both deficiencies. Optical-disk-drive speeds have increased substantially, and several techniques for enabling the device to write new data are now commercially available. This project with ETOM Technologies, a small start-up company, developed technology that greatly increases the amount of data that can be stored on optical disks.

\section{Large Jump in Storage Capacity}

The ETOM technology uses a glass, rather than plastic, disk onto which is laid a light-sensitive substrate that can be written and read by the lasers in conventional CD-
ROM drives. The core technology is called electron-trapping optical memory (ETOM). Data are written to the substrate by a low-power laser tuned to a specific frequency. The laser light raises individual electrons in the substrate to an elevated energy level, where they are trapped indefinitely. The data are read by a second laser, which releases the trapped electrons to return to their lower energy state, emitting a light signal in the process.

In addition to being a write-and-read device, the ETOM disk is able to store data at multiple energy levels, giving it the ability to use "multiple-ary" digits, as opposed to the binary digits (having two energy levels) used in conventional magnetic data storage. This capability greatly increases the amount of data that can be placed on the disk. For example, a byte (group of eight digits) using binary digits can store 256 different numbers. A byte using a polynary digit with three energy levels, however, can store 6,561 numbers. Thus, the use of just three different energy levels instead of two increases the disk's storage capacity more than 25 times.

\section{Unforeseen Obstacles Block Commercialization}

The company planned to manufacture and sell ETOMbased digital video recording products if the technology could be successfully developed. The technology was developed. But barriers arose that made it impossible to offer a cost-effective video CD-ROM. The company needed a green laser, but a commercial supply of them did not materialize as expected. Nor did the market matcrialize for a video-on-demand device, which would have 


\section{PROJECT HIGHLIGHTS}

PROJECT:

To develop new optical disk data-storage technology capable of recording digital video information on an ETOM (electron trapping optical memory) optical disk, a development that could substantially reduce the cost of storing digital information.

Duration: 2/15/1993 - 12/31/1994

ATP Number: 92-01-0122

FUNDING (in thousands):

ATP $\$ 1,433 \quad 56 \%$

Company $\$ 1,118 \quad 44 \%$

Total \$2,551

\section{ACCOMPLISHMENTS:}

ETOM demonstrated the ability to store data in a radically new optical datastorage mode. The company completed header pattern definition, mask fabrication, and software for reading and writing $\mathrm{M}$-ary (multiple-ary, as opposed to binary) data and developed specialized test equipment. It also:

received 12 patents for technologies related to the ATP project:

"Partial Response Coding for a Multilevel Optical Recording Channel"

(No. 5,537,382: filed 11/22/1994, granted 7/16/1996),

"M=7 (3,7) Runlength Limited Code for Multilevel Data"

(No. 5,657,014: filed 5/12/1995, granted 8/12/1997),

" $\mathrm{M}=5(0,2)$ Runlength Limited Code for Mlultilevel Data" (No. 5,659,310: filed 5/12/1995, granted 8/19/1997),

" $\mathrm{N}=6(2,4)$ Runlength Limited Code for Multilevel Data" (No. 5,659,311: filed 5/12/1995, granted 8/19/1997),

"M=10 (3,6) Runlength Limited Code for Multilevel Data" (No. 5,663,722: filed 5/12/1995, granted 9/2/1997),

"M=7 $(1,3)$ Runlength Limited Code for Multilevel Data" (No. 5,663,723: filed 5/12/1995, granted 9/2/1997),

" $\mathrm{N}=6(3,6)$ Runlength Limited Code for Multilevel Data" (No. 5,668,546: filed 5/12/1995, granted 9/16/1997),

" $\mathrm{M}=5(3,7)$ Runlength Limited Code for Multilevel Data"

(No. 5,670,956: filed 5/12/1995, granted 9/23/1997),

" $\mathrm{M}=5(4,11)$ Runlength Limited Code for Multilevel Data"

used the video CD-ROM to temporarily store movies and other videos downloaded by viewer request from a cableTV company.

. . ceased operations in January 1998 and filed for bankruptcy two months later.

After attempting to develop additional technologies to enable it to survive, ETOM ran into severe financial problems in late 1997. Private investors in ETOM decided it could not continue to operate without the business from a partnership to commercialize one of these technologies - a deal that ultimately fell through — so they
(No. 5,675,330: filed 5/12/1995, granted 10/7/1997),

"M=6 $(3,8)$ Runlength Limited Code for Multilevel Data" (No. 5,680,128: filed 5/12/1995, granted 10/21/1997),

" $\mathrm{N}=4(1,2)$ Runlength Limited Code for Multilevel Data" (No. 5,682,154: filed 5/12/1995, granted 10/28/1997), and

"M=6 $(4,11)$ Runlength Limited Code for Multilevel Data" (No. 5,682,155: filed 5/12/1995, granted 10/28/1997);

applied for 14 additional patents for technologies related to the ATP project;

prepared several technical papers for publication or presentation at professional conferences; and

entered into preliminary negotiations with potential users of its patented $\mathrm{M}$-ary coding algorithms.

CITATIONS BY OTHERS OF PROJECT'S PATENTS: See Figure 4.7.

\section{COMMERCIALIZATION STATUS:}

Commercialization of the original data storage device employing the ATPfunded technology faltered because not all necessary technical components were available for the system, and the expected market did not materialize. The company encountered severe financial problems in late 1997 and declared bankruptcy in March 1998.

\section{OUTLOOK:}

Although ETOM's recent bankruptcy precludes its commercialization of this technology, substantial knowledge was gained, as reflected in the patent applications and grants. The possibility exists that other companies will license and commercialize the technology.

Composite Performance Score: No Stars

COMPANY:

ETOM Technologies, Inc.

(formerly Optex Communications, Inc.)

2 Research Court

Rockville, MD 20850

Number of Employees: 30 at project start, 3 at the end of 1997

decided to close ETOM. It ceased operations in January 1998 and filed for bankruptcy two months later.

\section{ATP Critical to Developing New Technology}

ETOM reports that if it had not received the $\$ 1.4$ million ATP award, it could not have performed the research and probably would not have survived as a company long enough to conduct the research. It encountered difficulties in bringing to market an optical disk device incorpo-

... received 12 patents for technologies related to the ATP project . . . applied for 14 additional patents . . . 


\section{PATENT TREE KEY}

Original Patent

Second Generation Patent

Third Generation Patent

Fourth Generation Patent

Fifth Generation Patent

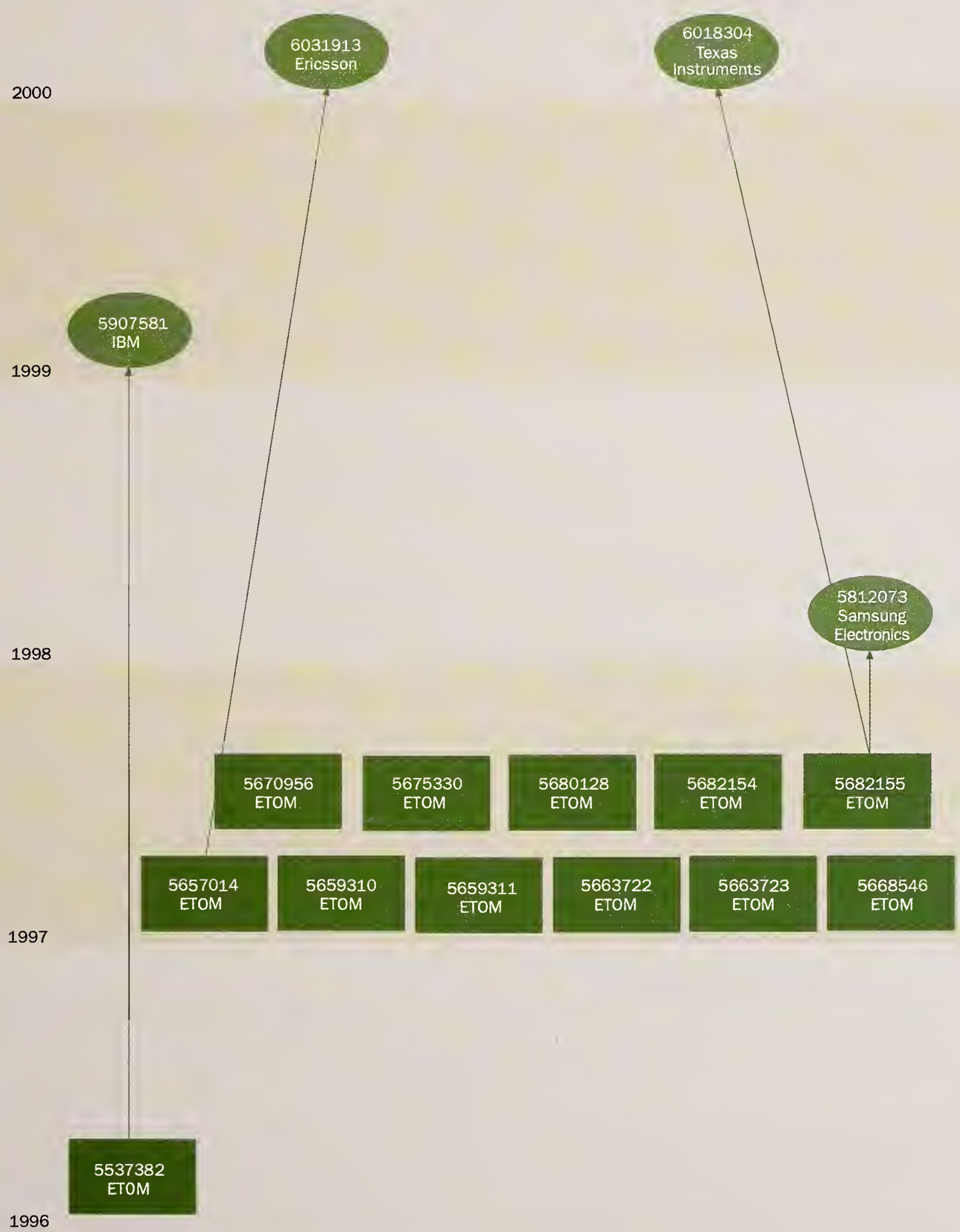

Figure 4.7 Patent Tree for Project Led by ETOM Technologies, Inc.:

Citations by Others of ETOM Technologies, Inc. Patents 
rating its new technology. Even though the company is no longer in business, the new approaches developed in this ATP project may eventually be picked up and used by some other company.

... the new approaches developed in this ATP project may eventually be picked up and used by some other company. 


\section{A Gas Method to "Dry" Clean Computer-Chip Wafers}

$M$

anufacturing processes create parts for further assembly or final use, as well as a certain amount of waste. Even if waste is severely controlled, the part that emerges from fabrication is almost always contaminated to a greater or lesser degree by unwanted particles. The level of unwanted particles varies with the process, and so does its effect on the rest of production. If the new part is a slice of silicon crystal about to be covered by microscopic integrated circuits, the presence of unwanted particles even in minute amounts - is disastrous. Extreme cleanliness, therefore, is the rule in silicon chip-making plants, where fabrication takes place in clean rooms designed to eliminate contamination.

COMPOSITE PERFORMANCE SCORE (Based on a four star rating.)

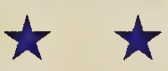

\section{New Technology to Clean Ever Smaller Chip Features}

In computer-chip fabrication, a silicon-crystal wafer is thoroughly cleaned before microscopic electronic components are deposited on it. Conventional cleaning techniques use caustic wet chemicals that could be hazardous to workers

\section{... the presence of unwanted}

\section{particles - even in minute amounts}

- is disastrous . . .

and that must be discarded after use, generating disposal costs and the potential for environmental pollution if the chemicals are not handled properly. In addition, for chips with feature sizes below a minimum, wet chemicals may not be able to get to some features, such as trenches, because of surface tension.

\section{Potentially Safer and Less Costly}

The ATP award allowed FSI International, which provides semiconductor wafer surface conditioning equipment and support products, to develop a "dry" cleaning procedure that uses chlorine, chlorine/hydrogen, and other gases to clean dirt, trace metals, and other particles from wafer surfaces. Researchers completed the assembly and installation of an experimental module and developed required support processes. Although the gases are toxic, they are more easily controlled than wet chemicals. And even though the gases incur disposal costs, the amount of chemical waste generated by the FSI technology is expected to be much smaller than that created via traditional wet cleaning. Thus, the new technology should improve human and environmental safety and reduce cleaning costs during wafer processing.

FSI's methodologies for gas-phase dry cleaning were developed for use in making computer chips and have potential applications in the fabrication of printed circuit boards, disk drives, and optoelectronics. If the market emerges and the FSI technology becomes widely used, substantial economic benefits would likely accrue all along the supply chain for computers and other equipment that

\section{. . . caustic "wet" chemicals that could} be hazardous to workers and that must be discarded after use, generating disposal costs and the potential for environmental pollution... .

include chips. The technology is undergoing initial testing at Texas Instruments. If the testing is successful, FSI officials say, Texas Instruments would likely buy and use systems incorporating the new technology.

ATP funding was critical to generating the gas-phase 


\section{PROJECT:}

To develop a cost-effective process to remove surface contaminants from computer-chip wafers during manufacturing, using dry gases (as opposed to wet chemicals) that can clean the ever smaller features on new generations of chips.

Duration: 3/1/1993 - 2/28/1995

ATP Number: 92-01-0022

\begin{tabular}{lll}
\multicolumn{3}{l}{ FUNDING (in thousands): } \\
ATP $\quad \$ 2,000$ & $36 \%$ \\
Company & $\underline{3,482}$ & $64 \%$ \\
Total & $\$ 5,482$ &
\end{tabular}

\section{ACCOMPLISHMENTS:}

FSI achieved its R\&D goal of developing a dry gas wafer-cleaning method. Evidence of progress is that the company:

received three patents related to the ATP project:

"UV-Enhanced Dry Stripping of Silicon Nitride Films"

(No. 5,534,107: filed 8/18/1994, granted 7/9/1996),

"Apparatus for Surface Conditioning"

(No. 5,580,421: filed 12/21/1994, granted 12/3/1996), and

"Cleaning Method"

(No. 5,716,495: filed 3/25/1996, granted 2/10/1998);

applied for nine additional patents, one of which has been unofficially granted (allowed but not yet published);

- presented or published nine technical papers in the area of dry cleaning, etching or stripping of surfaces;

received a license to complementary technology that could accelerate the commercialization of an advanced dry gas-phase cleaning system;

entered into an agreement with Texas Instruments for early-stage testing of a prototype; and

constructed a manufacturing facility to handle all FSI International

dry cleaning technology, FSI officials report. The company would not have done the research and development work at that time without it. The ATP award also enabled FSI to collaborate with Massachusetts Institute of Technology researchers during the project.

\section{Commercialization Delayed but Still Expected}

Since initiation of the ATP project, manufacturers of wafer-surface conditioning equipment have found ways to squeeze more improvements out of wet-chemical cleaning methods. Consequently, chip fabricators have less need for a dry cleaning technique than was initially anticipated. The company expected that the shift in 1997 to smaller (0.25 micron) minimum feature sizes for wafer processing would challenge the capabilities of conventional wet cleaning processes. Wet processing, however, continues to meet cleaning needs at this level and may even be viable to minimum feature sizes of 0.18 micron, which are expected to be introduced in 2000. Furthermore, progress has been made in reducing the amount of chemicals needed
Surface Conditioning Division manufacturing, including products incorporating the ATP-funded technology.

CITATIONS BY OTHERS OF PROJECT'S PATENTS: See Figure 4.8. COMMERCIALIZATION STATUS:

No commercialization has occurred so far, owing to unanticipated changes in demand for the new technology. The shift in 1997 to 0.25-micron minimum feature sizes for wafer processing was expected to challenge the capabilities of conventional wet cleaning processes. Wet processing, however, continues to meet cleaning needs for 0.25 -micron features and may even be viable to minimum sizes of 0.18 micron, which are expected to be introduced in the year 2000 .

\section{OUTLOOK:}

Commercialization prospects are uncertain. Much depends on how the market moves, as well as on remaining development work needed to demonstrate the robustness, manufacturability and reliability of the process and equipment in a chip-manufacturing environment. Although the ATP-funded technology has not replaced traditional wet cleaning in chip processing, as originally envisioned by the ATP-project proposal, FSI anticipates the emergence of new applications requiring the unique capabilities of its technology.

\section{Composite Performance Score: $\star \star$}

\section{COMPANY:}

FSI International, Inc.

322 Lake Hazeltine Drive

Chaska, MN 55318-1096

Contact: Jeff Butterbaugh

Phone: (612) 448-8089

Number of Employees: 540 at project start, 1,295 at the end of 1997 Unofficial collaborator: Massachusetts Institute of Technology, Department of Chemical Engineering

for wet cleaning processes.

Commercialization of the ATP-funded technology, therefore, depends on how much more the wet method can be extended, as well as on the remaining development

\section{... the new technology should improve human and environmental safety and reduce cleaning costs during wafer processing.}

work needed to demonstrate the robustness, manufacturability, and reliability of the process and equipment in a chip-manufacturing environment. Although the new technology has not become a broad replacement for traditional wet cleaning in wafer processing, as originally envisioned by the ATP-project proposal, FSI anticipates the emer- 
PATENT TREE KEY

Original Patent

Second Generation Patent

Third Generation Patent

Fourth Generation Patent

Fifth Generation Patent
Figure 4.8 Patent Tree for Project Led by FSI International, Inc.:

Citations by Others of FSI International, Inc. Patents

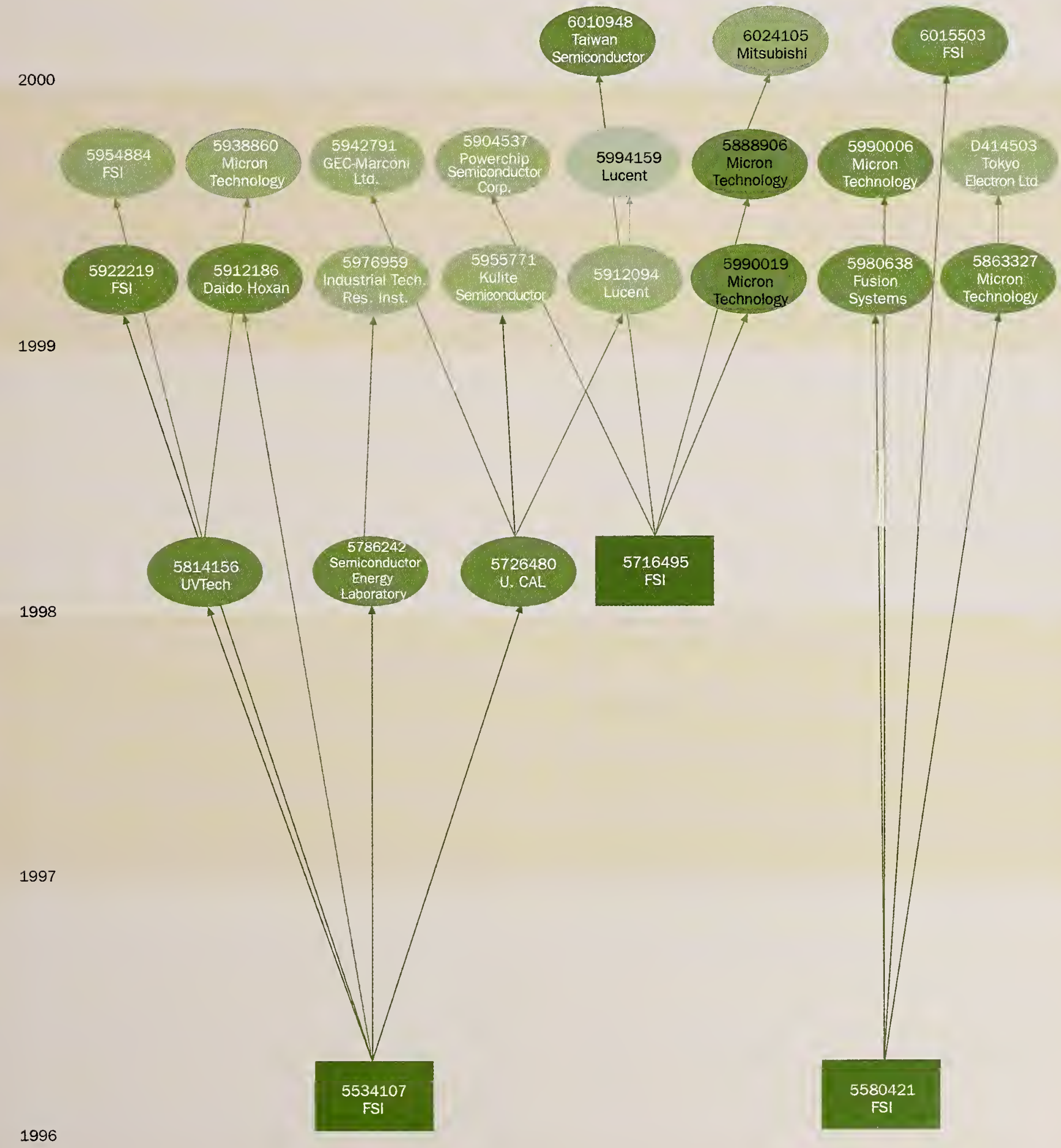

FSI INTERNATIONAL, INC. 
gence of new applications requiring the unique capabilities of its technology. If the dry cleaning technology is commercialized, chip fabricators that use the new technology might achieve process improvements worth up to five

FSI has continued to develop this technology while delaying commercialization until demand increases sufficiently.

times their costs for the technology, company officials say. FSI has continued to develop this technology while delaying commercialization until demand increases sufficiently. If that happens soon, the company could have a product on the market in 1999. 


\section{HAMPSHIRE INSTRUMENTS, INC. \\ (Joint Venture) \\ Large-Scale Diode-Array Laser Technology for X-Ray Lithography}

\section{T}

UV light through stencil-like masks onto silicon wafers to produce the tiny components of integrated circuits (ICs) or chips. To make higher-performing ICs, more transistors and denser circuitry will have to be packed onto each chip.

COMPOSITE PERFORMANCE SCORE

(Based on a four star rating.)

No Stars

\section{Ever Smaller, Denser Computer Chips}

Today's densest chips have feature sizes of about $0.15 \mathrm{~mm}$, which can barely be produced with deep-UV lithography. To make even smaller chips, the next generation of lithography equipment may use $\mathrm{x}$-rays, which have shorter wavelengths than visible or UV light. Shorter wavelengths are needed to make tinier features.

\section{An Inexpensive Laser Approach}

$\mathrm{X}$-ray lithography able to make chip features of $0.10 \mathrm{~mm}$ and smaller was demonstrated prior to the start of this project in 1991. But cost-effective x-ray lithography systems capable of large-scale IC manufacturing were not available. Research had shown that a relatively inexpensive device using a high-energy laser to stimulate $\mathrm{x}$-ray emission could be used to produce x-rays. Suitable material (neodymium-doped gadolinium gallium garnet, or $\mathrm{Nd}: G G G)$ for this type of laser was available. However, the inability to precisely control the energy used to pump up the material's energy level was a key problem in making such a laser work.

This ATP joint venture project by Hampshire Instruments and McDonnell Douglas Corporation (MDC), with help from Lawrence Livermore National Laboratory, solved the control problem by developing methods for using powerful arrays of laser diodes to pump Nd:GGG in a laser-based $\mathrm{x}$-ray lithography system. Hampshire, a small New York company, contributed its laser design expertise. MDC provided expertise in system design and the design of the critical high-power laser-diode pump. It also provided the world's largest laser-diode module manufacturing capacity to support post-project commercialization goals.

Prior to the ATP-funded work, MDC built a prototype laser-diode pump system with a peak power output of more than $300 \mathrm{~kW}$. The system was successfully used to pump a Hampshire laser being developed for a secondgeneration x-ray lithography system, and its pumping was significantly more efficient than that of the flash lamps Hampshire had used in its first-generation x-ray lithography system. In addition, life testing of laser-diode pump systems showed they lasted much longer than the longestlasting flash lamps then available.

\section{Doubling the Peak Power Output}

During the ATP project, MDC built two prototype laserdiode pump systems that each delivered more than 750 $\mathrm{kW}$ of peak power, by far the highest laser-diode power produced by any device then or now. Both met or exceeded all performance and reliability specifications. MDC kept one pump and delivered the other to Lawrence Livermore for testing in the second-generation $\mathrm{x}$-ray lithography system being developed by the lab and Hampshire. The pump, however, was never integrated with the Hampshire laser. Flash lamps with longer life became available, leading Lawrence Livermore to shift its focus to flash-lamp pumping of the laser. The lab continues to develop x-ray lithography. 


\section{PROJECT HIGHLIGHTS}

\section{PROJECT:}

To develop a laser-diode-pumped laser system for generating $\mathrm{x}$-rays in a new generation of lithography equipment to enable a major advance in the miniaturization of computer chips while reducing manufacturing costs.

Duration: 7/1/1991 - 9/30/1992

ATP Number: 90-01-0126

\begin{tabular}{|c|c|c|}
\hline \multicolumn{3}{|c|}{ FUNDING (in thousands): } \\
\hline A'TP & $\$ 926$ & $50 \%$ \\
\hline Company & $\underline{930}$ & $50 \%$ \\
\hline Total & $\$ 1,85$ & \\
\hline
\end{tabular}

\section{ACCOMPLISHMENTS:}

Researchers demonstrated the feasibility of using a powerful laser-diodearray to pump up the energy level of Nd:GGG (neodymium-doped gadolinium gallium garnet) in a laser intended for use in producing $\mathrm{x}$-rays. Such a laser could be scaled up to meet the technical, reliability and affordability requirements for third-generation $\mathrm{x}$-ray lithography systems. All planned tasks were accomplished. The company presented some results at the Advanced Solid State Laser Conference in 1992.

\section{COMMERCIALIZATION STATUS:}

No attempt to commercialize the technology has occurred. Soon after the ATP project was completed, Hampshire ran into serious financial problems, declared bankruptcy and was liquidated. The company's demise halted the effort to develop this type of laser-based $\mathrm{x}$-ray lithography and led to the collapse of MDC's laser-diode business.

\section{High Expectations Dashed by Bankruptcy}

Evidence at the start of the project suggested the ATPfunded technology would be rapidly commercialized if it could be successfully developed and demonstrated. Hampshire and MDC planned to sell the new $\mathrm{x}$-ray lithography system in a worldwide market expected, when the proposal was written, to exceed $\$ 1.5$ billion by 1994. They also hoped to sell the technology in solidstate laser markets.

Soon after the ATP project was completed, Hampshire ran into serious financial problems, declared bankruptcy and was liquidated.

Hampshire, however, ran into serious financial problems and failed to raise the additional funds needed to survive. The company declared bankruptcy and was liquidated. The New York Job Development Authority assumed ownership of practically all Hampshire assets, including its

\section{OUTLOOK:}

The New York Job Development Authority — which now owns practically all Hampshire assets, including intellectual property - shows no intention to commercialize the technology. Neither does MDC (Boeing). The semiconductor industry has shifted some of its attention from $x$-ray lithography to competing technologies such as deep ultraviolet (DUV) lithography utilizing excimer lasers. However, given the expectation that feature resolution limits of DUV lithography will be reached in a few years, $\mathrm{x}$-ray lithography continues to arouse interest. If the industry comes to view the $x$-ray approach as a viable candidate for a new generation of lithography equipment, the technology developed in this ATP project could be revisited.

\section{COMPANIES:}

Hampshire Instruments, Inc. (joint venture lead) (Since April 25, 1993, no longer in business)

\section{Composite Performance Score: No Stars}

Other joint venture participant:

McDonnell Douglas Corporation (MDC), now merged with The Boeing Company 5000 E. McDowell Road

Mesa, AZ 85215-9797

Contact: Henry B. Morris

Phone: (602) 891-2194

Informal collaborator: Lawrence Livermore National Laboratory

intellectual property. For a time, several organizations expressed interest in acquiring the technology, but none completed the acquisition. MDC intended to commercialize its laser-diode pumps for a variety of applications. With

\section{... MDC built two prototype laser-diode- pump systems that each delivered more than $750 \mathrm{~kW}$ of peak power, by far the highest laser-diode power produced by any device. . .}

Hampshire's demise, that plan did not materialize. There is currently no effort to commercialize the ATP-funded technology, either by Boeing (MDC) or government agencies. But this may change with renewed interest in $\mathrm{x}$-ray lithography in the future. 


\section{Exploiting Alexandrite's Unique Properties for a Less-Expensive, More-Reliable Tunable Laser}

Lasers today drive many devices throughout the consumer and commercial worlds. There are tiny ones in printers and $C D-R O M$ players, small ones in medical instruments and large ones in satellite communications systems. Besides coming in different sizes, lasers vary in the wavelength and strength of the light they produce. In almost all applications, the wavelength and power of the beam are fixed.

COMPOSITE PERFORMANCE SCORE (Based on a four star rating.)

\section{Tunable Lasers for Many Uses}

This ATP project with Light Age, a small privately held company, developed a convenient, reliable, tunable, compact laser source of ultraviolet (UV) light suitable for spectroscopy, medical applications, photochemical research, electronics fabrication, and laboratory studies of atomic and molecular science. Of particular importance, the new laser can be tuned to the shorter UV wavelengths known as vacuum UV (VUV) light.

\section{The new device is the brightest (most} powerful) available tunable source of laser light over much of the UV spectrum.

Light Age was founded in 1985 by two scientists who, at AlliedSignal, had pioneered and managed the development of a tunable-wavelength laser based on the alexandrite crystal. The new light source developed in the ATP project offered improvements over the AlliedSignal technology and is less expensive, operationally simpler and more reliable than other tunable laser light sources. It uses the fundamental output of the alexandrite laser, which is broadly tunable between 700 and 800 nanometers $(\mathrm{nm})$. That output is then converted to UV wavelengths of $190-$ $200 \mathrm{~nm}, 240-270 \mathrm{~nm}$ or $350-400 \mathrm{~nm}$. The new device is the brightest (most powerful) available tunable source of laser light over much of the UV spectrum.

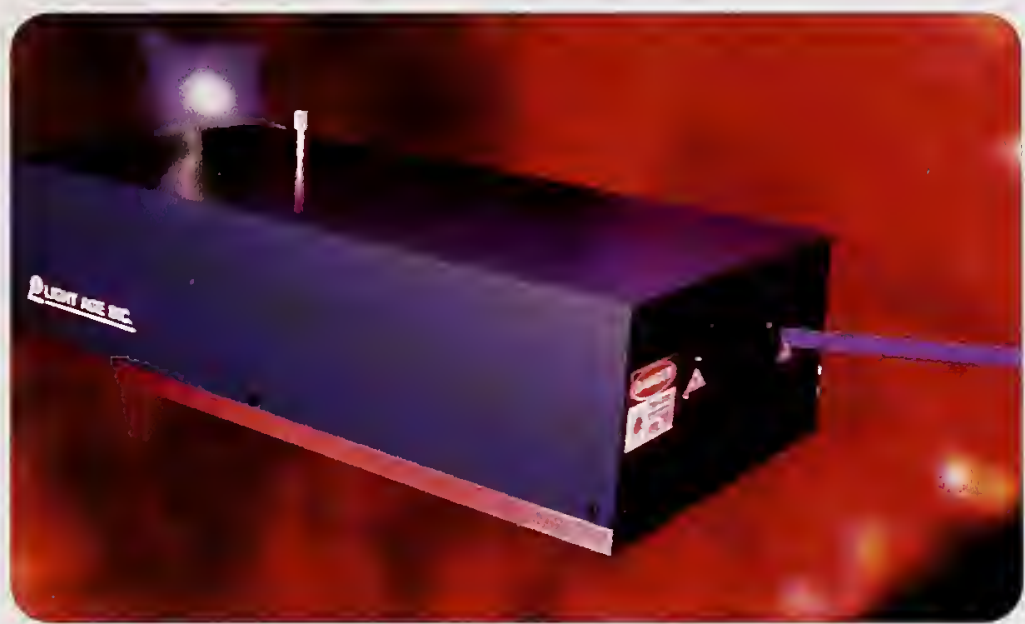

The Pal/Pro-UVTM laser system, tunable to 248 nanometers, 193 nanometers, and other ultraviolet wavelengths.

\section{Surgery and Photolithography}

The new tunable laser is particularly promising for corneal sculpting and angioplasty because it provides the control needed for these advanced applications. Its advantage stems from the fact that laser beams of certain wavelengths affect some tissue types but not others. The laser

The laser can be tuned, for example, to the wavelength of a light beam that destroys diseased tissue while leaving healthy tissue undamaged. 


\section{PROJECT HIGHLIGHTS}

\section{PROJECT:}

To develop a safe, compact, convenient, reliable, less-expensive, broadly tunable laser source of ultraviolet (UV) light — particularly at shorter UV wavelengths - suitable for use in science, medicine and photolithography.

Duration: 4/1/1991 - 9/30/1993

ATP Number: $90-01-0212$

FUNDING (in thousands):

ATP $\$ 702 \quad 41 \%$

Company $\quad \underline{1,010} \quad 59 \%$

Total $\$ 1,712$

\section{ACCOMPLISHMENTS:}

Light Age accomplished its R\&D goal. The company also:

introduced several new or improved laser products incorporating the ATP technology, including:

$\mathrm{UVO}^{\mathrm{TM}}$ - a continuous-wave, diode-pumped, solid-state laser producing UV light, PAL/UVTM - a solid-state laser source of 193-nanometer light, and PAL/PROTM — a narrow spectral bandwidth version of the PAL ${ }^{\text {TM }}$ laser;

increased revenues an average of 50 percent per year since the end of the ATP project in 1993, with 1997 revenues exceeding $\$ 2.8$ million on sales of lasers incorporating the new technology; and

received more than $\$ 10$ million worth of product orders, which are currently being filled.

can be tuned, for example, to the wavelength of a light beam that destroys diseased tissue while leaving healthy tissue undamaged.

Another, quite different potential application is in photolithography equipment for the production of faster, higher-density, next-generation computer chips. Shorterwavelength light is needed to produce the finer features on these chips. And reliable lasers that can generate shorter-wavelength light are needed to move beyond this manufacturing choke point. As recently as 1995, almost all chip photolithography used light in the near-UV range (around $350 \mathrm{~nm}$ ) produced by UV light bulbs. Today, the industry is rapidly moving toward deep-UV laser sources that produce light at $248 \mathrm{~nm}$. Future generations of computer chips may require VUV laser sources that produce light at wavelengths of about $193 \mathrm{~nm}$ or even shorter.

\section{Large Benefits to Intermediate Users and Customers}

Light Age makes UV and VUV lasers costing $\$ 20,000$ to $\$ 200,000$. They are used in applications such as health care and scientific equipment that may generate big payoffs to the economy as a whole. In most of these markets, the company's technology faces global competition.

Nonetheless, Light Age is already a significant exporter
COMMERCIALIZATION STATUS:

Light Age lasers incorporating the ATP-funded tunable-laser technology are being sold and put to use in academic R\&D and in clinics, hospitals and doctors' offices around the world.

\section{OUTLOOK:}

Prospects for wider use of this technology are promising, particularly in medicine for corneal sculpting and angioplasty. Products based on the ATPfunded technology may generate large payoffs to the U.S. economy in science, health care and electronics manufacturing. The company's lasers are also being used in studies to refine and extend global weather prediction methods. If atmospheric research using the new lasers leads to improved weather forecasts, the benefits in this area alone could be huge for businesses and individuals worldwide.

\section{Composite Performance Score: $\star \star \star$ \\ COMPANY: \\ Light Age, Inc. \\ 2 Riverview Drive \\ Somerset, NJ 08873}

Contact: Donald F. Heller

Phone: (732) 563-0600

Number of employees: 10 at project start, 28 at the end of 1997

of laser systems for scientific and medical applications and expects strong, continued growth of these exports.

Economic benefits are accruing to intermediate customers and end users of the new technology in medical applications. Many applications of the new laser technology are in environments such as medicine and weather forecasting, where the economic benefits to others besides Light Age are likely to be large.

\section{Light Age is already a significant exporter of laser systems . . .}

\section{Potential for Improved Weather Prediction}

The company's lasers are being used in institutional and government research on the upper atmosphere to refine and extend global weather prediction methods. In these applications, lasers are a required technology. The research uses UV lidar (light detecting and ranging) to illuminate particular atoms in the mesosphere - about 70 miles above the earth. Specific effects of the illumination are viewed with powerful telescopes, recorded and used to determine the temperature of the environment at that altitude. 
This research aims to develop methods for measuring the temperature and wind speed at very high altitudes. Current measurement systems mainly use only groundlevel data. Researchers believe that data on several atmospheric strata measured at selected points around the earth could significantly improve the quality of the very large weather prediction computer models now in use. If research using the tunable laser does lead to better weather predictions, the benefits would likely be huge for businesses and individuals not just in the United States, but around the world.

The tunability of the alexandrite laser from Light Age has made this new research feasible. To show their effects, different types of atoms must each be illuminated by a lidar laser of a specific wavelength. With the Light Age laser, that wavelength can be set by a technician using conventional controls. Alternative laser sources for this research are hand-constructed for just one wave-length, which limits their use and makes them much more expensive than the mass-produced Light Age lasers.

\section{Greater Sales and Revenues}

Light Age has done well commercially. The company has expanded product offerings and increased sales each year since beginning the ATP project in 1991. The new technology helped Light Age boost revenues an average of more than 50 percent per year after completing the project in 1993. In 1997, the company generated more than $\$ 2.8$ million in revenues and, at the beginning of 1998 , had back orders worth more than four times its 1997 sales.

\section{If atmospheric research using the new lasers leads to improved weather forecasts, the benefits in this area alone could be huge for businesses and individuals worldwide.}

Light Age sees itself as an up-by-your-own-bootstraps company in terms of finances. A large part of its success comes from paying detailed attention to financial management, tightening its budgetary belt, retrenching temporarily when needed, pushing new technology-driven products through to market and staying in product areas where its strengths lie. The company has adopted a stringent approach to financial matters, plowing all earnings back into additional research. ATP's participation compelled Light Age to adopt rigorous financial discipline during the company's early development in order to meet the ATP requirement for cost sharing. The belt-tightening was difficult for Light Age in the short run, company officials say, but served the long-term interests of the company.

The ATP funds enabled Light Age to double its research budget during the funding period, a move that allowed the research and development work to be completed 12 to 36 months sooner than it would have been without the award. In addition, company officials say, the visibility generated by winning the ATP award helped Light Age establish agreements with research partners and, coupled with the success of the ATP project, enabled it to secure additional funding from private investors. 


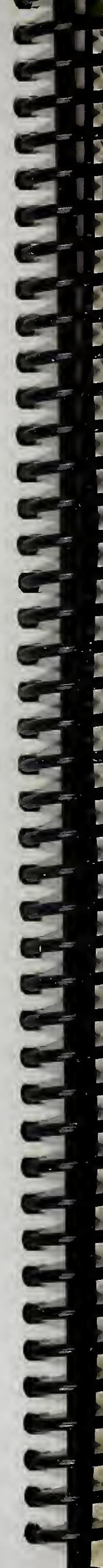




\section{LUCENT TECHNOLOGIES INC. \\ (formerly AT\&T) \\ Precision Mirrors \\ for Advanced Lithography}

\section{ranced Optics to Enable Chip Miniaturization}

ATP project with Lucent Technologies (formerly

$8 x$ ) Bell Laboratories significantly improved the accuof precision reflective optics - complex multilayered mirrors - that are critical for extreme ultraviolet J) lithography. EUV, or soft x-ray, technology is one everal possible approaches to advanced lithography for iufacturing chips.

\section{A new approach to lithography that can}

erate at shorter wavelengths is essential if the integrated circuit industry is to continue to advance toward more powerful computer chips.

The goal of the project was to discover whether it is sible to create ultrahigh-precision aspherical mirrors properly reflect EUV wavelengths for use in lithograThis was a high-risk, technically challenging project. cost sharing enabled Lucent to move ahead with a ect that otherwise would have been difficult to justify, icularly because so much of the funding would go to aborators outside the company. Ultimately, the ATP ect showed that the technical obstacles were surantable and that the optics can be manufactured, ssured, and aligned.
Characterizing the complex shapes of these mirror surfaces with the high level of precision required for EUV lithography was well beyond the state of the art when the ATP project began. Working with Lucent, Tropel developed a specialized interferometer to measure aspheric surface characteristics, a device that it now uses in other applications. Lucent, in collaboration with Brookhaven and Sandia National Laboratories and the University of Wisconsin, developed other techniques required to characterize aspheric mirrors. The project also generated increased understanding of multilayer-coated aspherical optics and optics surface finishing, advanced techniques for multilayer coating of mirrors, improved methods for mirror alignment, and new test equipment.

To see whether this new technology would work, Lucent and its collaborators conducted a two-stage, roundrobin test. In the first stage, four subcontractors fabricated prototype mirrors using the knowledge created in the project. Then each subcontractor tested mirrors fabricated by each of the four. The mirrors made by Tinsley Laboratories proved to be dramatically better than any of this type ever seen before.

\section{Commercialization Status}

When this project began, it was uncertain whether aspheric mirrors with the high level of accuracy required for EUV lithography could be made. And even if they could, it was not clear whether they could be measured with sufficient accuracy to verify that they met the extreme precision demanded by the specifications. Thus, this high-risk 


\section{PROJECT HIGHLIGHTS}

\section{PROJECT:}

To develop new fabrication, testing, and alignment techniques for making extremely precise aspheric (nonspherical curvature) mirrors to use for lithography in the extreme ultraviolet (EUV) portion of the spectrum. This is one of several approaches being considered for fabricating future generations of computer chips with extremely dense, compact microelectronic circuits.

Duration: 5/15/1991 - 5/14/1994

ATP Number: $90-01-0121$

\section{FUNDING (in thousands):}

ATP $\$ 2,000 \quad 36 \%$

Company $\quad 3,525 \quad 64 \%$

Total $\$ 5,525$

\section{ACCOMPLISHMENTS:}

Lucent and its subcontractors developed dramatically improved techniques for fabricating, testing, and aligning extremely precise aspherical, multilayercoated mirrors essential to EUV technology, a candidate for future lithography systems. Lithography is a key step in manufacturing integrated circuits. Aspheric mirrors, whose surfaces have nonspherical curvature, are much more difficult to make and measure than mirrors with flat or spherically curved surfaces. They are particularly difficult to make for the ultrashort wavelengths used in this technology. Researchers significantly advanced the state of the art of the physics and metrology for these EUV lithography systems. Signs of the project's success are:

- Lucent contracted with Tropel to develop a new advanced interferometer for measuring the surface properties of aspheric optics. Tropel succeeded and is now using this technology for its own products.

Tinsley Laboratories, a subcontractor, fabricated mirrors 10 times more precise than any produced before the ATP project. Tinsley has applied the improved methods learned in the project to all its products. In part, because of its improved manufacturing technology, Tinsley doubled its sales between 1991 (the start of the ATP project) and 1996.

the researchers presented or published more than two dozen papers about precision metrology, aspheric mirror fabrication and lithography systems development.

three computer chip fabrication companies have agreed to invest $\$ 250$ million over three years to continue the research, development and perhaps ultimate commercialization of EUV lithography technology. A criti-

project aimed to find out whether the EUV approach to lithography deserved further consideration or whether the mirrors constituted a showstopper technical barrier that could not be surmounted. The project demonstrated that the mirror technical barrier could, indeed, be overcome.

... this high-risk project aimed to find out whether ... the mirrors constituted a showstopper technical barrier that could not be surmounted. cal component of this technology is the multilayer-coated mirrors that were the focus of this ATP project.

\section{COMMERCIALIZATION STATUS:}

Although Lucent has decided to concentrate on another advanced-lithography approach that appears more promising at this time to the company, some technologies developed during the ATP project have already been commercialized, and others may be commercialized in the future. Tinsley's business rose sharply as a result of manufacturing improvements the firm developed to fabricate the aspheric mirrors for this project. Tropel is using the measurement technology resulting from its involvement in the project. And several computer chip manufacturers are incorporating the project results into their lithography R\&D. If the EUV approach meets the technical and economic requirements of the chip industry, the ATP-funded technology will be incorporated into equipment used to produce computer chips in the first decade of the twenty-first century.

\section{OUTLOOK:}

The high-quality Tinsley mirrors, fabricated and tested with methods discovered during the ATP project, are a key component of the EUV approach to new generations of lithography equipment. If this approach proves to be technically and commercially viable, it will enable a new generation of chipmaking equipment that will generate benefits for chip manufacturers, as well as users of computers, communications equipment, and other electronic devices containing the new chips.

\section{COMPANY:}

Lucent Technologies Inc., Bell Laboratories

(formerly AT\&T Bell Laboratories)

Room 3C-428

600 Mountain Ave.

Murray Hill, NJ 07974

\section{Composite Performance Score:}

Contact: Richard P. Muldoon

Phone: (908) 582-5330

Subcontractors: Itek Optical Systems, SVG Lithography, Tinsley Laboratories and Tropel Corp.

Informal collaborators: Sandia, Brookhaven and Lawrence Livermore National Laboratories and NIST.

Progress on all the advanced-lithography candidate technologies developed in parallel at industry and government laboratories during the early 1990s. As data accumulated, Lucent decided in 1995-1996 (well after the ATP project ended) to reduce its effort in EUV lithography and focus its attention on another option - scattering with angular limitation projection electron-beam lithography (SCALPEL) - which it deemed more promising. Lucent still monitors developments in all areas of advanced lithography, and substantial work on EUV lithography continues elsewhere, particularly at Lawrence Livermore and Sandia National Laboratories. 
In 1996 Intel, AMD, and Motorola formed the Extreme Ultraviolet Limited Liability Company to pursue EUV lithography. In September 1997, this consortium and the Virtual National Laboratory (a collaboration of Lawrence Berkeley, Lawrence Livermore, and Sandia National Laboratories) agreed to collaborate on the development of EUV lithography. EUV systems would draw on

The high-quality Tinsley mirrors, fabricated and tested with methods discovered during the ATP project, are a key component of the EUV approach to new generations of lithography equipment.

the optics work from the ATP project and related technology developed at the national laboratories. The three chip makers intend to invest about $\$ 250$ million over three years in the collaboration to determine whether the technology is commercially viable and, if it is, to pursue commercialization via lithography equipment manufacturers.

It is too early to tell whether the EUV or one of the other approaches to lithography will ultimately win in the marketplace. But it is clear that the ATP project has helped the industry understand the technical barriers to one major candidate technology and how to overcome them. The ATP project results are important to this effort because the kind of aspheric mirrors that Tinsley learned to make under contract to Lucent will be a critical component of the EUV lithography equipment.

The researchers presented or published more than two dozen papers about precision metrology, aspheric mirror fabrication, and lithography systems development.

\section{ATP-Project Benefits Could Be Huge}

Benefits have already started accruing to Tinsley, which produced the best aspheric mirrors, and to its customers who use the mirrors. Tinsley attributes much of its recent success to the ATP project, because the company was able to apply the improved manufacturing processes - developed to supply aspheric optics for the project - to all its products. Tinsley's sales have approximately doubled since the ATP project. Furthermore, in just 27 months the value of Tinsley's stock increased 600 percent, indicating the value the market places on the company's enhanced capabilities. Tropel and its customers are also continuing to reap benefits from the interferometer.

If EUV lithography equipment incorporating the new aspheric mirror technology becomes the technology of choice for the next generation of chip-making equipment, the benefits of the ATP project would be far broader. The new technology would have a huge economic impact on the semiconductor industry and generate spillover benefits to companies that use the improved computer chips in a wide variety of products, as well as to consumers who use these products. Even if another lithography approach becomes the technology of choice, benefits to companies like Tinsley and Tropel and to their customers will continue to accrue.

\section{. . . in just 27 months the value of}

Tinsley's stock increased 600 percent, indicating the value the market places on

the company's enhanced capabilities.

This project illustrates the important fact that a lack of immediate commercialization after an ATP project ends does not mean that the new technology will not eventually be commercialized and yield large benefits.

Information gathered in this project helped Lucent better understand the technical issues related to EUV lithography. Publication of numerous technical papers resulting from the project has advanced the state of the art for everyone in this technical community. And although Lucent later decided to pursue an alternative lithography approach, other companies have incorporated the ATPfunded technology into research and development work that could lead to systems that are commercialized in the future. 



\section{Joining Several Chips Into One Complex Integrated Circuit}

In the race to boost the performance and decrease the size of the integrated circuits (ICs) used in computers, one limitation gets a lot of notice: the two-dimensional (2D) nature of ICs. An IC, or chip, is flat. Its operating speed depends greatly on the length of the wires interconnecting its tiny components. Chip designers spend enormous resources to make the longest wire as short as possible and to reduce component size so they can be placed closer together. But as long as chips are $2 D$ devices, wire length constrains how fast they can operate.

COMPOSITE PERFORMANCE SCORE (Based on a four star rating.)

\section{New Capabilities From Interconnected Chips}

On a seemingly unrelated front, the need frequently arises for large electronic displays - in hospital operating rooms, military command centers, industrial applications, and even sports bars. Sometimes the display must also be flat. For home use, a display that mounts flat on the wall like a picture is ideal and is much sought after by technology leaders. Large CRT (cathode-ray tube) displays are available. But a 35 -inch CRT display may be 30 inches deep and weigh 150 pounds. Flat-panel displays, like those in notebook computers, are also widely available. But they are typically small, since the display usually has just one panel consisting of a single, broad, light-emitting IC.

\section{. . raised $\$ 26.6$ million from a second public stock offering in March 1993 . . .}

Attempts to greatly increase the scale of single-IC fabrication have been accompanied by commercially unacceptable levels of defects. Interconnecting several chips introduces other problems.

\section{One Technology for Two Major Needs}

The Multi-Film Venture (MFV) - a partnership between MCC and Kopin Corporation (a small company spun off in 1984 from Lincoln Laboratory at the Massachusetts Institute of Technology) - used ATP funding to speed up by two years the development of technology to address the needs for larger flat-panel displays and for shorter IC component connectors. The new technology can be used to join several broad light-emitting ICs into a single large display with no visible seam. It can also be used to join small ICs, stacked like a deck of cards, so that wire lengths can be shortened. ATP funding made this joint venture possible, and the project's success attracted further research and development funding from outside sources.

The new technology is based on ATP-funded development of advanced methods for positioning IC components with micron-scale alignment and for connecting individual ICs, as well as new adhesive procedures for bonding chips together. It is also based on proven IC fabrication methods and proprietary thin-film transfer technology previously developed by Kopin. MCC contributed its expertise in adhesives, bonding, and positioning.

During the ATP project, MFV researchers proved the feasibility of transferring thin-film, single-crystal silicon ICs to a substrate and interconnecting them to form a functioning multifilm module (MFM). They designed, built, and successfully demonstrated a large-area, flatpanel display to show seamless joining of several panels (single, broad, light-emitting ICs) arranged side by side like floor tiles, to form the display.

\section{Giant Flat Screens and 3D Microprocessors}

The earliest commercial use of the new MFM technology is likely to be in military, medical, and industrial flat-panel displays and large high-resolution displays. The tiled displays would replace conventional CRT displays. When cost considerations make it profitable, they would replace 


\section{PROJECT:}

To show the feasibility of interconnecting thin-film integrated circuits (ICs), packed side by side or in layers, to form a complex, multifilm module (MFM), and to demonstrate this technology in a large flat-panel display. Duration: 9/15/1992 - 9/15/1995

ATP Number: 91-01-0262

\begin{tabular}{|c|c|c|}
\hline \multicolumn{3}{|c|}{ FUNDING (in thousands): } \\
\hline ATP & $\$ 2,776$ & $48 \%$ \\
\hline Company & 2,973 & $52 \%$ \\
\hline Total & $\$ 5,749$ & \\
\hline
\end{tabular}

\section{ACCOMPLISHMENTS:}

MFV developed the MFM technology and demonstrated it in a large, flat-panel display. In actions related to the project, Kopin:

received two patents for project-related technology: "Single Crystal Silicon Tiles for Liquid Crystal Display Panels Including Light Shielding Layers" (No. 5,377,031: filed 8/18/1993, granted 12/27/1994),

"Method for Forming Three-Dimensional Processor Using Transferred Thin-Film Circuits" (No. 5,656,548: filed 9/19/1995, granted 8/12/1997);

raised $\$ 8.1$ million from private sources during the ATP project; raised \$26.6 million from a second public stock offering in March 1993; received (with Northeastern University) $\$ 2$ million from the Office of Naval Research in June 1996 for R\&D work, based directly on the ATPfunded MFM technology, to design and fabricate a 3D microprocessor;

received (with Northeastern and Polaroid) $\$ 5$ million from the Defense Advanced Research Projects Agency in June 1996 for R\&D work using the ATP-funded MFM technology — on 3D computational image sensors for compact low-power video cameras;

large single-panel displays based on relatively expensive technologies such as liquid crystal display. The new technology also has potential applications in desktop computer

... researchers proved the feasibility of transferring thin-film, single-crystal silicon ICs to a substrate and interconnecting them to form a functioning multifilm module... .

displays and - with volume production and lower prices — in wall displays for the home. In addition, the ATP technology should be competitive for very high resolution screens, those with resolutions of 2,000 by 2,000 pixels per inch up to 10,000 by 10,000 pixels. raised $\$ 31.8$ million via private equity investments since the end of the ATP project.

\section{CITATIONS BY OTHERS OF PROJECT'S PATENTS:}

See Figure 1.6, Chapter 1, and Figure 4.9.

\section{COMMERCIALIZATION STATUS:}

Commercialization is expected within one or two years for products incorporating the 3D microprocessor technology. Large-area flat-panel displays based on the MFM technology are expected to be commercialized when their market develops.

\section{OUTLOOK:}

The outlook is very promising. Products based on the ATP-funded technology are being developed by Kopin and are expected to be introduced to the market soon.

\section{Composite Performance Score: $\star \star \star$ \\ COMPANIES:}

Multi-Film Venture

(MFV; formerly the American Scaled-Electronics Consortium)

Kopin Corporation (joint venture lead)

695 Myles Standish Blvd.

Taunton, MA 02780

Contact: Ollie Woodard

Phone: (508) 870-5959

Number of employees: 70 at project start, 100 at the end of 1997 Other joint venture participant: MCG, Inc. (formerly Microelectronics \& Computer Technology Corporation)

The MFM process is expected to be useful for making devices with directly joined layers of ICs that perform different functions. In one application, Kopin is collaborating with Northeastern University (using $\$ 2$ million from the Office of Naval Research) to design, fabricate, and demonstrate a three-dimensional (3D) microprocessor.

In a second application, Kopin is working with Northeastern and Polaroid in a five-year project, begun in June 1996, to develop a 3D computational image sensor for compact low-power video cameras. The sensor will be a stack of three chips: a sensor IC, a computation IC, and a read-out $\mathrm{IC}$. The chips will be connected using the ATP-funded MFM technology. This project is supportedby $\$ 5$ million from the Defense Advanced Research Projects Agency.

\section{Kopin Succeeds in Capital Markets}

Although products incorporating the ATP-funded technology are not yet on the market, they are likely to arrive 
Figure 4.9 Patent Tree for Project Led by Multi-Film Venture: Citations by Others of Multi-Film Venture Patents ${ }^{1}$

PATENT TREE KEY

OrIglnal Patent

Second Generation Patent

Third Generation Patent

Fourth Generation Patent

Fifth Generation Patent
1999

1998

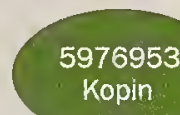

5972780
... potential applications in desktop

computer displays and - with volume

production and lower prices - in wall

displays for the home.

soon. Kopin has shown that it can carry out commercialization plans, as evidenced by its introduction of other products after more than a decade of work on the underlying technology. Also, Kopin's success at raising funds in the private-capital market reflects investor confidence in the company's ability to commercialize its technology. Kopin has raised an additional $\$ 31.8$ million via private equity investments since the end of the A'TP project.

When the new products - flat-panel displays and 3D microprocessors - are introduced, intermediate companies (which purchase components produced by Kopin), final-product manufacturers, and consumers are expected to reap large benefits from the ATP-funded technology.
${ }^{1}$ Also see the patent tree for a different patent from the same project shown in Figure 1.6, Chapter 1. 

NATIONAL CENTER FOR MANUFACTURING SCIENCES (NCMS)

\section{A Collaborative Effort to Address Advanced Technology Needs of the U.S. Printed Wiring Board Industry}

$P$ the platform on which to mount integrated circuit chips, capacitors, and connectors for the manufacture of everyday products ranging from toys, toasters, copy machines, and pagers to computers. Circuit patterns in copper or another conductor are etched on the surface of an insulating material to make connections among components typically mounted on the fiberglass board. And because they are a component to any larger electronics assembly, PWBs are an essential component of many other U.S. technologies.

COMPOSITE PERFORMANCE SCORE (Based on a four star rating.)

\section{U.S. Producers Loosing in Global Competition}

Between 1984 and 1990, the U.S. world share in the manufacture of printed wiring boards declined significantly, from 42 percent to 26 percent, with lost market share captured by lower-cost foreign competitors using increasingly sophisticated technology. In 1991, the profile of the U.S. PWB industry was one of many small firms with little market power or research capability: 725 firms produced PWBs, but most had annual sales of less than $\$ 5$ million in specific niche markets. These small firms lacked the

\section{...the profile of the U.S. PWB industry was one of many small firms with little market power or research capability...}

resources to undertake $R \& D$ on a scale that would achieve technology breakthroughs, and could only support R\&D that addressed particular and immediate product development goals. Meanwhile, users of PBWs were forecasting that in the near future they would have to procure an increasing share of PWBs from foreign producers whose technical advances were outstripping those of U.S. producers.

\section{ATP Supports Collaborative R\&D Initiative for "Leapfrog" Technical Advances}

A few leading equipment suppliers with advanced research capabilities, concerned with the decline of the U.S. domestic PWB industry, coalesced to form a research

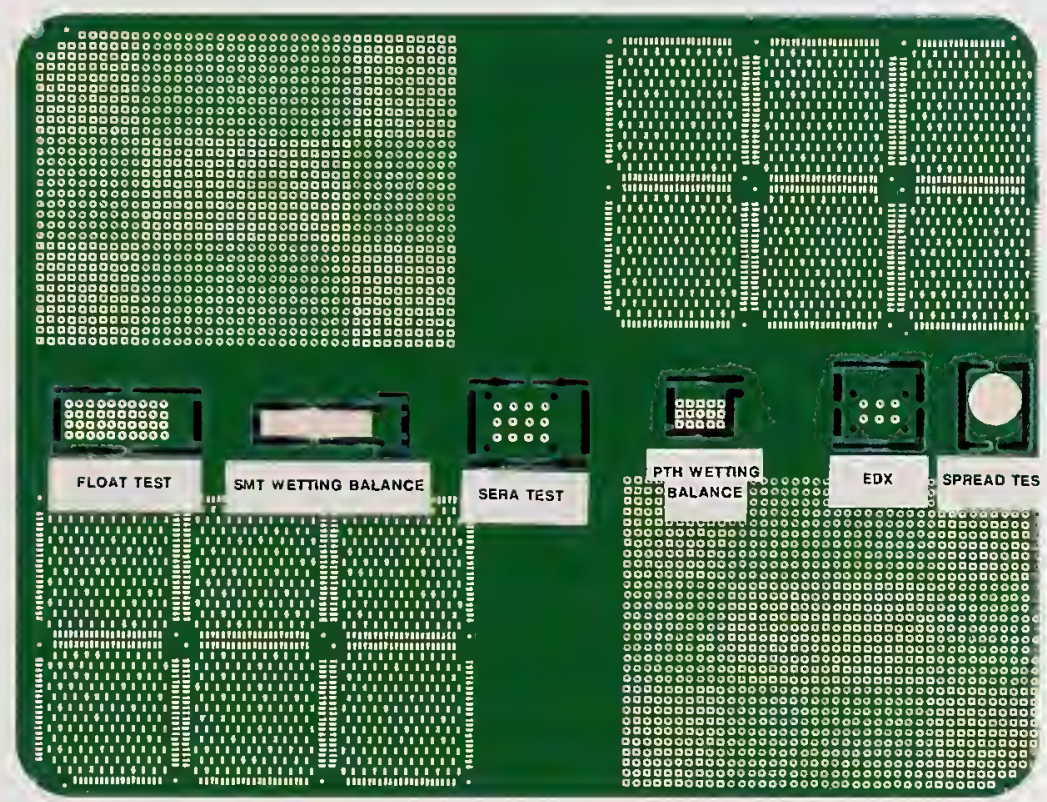

A printed wiring board test vehicle used by the surfaces finishes team, with different solderability test method coupons labeled.

joint venture to address the technology gap faced by domestic PWB producers. These equipment producers, all major consumers of PWBs, utilized their membership in the National Center for Manufacturing Sciences, a nonprofit organization that specializes in brokering collaborative $R \& D$ projects, to organize the joint venture. The NCMS helped to organize the collaborative project among four of its member companies.

The joint venture, comprised of the four major companies, with NCMS as the coordinator, applied in the ATP's 1990 General Competition for a five-year project. The initial participants were AT\&T, Digital Equipment Corporation (DEG), Hamilton Standard Interconnect 


\section{PROJECT HIGHLIGHTS}

\section{PROJECT:}

To develop advanced processes and procedures for making printed wiring boards (PIVBs), the backbone of all U.S. electronics products, that would leapfrog existing domestic and foreign technologies, thereby re-energizing the U.S. PIVB industry in the face of severe international competition. The goal was to assist U.S. suppliers of printed wiring boards to become able to supply the boards of the future, through advances in materials, surface finishing, imaging, and overall product design.

Duration: $4 / 15 / 91-4 / 14 / 96$

ATP Number: 90-01-0154

$\begin{array}{lll}\text { FUNDING (in thousands): } \\ \text { ATP } & \$ 12,866 & 48 \% \\ \text { Company } & \underline{13,771} & 52 \% \\ \text { Total } & \$ 26,637 & \end{array}$

\section{ACCOMPLISHMENTS:}

The project teams undertook many tasks in four technical areas and made a number of significant accomplishments. Accomplishments achieved by the team or following from those achievements include:

demonstration that single-ply fiberglass could be produced with a sufficiently regular surface to allow for reliable electrical performance at a substantial cost savings, such that it has become the industry standard and the military has adopted it as a reliable product;

broader applications for an imidazole treatment for copper that improves on the use of soldering as a way of preventing oxidation of copper surfaces, to which component leads must be connected;

a test procedure for evaluating the process for producing PWBs, which allowed users of PIVBs to conduct quality tests on sample boards, thus enabling them to evaluate the production methods used by PWB suppliers;

demonstration of the effectiveness of thin copper plating in adhering to fiberglass in order to reduce the amount of copper used (saving resources) and lessening processing time (increasing productivity);

a new interconnect structure-Multilayer Organic Interconnect Technology (MOIT) that may revolutionize the fabrication of PWBs, by achieving much higher wiring density than does current PWB technology;

a plasma monitoring device which was, in turn, furthered by Sandia through a Sematech project, and eventually commercialized by a spin-off company-Peak Sensor Systems - formed by Sandia scientists;

- commercialization of single-ply glass technology by a leading supplier of glass laminate to PIVB producers;

commercialization of thin copper by Polyclad, a leading supplier of copper plating to PWB producers;

further development of imidazole treatment for conducting surfaces (earlier patented), and licensing of it to LeaRonal, Inc., which supplies the treatment to PIVB producers;

- formation of a new company, Conductor Analysis Technologies, Inc. (CAT), to commercialize the testing procedure developed by the imaging team and used by equipment manufacturers to verify that PWB shops have the technical capabilities necessary to build new high tech designs

214 papers presented on the project;

two best-paper awards at industry conferences;

a patent on conductor analysis technology filed and received by NCMS, which then licensed the technology to a start-up company: "System and Method for Analyzing Conductor Formation Processes" (No. 5,659,483)

a patent for prepeg bonding copper filed by NCMS but not yet received;

development of novel PWB applications for block copolymer adhesion promoters, which facilitate lower copper profiles and thinner materials, by Sandia scientists working on the project, and a patent for a solder delivery method filed but not yet received by Sandia scientists; ${ }^{2}$ and

a patent for the test method developed to quantify capillary flow solderability was filed and received by Sandia National Laboratories "Solderability Test System" (No. 5,827,951).
CITATIONS BY OTHERS OF PROJECT'S PATENTS: See Figure 4.10. COMMERCIALIZATION STATUS:

The different joint venture participants and their licensees have been able to successfully commercialize component technologies arising from this project. A leading supplier of glass laminate to PWB producers brought the single-ply fiberglass technology to market. Polyclad, a supplier of copper plating to PWB producers, has been able to commercialize thin copper. Joint venture member AT\&T licensed the imidazole treatment that was developed earlier, but demonstrated for PIVB applications in the project, to LeaRonal, Inc., which now supplies the treatment to PIVB producers under the brand name Ronacoat OSP. It is used in large volume by leading board manufacturers such as Omni-Circuirs, Inc., in Chicago, Illinois, and Pacific Circuits, Inc. (now part of TTM Technologies, Inc.) in Redmond, Washington.

Conductor Analysis Technologies, Inc. (CAT), the company created as a spin-off of research conducted by the imaging team, offers to leading equipment producers, such as Motorola and Hewlett Packard, rapid, reliable tests of sample boards. The testing services offered by CAT allow the equipment producers to evaluate the capabilities of PWB suppliers, thereby decreasing the amount of time and money spent moving new PWB designs into production. Faster market entry in turn translates into cheaper and better products for consumers of electronics.

\section{OUTLOOK:}

The adoption of project-related technical advances coincided in a turnaround in the performance of the U.S. PWB industry. According to the IPC's 1999 Report on the World Market for Printed Wiring Boards and Substrate Materials, world production of PWBs in 1998 posted a record high of $\$ 34.3$ billion, up from $\$ 32.5$ billion in 1997. Growth in the U.S. share of global PWB production has become positive, where it had been negative a decade ago. Recent IPC figures show that U.S. growth in the PIVB industry is expected to be about 3.8 percent in 1999, and worldwide growth about 6.6 percent. ${ }^{1}$ The outlook appears much brighter now for the U.S. PIVB industry than it did at the beginning of the project. With further dissemination of the technology developed in the project, further strengthening is expected.

The outlook for technologies developed under this project are manifold: some of the component technologies have already been absorbed and surpassed in an industry where any development is a moving target, or have become building blocks to further developments and sparked further research. Others, such as the single ply laminates, have become the standard for the industry. Some products based on the ATP funded technologies are available commercially, i.e., Ronacoat OSP and the CAT testing service. Some of the component technologies have yet to be fully explored, or are still being pursued independently by former project participants. Many benefits from this project have been and are being realized, and future benefits are expected.

\section{Composite Performance Score: $\star \star \star \star \star$ COMPANIES:}

National Center for Manufacturing Science (joint venture lead) Ann Arbor, MI

Contact: Edward Miller

Phone: (734) 995-0300

Joint Venture Participants: AT\&T, Digital Equipment Corporation, Hamilton Standard Interconnect Systems, Inc., Texas Instruments, Sandia National Laboratories, Allied Signal, Hughes Electronics, and IBM. 
Systems, Inc. (a division of United Technologies, Inc.), and Texas Instruments. Sandia National Laboratories joined the project shortly after it was formed.

ATP awarded the project $\$ 13.8$ million. Industry participants matched A'TP's funding with $\$ 14.7$ million, with a total project budget of $\$ 28.5$ million. Based on the proposal submitted by NCMS, ATP awarded NCMS $\$ 13.8$ million toward the five-year project, scheduled to break ground in April 1991. Industry participants matched ATP's funding with $\$ 14.7$ million, with a total project budget of $\$ 28.5$ million. During the project, Sandia, funded by the Department of Energy, contributed an additional $\$ 5.2$ million to the project.

Over the life of the project, membership in the joint venture changed. Eighteen months into the project, DEC decided to withdraw. During the next three years, Allied Signal, Hughes Electronics, and IBM joined, fulfilling the research agenda originally assigned to DEC.

\section{This largely horizontally structured joint} venture appears to have been unusually successful in achieving active collaboration among participants, substantive teaming to carry out major project tasks, and extensive sharing of information.

\section{Successful Collaboration in a Horizontally Structured Joint Venture}

Studies have shown that horizontally structured joint ventures of direct competitors may experience difficulties in establishing trust and sharing information. ${ }^{3}$ And most of the participating companies produced PWBs. This largely horizontally structured joint venture, however, appears to have been unusually successful in achieving active collaboration among participants, substantive teaming to carry out major project tasks, and extensive sharing of information. There are several factors that seem to have contributed to its collaborative success.
One factor is that the companies, though producers of PWBs, were also consumers of PWBs and rarely direct competitors with each other. They utilized PWBs for significantly different products.

Another factor that appears to have contributed to the successful collaboration is the administrative and management arrangement. The NCMS, as project coordinator, handled the administrative tasks, including accounting, contract details, and legal and intellectual property issues. A steering committee, staffed by technical personnel from each joint venture participant, managed the technical aspects of the project.

\section{Project Goals}

The NCMS project sought progress in PWB technology and manufacturing in four areas: materials, soldering, imaging, and chemical processes. Research teams staffed by technical personnel from each joint venture participant - were formed for each area.

Although there are two types of PWBs, rigid and flexible, rigid PWBs account for approximately 90 percent of global PWB production. Rigid PWBs are constructed from a fiberglass base, made by taking woven fibers of glass, filling the weave with epoxy resin, and applying pressure to form the sheets that harden and become rigid. The materials team focused on the construction of rigid PWBs, usually made from sheets of double-ply fiberglass, in turn made from two layers of woven glass. The materials team sought to develop cost-saving, single-ply boards. They had to overcome a commonplace obstacle presented by singleply sheets: these tended to have surface irregularities that led surface metal circuits to meet and short out when the surface warped under heat or pressure. Thus, the materials team had to deliver a regular surface on a single-ply, rigid PWB.

Industry recognition of the successful research efforts of this project includes best paper awards to two of the many research papers that came out of the project.

\footnotetext{
${ }^{1}$ The Sandia scientists received a patent for the concurrent technology supported by internal Sandia funding — "Block Copolymer Adhesion Promoters via Ring-Opening metathesis Polymerization," patent number 5,603,985.

2IPC, "Management Briefing on the Global Outlook for 1999," available by request from the IPC director of market research via e-mail <CarlaWehrspann@ipc.org>.

${ }^{3}$ See, for example, Jeffrey Dyer and Benjamin Powell, Determinants of Success in ATP-Sponsored ReD Joint Ventures, NIST Contractor Report (December 2001).
} 
The components on a PWB are connected by soldering component leads to the surface of the PWB. Soldering defects are a significant problem in the production of printed wiring assemblies, basically PWBs that are populated with components, such as integrated circuits. The soldering team aimed to develop ways to automate testing, to reduce the number of defects by identifying and using different materials in the soldering process, and to produce alternative surface finishes. The testing and repair of soldering defects provided an area of potential cost saving: most testing heretofore was performed manually.

The soldering team also sought to develop an alternative to solder to prevent the oxidation of copper surfaces on PWBs in storage. Oxidation of the copper on the stored boards renders the contacts-the copper surfaces to which component leads are attached-unsolderable. In the past, contact surfaces have been preserved by solder. The use of solder, however, is messy and imprecise and limits the application of PWBs in circuit designs requiring increasingly fine connections. The goal of the soldering team was to develop a surface finish that would prevent oxidation, but at the same time would leave the copper surface free of obstacles to the etching of fine circuit patterns.

The imaging team sought to investigate and stretch the bounds of the imaging process to improve resolution, conductor yield, and dimensional regularity. It aimed to improve the projection of patterns along which circuits are placed to reduce the number of defects on boards.

The fourth team, originally known as the chemical processes team, later the product team, sought to advance the understanding of the chemical processes involved in producing the copper plating used in the PWBs to interconnect the components. The chemical processes team aimed to develop a thinner copper plating that would adhere to the PWB fiberglass base. This approach was seen as a way to save money by using less copper and reduce processing time. In cooperation with Polyclad, a copper plating supplier, they tested the performance of thinner copper plating. When the chemical processes team ran into difficulty securing financial support from joint venture participants for other copper research not considered high priority, the joint venture steering committee formed another team. The new product team had the more general goal of developing high-density interconnect structures, considered a high priority goal. In making this change, NCMS worked with A'TP to redefine the research effort.

\section{Research Achievements}

The efforts of the various teams paid off. The materials team achieved the noteworthy goal of developing and demonstrating the feasibility of single-ply fiberglass for

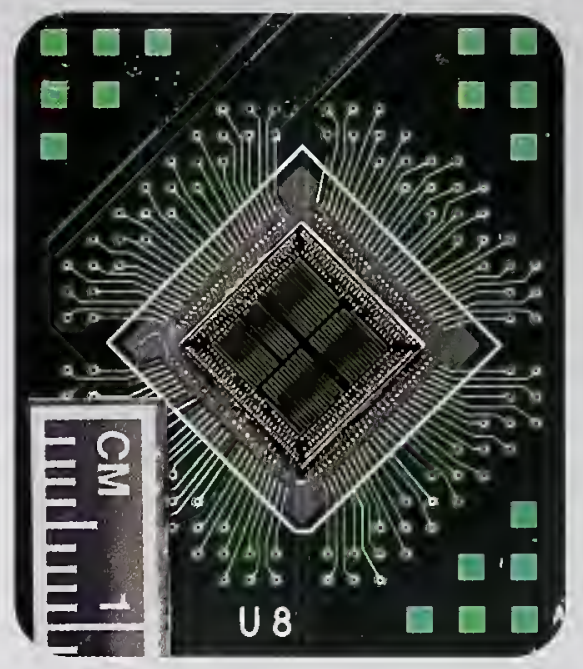

A close-up of an individual chip attached to a printed wiring board. use in PWBs. They demonstrated that it could be produced with a sufficiently regular surface to allow for reliable electrical performance at a substantial cost savings. It has become the industry standard and the military has adopted it as a reliable product.

The materials team also developed a plasma-monitoring tool, which has a large potential for cost avoidance. Originally developed to monitor printed circuit boards, Sandia National Laboratories, in the post-project period, extended the application from PWBs to detect defects in microchips. If a defect in microchip manufacturing goes unnoticed after the wafer has undergone multiple processes - for instance, if circuits are etched to the wrong depth it can translate into millions of dollars in expenses or lost sales after the ATP project was over, as part of a Sematech project. The effort resulted in a spin-off company formed by Sandia scientists, Peak Sensor Systems, which has filed 19 patents for related technologies, and has had 3 granted. Now in its third year, the company has three models of the Peak Propak plasma-monitoring device, and has achieved $\$ 1$ million in sales. The research path is sketched out past the ATP project, in this case, to illustrate the complementarities that often exist across research efforts.

The materials team also developed PWB applications for a block copolymer that facilitates lower copper profiles and thinner materials. Scientists from Sandia, concurrent with the A'TP project, developed a block copolymer technology under internal Sandia funding, which they were able to patent. The Sandia scientists as part of the materials team developed PWB applications for the block copolymer technology. Sandia also has a patent pending for prepeg bonding copper.

The soldering team successfully developed better methods of testing solder and produced a surface finish that adequately protects the board in multiple soldering applications. The team also explored applications of the imidazole solution-originally developed by Bell $\mathrm{Labs}^{4}-$ to prevent oxidation of copper surfaces in a solder-free manner, and to demonstrate its applicability for a wide 
range of uses. Joint venture participant AT\&T subsequently licensed the technology to LeaRonal, Inc., which commercialized the treatment under the brand name Ronacoat OSP. The company describes its product as a "production-proven, low-cost, environmentally benign alternative" to substitute products."

The imaging team was able to achieve PWB production process improvements. The imaging team developed methods to increase the yield of PWBs without flaws, and in fact, the yield on 3-mil board increased from 30 to 50 percent, and the yield for 2 mil boards from 10 to 50 percent. Another way the imaging team improved quality control was to introduce a test procedure for evaluating the underlying process used to produce PWBs, based on the analysis of a sample board. This development stimulated the creation of a spin-off company-Conductor Analysis Technologies. The company sells this testing service to equipment manufacturers and PWB shops.

The imaging team was also successful in demonstrating the feasibility of a new photolithography tool called Magnified Image Projection Printing. This tool has the potential to provide a contact-free way of printing PWBs, which could in turn eliminate problems caused by the current imaging-etching process. If successful, this technique could significantly improve manufacturing of the boards by allowing for finer, more tightly interconnected lines as little as three mils apart. The NCMS decided to pursue the development of the prototype tool as a separate project, without ATP support, and the final report of this research effort is now available from NCMS. ${ }^{6}$

Before it was regrouped as the product team, the chemical processes team developed thinner copper plating and tested its performance in cooperation with Polyclad. The chemical processes team was able to demonstrate the effectiveness of thin copper plating in adhering to fiberglass. The approach saves money because it uses less copper. It also reduces processing time, because less copper has to be etched away to make connections on the board.

Research efforts by the product team on high-density interconnect structures produced a novel interconnect structure-the Multilayer Organic Interconnect
'Technology (MOI'T) - that has the potential to revolutionize the fabrication of PWBs. By radically increasing the number of connections to and from a device on the board by taking advantage of making connections from the bottom of the board, in addition to the standard surface connections, the MOIT offers the possibility of achieving much higher wiring density than current PWB technology. IBM Endicott is pursuing MOIT.

\section{Public Recognition}

Industry recognition of the successful research efforts of this project includes best paper awards to two of the many research papers that came out of the project. One of these awards was presented at the fall 1994 meeting of the Institute for Interconnecting and Packaging Electronic Circuits ( $\left.\mathrm{IPC}^{7}\right) .{ }^{8}$

The president of NCMS, John DeCaire, also bestowed public praise on the project at a press conference in 1997. He stated that the ATP project had "quite literally saved the [then] $\$ 7$ billion U.S. PWB industrya key segment of the $\$ 20$ billion domestic electronic interconnection industry that employs over 200,000 people."

\section{Technology Diffusion and Industry Impacts}

The NCMS project achieved significant technical successes in each of the four areas targeted by the joint venture participants. Three of the efforts-single-ply boards, thin copper plating, and conductor analysis technology-delivered commercial advantages to the PWB industry and

\section{The president of NCMS, stated that the ATP project had "quite literally saved the [then] \\ $\$ 7$ billion U.S. PWB industry-a key seg- ment of the $\$ 20$ billion domestic electronic interconnection industry that employs over 200,000 people."}

\footnotetext{
${ }^{4}$ Bell Labs patented the formula in 1983 , patent number 4373656 , and AT\&T licensed the technology to LeaRonal, Inc. Viasystems is the successor owner of the patent.

${ }^{5}$ See LeaRonal's, website at <www.learonal.com $>$ for a listing of products and their applications.

${ }^{6}$ See the NCMS website at <www.ncms.org > for a description of the report, Magnified Image Projection Printing Project Final Report. The MIPP project was dissolved prior to the completion of the illumination system design and building of the prototype due to the withdrawal of the system integrator, and no viable commercial integrator showed interest in participating in the project. The intent of the report is to preserve the knowledge generated during the project if any future efforts are undertaken.
}

${ }^{7}$ IPC is a U.S. based trade association of nearly 2,500 member companies representing all facets of the electronic interconnection industry, including design, PWB manufacturing, and electronics assembly. 
economic benefits to the equipment manufacturers who are their customers.

The project's successes and the acclaim received have furthered PWB technology diffusion within the industry. Technology diffusion among industry suppliers was aided by the decision of project leaders to include suppliers to the PWB industry in the process of developing the technologies. In fact, over the life of the project, almost every team meeting involved working with suppliers across various industries such as glass manufacturers, weavers, laminators, resin manufacturers, equipment manufacturers, printers, and chemical suppliers.

\section{... almost every team meeting involved working} with suppliers across various industries such as glass manufacturers, weavers, laminators, resin manufacturers, equipment manufacturers, printers, and chemical suppliers.

Producers of PWBs report gains from project related advances that have been implemented into production. For example, 85 percent of the PWBs used by AT\&T now incorporate single-ply technology, and this conversion to single-ply technology has saved AT\&T at least $\$ 3$ million per year. Another company reported a 50 percent decrease in solder defects, due to the soldering process improvements developed during the ATP project. ${ }^{10}$

The ATP catalyzed a small group of companies with advanced research capabilities to undertake a wide-reaching project that would benefit the entire industry. The resulting NCMS-coordinated project conducted a research effort that would otherwise not have been pursued by the individual equipment manufacturers and PWB producers without the ATP, or only at a slower pace and in a far more costly way. The project encouraged the research teams to pursue two technologies-single-ply boards and thin copper plating-that challenged conventional wisdom, which held that these options were unfeasible.

An independent study undertaken on behalf of the ATP concluded that the ATP's presence supported and sustained research outcomes. The study's survey of joint venture participants found that "of the 62 research tasks completed by the PWB joint venture, about one-half would not have been undertaken at all in the absence of ATP funding, and the remaining one-half would have been delayed by at least one year without the ATP, in an industry where timing is critical." "In addition, the study found that by collaborating on the research, the companies

\section{...a 50 percent decrease in solder defects}

saved an estimated $\$ 35.5$ million on those tasks they would have undertaken anyway, although at a slower pace. Savings resulted mainly from the labor efficiencies achieved and the duplicative test equipment avoided. (The study did not assess in a systematic way the benefits from the part of the research that would not have been done at all without the ATP.)

\section{Figure 4.10 Patent Tree for Project Led by NCMS: Citations by Others of NCMS Patents}
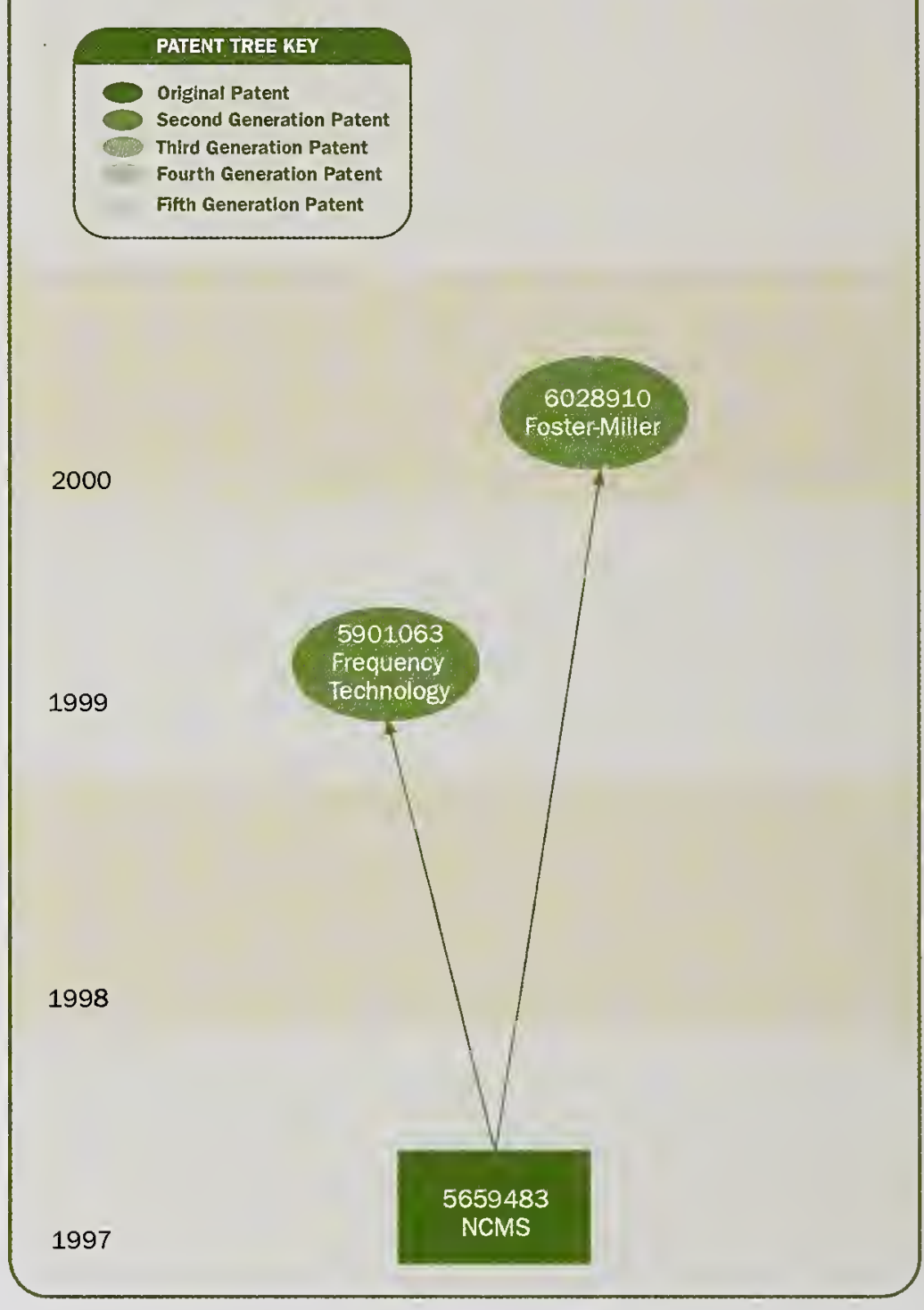

\footnotetext{
${ }^{8}$ Albert Link, Farly Stage Imparts of the Printed Wiring Board Research Joint Venture, Assessed at Project End (1997), p. 28.
}

${ }^{9}$ May 13, 1997, NCMS News Release, "Landmark Collaborative Research Program Credited with Saving Domestic Printed Wiring Board Industry."

${ }^{10}$ Link, Early Stage Impacts p. 26.

${ }^{11}$ Link, Early Stage Impacts, p. iv. 


\section{NET OPTIX CORP. \\ (formerly Galileo Corporation) \\ Low-Cost Night-Vision Technology}

bjects around us emit or reflect electromagnetic radiation, some of it in the form of visible light that we can see. None of us sees well when the light is poor, whether at night, in fog, or under other circumstances of darkness.

COMPOSITE PERFORMANCE SCORE

(Based on a four star rating.)

No Stars

\section{Seeing in the Dark}

If a way could be found to magnify the unseen emissions that remain even in darkness, by passing them through special glasses, then we could see things even when the light is too dim to sense objects with the naked eye.

\section{... a much less expensive process to} make devices widely available to law enforcement officials and the estimated 400,000 Americans suffering from retinitis pigmentosa...

Such glasses already exist. They were developed for military use and are quite expensive. High-performance night-vision devices typically cost more than $\$ 1,000-$ too much for general consumer use.

This ATP project with Galileo Corporation, founded in the middle 1970s to develop microchannel plates (MCPs), aimed to develop a much less expensive process technology that would make night-vision devices widely available to, for example, law enforcement officials and the estimated 400,000 Americans suffering from retinitis pigmentosa (night blindness). Another potential use of the technology is in detector components for highly miniaturized analytical instruments. Funding from the ATP enabled Galileo to perform research to develop the new fabrication processes and higher performance prototype MCPs that it would otherwise have been unable to do and helped the company form alliances with research partners and contractors.

\section{New Electron Multipliers}

The ATP project involved the development of new kinds of electron multiplier devices based on the same kind of manufacturing technology used in semiconductor fabrication. An MCP is a flat, usually disc-shaped array of closely packed microscopic tubes that act as tiny amplifiers.

Electrons, photons, or ions entering one side of the plate trigger a cascade of thousands of electrons out the other side. MCPs form the heart of image intensifiers used in night-vision and scientific devices and electronic imaging systems. MCPs are currently made using glass-working techniques developed for producing fiberoptic bundles. The process has been improved greatly over the years but has reached its limits in terms of further cost reductions and performance improvements.

Galileo's ATP project abandoned the glass-fiberoptic production approach to MCPs and instead used the photolithography, dry-etch, wet-etch, and thin-film deposition technologies developed by the semiconductor industry to develop improved MCPs. The company succeeded in the technical goals of the project, developing new fabrication procedures and using them to demonstrate prototypes of working, high performance electron-multiplier devices. 


\section{PROJECT HIGHLIGHTS}

\section{PROJECT:}

To develop fundamentally new, lower-cost fabrication processes for and prototypes of higher quality microchannel plates (MCPs) - which form the heart of image intensifiers used in night vision - to enable wider use of the technology, including applications for the estimated 400,000 Americans suffering from retinitis pigmentosa (night blindness).

Duration: $4 / 1 / 1993$ - 5/31/1995

ATP Number: 92-01-0124

FUNDING (in thousands):

ATP $\$ 1,910 \quad 57 \%$

Company $\quad 1,428 \quad 43 \%$

Total $\$ 3,338$

\section{ACCOMPLISHMENTS:}

Galileo developed new processes for fabricating MCPs and other types of electron multipliers, using techniques from semiconductor fabrication, and used the new processes to produce prototype MCPs. As evidence of these accomplishments, the company:

received four patents for ATP-related technology:

"Method for Fabrication of Discrete Dynode Electron Muitipliers" (No. 5,618,217: filed 7/25/1995, granted 4/8/1997),

"Method for Fabrication of Microchannel Electron Multipliers" (No. 5,569,355: filed 1/11/1995, granted 10/29/1996),

"Microfabricated Electron Multipliers"

(No. 5,568,013: Filed 7/29/1994, granted 10/22/1996) and

"Fabrication of a Microchannel Plate From a

Perforated Silicon Workpiece"

(No. 5,544,772: filed 7/25/1995, granted 8/13/1996);

published five technical papers, including one as a dissertation and four in professional journals;

produced working vacuum-electron multipliers by microfabrication methods; and

\section{Financial Distress}

During the last 6 months of its 26-month ATP project, Galileo encountered financial problems and decided to abandon its original goal of in-house commercialization of

\section{During the last six months of its 26} month ATP project, Galileo encountered dire financial problems and decided

$$
\begin{aligned}
& \text { to abandon its original goal of } \\
& \text { in-house commercialization . . . }
\end{aligned}
$$

the new process technologies for electron multipliers. The company has continued to produce MCPs using its earlier fabrication process and sell them. Even though feasibility developed thin-film techniques to produce dynode structures that support electron multiplication in MCPs and other channel electron multiplier devices.

\section{CITATIONS BY OTHERS OF PROJECT'S PATENTS: See Figure 4.11.}

\section{COMMERCIALIZATION STATUS:}

No products based on the ATP-funded technology have yet reached market.

\section{OUTLOOK:}

Prospects for commercialization of this technology are uncertain. Financial difficulties forced Galileo to abandon plans to directly commercialize the ATP technology. The company now is working with the Center for Advanced Fiberoptic Applications (CAFA), a nonprofit consortium charged with commercializing technologies developed by Galileo and other CAFA members. If CAFA can commercialize the ATP technology to benefit people suffering from night blindness, or if the technology is adopted for use in producing miniature scientific and analytical instruments, such as a mass spectrometer on a chip, the broad economic benefits could be very large.

\section{COMPANY:}

NetOptix Corporation (formerly Galileo Corporation)

Sturbridge Business Park

Sturbridge, MA 01566

\section{Composite Performance Score: No Stars}

\section{Contacts:}

Enrique Bernal G.

Galileo Corporation

Phone: (508) 347-4291

William Tasker

Center for Advanced Fiberoptic Applications

Phone: (508) 765-0180

Number of Employees: 314 at project start; 240 at the end of 1997

of the new approach was demonstrated by the A'TP project, Galileo officials reported that another $\$ 5$ million investment would have been needed to commercialize the advanced performance MCPs using the new process. They say they could not justify the investment for commercialization, given the company's financial difficulties and the length of time needed to build revenue streams.

\section{Commercialization Potential}

At the close of the project, the company entered into an agreement with the Center for Advanced Fiberoptic Applications (CAFA), a new nonprofit consortium charged with commercializing technologies developed by Galileo and other CAFA members, mainly small to medium sized optics companies in the mid-Massachusetts area. Galileo granted a nonexclusive royalty-free license of the ATPfunded technology to CAFA. The principal investigator on the ATP project left Galileo to become section head 
Figure 4.11 Patent Tree for Project Led by NetOptix: Citations by Others of

\section{NetOptix Patents}

\section{PATENT TREE KEY}

Original Patent

Second Generation Patent

Third Generation Patent

Fourth Generation Patent

Fifth Generation Patent for microelectromechanical systems in the CAFA consortium. In addition to licensing agreements, CAFA is pursuing partnerships with a number of companies as an avenue for commercializing the ATP-funded MCP technology, but the chances for commercialization are uncertain at this time.

\section{NetOptix granted a nonexclusive, royalty-free license of the ATP-funded technology to CAFA.}

In theory, it is expected that the technology will reduce the costs of MCP production and improve performance, but these effects have not yet been shown in practice. The prototype demonstration focused on the feasibility of the new process technology adapted from the semiconductor industry to produce MCPs and on improved MCP performance, rather than on their comparative costs. Laboratory tests and calculations suggested that production costs would be lower using the new technology, but no pilot project has yet been developed, so those predictions have not been confirmed. Demonstrated lower costs and improved performance would make it more feasible to pursue new market opportunities for applications to address night blindness.

\section{...CAFA is pursuing partnerships with a number of companies as an avenue for commercializing...}


NONVOLATILE ELECTRONICS, INC. (NVE)

\section{Computer RAM Chips That Hold Memory When Power Is Off}

lonventional random access memory (RAM) computer chips record information written or copied into them by a computer, and they hold that data as long as electricity flows through the chips. Once the power is turned off, the information is lost unless it has been saved to a floppy disk or to the computer's hard disk, which hold data even when the power is off. Many computer users have learned this fact only after a power outage or other mishap suddenly erases the data they were working on. Program manuals and technical support staff repeatedly advise computer users to save often.

COMPOSITE PERFORMANCE SCORE (Based on a four star rating.)

\section{RAM That Remembers Without Power}

If a memory chip could store data permanently, it would prevent these accidental loses of information. And if it could be produced in small sizes at competitive costs, the new chip would greatly affect how computers are configured and used. For example, an insertable card containing memory chips (which have no moving parts) could be substituted for a hard disk drive.

\section{Civilian Use of MRAM Technology}

This ATP project with Nonvolatile Electronics (NVE), founded in 1989 (and operated from the founder's house until the ATP award), aimed to develop such a memory

\section{GMR sensors have many applications ...}

chip. The founder co-invented "magnetoresistive" RAM (MRAM) technology for defense applications while at Honeywell, which subsequently licensed the technology to NVE for civilian uses. For these applications, the technology had to achieve greater density, signal strength, and production yield to meet cost considerations, which are more important in consumer markets than in the military market.

A metal is magnetoresistive if it shows a slight change in electrical resistance when placed in a magnetic field. In 1988, scientists discovered that a sandwich of metals shows a much larger change in resistance than a single

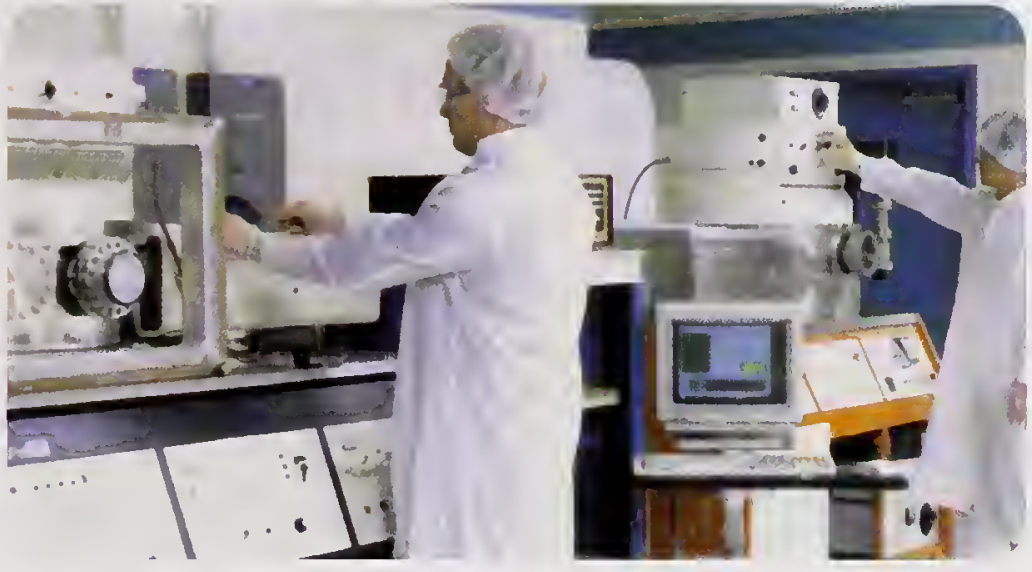

The clean room at Nonvolatile Electronics in which GMR sensors and other devices are fabricated.

metal of the same size. This effect was named "giant magnetoresistance," or GMR.

Researchers at NVE saw the use of GMR materials as a way to achieve advances in signal strength, and they made important advances in the producibility of GMR materials. They also achieved the project's circuit density goals and made substantial improvements to production throughput, or yield. These developments are all important for lowering barriers to commercializing the technology for civilian applications. 'The researchers made prototype high-quality MRAM cells that were successfully demonstrated at Honeywell.

\section{A Promising Spin-off Application}

As NVE focused on GMR materials advances, it saw a potential spin-off application that received only marginal attention when the company started its ATP project: GMR 


\section{PROJECT HIGHLIGHTS}

\section{PROJECT:}

To develop magnetoresistance technology for use in making computer random access memory (RAM) "nonvolatile" - data will not be lost when power is turned off.

Duration: 4/1/1991 - 3/31/1994

ATP Number: 90-01-0166

\begin{tabular}{|c|c|c|}
\hline \multicolumn{3}{|c|}{ FUNDING (in thousands): } \\
\hline ATP & $\$ 1,785$ & $67 \%$ \\
\hline Company & 869 & $33 \%$ \\
\hline Total & $\$ 2,65$ & \\
\hline
\end{tabular}

\section{ACCOMPLISHMENTS:}

In its quest to develop magnetoresistive RAM (MRAM), NVE made significant advances in producibility, circuit density and signal strength by using giant magnetoresistance (GMR) materials. In the process, the company developed an important spinoff application of the technology in sensors. Indicative of progress, NVE:

- started producing an initial commercial product, a GMR magnetic bridge sensor, in 1994 , selling about 50,000 by the end of 1997 to other companies for examination purposes and earning revenues of more than $\$ 150,000$ that year alone;

untered into an agreement with Motorola in 1995 to develop MRAMs (development is still under way, with sales possible in 1999);

Entered into an agreement with Microtrace in 1996 to use a GMR-based procedure to make counterfeiting of aircraft parts much easier to detect (development work is under way);

licensed the ATP-funded technology to Honeywell (for use in military and avionics applications), which incorporated it into computer systems placed in government agencies; and

sensors. A major application for sensors based on the new technology is possibly in antilock brake systems in automobiles and trucks. These systems use a clamp to grip the edge of a steel disk attached to the wheel. If the clamp grabs too tightly, the brake locks, the wheel stops rotating, and the tire slides on the road surface instead of gripping it. In an antilock brake system, a sensor detects the rotation of the disk and feeds that information into a computer. If the computer detects overly rapid deceleration indicating the brake is about to lock - it directs the braking mechanism to reduce clamp pressure to keep that from happening.

The new NVE sensors are substantially more sensitive than conventional sensors. They can be farther from the monitored object while performing equally well. Their magnets can be smaller, so the cost is less. And the NVE sensors can detect rotational speeds closer to zero, which means the computer receives more accurate data to use in controlling the brake mechanism. In a vehicle equipped with an antilock brake system incorporating NVE sensors, the driver will have better skid and stopping control. transferred knowledge about GMR materials to members of an ATP joint venture working on technology for magnetic disk storage based on the GMR effect.

\section{COMMERCIALIZATION STATUS:}

NVE is successfully making and selling - with a recent growth rate of about 3,000 percent - GMR-based sensing products, a spin-off from its MRAM technology development project. It is also pursuing commercialization of MRAMs through an agreement with Motorola, an endeavor that could lead to a substantial share of a $\$ 45$ billion/year market.

\section{OUTLOOK:}

The outlook is excellent for expanded use of GMR sensors, which have many applications, including pace makers, engine control, shock absorbers, antilock brake systems, current monitoring, cylinder position sensing and automatic meter reading. The outlook for commercialization of the nonvolatile memory chips is potentially bright. But with several more years of development, the extent of use remains uncertain. Spillover benefits are potentially large.

\author{
Composite Performance Score: \\ COMPANY: \\ Nonvolatile Electronics, Inc. (NVE) \\ 5805 Amy Drive \\ Edina, MN 55436 \\ Contact: James M. Daughton \\ Phone: (612) 996-1607 \\ Number of employees: 10 at project start, 56 at the end of 1997
}

\section{Product Sales and Commercialization Agreements}

NVE expects to apply its sensor technology in several other industries, too, including medical devices, consumer products, and machine tool manufacturing. Production for these markets is planned for the near future. According to NVE, it is the first to make and sell GMR-based sensing products for the general market, and it has established a

\section{In a vehicle equipped with an antilock brake system incorporating NVE sensors, the driver will have better skid and stopping control.}

new company division for this purpose. Its sales of GMRbased sensors have grown by about 3,000 percent recently, from around \$5,000 in 1994 to more than $\$ 150,000$ in 1997. The company has also generated revenues from engineering 


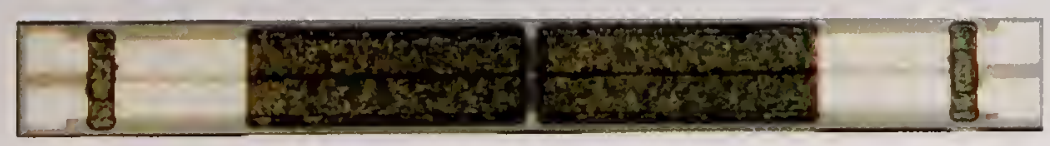

Photomicrograph of a GMR magnetic field sensor, with actual dimensions of $436 \times 3370$ microns.

contracts, as well as royalties from companies that license its technology.

NVE entered into an agreement with Motorola in 1995 to develop MRAMs, and the development work is under way. Production could begin in 1999. If this effort succeeds, NVE expects to capture a sizable share of the $\$ 45$ billion annual market for memory and hard-disk drive products. The company also signed an agreement with Microtrace in 1996 to use a procedure based on GMR

\section{NVE entered into an agreement with}

\section{Motorola in 1995 to develop MRAMs ...}

techniques to make counterfeiting of aircraft parts much easier to detect. The development work is under way, and products for this application are also expected in 1999.

For GMR applications beyond its own pursuits, NVE has offered its knowledge to other companies, universities, and national laboratories. This was done through another ATP project (\#91-01-0016: "Ultrahigh-Density Magnetic Recording Heads") conducted by a large joint venture led by the National Storage Industry Consortium. NVE officials consulted on fabrication methods for making GMR films and supplied samples of the films made by NVE.

\section{NVE has offered its knowledge to other companies, universities and national laboratories.}

\section{Benefits From the Technology}

Because NVE is selling only sensors, all benefits will initially come from that product. When the sensors actually begin appearing in commercial products - some time after 2000 - end users will have access to competitively priced devices that operate at much greater temperature extremes than do conventional sensors. Additional benefits will accrue from GMR sensors as more are used in a variety of applications.
GMR sensors will likely generate substantial economic benefits beyond those realized by NVE. A sensor is a small part of an antilock brake system, which is a small part of a much larger device - an automobile. Several manufacturing and subassembly stages lie between the development of the sensor and the final product, and the sensors add value to the product at each stage. According to NVE, the total of this spillover benefit will likely be more than 10 times greater than what the company earns for the use of its new technology. And the aggregate benefit will increase as more cars are equipped with antilock brake systems incorporating NVE sensors. Spillover benefits promise to be even larger when the sensors are used in other applications.

In addition to these applications, the company's GMR sensors are being used for portable traffic monitoring instruments, and they may be very useful for instruments used to detect land mines. Geometrics, Inc., in Denver, Colorado, has contracts to design and test devices to detect antipersonnel mines for the U. S. military, and it has subcontracted with NVE to supply GMR sensors for the detectors. If the design and testing lead to workable detection instruments, a much better job of finding and removing unwanted land mines will be the result. There are 100-200 million such land mines throughout the world in areas that were formerly areas of warfare, and they kill and maim tens of thousands of innocent people each year.

The market for MRAMs - the application initially targeted by NVE - may eventually be important, but it is still in the future. If MRAMs ultimately reduce accidental loss of information to computer users, benefits will be large.

\section{ATP Project Saves Company}

Before the ATP project, NVE was a tiny, undercapitalized company facing significant technological risks in developing the technology for commercial uses. Funding from the ATP, however, enabled the project to be done and prevented the company from failing, NVE officials say. In addition, the ATP award improved the company's ability to attract capital from other sources.

\section{Funding from the ATP enabled the project}

to be done and prevented the company from failing . . . and improved the company's ability to attract capital from other sources. 



\section{A Feedback-Controlled, Metallo-Organic Chemical Vapor Deposition Reactor}

Jaser diodes are the tiny workhorses in many industrial and consumer products. Every CD-ROM player has at least one, and many printers and photocopiers have a large array of them. More than 20 million laser diodes are needed each year for this market alone, and the number is growing.

COMPOSITE PERFORMANCE SCORE (Based on a four star rating.)

\section{Advanced Fabrication Control for Improved Electronic Devices}

This ATP project with Spire Corporation developed a new way to make laser diodes and other optoelectronic devices. Founded in 1969, Spire is a specialty manufacturer of semiconductor wafers and metallo-organic chemical vapor deposition (MOCVD) equipment. The company's new method makes possible the manufacture of individual lasers and laser arrays at lower cost and with higher performance characteristics.

Spire built and demonstrated an advanced MOCVD reactor designed for the fabrication of laser diodes. Laser diodes are intricate multilayer structures generally grown by MOCVD on compound semiconductor wafers.

Researchers developed in-process sensors to monitor the development of layers on the substrate, as well as control systems to automatically adjust the many process parameters. They demonstrated that the new technology can control the growth rate of the layers. They also showed that the new reactor performed better than conventional reactors in terms of epitaxial layer uniformity over the entire wafer, as well as run-to-run consistency. These two factors can contribute significantly to reducing the cost of making laser diodes.

\section{Potential for Commercial Products}

The project did well technically, and limited commercialization is under way. Spire is pursuing its original plan to produce and sell reactors and license the technology to other manufacturers, and it is in discussions with several

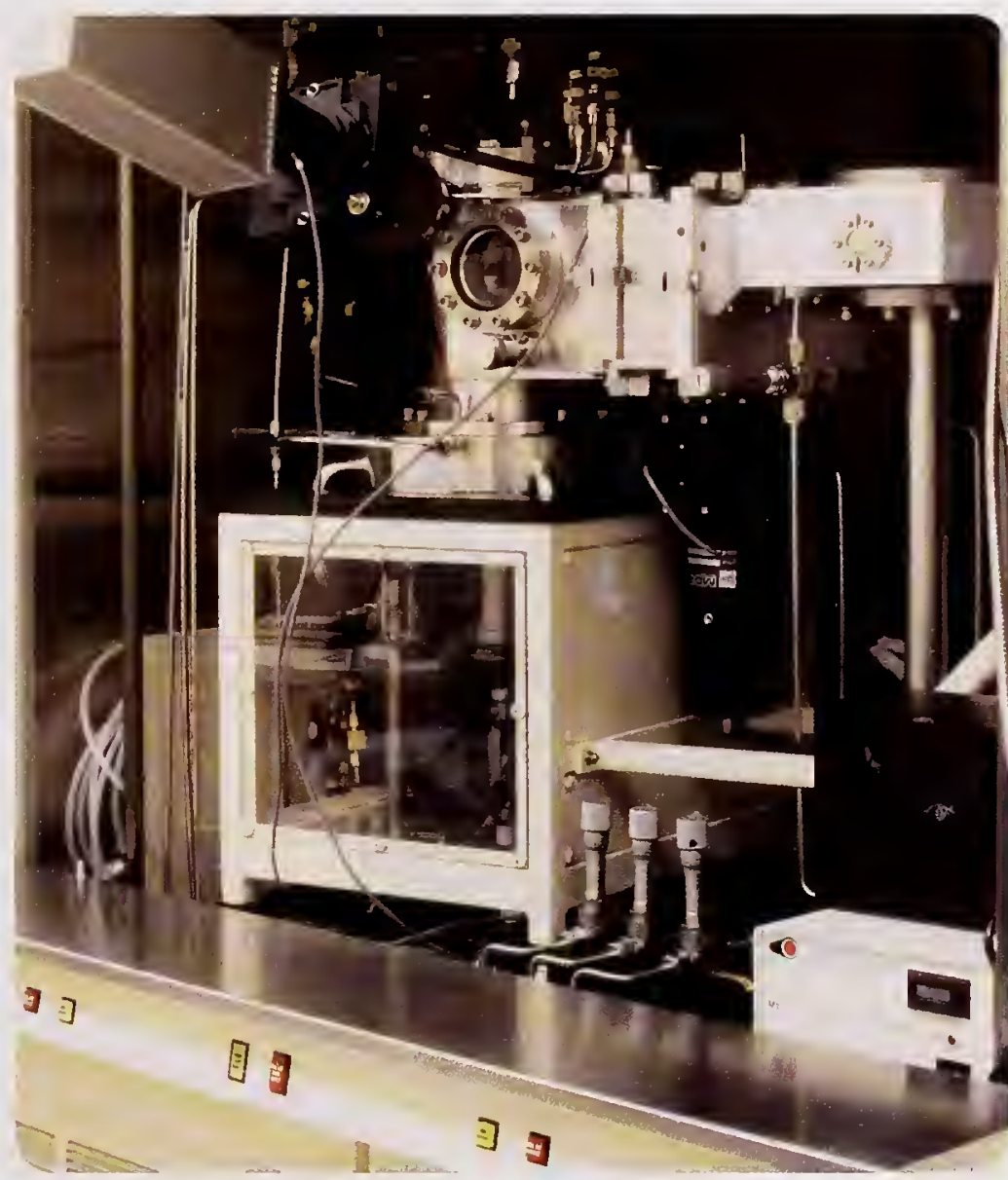

The advanced metallo-organic chemical vapor deposition reactor constructed with funding from ATP.

potential customers. The company also planned to produce low-cost laser diode arrays in competition with foreign producers, but that market did not develop.

Spire has successfully used the prototype reactor to perform customer-specific research and development and 


\section{PROJECT HIGHLIGHTS}

PROJECT:

To develop an advanced feedback-controlled, high-throughput, metalloorganic chemical vapor deposition (MOCVD) reactor for fabricating low-cost, high-quality laser diode arrays.

Duration: 6/15/1992 - 3/31/1995

ATP Number: 91-01-0263

FUNDING (in thousands):

ATP $\quad \$ 1,223 \quad 56 \%$

Company $\quad \lcm{973} \quad 44 \%$

Total \$2,196

\section{ACCOMPLISHMENTS:}

Spire achieved the project's research goal and afterward conducted additional, company-funded development to commercialize the technology. A prototype reactor is being used for commercial wafer production and customer-specific development work. Signs of the project's success include the fact that the company:

published four papers and presented several others at professional conferences during the award period;

demonstrated the ability to grow epitaxial wafers with high-quality uniformity of composition and thickness over an entire wafer 2.25 inches in diameter;

demonstrated the ability to fabricate vertical cavity surface emitting lasers (VCSELs) with state-of-the-art performance characteristics;

published a 1997 update on use of the ATP-funded reactor, "In Situ Monitoring and Control for MOCVD Growth of AIGaAs and lnGaAs," in the Journal of Electronic Materials;

received $\$ 356,000$ from two large manufacturers for development of

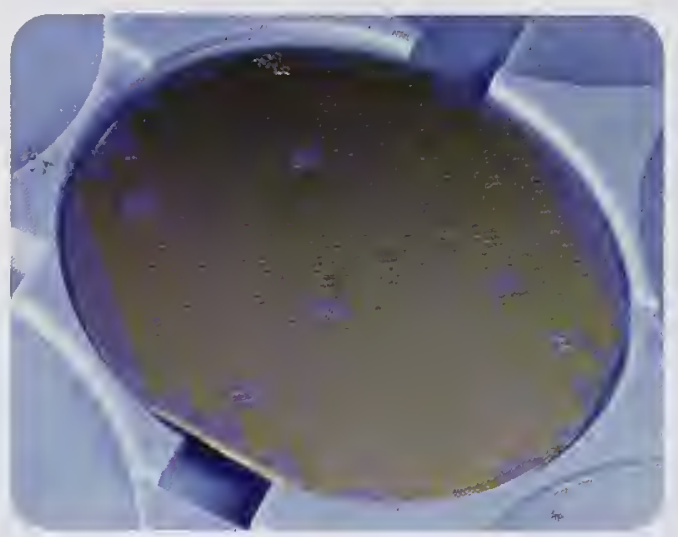

A wafer populated with arrays of vertical cavity surface emitting lasers.

to produce epitaxial laser wafers of a demanding structure. One customer has invested more that $\$ 250,000$ with Spire to develop vertical cavity surface emitting laser (VCSEL) wafers and plans to invest another $\$ 450,000$ in the effort in the near future. A VCSEL emits light in a cylindrical beam vertically from its surface and may offer significant advantages over edge-emitting lasers in some applications. This customer may also buy an MOCVD reactor from Spire in the next two years, following completion of the initial development project.

Spire is focusing on use of the new feedback-con- advanced VCSEL epitaxial wafers and wafer production processes, with an additional $\$ 450,000$ to $\$ 750,000$ expected in the near future; and

- expanded sales of commercial epitaxial wafers (mostly for lasers and light-emitting diodes), with sales revenue of about $\$ 200,000$ in 1998 .

\section{COMMERCIALIZATION STATUS:}

Limited commercialization has been under way since 1996. The ATP-funded technology has been incorporated into an MOCVD reactor being used for commercial production of optoelectronic epitaxial wafers. These include VCSEL epitaxial wafers that are being developed for high-speed laser printing. Spire is also using the reactor for two development projects funded by other companies.

\section{OUTLOOK:}

Spire expects to produce substantial numbers of VCSEL devices in the future. Because the market is growing rapidly, the company is positioned to exploit its superior in-house epitaxial wafer growth capability, based on the ATP-funded technology, to produce large quantities of whole epitaxial wafers, as well as wafers processed into optoelectronic devices ready for packaging.

\section{Composite Performance Score: $\star \star$}

\section{COMPANY:}

Spire Corporation

1 Patriots Park

Bedford, MA 01730-2396

Contacts: Harvey B. Serreze or Kurt J. Linden

Phone: (781) 275-6000

Number of employees: 180 at project start, 150 at the end of 1997

trolled reactor for growing laser wafers for VCSELs and edge-emitting lasers. VCSELs would be used in highspeed laser printers and in optical interconnects for computer links, and edge-emitting lasers would be used in solid-state laser pumps and in measurement and material processing applications. The company contracted with another large manufacturer in late 1997 to develop

... planned to produce low-cost laser diode arrays in competition with foreign producers, but that market did not develop.

VCSEL arrays for advanced optical computer interconnects. Spire has already been paid $\$ 106,000$ for the project and could potentially receive another $\$ 300,000$. If the development work succeeds, Spire believes it will enable the company to enter the huge market for optical interconnect components. 


\section{ATP Project Opens Doors}

If the ATP funds had not been available, Spire would not have done the project, company officials say. The ATP award enabled Spire to overcome technical barriers to volume production of VCSEL wafers, some of which contain more than 650 epitaxial layers. These complex structures had been previously grown only in a few laboratories and in small lots and sometimes virtually by hand. Spire's new capability, in turn, has attracted an entire new line of customers.

The company's new method makes possible the manufacture of individual lasers and laser arrays at lower cost and with higher performance characteristics.

The potential for alliances with research and development partners is now high, and Spire is already working on advanced device development projects with several companies. The benefits to users of new devices made from these complex wafers can be significant. The ATPfunded reactor enables production of many kinds of wafers at lower costs. It also enables the production of some devices, made from VCSEL wafers, that could not be fabricated any other way. The benefits, however, can occur only if the company's limited commercialization expands into full-scale success, and it is still too early to tell whether that will happen. 



\section{Flat Fluorescent Lamps for Displays}

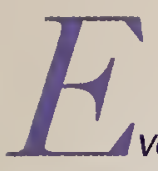

very cockpit in a large airplane contains small windows that are mainly used when the plane is on the ground. While flying, pilots see the world not by looking out the windows, but by looking at the text and images shown by instrument displays mounted on the walls of the cockpit. The quality of these images bears directly on the quality of the flying.

\section{More-Visible Instrument Displays for Safer Flying}

Today, almost every cockpit display uses cathode ray tube (CRT) technology. CRTs are a proven technology, have a long history and are fabricated by Thomas Electronics which undertook this ATP project - for use in the manufacture of cockpit displays. CR'T displays, however, have

\section{In some circumstances, such as} bright sunlight, visibility of displays may be seriously diminished.

a well-known drawback: the surface is glass, and the view one gets through it depends on the amount of light in the cockpit and the direction the light is coming from. In some circumstances, such as bright sunlight, visibility of displays may be seriously diminished.

\section{Creating a Flat Fluorescent Lamp}

Liquid-crystal displays (LCDs) - the flat-panel displays used in notebook computers - would be a good alternative to CRT displays. The drawback to LCDs, however, is that their light source is not nearly bright enough for use in airplane cockpits. This ATP project addressed that problem by developing the technology needed to make a flat, bright fluorescent lamp for backlighting an LCD. The new lamp would be about a quarter of an inch thick, have the same length and width as the LCD, and be attached to its back.

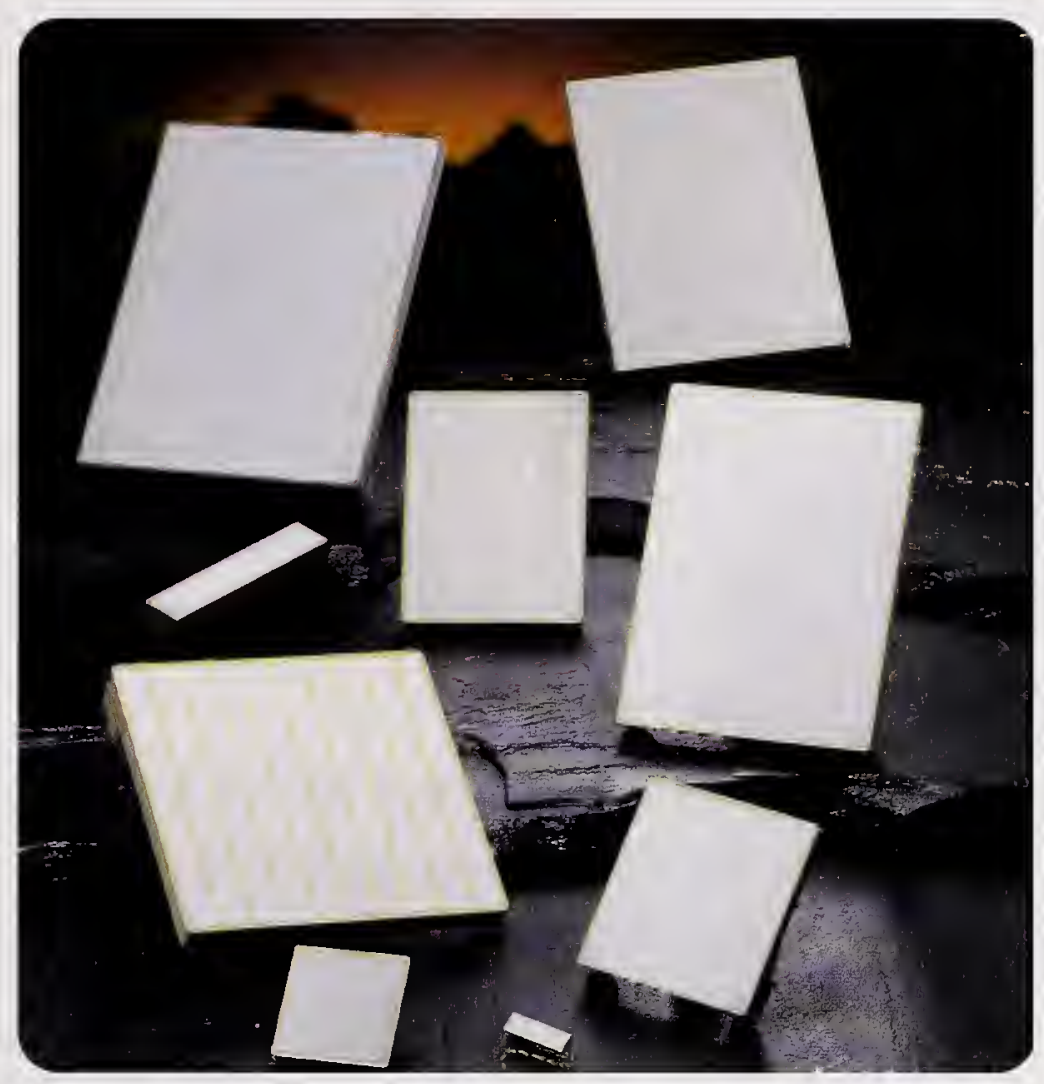

Flat fluorescent lamps for flat panel display backlighting, in a variety of sizes, ranging from 1.5 inches to 12.5 inches on the diagonal.

In conventional fluorescent lamps, a cathode discharges electrons that excite mercury vapor to emit ultraviolet light that, in turn, induces the phosphor coating on the interior of the lamp to glow white. Flat fluorescent lamps were not developed earlier because of the difficulty in generating a bright plasma in the thin space between wide, flat sheets. Conventional cathodes are too inefficient 


\section{PROJECT HIGHLIGHTS}

\section{PROJECT:}

To develop a high-efficiency electron source for fluorescent lighting to enable a new class of efficient, bright, flat lamps with wide applications in computer and instrument displays, high-definition TV displays and wide-area ultraviolet light sources for industrial use.

Duration: 2/1/1994 - 1/31/1997

ATP Number: 93-01-0109

\section{FUNDING (in thousands):}

ATP $\quad \$ 718 \quad 77 \%$

Company $\lcm{215} \quad 23 \%$

Total $\$ 933$

\section{ACCOMPLISHMENTS:}

Thomas developed the high-efficiency electron source needed to construct flat fluorescent lamps, which was the goal of the project. The company achieved the following:

entered pilot production of flat lamps for key customers in the U.S. display industry;

received orders for further evaluation and field testing of the new rechnology in cockpit applications from Optical Image Systems, AlliedSignal, Honeywell, Litton Industries, Kaiser Electronics, and five other companies; and

placed prototypes with three military contractors for rugged displays in tanks and other ground vehicles.

to create enough light for the color LCDs used in avionic displays. And although barium dispenser cathodes (BDCs) are efficient enough for the task, they were never used in the presence of mercury, which is believed to poison the barium and quickly reduce both the efficiency and life span of the device. Thomas solved the mercury problem with BDCs by using a new hollow-cathode design that enabled

\section{Flat fluorescent lamps were not developed earlier because of the difficulty in generating a bright plasma in the thin space between wide, ${ }^{3}$ flat sheets.}

the company to construct a truly flat fluorescent lamp.

In addition, Thomas introduced new materials to flat fluorescent lighting. The front of the lamp is glass. But the back is hardier ceramic material and has all the light-producing components embedded in it. The ceramic back enables the lamp to withstand severe shock and vibration much better than if both sides were glass. In addition, the thermal properties of the ceramic material allow the lamp to operate at significantly higher temperatures than com-

\section{COMMERCIALIZATION STATUS:}

Current sales of prototypes and pilot models of flat fluorescent lamps to avionics customers range from 30 to 50 units per month. If customer tests prove the technology works for them, regular commercial sales are expected to begin after the flat-panel displays have been certified by the Federal Aviation Administration for use in cockpits.

\section{OUTLOOK:}

Full commercialization is expected after refinements to the technology based on feedback from customers using prototype units. If the technology is commercialized, its users - aircraft manufacturers, airlines and their passengers — will benefit from brighter, more reliable and cheaper backlights for flatpanel displays in airplane cockpits.

\section{Composite Performance Score: $\star$ \\ COMPANY: \\ Thomas Electronics, Inc. 100 Riverview Drive \\ Wayne, NJ 07470}

Contact: Douglas Ketchum

Phone: (973) 696-5200

Number of employees: 251 at project start, 324 at the end of 1997 Informal collaborator: Princeton University

parable lamps made solely of glass. As a result, these new lamps can be used for rugged flat-panel displays in applications such as military tanks.

\section{Field Testing Underway}

Follow-on research and development work is on track to meet the project's commercialization goal - the introduction into commercial and military airplane cockpits of flatpanel displays containing the new fluorescent lamp. To date, Thomas has invested more of its own money in the effort than it received from ATP, and the work is beginning to pay off. The company is completing a pilot production plant and has received orders for further evaluation and field testing of the new technology from Optical Image Systems, AlliedSignal, Honeywell, Litton Industries, Kaiser Electronics and five other companies. The field testing must yield positive results before the Federal Aviation Administration will certify the flat-panel displays for use in cockpits.

About 10,000 displays are installed in airplane cockpits each year. Compared with CR'T devices, the new flatpanel displays will be more effective (they produce more light), more reliable (the ceramic material is hardier than glass), and less-costly (the ceramic material can be machined more easily than glass). Ultimately, their use is expected to benefit aircraft passengers, who will enjoy safer 
air travel because pilots have more-effective, more-reliable instrument displays. It is also expected to benefit flat-panel display manufacturers, aircraft manufacturers and airlines through cost reductions and quality improvements.

... these new lamps can be used for rugged flat-panel displays in applications such as military tanks.

Potential uses for the flat-lamp technology include displays in military ground vehicles, such as tanks. Displays in these applications must withstand greater extremes in vibration, temperature, and other operating conditions than ordinary displays. Three companies specializing in such displays have ordered flat-lamp prototypes from Thomas.

\section{ATP Bolsters U.S. Technology}

Without the ATP award, 'Thomas officials say, the company would not have done the research and development work for this project. The company would have struggled along with its conventional CR'T technology and would have stood virtually no chance of competing with other display-component suppliers, all of which are foreign companies. In addition, the award helped Thomas establish connections with scientists at Princeton University and form alliances with contractors.

Without the ATP award . . . the company would have stood virtually no chance of competing with other display-component suppliers, all of which are foreign companies. 



\section{Gallium Arsenide: a Faster Alternative to Silicon for Microprocessors and Telecommunications Applications}

$N$ the base on which IC technology has advanced. But silicon has its limits. Electrons pass through GaAs about five times faster than through silicon, suggesting potential for achieving higher processing speeds from ICs fabricated from GaAs. In the 1970 s and 1980s, research efforts were undertaken to develop gallium arsenide (GaAs) as an alternative material for fabricating integrated circuits.

COMPOSITE PERFORMANCE SCORE (Based on a four star rating.)

\section{Barriers to Use of GaAs-based ICs}

Despite their speed advantage, GaAs-based ICs, developed in the 1980s, did not find widespread commercial use. One barrier to their use was price. GaAs cost as much as 10 times more than silicon in the early years. The wafers from which GaAs chips are made were difficult to produce without a high level of defects. And, they were difficult to produce at all. More recently, this cost barrier has been significantly reduced as wafer suppliers and chip producers have perfected manufacturing techniques.

Another barrier to widespread commercial use of GaAs-based ICs was their high power consumption. Unlike silicon ICs, which consume power only while performing processing tasks, GaAs ICs consume power even when they are not in operation. The use of GaAs as a substrate for ICs had been pioneered for military applications, namely in microproccessors for supercomputing. Military users were willing and able to pay the considerable premium for GaAs-based chips in return for superior processing speed. Commercial users, however, saw the high power requirements as an unacceptable obstacle.

The high power requirements placed limits on the exploitation of the inherent speed advantage of GaAs. More wiring was needed to transmit more power to the chip, crowding out the wiring needed to transmit the input and output signals; thus fewer transistors could fit on the same chip. So constrained, GaAs technology had to employ several chips to equal the capacity of a single silicon chip, causing much of the speed advantage of GaAs to be lost in the time delays between chips.

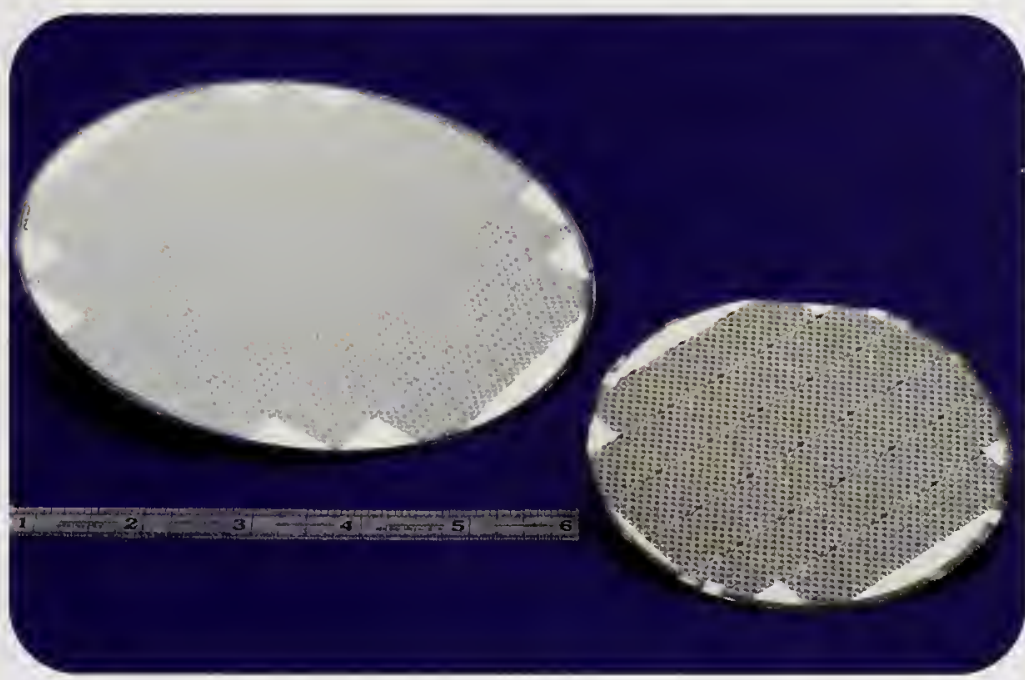

Vitesse's ability to fabricate chip's on 6" wafers in it's new plant, (instead of 4" wafers) more than doubles the number of intergrated circuits that can be fabricated on each wafer and increases the efficiency of production.

The ability of GaAs to compete with silicon for use in ICs was contingent on design innovations that allow the particular advantages of $\mathrm{GaAs}$ to be exploited effectively. The years of accumulated design and manufacturing process refinements, however, had been devoted to silicon-based ICs, not GaAs-based ICs.

\section{Vitesse Proposes GaAs Design Innovations}

Vitesse Semiconductor Corporation, at that time a small company, proposed a project for GaAs innovations in ATP's 1993 General Competition. A'TP made an award of $\$ 2$ million to Vitesse for a 33-month project, later 


\section{PROJECT HIGHLIGHTS}

\section{PROJECT:}

To achieve design innovations needed to exploit the speed and power advantage of GaAs, a substrate material for fabricating high-performance integrated circuits (ICs) for use in microprocessors, transceivers, and ICs used in automatic testing equipment.

Duration: 3/01/94-12/31/96

ATP Number: 93-01-0124

FUNDING (in thousands):

ATP $\$ 2,000 \quad 30 \%$

Company $\quad \mathbf{4 . 6 3 4} \quad 70 \%$

Total $\$ 6,634$

\section{ACCOMPLISHMENTS:}

Initial applications of GaAs design innovations in the development of a supermicroprocessor for use in supercomputers and workstations were abandoned due to market uncertainty. Vitesse refocused its efforts on the development of GaAs design innovations for transceivers used in telecommunications and data communications, and for ICs used in automatic test equipment. Project accomplishments inciuded:

400 percent increase in memory per chip;

50 percent decrease in size of an IC for equivalent functionality;

50 percent reduction in power consumption;

GaAs design innovations commercialized as H-GaAs IV-based technology in transceivers and ATE;

construction of a new, more efficient chip fabrication plant to fabricate GaAs chips on six inch wafers instead of four inch wafers;

- disseminated the technology through articles in the Electronic Engineering Times, Computer Design Magazine, Lightwave, and Semiconductor FabTech; and enabled ATE producers to be able to test increasingly fast ICs.

\section{COMMERCIALIZATION STATUS:}

The design innovations in GaAs have been commercialized in the form of $\mathrm{H}$-GaAs IV-based IC technology. It is being applied to transceivers for use in telecommunications and data communications, which now account for approximately 80 percent of Vitesse's revenues. H-GaAs IV-based ICs are also used in automated test equipment (ATE), accounting for the remaining 20 percent of Vitesse's revenues. Virtually all ATE makers have purchased H-GaAs IV-based ICs from Vitesse. Every Intel Pentium microprocessor built has been tested by ATE using Vitesse ICs. Success in these markets has allowed Vitesse to build a new and more efficient chip fabrication plant.

\section{OUTLOOK:}

H-GaAs IV IC technology has enabled Vitesse to produce transceivers and chips for automated testing equipment that offer substantially lower system costs than silicon IC sets previously used. H-GaAs IV IC technology has allowed ATE producers to overcome the technological limits of silicon IC technology to be able to test increasingly faster ICs. The project has reduced or eliminated major barriers limiting the use of $\mathrm{GaAs}$, and the company has taken the technical advances achieved in the project into commercialization. The outlook appears strong.

\section{Composite Performance Score: $\star \star \star \star$}

COMPANY:

Vitesse Semiconductor Corporation

741 Calle Plano

Camarillo, CA 93012

Contact: Mr. Ira Deyhimy

Phone: 805-388-7511

cal and process models to help determine the optimal design of GaAs ICs that would exploit their speed advantage. With the insights provided by these simulations, Vitesse created a library of basic IC components that permitted the construction of a demonstration vehicle to test design performance. The initial demonstration vehicle was a microprocessor, which, in turn, was to be used to test designs of the supermicroprocessor.

\section{Market Changes Compel Reorientation of Project}

Unexpectedly, Vitesse was forced to abandon its supermicroprocessor objective at the end of the first year of the project. Although the supercomputer and workstation markets for GaAs supermicroprocessors appeared to be a reasonable target at the time of the project's proposal and selection, subsequently the market for supercomputers steeply declined. The decline was due in part to the collapse of government and aerospace demand for supercomputers. Early in the project, Convex Computers, the only supercomputer producer using GaAs-based microprocessors (and Vitesse's only customer in this application) suf- 
fered serious losses. Convex Computers had accounted for half of Vitesse's revenues.

\section{Vitesse requested a change \\ in the project, and ATP agreed to allow a change in focus...}

Vitesse confronted a large investment risk in entering the high-performance microprocessor market. Higher performance microprocessors are split between two competing standards: complex instruction set computers (CISC) and reduced instruction set computers (RISC). Within these broad classes, many fundamental architectural differences exist, each with its own specific demands. Vitesse would have to bet on one. Moreover, Vitesse would have to supply compilers, linkers, math libraries, and other high-level software to complement any microprocessor that it chose to make. This would require a daunting investment of up to $\$ 30$ million. 'The company's financial condition and the uncertainty characterizing the direction of the high-performance microprocessor market led Vitesse to seek alternative opportunities for GaAs technology during the first year of the project.

Vitesse requested a change in the project, and ATP agreed to allow a change in focus on developing and testing GaAs design innovations for use in the development of wire-line transceivers and ICs for automatic test equipment (ATE). This use for GaAs IC technology was on the rise. Networks of workstations, configured to emulate a supercomputer at far less cost, were becoming increasingly popular, and these workstations, like other local area networks (LANs), require the use of transceivers for data transmission and error-checking.

There are also many other applications for transceivers. They are essential in telephone communications that share large volumes of digital data among various points, such as central switching offices and cellular transmission sites.

Credit card companies also rely on transceivers for the data links that connect databases and terminals, ensuring speedy authentication during transactions. Transceivers will also be an essential component in digital television. Transmission of digital television signals from television stations to home sets, between the cameras and the studio, and between the studio and the network facilities will all require very highspeed links with transceivers at either end.

\section{ATP Flexibility Important to Company's Future Success: Funding Supports Critical Shift in Business Strategy}

By accepting Vitesse's request that it be allowed to shift the project's focus for applying the technology rather than stopping the project, ATP enabled Vitesse to continue the development of GaAs technology following the business reverses of its main customer. According to Ray Milano of Vitesse, ATP funding was essential for sustaining its development of GaAs technology. Accomplishments in the project ultimately allowed the company to build its position in wire-line transceivers and ICs for automatic testing equipment. ${ }^{2}$

\section{Design Innovations Achieved}

Vitesse made substantial progress toward the revised project goals. Vitesse designated the new generation of GaAs IC technology developed from the project's design innovations as $\mathrm{H}-\mathrm{GaAs}$ IV. The H-GaAs IV embodies a 50 percent decrease in size for equivalent functionality, and requires just half as much power to deliver the same amount of processing speed. Memory per chip was increased four-fold.

\section{The H-GaAs IV embodies a 50 percent} decrease in size for equivalent functionality, and requires just half as much power to deliver the same amount of processing speed.

Higher levels of integration and reduced power consumption made possible by project-related design innovations have allowed Vitesse to provide GaAs-based ICs with clear advantages over traditional silicon-based ICs, both for transceivers and ICs for automatic testing equipment (ATE).

\section{Project Innovations Embodied in Transceivers and ATE Equipment}

The old technology for ATE employed multiple, linked silicon ICs to perform the same task as one H-GaAs IV IC. The greater number of connections required to link the silicon ICs with the IC to be tested, the greater space they took up, the power consumed, and the amount of heat generated caused ATE producers to be very receptive to Vitesse's H-GaAs IV. Virtually all ATE makers, including

\footnotetext{
${ }^{1}$ This estimate was developed in discussions between Vitesse and Compaq, a prospective customer and development partner.
}

${ }^{2}$ In-person communication between Phil Perconti, ATP, and Ray Milano, Vitesse, March 1999. 


\section{Every Pentium microprocessor built has}

\section{been tested by ATE using Vitesse ICs}

Intel, have purchased GaAs chips from Vitesse. Every Pentium microprocessor built has been tested by ATE using Vitesse ICs.

Overall, the chief commercial application of $\mathrm{H}-\mathrm{GaAs}$ IV-based IC technology has been for transceivers used in telecommunications and data communications. Customers include telecommunication equipment makers such as Lucent Technologies, Alcatel, and Ericsson.

\section{...the chief commercial application of $H$-GaAs IV-based IC technology has been for transceivers used in telecommunications and data communications.}

Success in these markets allowed Vitesse to build a major new chip fabrication plant. This plant will fabricate chips on six-inch wafers. Heretofore, GaAs ICs have been fabricated on four-inch wafers. The shift to six-inch wafers will more than double the number of ICs that can be fabricated on each wafer, dramatically increasing the efficiency of GaAs IC production.

\section{Producers and Customers Benefit from Lower Costs, New Capabilities}

H-GaAs IV-based ICs offer a superior alternative to silicon-based transceivers. Because just one IC must be purchased, and because the Vitesse transceiver consumes less power than the set of silicon ICs, total system cost is substantially less.

\section{...substantial cost and performance advantages over silicon ICs...}

H-GaAs IV IC technology has been instrumental in meeting the needs of ATE producers and their customers. The ICs used in ATE must be faster than the ICs to be tested. Silicon technology was running up against technical limits. H-GaAs IV IC technology has allowed ATE producers to overcome the technological bottleneck and produce equipment with the capability to test increasingly fast ICs.

Increased levels of integration and reduced power consumption made possible by project-related design innovations in GaAs-based IC technology have enabled Vitesse to provide substantial cost and performance advantages over silicon ICs, both for transceivers and for ICs used in automatic testing equipment. 
ADVANGED TECHNOLOGY PROGRAM

CHAPTER 5

Information

Technology 



\section{Computer Recognition of Natural Handwriting}

S

ince the beginning of the computer age during World War II, virtually all data have been entered into computers via the keyboard. Teletype machines were adapted so that typing created a punched paper tape, which was read by a second device attached to the computer. Later, the key-punch machine was developed; it created holes in cards that were read by a card reader connected to the computer. In time, keyboards were used to enter data directly into computers, first via terminals connected to mainframe computers, and then for desktop computers as well.

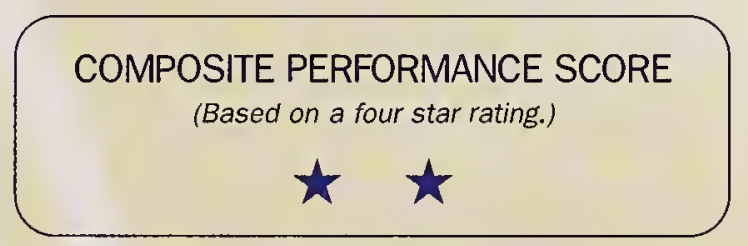

\section{Handwriting: An Easier Way to Enter Computer Data}

Each development advanced the science of data entry, but keyboards have continued to be problematic. Some people cannot use them because of physical limitations, such as arthritis or carpal tunnel syndrome, or because they do not know how to type. Others find them difficult to use in

\section{... received, in early 1997, the "Ease-of-Use Seal of Commendation" from the Commendation Program of the Arthritis Foundation . . .}

particular settings and circumstances, such as conducting inventory on the shop floor or a geology survey in the wilderness, where using a keyboard is cumbersome. Difficulty in using keyboards and their inappropriateness in certain situations were seen as two of the obstacles limiting computer use to only about five percent of the U.S. population when this project was proposed in ATP's first competition in 1990.

\section{Software That Recognizes Cursive Writing}

Communication Intelligence Corporation (CIC), a small California company spun off from SRI International (formerly Stanford Research Institute), has addressed these

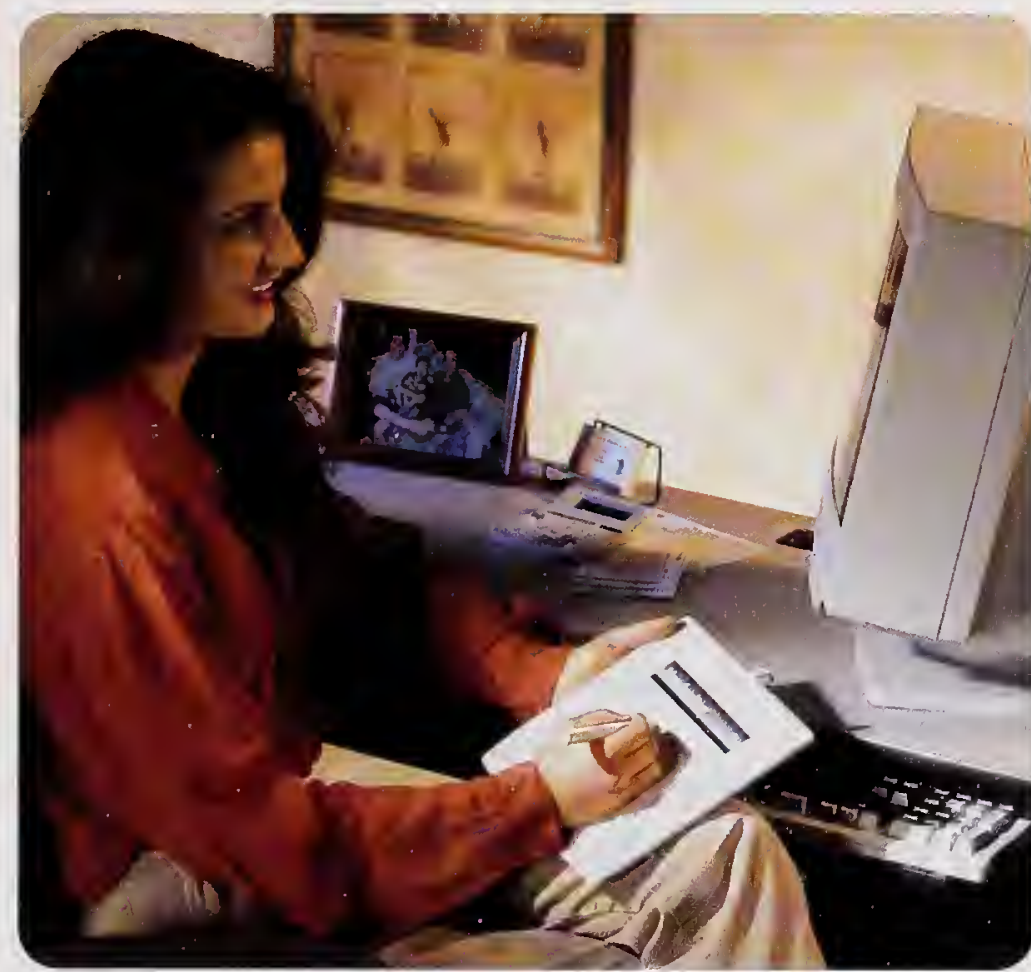

A computer user entering information into her PC with a pad and sty lus. Company software in the PC converts the data from the pad into letters and words.

keyboard problems by using technology created in its ATP project for a reliable, cost-effective alternative: a stylus and pad that can be used by the computer to read handwriting. The hardware was simple to implement, since touch-sensitive pads already existed. The difficult part was perfecting techniques for software that would effectively recognize fully cursive handwriting.

CIC researchers accomplished this technical goal during 


\section{PROJECT:}

To develop a natural handwriting data-entry system for computers for applications where pen-based entry works best and for use by people who do not or cannot use a keyboard.

Duration: 4/1/1991 - 9/30/1993

ATP Number: $90-01-0210$

FUNDING (in thousands):

$\begin{array}{lrr}\text { ATP } & \$ 1,264 & 58 \% \\ \text { Company } & -912 & 42 \% \\ \text { Total } & \$ 2,176 & \end{array}$

\section{ACCOMPLISHMENTS:}

CIC developed new data-entry software technology that recognizes each user's natural handwriting without training the computer or the user.

The company:

incorporated some of the ATP-funded technology into an existing software product, Handwriter $($, giving it the ability to recognize connected letters in cursive writing in limited circumstances (previously, it recognized only handprinting);

licensed the Handwriter ${ }^{\circledR}$ software to more than a dozen computer manufacturers around the world, generating $\$ 360,000$ in revenue from sales of 30,000 units in 1997 ;

launched a new product in 1996 called Handwriter ${ }^{\circledR} \mathrm{Mx}^{\mathrm{TM}}$, a stylusand-tablet data-entry device using the upgraded Handwriter ${ }^{\circledR}$ software;

sold 11,000 copies of Handwriter ${ }^{\circledR} \mathrm{Mx}^{\mathrm{TM}}$ in 1997 , with sales totaling more than $\$ 2.2$ million; and

the project by collecting a database with thousands of cursive handwriting samples and developing new recognition algorithms. After analyzing the handwriting-sample database and developing the recognition methods, they also developed procedures that permit fast computation with modest computer memory requirements.

\section{New and Upgraded Products}

Prior to its ATP project, CIC was marketing a software product called Handwriter ${ }^{\oplus}$, which could recognize handwritten printing but not cursive writing. The company has now incorporated some components of the ATP-funded technology into Handwriter ${ }^{\circledast}$. Even though the technology for recognizing fully cursive handwriting has been developed, the upgraded software currently available commercially cannot yet read fully cursive handwriting. It is able, however, to recognize connected letters in cursive writing in limited circumstances. CIC has licensed Handwriter ${ }^{\circledast}$ to most of the PC manufacturers in the world, and the upgraded Handwriter ${ }^{\oplus}$ software is now incorporated in a number of pen-based, hand-held computer devices on the market. received, in early 1997, the "Ease-of-Use Seal of Commendation" from the Commendation Program of the Arthritis Foundation, for the company's Handwriter products - indicating their value to disabled people who have trouble with keyboard entry.

\section{COMMERCIALIZATION STATUS:}

The ATP-funded software technology is widely licensed, and a new product fully incorporating the software is due on the market soon. Both are generating revenue.

\section{OUTLOOK:}

The outlook for this technology is strong, since it opens up possibilities for much wider use of computers and expanded market opportunities for U.S. producers of hardware and software. The potential is likely to increase further as languages other than English are incorporated into the approach. The company is actively seeking additional market opportunities for further distribution of its products.

\section{Composite Performance Score: $\star \star$ \\ COMPANY: \\ Communication Intelligence Corporation (CIC) \\ 275 Shoreline Drive, Sixth Floor \\ Redwood Shores, CA 94065}

Contact: Russ Davis

Phone: (650) 802-7757

Number of employees: 33 at project start, 93 at the end of 1997

The company also developed two new consumer products based on the ATP-funded technology. One product is Handwriter ${ }^{\circledast} \mathrm{Mx}^{\mathrm{TM}}$, which includes a stylus and pad, as well as the upgraded Handwriter ${ }^{\otimes}$ software. In late 1996, CIC began marketing Handwriter ${ }^{\circledast} \mathrm{Mx}^{\mathrm{TM}}$ in a

\section{... this technology . . . opens up possibili- ties for much wider use of computers and expanded market opportunities for U.S. producers of hardware and software.}

large computer chain, with a retail price of about $\$ 200$. The other product, Handwriter ${ }^{\circledast} \mathrm{fx}^{\mathrm{TM}}$, also contains the upgraded software but has a larger writing pad and other features useful to graphics artists. In early 1997, CIC began marketing it in the same computer chain. During that year, the company sold more than 11,000 units of these two products, generating revenues in excess of $\$ 2.2$ million. 
Company officials say the Handwriter ${ }^{\circledR}$ software will be upgraded again in the near future to fully recognize cursive handwriting. One barrier to complete implementation of the ATP-funded technology has been the need for tuning the software system to operate with the standard amount of memory available in modern desktop computers and to run fast enough to keep up with a typical person's handwriting speed. That obstacle is now being addressed.

\section{... thousands of cursive handwriting}

\section{samples . . .new recognition algorithims ... fast computations . . .}

\section{Broadening Access to Computers}

CIC's handwriting-recognition system should prove extremely beneficial. Computer users are now able to enter data via the digitizer tablet, as well as by keyboard or other means. This advance makes computers more useful for more people, especially those whose keyboard use is limited by physical problems or other circumstances. Other computer users may find a note-taking stylus a useful adjunct to the keyboard. For some jobs, particularly those that involve field work, the pen-based computer is the only reasonable solution, and the benefits of having it may be quite high for the user.

As more languages besides English are added to the software, users who write in these languages will benefit from using a handwriting input device that readily accepts all manner of handwriting styles. Markets for hardware and software should expand in response to wider use of computers and related products.

\section{ATP Partnership Speeds Technology Development}

ATP's participation in this project advanced development of the technology by 18 to 24 months and improved the company's credibility with commercial partners. This credibility was important in establishing the licensing and manufacturing relationships needed for rapid commercial deployment of the technology.

The history of this ATP project offers a good example of the amount of time needed by a well-run program to both develop and commercialize a new technology. CIC estimated at the start of the project in 1991 that the overall research, development, and marketing effort needed to get to market would take four to five years. In 1996, three years after completing the two-and-a-half year ATP research project, the company launched Handwriter ${ }^{\circledast}$ $\mathrm{Mx}^{\mathrm{TM}}$, and in 1998, seven years from the time the project began, the company was nearing release of a new software version that fully met the original goals.

\section{Help for Victims of Arthritis}

In early 1997, the Arthritis Foundation awarded CIC its "Ease-of-Use Seal of Commendation" for the company's Handwriter products. The Foundation's Commendation Program, founded in the late 1980 's, recognizes products and packaging that are particularly accessible and easy to use. The award followed a favorable review by health professionals and arthritis patients.

ClC projected at the start of the project in 1991 that the overall research, development, and marketing effort needed to get to market would take four to five years. 


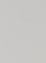




\section{Chinese Character-Recognition Methods for Computer Data Entry}

Inina is the world's most populous country, and in the last decade its economy has begun to mushroom. Because modern economies rely heavily on computers, the potential market for computers in China has grown along with its economy.

COMPOSITE PERFORMANCE SCORE

(Based on a four star rating.)

\section{Accessing China's Giant Computer Market Potential}

A major technical problem, however, impedes the widespread use of computers in China: the Chinese language is ideographic, using symbols to form characters representing things or ideas rather than letters to form words. Written Chinese employs thousands of symbols, as opposed to the 26 letters used in written English. Some keyboard methods exist for entering Chinese characters into a computer, but they are laborious. This technical barrier means that the large potential Chinese market is not readily accessible to U.S. computer businesses.

\section{... the large potential Chinese market} is not readily accessible to U.S. computer businesses.

This ATP project enabled Communication Intelligence Corporation (CIC), a small California company, to develop a stylus-and-tablet method for writing Chinese directly into a computer. CIC is a spin-off from SRI International (formerly Stanford Research Institute) and was founded in 1984 to commercialize English handwriting recognition technology. In its first ATP project, CIC developed technology for a digitized stylus-and-pad system that can be used to enter cursive handwriting in English into a computer. In this second ATP project, GIC

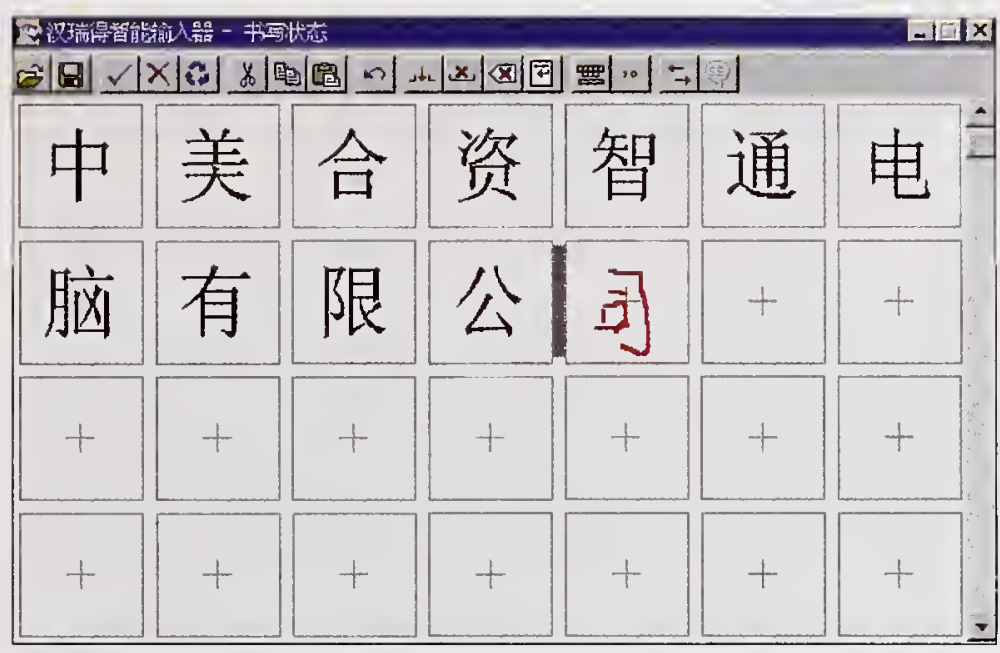

A screenful of Chinese characters, with one in the process of being composed. They were entered into the computer after being written on a pad using a stylus.

applied several techniques from its earlier work: using a tablet and stylus to record pen strokes, getting tablet sensory data into the computer, and using algorithms to convert graphics signals to digital form. In addition, the company created a way to recognize handwritten Chinese characters.

\section{A System That Recognizes Nonalphabetic Writing} For the foundation of its system, CIC developed a highquality database of about 750,000 characters penned by 2,800 Chinese writers. It also developed an algorithm that recognizes 6,763 Guojia Biaozhun characters, the standard set of characters determined by the Chinese government to be used by schools, publishers, and other institutions. 


\section{PROJECT:}

To develop a Chinese character-recognition system to be used in place of a keyboard for computer entry of information in Chinese, opening Chinese markets to U.S. computer products.

Duration: 12/20/1993 - 3/19/1996

ATP Number: 93-01-0211

\begin{tabular}{|c|c|c|}
\hline \multicolumn{3}{|c|}{ FUNDING (in thousands): } \\
\hline ATP & $\$ 1,480$ & $62 \%$ \\
\hline Company & 911 & $38 \%$ \\
\hline Total & $\$ 2,391$ & \\
\hline
\end{tabular}

\section{ACCOMPLISHMENTS:}

CIC fulfilled its goals by developing a recognition system for Chinese characters. The company's progress is indicated by the fact that it:

collected a high-quality database of about 750,000 Chinese characters penned by 2,800 Chinese writers;

developed a recognition algorithm that supports 6,763 Guojia Biaozhun characters, the standard set of characters determined by the Chinese government to be used by printers, schools, and so forth;

- entered into a joint venture with the Ministry of Electronic Industries of Jiangsu Province, China, to perform system integration services and to market the company's pen-based business computer systems to Chinese businesses and government agencies;

released the first major product version of its character-recognition software in September 1997; and

The technology can be applied to personal computers in the People's Republic of China, the Republic of China, Taiwan and countries such as Japan and Korea, where Chinese characters are part of the written language.

The technology will also be useful in applications for other languages that use nonalphabetic writing. Most important is Japanese, which uses symbols to represent the syllables of words and employs two different syllable sets - hiragana (made with more-flowing strokes) and katakana (made with more-angular strokes). Application to handwritten Japanese is also complicated by the interspersion of Chinese characters and English words in Japanese writing.

\section{Entering the Chinese Market}

The company has entered into a joint venture, which is called CICG and has 50 employees, with the Ministry of Electronic Industries of Jiangsu (the coastal province that includes Shanghai). Under the agreement, CIC will perform system integration services and market its pen-based business computer systems (incorporating the ATP-funded technology) to Chinese business and government users. The goal of the venture is to develop and market a "Chinese computer" designed specifically to meet Chinese business requirements. antered into discussions with several major U.S. computer companies about incorporating the CIC character recognition technology into their computers for sale in China.

\section{COMMERCIALIZATION STATUS:}

Commercialization is in progress. CIC recently closed its first major deal with a Chinese company to incorporate the ATP-funded technology into its products. CIC is also in discussions with major U.S. computer companies to incorporate the technology into their products for China.

\section{OUTLOOK:}

Benefits from this project are expected to accrue to U.S. companies through U.S. leadership in China's computer market, the development of computer standards in China based on U.S. technology, and large direct sales of U.S. computer components into China's markets.

\section{Composite Performance Score: $\star \star$}

\section{COMPANY:}

Communication Intelligence Corporation (CIC)

275 Shoreline Drive, Suite 520

Redwood Shores, CA 94065-1413

Contact: Russ Davis

Phone: (650) 802-7757

Number of employees: 66 at project start, 93 at the end of 1997

Part of the agreement specifies that the company will package U.S. hardware and office automation software as part of the Chinese computer. To implement this agreement, CIC is in discussions with several major U.S. computer companies about installing the GIC character-recognition software in their products before selling them in the Chinese market.

\section{. . . entered into discussions with several major U.S. computer companies about incorporating the $\mathrm{ClC}$ character recognition technology into their computers for sale in China.}

The sale of its products in the Chinese market will open a huge opportunity for CIC, as well as many other U.S. sellers of personal computer hardware and software in China. For a country with a population of about one billion (few of whom now use computers), the potential market is vast. But solving the technical barrier to entering 
data in Chinese was a necessary step in actualizing the market and making it accessible to U.S. producers of computers and computer products.

\section{ATP Accelerates Technology Development}

CIC officials say the company was able to accomplish this technology development 18 to 24 months sooner than it could have without the A'TP funds. Moreover, the A'TP award helped the company develop licensing agreements and secure a joint-venture partner.

... the ATP award helped the company develop licensing agreements and secure a joint-venture partner. 


\section{Three-Dimensional Anatomy of Human Body, With Animation, for Medical Training}

\section{4}

very day, surgeons operate on thousands of patients around the country. For each operation, the surgeon and support staff have trained in some way to perform the delicate surgical procedures, some of them training on cadavers in medical school and others learning by doing. For each operation, the patient has gone through a learning experience as well, via conversations with doctors and nurses, while first considering and then preparing for the surgery. Occasionally, patients get to see a video of another person undergoing the procedure to be performed on them.

COMPOSITE PERFORMANCE SCORE (Based on a four star rating.)

\section{Animated 3D Anatomy}

This ATP project enabled Engineering Animation, Inc. (EAI) - a small company founded in 1988 in Ames, Iowa, and specializing in three-dimensional (3D) visualization to develop a new set of computer-based technologies for

\section{The $3 D$ aspect is critical, because flat} pictures do not provide enough information for a good understanding of anatomy and surgical procedures.

making training tools to help surgeons and patients better understand important aspects of surgical procedures before they are performed. The technology was developed for use in health care, medical research, medical education, surgical planning, rehabilitation equipment design, and patient education prior to surgery.

EAI was established to create software that can show animated 3D objects, and its initial products were used in court cases to present re-enactments of car crashes and other events. The company sought ATP funding to develop new methods that would enable it to extend its technical capabilities to depict the inner parts of the body, not just the exterior. In the process, the company hoped to extend understanding of human anatomy. Its attempts would be path-breaking, since there were then no other

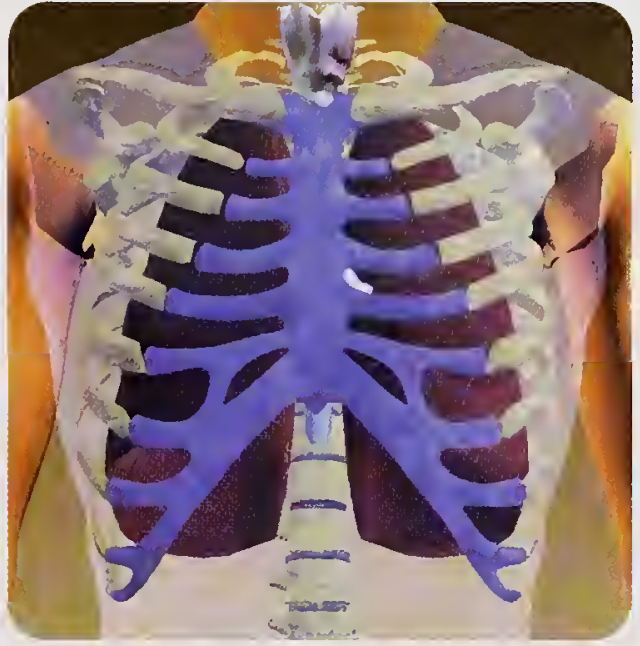

The breathing patterns of asthma patients are demonstrated with a computer-generated dynamic model of the lungs. This is one of a sequence of images - the next one in the sequence has the ribs removed.

known efforts to gather digital anatomical data from different sources into one uniform database or to present that data in $3 \mathrm{D}$ motion.

\section{"Walk-Through" Surgery}

During the ATP project, EAI researchers developed algorithms for a system that can show realistic $3 \mathrm{D}$ images of human body parts and their motion. The pictures of tissues and organs can be manipulated to present a walkthrough of surgery. The $3 \mathrm{D}$ aspect is critical, because flat pictures do not provide enough information for a good understanding of anatomy and surgical procedures. Dynamics, or animation, is also important because joints bend, the heart beats and the lungs contract and expand. Seeing these motions is extremely useful to surgeons planning an operation. Realism, too, is critical so that the images look like natural anatomy. 


\section{PROJECT HIGHLIGHTS}

\section{PROJECT:}

To develop computer visualization and computational dynamics technology for presenting animated 3D images of the human body and its parts in order to improve medical education and surgical simulation.

Duration: 7/1/92 - 6/30/95

ATP Number: 91-01-0184

\begin{tabular}{|c|c|c|}
\hline \multicolumn{3}{|c|}{ FUNDING (in thousands } \\
\hline ATP & $\$ 1,947$ & $76 \%$ \\
\hline Company & 625 & $24 \%$ \\
\hline Total & $\$ 2,572$ & \\
\hline
\end{tabular}

\section{ACCOMPLISHMENTS:}

EAI developed core algorithms to enable the creation of 3D images from sets of 2D cross-sectional images of the human body. Researchers organized and integrated these digitized images in a large database and developed the technology to present them as animated visualizations of human anatomy. The company also:

received the Smithsonian Award from Computerworld magazine in 1994, for the use of information technology in the field of medicine;

received the Award of Excellence in Animation from the Association of Medical Illustrators in 1995;

was a finalist, together with Walt Disney Studios, in the International ANNIE Awards category in 1995, for best animations in the film industry;

produced and started offering the Virtual Human software, to run on a Silicon Graphics workstation, in June 1995;

adapted the Virtual Human technology for three CD-ROMs using dynamic 3D visualization and for two publications, all of which are now on the market;

incorporated the ATP-funded technology in the tools EAI uses to provide custom modeling in biomedicine, health education, and custom animation;

raised $\$ 30.5$ million via an initial public stock offering in February 1996; opened international offices in 1997 and 1998, in England, France, Germany, Italy, and Malaysia;

received one of the 25 Technology and Innovation Awards from Industry Week in 1996;

entered into an agreement in January 1997 to develop software that supports Endovascular Technologies' Endovascular Grafting System a less-invasive, less-costly alternative to open vascular surgery that should lead to lower mortality, fewer complications, shorter hospital stays, and quicker recoveries; r

raised another $\$ 26.6$ million via a second public stock offering in June 1997;

was named one of "America’s Fastest Growing Companies" by Individual Investor magazine, September, 1997;

$\square$ had its CEO, Matthew Rizai, recognized as one of the best entrepreneurs of 1997 by Business Week magazine, January 12, 1998; and

was recognized as one of the 100 most dynamic technology companies in the US - with a rank of number eight - by Forbes ASAP magazine Feb. 23, 1998.

\section{COMMERCIALIZATION STATUS:}

The new computer visualization and computational dynamics technology developed in this project has been successfully commercialized. Though an early product called the "Virtual Human" was not commercially successful because it could only be run on a very expensive work station, much of the technology was adapted for three CD-ROMs and two print publications and has also been used to create CD-ROMs that supplement medical books and are sold as a bundled package. Increased sales of medical books are attributed to the CD-ROMs. Software to support open vascular surgery is being tested and has shown promising results. This rapidly expanding company is now active in a multiplicity of applications featuring $3 \mathrm{D}$ animations which utilize computer visualization and computational dynamics.

\section{OUTLOOK:}

Further potential applications of the technical capabilities developed in the ATP project - and extended by subsequent research and product development - appear abundant. When a reduced-price hardware/software system to support the Virtual Human technology becomes available, potential economy-wide benefits should be large as a result of likely wide-spread use of the technology in health care.

\section{Composite Performance Score: \\ COMPANY: \\ Engineering Animation, Inc. (EAI) \\ 2625 N. Loop Drive \\ Ames, IA 50010}

Contact: Mike Sellberg

Phone: (515) 296-9908

Number of employees: 20 at project start, 400 at the end of 1997 Informal collaborators: The Mayo Clinic, Biomechanics Laboratory; Johns Hopkins University

and the associated technologies for storing and accessing the information. The project succeeded in depicting the whole body (male and female versions) as a $3 \mathrm{D}$ computergenerated image, as well as separately showing each interior part - bones, muscles, heart, lungs, brain and so forth.

\section{Software Tools Commercialized}

Substantial commercialization has been achieved and further effort is under way. After making sufficient progress on the research and development work of the ATP project, EAI used its own funds to combine the new technology 


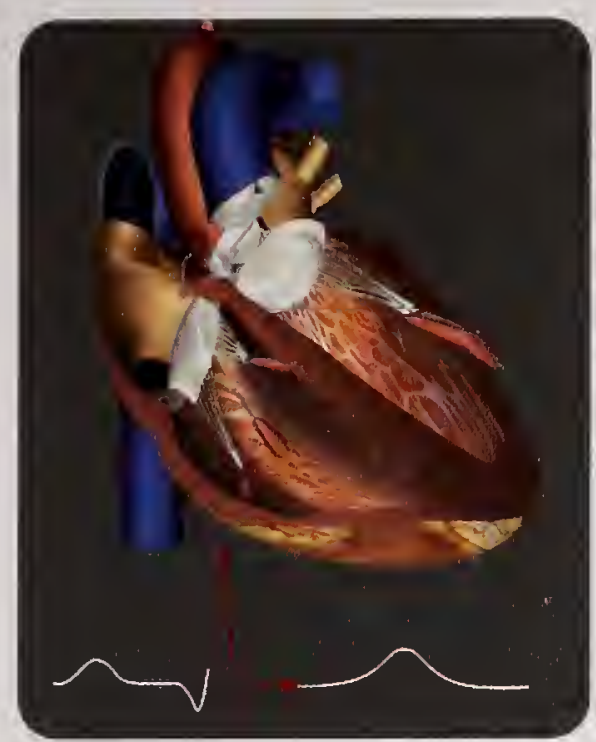

A snapshot of the beating human heart shown with the output of an EKG, at one point in time. In use, both are dynamic - the heart beats in time with the EKG, so medical students can visualize the relation of the beating heart to electrical impulses captured by the EKG.

and databases with its existing software in a new product - the Virtual Human - for use in medical training. The company began offering the Virtual Human at the end of the ATP funding period but was unable to sell a single copy of it because the hardware was so expensive. The costs for setting up the system using a Silicon Graphics workstation and the Unix operating system ran as high as $\$ 100,000$. The company delayed commercialization of that product to modify the software and databases to operate on lower-cost personal computers running the Microsoft NT operating system. The company has recently successfully converted other products to run on the lower-cost systems, and is on track to do the same for products derived from the Virtual Human product.

\section{. . 20 employees at project start, 400 at the end of 1997 . . .}

In the meantime, much of the ATP-funded technology that went into the Virtual Human has been adapted to three CD-ROMs (The Dissectable Human ${ }^{\mathrm{TM}}$, The Dynamic Human ${ }^{\mathrm{TM}}$, and CardioViewer 3D ${ }^{\mathrm{TM}}$ ) and two medical books which use unique prints showing layers of body parts. All five products are now being marketed by Mosby-Year Book, a subsidiary of Times-Mirror. In addition, EAI has formed an alliance with Elsevier Science to create $3 \mathrm{D}$ multimedia titles in the neuroscience area.

These products have achieved several of EAI's original marketing objectives and have been used successfully in training medical students. One professor who used The Dynamic Human ${ }^{\mathrm{TM}}$ as a teaching aid reported that her students "seem to retain more information after using this visual tool" and "are more excited about anatomy and physiology when the material is viewed with $3 \mathrm{D}$ animation and graphics on a computer screen." The company has also incorporated its ATP-funded technology, both the anatomical database and the motion capability, in the tools it uses to provide custom modeling in biomedicine, health education, human body animation, and entertainment.

EAI is especially interested in offering its software as training tools for surgery via laparoscopy (for example, using a laparoscope to look into the abdomen) or other less-invasive surgical procedures. One candidate for this type of treatment is abdominal aortic aneurysm, which afflicts 1.5 million people in the United States each year. If left untreated, the aorta can rupture, usually causing death. This type of open-surgery repair has a morbidity rate of 15 percent to 40 percent.

In January 1997, EAI entered into an agreement to develop software that will support Endovascular Technologies's Endovascular Grafting System, a less-invasive, less costly alternative to open vascular surgery that should lead to lower mortality, fewer complications, shorter hospital stays, and quicker patient recoveries. The software will automatically calculate key aortic measurements, based on actual CT (computerized tomography) data, and enable doctors to walk through a patient's anatomy on the computer. The software allows doctors to identify structures, discern damaged and healthy tissue, and determine a patient's condition without performing invasive procedures. This application is directly dependent on the technology developed by the ATP project.

\section{Better-Trained Doctors}

The CD-ROMs and books developed or bundled with the new technology and databases have benefited anatomy and physiology students. The successful modification of the Virtual Human product for less-expensive computers, which will bring down the cost of the complete system, has the potential for creating large economy-wide benefits.

\section{One professor who used The Dynamic Human ${ }^{T M}$ as a teaching aid reported that her students "seem to retain more information after using this visual tool" . . .}

In many areas of surgery, less physically invasive procedures are replacing traditional techniques. Angioplasty, for example, can often be used instead of open surgery to repair blood vessels. If the Virtual Human proves valuable in training for these and other surgical techniques, then less-invasive procedures would likely be used more often in surgery. And by reducing the need for painful, highly 


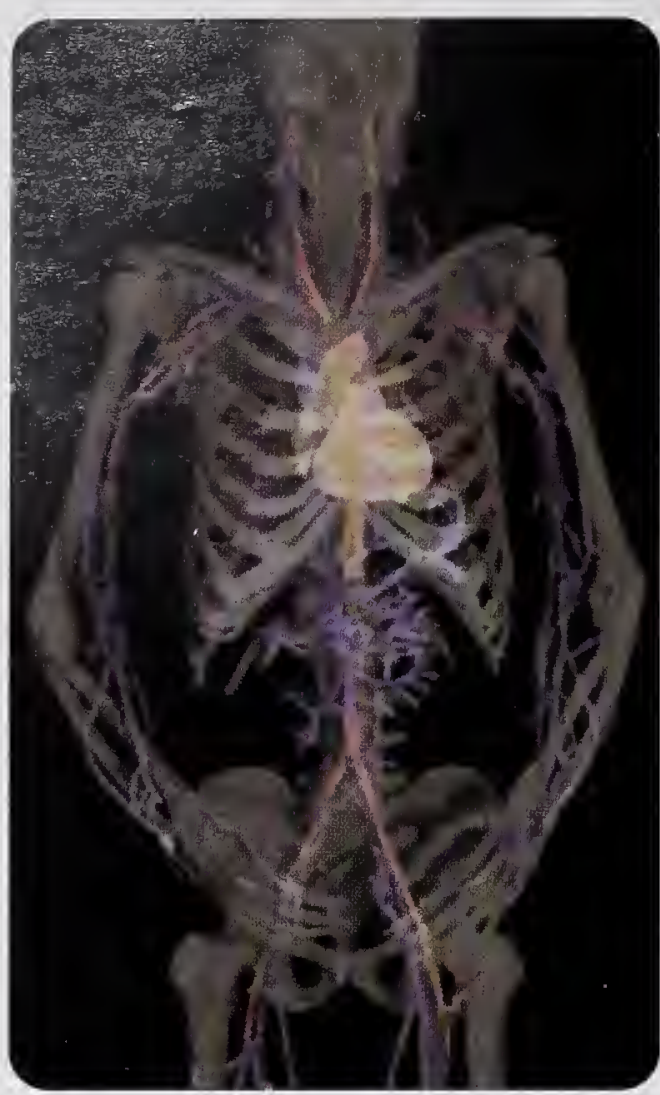

A person's body is more than just the "dry bones" of the skeleton; here the heart and major arteries and veins are shown in their proper places within or alongside the bones.

invasive surgeries, the ATP-funded technology would lower the costs and improve the quality of health care. If this happens, the value of the resulting benefits will be counted in the hundreds, possibly thousands, of dollars for each patient treated by a doctor trained with the system and could amount to life itself.

\section{Transition from Consulting to Software Products}

At the beginning of the ATP award period, June 1992, the company had 20 employees. By the end of 1997 it had 400 employees, and near the end of 1998 it had more than 900. Total revenues in 1992 were $\$ 1$ million. By 1994 they had grown to $\$ 5.5$ million, and in 1996 they were $\$ 20.4$ million. By 1997, after accounting for mergers, revenues had grown to $\$ 49.7$ million.

\section{... much of the ATP-funded technology} has been adapted to three CD-ROMs (The Dissectable Human'M, The Dynamic

$$
\begin{gathered}
\text { Human }^{T M} \text {, and CardioViewer } 3 D^{T M} \text { ) } \\
\text { and two medical books ... }
\end{gathered}
$$

EAI reports that the ATP project was a huge part of this commercial success. "This cost sharing enabled us to assemble technology," said Dr. Martin Vanderploeg, EAI executive vice-president, in 1994 during the ATP project.
"The award was a major event that launched us into this growth phase," he added. In 1994, EAI's total expenditures on research and development were $\$ 869,000$, and in that year it received $\$ 564,000$ from its ATP grant, about 65 percent of its total research and development budget.

When it applied for the ATP grant in 1991, EAI's only revenues were from consulting fees for providing support in court cases, and it had no software products on the market. By 1997, it was no longer reporting this line of business separately, and its computer animation software products had become its major activity.

The company has since its inception sought to exploit synergies among all its technological assets, continually seeking ways for the company's product lines to benefit from and build upon each other. For instance, it utilizes its $3 \mathrm{D}$ visualization software products internally, to improve its ability to deliver high-quality, interactive animation software products, such as CD-ROM medical education products, in a timely manner. But the flow of technology works in the other direction as well, according to company publications, because it is continuously modifying and enhancing the $3 \mathrm{D}$ visualization software as it develops new interactive software products.

\section{Awards for Technical Achievements Roll In}

EAI began to receive awards for its technical achievements in 1994. In that year, it received the Smithsonian Award from Computerworld magazine for the use of information technology in the field of medicine. The next year, it received the Award of Excellence in Animation from the Association of Medical Illustrators, and was a finalist, together with Walt Disney Studios, in the International ANNIE Awards category for best animations in the film industry. And in 1996, EAI was one of 25 recipients of the Technology and Innovation Award from Industry Week, specifically for its interactive $3 \mathrm{D}$ visualization and dynamics products used in the manufacturing sector for product development.

\section{ATP Funding Plays a Crucial Role}

According to EAI officials, the company would not have been able do its research and development work without the ATP funds. The award enabled EAI to establish collaborations with the Mayo Clinic and Johns Hopkins University, and work performed during the ATP project facilitated collaboration with the National Library of Medicine on a later project. And it enabled the company to significantly extend its capabilities in computer visualization and computational dynamics, providing new technology that could be applied to other areas of the company's activities. 
Having the award and doing the project also made EAI more attractive to potential investors. This was crucial in the early years of the company. In a 1995 interview with a reporter from the Wall Street Jourual, Matthew Rizai, CEO of the company, noted that winning the ATP award - which was for $\$ 1.9$ million - gave him leverage with

The award enabled EAl to establish collaborations with the Mayo Clinic and Johns Hopkins University, and work performed during the ATP project facilitated collaboration with the National Library of Medicine on a later project.

private investors, from whom he raised an additional $\$ 1.5$ million. And the company says the ATP grant continued to be important to investors as it conducted its initial public stock offering in February 1996, a few months after the ATP project ended, raising $\$ 30.5$ million.

\section{Outstanding Commercial Performance}

The company's recent rapid growth, accomplishments, and recognition received are impressive. Over the past 10 years it has emerged from the ranks of start-up to a company employing nearly 1,000 people. It has made the transition from a company heavily dependent on consulting revenues to one which relies on high-value software products. Its success has depended substantially on the internal integration of all its technical assets to develop new products in a variety of fields that draw on its technologies for very large database manipulation and visualization of motion, and on its belief that the company can succeed only if it brings those new products into the market.

In the September 1997 issue of Individual Investor magazine, EAI was named one of "America's Fastest Growing Companies." And, early in 1998, two additional magazines recognized the company's achievements.

\section{Awards for technical achievements roll in.}

Business Week magazine, in its January 12, 1998, issue, recognized Matthew Rizai, the company CEO, as one of the best entrepreneurs of 1997, and Forbes ASAP magazine, in its Feb. 23, 1998, issue, recognized the company as one of the 100 most dynamic technology companies in the United States - with a rank of number eight. 


\section{Mathematical Technology to Restore or Enhance Movies}

Marlo

any old movies are extremely valuable. If they were made for entertainment, reviving them for current showing can earn sizable profits in addition to providing viewing pleasure to consumers. The film archives of some movie studios, in fact, are worth hundreds of millions of dollars. Documentary movies with footage of important people, industrial processes, and current or historical events have great value, too, for educational and archival purposes.

COMPOSITE PERFORMANCE SCORE (Based on a four star rating.)

\section{Old Movies: a Resource Too Valuable to Waste}

Movies mean reels of film. Commercial moviemaking uses a master film from which others are copied. Film is a physical thing that can be damaged, soiled, or broken like any other object. But unlike a scratch on a single car, a scratch or other artifact on an old movie master can affect the film's usefulness to viewing audiences and the fortunes of the company that owns it. If the master film is marred, each copy will also be marred. Even if the master film is converted to digital form for making video copies, the artifacts will persist. Everything on the old film, trash and all, is converted to electronic data that go onto the video copy.

\section{Viewers of many films, both current} and archival, are benefiting from what they do not see: defects removed by the technology.

Another difficulty with movies and other videos is the existence of several formats. It would be useful for film companies to be able to change films from one format to another so that current films could be easily converted to video, and older films could be made to fit today's video and film equipment. Format has to do with the technicalities of converting movies to digitized videos that can be
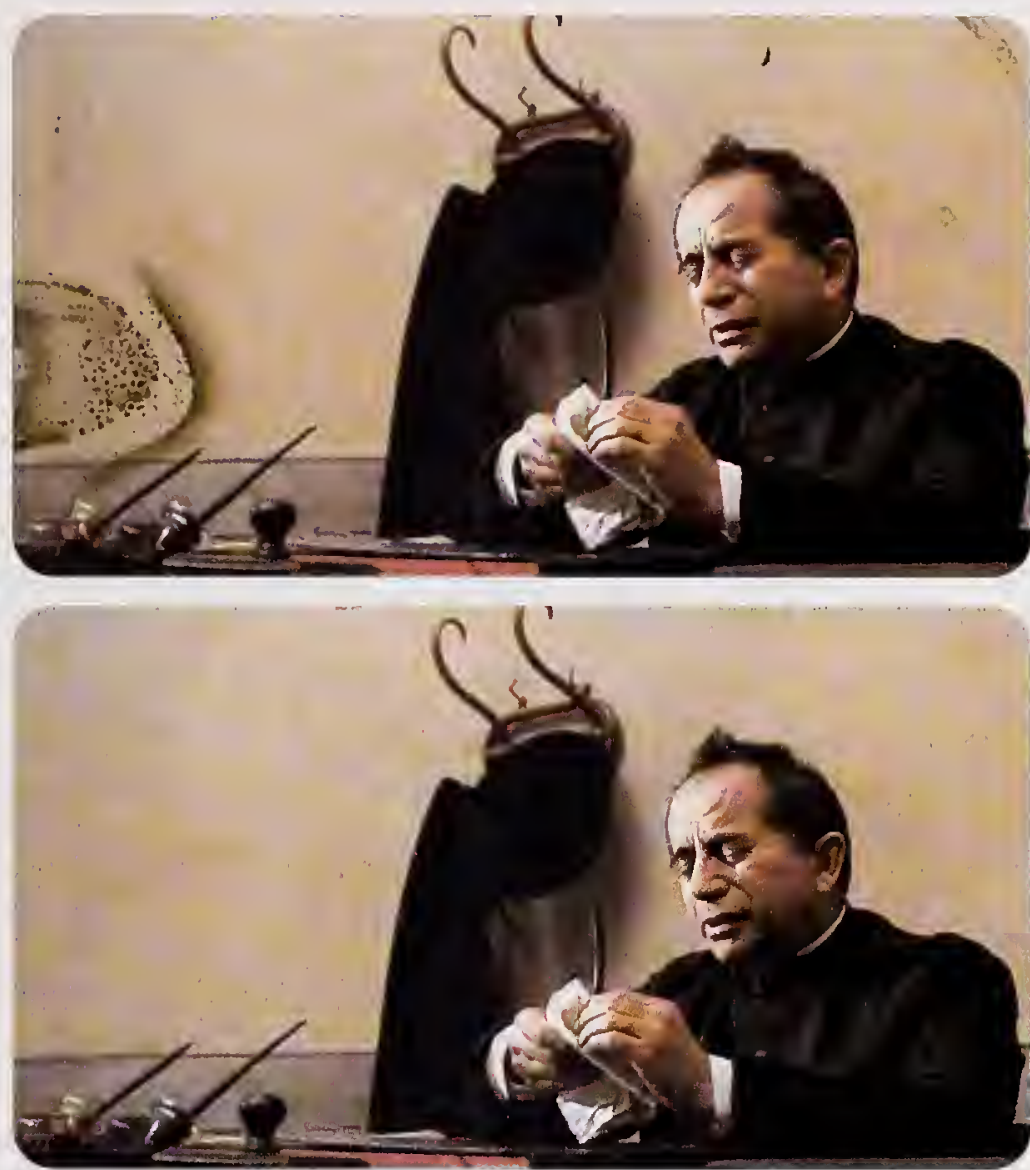

A frame from the movie Amacord, shown first with several areas that are damaged, and then shown after digital restoration automatically removed the damaged spots and replaced them with the original images.

shown on TV. One format problem involves resolution. The U.S. standard for TV is 525 scan lines and 60 hertz $(\mathrm{Hz})$ - the frame rate. The European standard is 625 


\section{PROJECT HIGHLIGHTS}

\section{PROJECT:}

To develop generic software technology that can repair, enhance, or reformat movie and video sequences, enabling the restoration of damaged movies, enhancement of military images, and conversion between digital image formats.

Duration: 5/1/1993 - 8/31/1995

ATP Number: 92-01-0053

FUNDING (in thousands):
$\begin{array}{llc}\text { ATP } & \$ 989 & 88 \% \\ \text { Company } & 136 & 12 \% \\ \text { Total } & \$ 1,125 & \end{array}$

\section{ACCOMPLISHMENTS:}

MTI developed technology to remove artifacts (unwanted defects) from movies, whether archived or newly created. It made progress in developing the reformatting technology, but this work is still experimental. The company also:

formed MTI Digital Restoration Services early in 1996, a division now actively marketing software and restoration services in video post-production;

received jacket-cover credit for restoration work on the laser disc version of the 1958 film A Night to Remember, about the sinking of the Titanic;

- participated, via MTI Digital Restoration Services, in acclaimed restorations of recent rereleases of Federico Fellini's Amarcord and Cecil B. DeMille's Ten Commandments; and had its software used in the perfection or restoration of hundreds of new and old films for new video releases since 1995.

\section{COMMERCIALIZATION STATUS:}

Commercialization is in progress. Film-restoration sof tware and services are being sold by MTI Digital Restoration Services, and MTI has other products under development. Viewers of many films, both current and archival, are benefiting from what they do not see: defects removed by the technology.

\section{OUTLOOK:}

In the restoration of old movies and the polishing of new releases, there are excellent expectations for the mathematical algorithm technology. It also has potential applications in forward-looking infrared imagery and in medical imaging areas like ultrasound and fluoroscopy. Completion of the technology for conversion between formats will widen applications further, particularly in high-definition TV.

\section{Composite Performance Score: \\ COMPANY: \\ Mathematical Technologies Inc. (MTI) \\ 1 Richmond Square \\ Providence, RI 02906-5139.}

Contact: Donald E. McClure

Phone: (401) 831-1315

Number of employees: 4 at project start, 6 at the end of 1997

commercial applications via new programming technologies, and its defect-removal research during the ATP project was particularly successful. Researchers developed mathematical algorithms to create data for filling in damaged areas of the digitized versions of movie-frame images, a process that essentially restores the images to their original quality. 'Texture matching is an important problem that had not been anticipated but had to be solved in order to repair severe, wide scratches, and other defects involving substantial amounts of missing data.

\section{Researchers developed mathematical algorithms to create data for filling in damaged areas...}

\section{A Mathematical Approach to Repairing and Converting Films}

This ATP project with Mathematical Technologies Inc. (MTI), a small company formed in 1981, has solved many of the problems of reformatting and removing defects from films. M'TI specializes in bringing mathematical theory to

scan lines and $50 \mathrm{~Hz}$. High-definition 'TV will have a

A second format problem concerns how to preserve the natural speed of motion depicted in a film when translating, for example, from a format that requires a speed of 24 frames per second to one that calls for 30 . Because of the need to compensate for these differences in resolution and film speed, translation from one format to another is not a trivial process. 
MTI researchers succeeded in developing some components needed for format conversion. Work on other components is still experimental. The researchers thoroughly investigated motion compensation (which concerns the way moving objects are detected in a movie) and determined how to make adjustments for motion so that the new technology does not create new artifacts. Specifically, they estimated the frame-to-frame motion of objects and developed technology for the rapid calculation of the most significant motions. This technology is critical both for restoration of damaged images and for translating between film and video recording standards.

\section{New Products and Services for Film and Video Industries}

Commercialization is under way. Near the end of the ATP project, MTI established a division called Digital Restoration Services that sells movie-restoration software and services, and the company is developing other products that would use the ATP-funded technology, too. MTI has invested heavily in the development of new software for film and video post-production since the ATP project was completed. A new state-of-the-art algorithm for converting from ordinary video resolution to high-definitionTV resolution was demonstrated at the National Association of Broadcasters trade show in April 1998.

The new MTI offerings face competition from several other products - virtually all of them from abroad.

Competitor products, however, tend to focus on the artistic end of the of the movie restoration business rather than on the technical end. MTI's products focus on the technical end, and the company reports it is currently the only one to provide such software technology for automated restoration.

MTI initially intended to develop applications for motion-compensated reformatting and standards conversion, as well as restoration. After the ATP project began, the company decided to focus almost exclusively on restoration, based on a reassessment of the market for conversion software and services. It planned to offer filmrestoration software running at commercially viable speeds (perhaps three to four times slower than real-time) on graphics workstations or high-performance personal computers costing well under $\$ 100,000$. MTI succeeded, and it is offering the software for use with contemporary and archived movies. In addition, the company says it is about two years ahead of where it would have been without the ATP funds.

\section{Restored Ten Commandments}

Viewers of the many films, both contemporary and archival, restored with MTI's technology have benefited. When Cecil B. DeMille's Ten Commandments was restored with the ATP-funded technology and rereleased, a commentator on the television program "Entertainment Tonight" reported that "the difference between the original and this new vibrant version is a revelation. . . Digital technology is the modern miracle that's made it possible."

As MTI's mathematical algorithm technology is applied to more films, more viewers will benefit. Further benefits will emerge if the technology is used in other areas. It has potential applications, for example, in forward-looking infrared imagery, which is used by the military to detect objects at night, and may also be useful in medical imaging procedures such as ultrasound and fluoroscopy. Additional benefits will materialize if the technology for standards conversion is completed.

\section{A new algorithm for converting from ordi- nary video resolution to high-definition-TV resolution was demonstrated. . . in April 1998.}

The film-restoration technology already commercialized promises spillover economic benefits to the viewing public and to owners of films with defects. Many films of historical interest, once they are restored with the new technology, will be available to viewers. The number of viewers will grow over the years as the restored or enhanced films are shown again and again, so spillover benefits will grow, as well. If the reformatting technology is completed and commercialized, additional benefits will accrue. 

TORRENT SYSTEMS, INC. (formerly Applied Parallel Technologies, Inc.)

\section{A User-Friendly Programmer's Tool for Writing Parallel-Processing Software}

Mast solving many formerly intractable computing problems in government and industry. Estimates suggest that parallel processing would save the U.S. airline industry alone more than $\$ 1$ billion annually through more efficient scheduling of flight crews. It could enable U.S. oil companies to reduce exploration costs and increase oil reserves. Analysis of massive transaction databases using parallel processing could recover much of the tens of bitlions of dollars lost annually to health care and credit card fraud.

COMPOSITE PERFORMANCE SCORE (Based on a four star rating.)

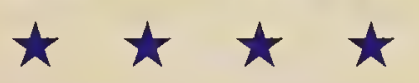

\section{Easy-to-Do Programming for Parallel Processing}

A difficulty with parallel processing, however, is that writing its software is more art than science, an art practiced well by a relatively small number of programmers. Torrent Systems, founded as a two-person company in 1993, had an idea for solving this problem but was unable to find venture capital to finance the research to develop the technology. The company then sought and won ATP funding that enabled it to proceed. Torrent ultimately developed a component software system that allows programmers to build parallel-processing software systems without needing to explicitly understand how the system exploits the underlying parallel-processing hardware. To accomplish this project, researchers studied the actual application needs of typical users - to assure that the results would be widely applicable and useful.

\section{Quick to Market}

Torrent produced a research prototype of a parallelsoftware component framework, created its basic components, and performed limited testing on them. It also planned to develop a library of reusable code - containing components for a parallel-processing system. If such a library were available for other developers, then even more applications could come on line sooner. The company, however, did not complete this research task. Torrent closed the project before its anticipated completion date in order to commercialize early technical results and generate needed revenue.
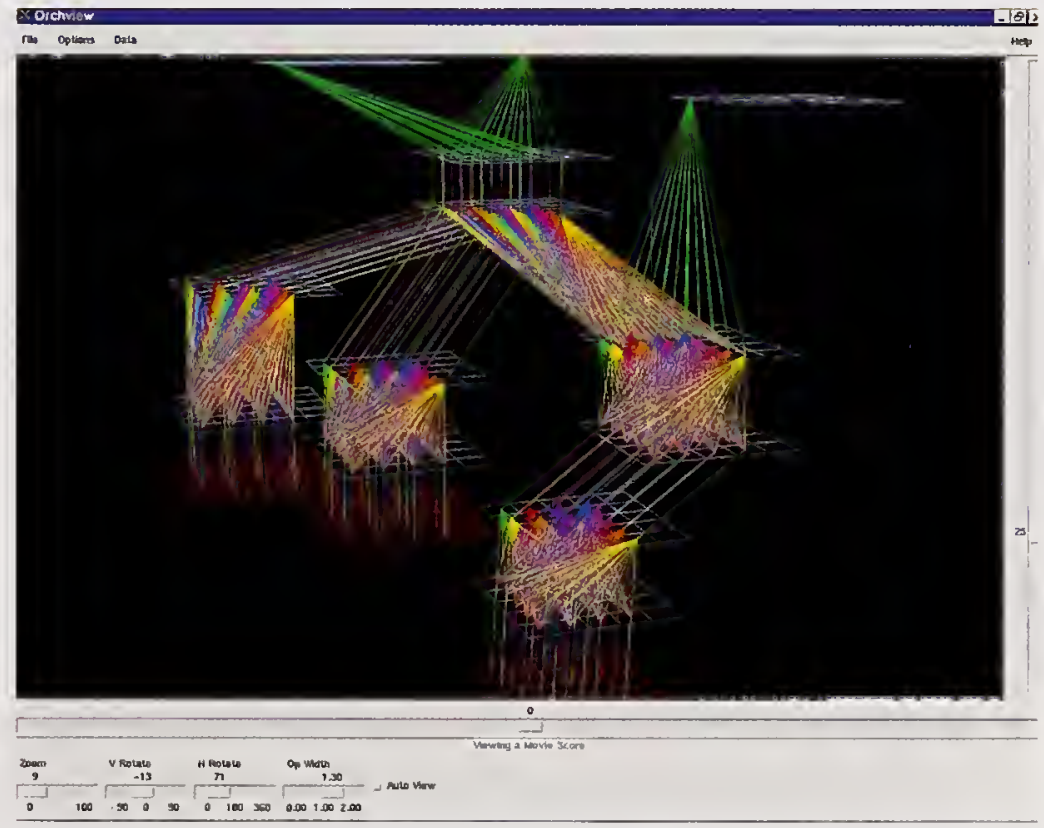

A graphic illustration of a 16 processor system under the control of Orchestrate - three sources of input data (shown at the top of the screen in green) are split into many parallel data streams, each to be manipulated by a sequence of software components (the grids at the bottom in red) which apply the same logic to each stream.

Torrent incorporated the ATP-funded componentbased technology in a product called Orchestrate ${ }^{\mathrm{TM}}$, which the company describes as a "parallel application environment that insulates you from the complexities of parallel programming while delivering scalable applications." United Airlines and Citicorp were two of the first corporations to license it. 


\section{PROJECT HIGHLIGHTS}

PROJECT:

To develop component-based tools for writers of parallel-processing software, as well as a library of reusable parallel-processing software components.

Duration: $12 / 1 / 1994$ to $7 / 31 / 1996$

ATP Number: 94-06-0024

FUNDING (in thousands):

$\begin{array}{lrr}\text { ATP } & \$ 1,117 & 77 \% \\ \text { Company } & 325 & 23 \% \\ \text { Total } & \$ 1,442 & \end{array}$

\section{ACCOMPLISHMENTS:}

Torrent accomplished most of the project goals, including development of a software environment for building parallel data-processing applications. The company did not develop as extensive a library of reusable components as originally anticipated. It halted the project sooner than originally planned to exploit the excellent commercial opportunities for technology developed early in the project. Torrent's outstanding progress toward commercialization is indicated by the following:

The company applied for a patent on parallel training of neural networks, as well as patents on several other inmovations.

Torrent incorporated the ATP-funded technology in a product called Orchestrate ${ }^{\mathrm{TM}}$, introduced to the market in 1996. The company describes it as "a parallel development environment that insulates you from the complexities of parallel programming while delivering scalable applications."

- Orchestrate ${ }^{\mathrm{TM}}$ was described in a December 1996 Datamation article, "Build Your Warehouse on MPP," as one of a number of approaches to use in data warehousing.

Orchestrate ${ }^{\mathrm{TM}}$ was selected in 1997 for use by KO1, IBM, Citicorp, Autozone, Sears Roebuck, and United Airlines.

Torrent entered into a strategic partnership in July 1997 with IBM, which will promote Orchestrate ${ }^{\mathrm{TM}}$ as a standard computer application. IBM is focusing on rapid development and deployment of a parallel-processing software system that can be enlarged without needing to be replaced by a new version, because expansion of the system is built into its architecture. Orchestrate ${ }^{\mathrm{TM}}$ plays a key role in the expansion capability of the IBM system. Torrent extended the partnership in September 1997, with IBM agreeing to resell Orchestrate ${ }^{\mathrm{TM}}$.

Torrent entered into partnerships in September 1997 with three new vendors: The MEDSTAT Group, i.d.Centric, and Knowledge Discovery One.
The company also negotiated bundling arrangements (selling two or more separately produced products as a unit) with independent software vendors and manufacturers including Emergent, Knowledge Discovery One, Lockheed Martin IS\&T, and MRJ Technology Solutions.

During 1997, several commercial software vendors chose Orchestrate ${ }^{\mathrm{TM}}$ for building their software products. The first such product, produced by the SAS Institute, reached the market in late 1997.

- At the end of 1997, Computerworld magazine recognized Torrent as one of the "100 Hot Emerging Companies."

- Torrent had attracted investments of $\$ 3.8$ million by the end of the ATP project in July 1996 , and it increased the total to $\$ 10$ million over the next 18 months.

U United Airlines, an early customer, is using Orchestrate ${ }^{\mathrm{TM}}$ and an IBM parallel-processing computer to design a system for managing airplane seat assignments. United expects the new system to generate between $\$ 50$ million and $\$ 100$ million per year in increased revenue. The company is spending only about $\$ 17$ million on the system, which would not work without Orchestrate ${ }^{\mathrm{TM}}$.

\section{COMMERCIALIZATION STATUS:}

The ATP-funded programmer's tool for writing parallel processing software has been commercialized. It is embodied in Orchestrate ${ }^{T M}$, as well as in derivative products.

\section{OUTLOOK:}

The outlook for further commercialization and economic benefits is excellent. The strong market interest in Orchestrate ${ }^{\mathrm{TM}}$ indicates its usefulness in processing immense amounts of data. Since government and many industries - retail, health care, energy, and transportation - use massive databases, new tools that can dramatically increase processing efficiency stand to yield billions of dollars in savings across the economy. The benefits from this project will accrue mostly to users of the technology, rather than to Torrent.

\section{Composite Performance Score: \\ COMPANY: \\ Torrent Systems, Inc. \\ (formerly Applied Parallel Technologies, Inc.) \\ 5 Cambridge Center, Seventh Floor \\ Cambridge, MA 02142}

Contact: Robert Utzschneider

Phone: (617) 354-8684 ext. 1162

Number of employees: 2 at project start, 32 at the end of 1997

type of business. Torrent extended that partnership a few months later, with IBM agreeing to resell Orchestrate ${ }^{\mathrm{TM}}$.

United Airlines, an early customer, reported in a alliances. It formed a partnership with IBM in July 1997, under which IBM will promote Orchestrate ${ }^{\mathrm{TM}}$ as a standard computer application. IBM's focus is rapid development and deployment of a parallel-processing hardware/software system that can be enlarged without needing to be replaced by a new version, because expansion is built into its architecture. Orchestrate ${ }^{\mathrm{TM}}$ plays a key role in that expansion capability. The IBM system is specifically designed to make full use of customer sales and other data across an entire company, regardless of the

$$
\text { ... halted the project sooner than }
$$

originally planned to exploit the excellent commercial opportunities for technology developed early in the project. 
November 1997 Chicago Tribune article that it had installed a new IBM RS6000/SP2 parallel-processing computer. The software supplied by IBM included Orchestrate $^{\mathrm{TM}}$ under a licensing agreement between Torrent and IBM. United paid $\$ 3.5$ million for the hardware and planned to spend another $\$ 13.5$ million to get the computer running. The system is expected to generate between $\$ 50$ million and $\$ 100$ million per year in increased revenue by doing a better job of matching potential fliers with available airplane seats. Orchestrate ${ }^{\mathrm{TM}}$ is a critical component that enables United personnel to program the computer, which United would not otherwise have bought. This advance is important, since the RS6000/SP2 has been on the market for several years.

\section{... new tools that can dramatically} increase processing efficiency stand to yield billions of dollars in savings across the economy.

Torrent also formed a marketing partnership with Sun Microsystems in 1997. An early outgrowth of this alliance was a joint demonstration showing the advantages of using Orchestrate ${ }^{\mathrm{TM}}$ in a typical data warehousing application. Orchestrate $^{\mathrm{TM}}$ was used to integrate the basic Torrent components and specialized components from three other vendors into a single test application. The test involved data cleaning of a name-and-address file of about 13 million records, which was then merged with a demographics file of about 16 million records. When the test was run without

. . . a component software system

\section{that allows programmers to build parallel-} processing systems without needing to explicitly understand how the system exploits the hardware.

using parallel processing, the application took 32.5 hours on a machine using four processors. With Orchestrate ${ }^{\mathrm{TM}}$, the application took only 9 hours. When the number of processors was increased to 12 , the Orchestrate ${ }^{\mathrm{TM}}$-based application finished in just 3 hours.

Torrent also entered partnerships in September 1997 with three new software vendors: The MEDSTAT Group,
i.d.Centric, and Knowledge Discovery One. And it negotiated bundling arrangements (selling two or more separately produced products as a unit) with independent software vendors and manufacturers, including Emergent, Knowledge Discovery One, Lockheed Martin IS\&T, and MRJ Technology Solutions.

\section{Potential for Huge Benefits}

Torrent has succeeded in marketing its technology, and substantial broad-based benefits can be expected to flow from the use of the new technology incorporated in its software. Users of Orchestrate ${ }^{\mathrm{TM}}$ have benefited from the removal of the need to pay attention to programming details for $\mathrm{C} / \mathrm{C}++$ (the most common language used to write programs for parallel processing), because Orchestrate $^{\mathrm{TM}}$ handles them. As more applications of the new technology are implemented through the use of Orchestrate $^{\mathrm{TM}}$ and other 'Torrent products, more analyses of large databases will be done. Another product that uses the ATP-funded technology is Orchestrator for the SAS System $^{\mathrm{TM}}$, recently released by the SAS Institute.

\section{... this technology . . . is embodied in industrial strength computer programs used in diverse industries and by government agencies.}

Economic benefits are likely to be large and widespread for this technology. It is embodied in industrial strength computer programs used in diverse industries and by government agencies. Users in these areas say they anticipate dramatic savings. Consumers will also benefit from these savings, as lower operating costs are passed on to them. Torrent, a small company, will be able to collect only a small percentage of the total additional value created by its technology, while the rest will spill over to others in the economy.

The benefits from the ATP project would likely be even greater if 'Torrent had been able to fully develop and make available the library of reusable components as originally planned. However, as is often the case with small, near-startup companies, cash-flow concerns related to ensuring company survival dictated a fast move to generate revenue. In this case, given its limited resources, Torrent felt it had to stop the research project early and commercialize the technology. As customers suggest needs for other components, they will be developed and integrated into the company's products. 


\section{ATP Project Speeds}

\section{Exploitation of Parallel Processing}

ATP funding for this project allowed Torrent to research and develop a prototype of a component software system that allows programmers to create parallel-processing software in a user-friendly way. Without the ATP funds, Torrent officials say, it is doubtful that the technology could have been successfully developed at all. Venture capital funding had been sought but was unavailable. ATP funded the project to enable U.S. industry to broadly and rapidly exploit parallel processing, expecting that it would generate significant benefits throughout the economy. The speedy adoption of Torrent's first commercial products confirms that expectation.

Venture capital funding had been sought but was unavailable. ATP funded the project

to enable U.S. industry to broadly and rapidly exploit parallel processing. 


\section{On Time with Rail-Traffic Optimization Technology}

ver 80 percent of raw materials and goods travel by rail at some point during shipment. Rail transport is prone to unexpected delays caused by routing conflicts, accidents, and power outages that inconvenience passengers and impair shipments between suppliers, manufacturers, and retailers. These delays play havoc with just-in-time delivery that manufacturers and distributors use to keep inventories low, and can increase costs. Punctuality is equally important for passenger trains: delays are a primary barrier to increasing ridership. And because passenger and freight trains share 95 percent of the same track miles, any delay can affect much of the rail system.

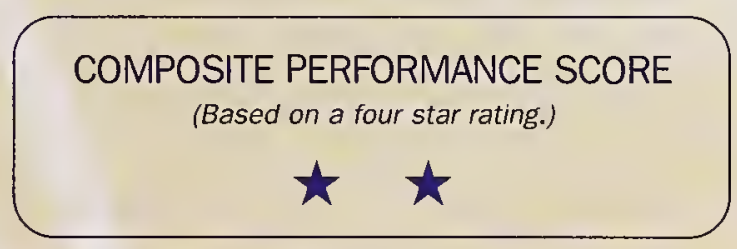

\section{Problems with Existing Optimization Approaches}

Traditional optimization software employs a linear decisionmaking process whereby a single solution is reached. Traditional optimization techniques generally seek a single solution, such as maximizing profit or reducing cost. Each change in the environment (e.g., train delays or equipment fault) triggers the optimization system to start again from scratch to search for a new solution. This approach is both time-consuming and unrealistic for effective use in planning real-time train movement. In contrast, standard planning of train movement requires several objectives to be addressed simultaneously, e.g., minimizing the cost of crews and minimizing lateness.

\section{Union Switch and Signal Company Sees Opportunity in University Research}

Prior to applying to the ATP, Union Switch and Signal, Inc. (US\&S), a leading supplier of equipment to the railroad industry, was working with a Carnegie Mellon University (CMU) research team on technology for improving the safety and viability of railroad equipment. In that process, US\&S became familiar with optimization

\section{US\&S saw an opportunity to} build on the research by CMU to break through the technical challenges of optimization for rail traffic scheduling.

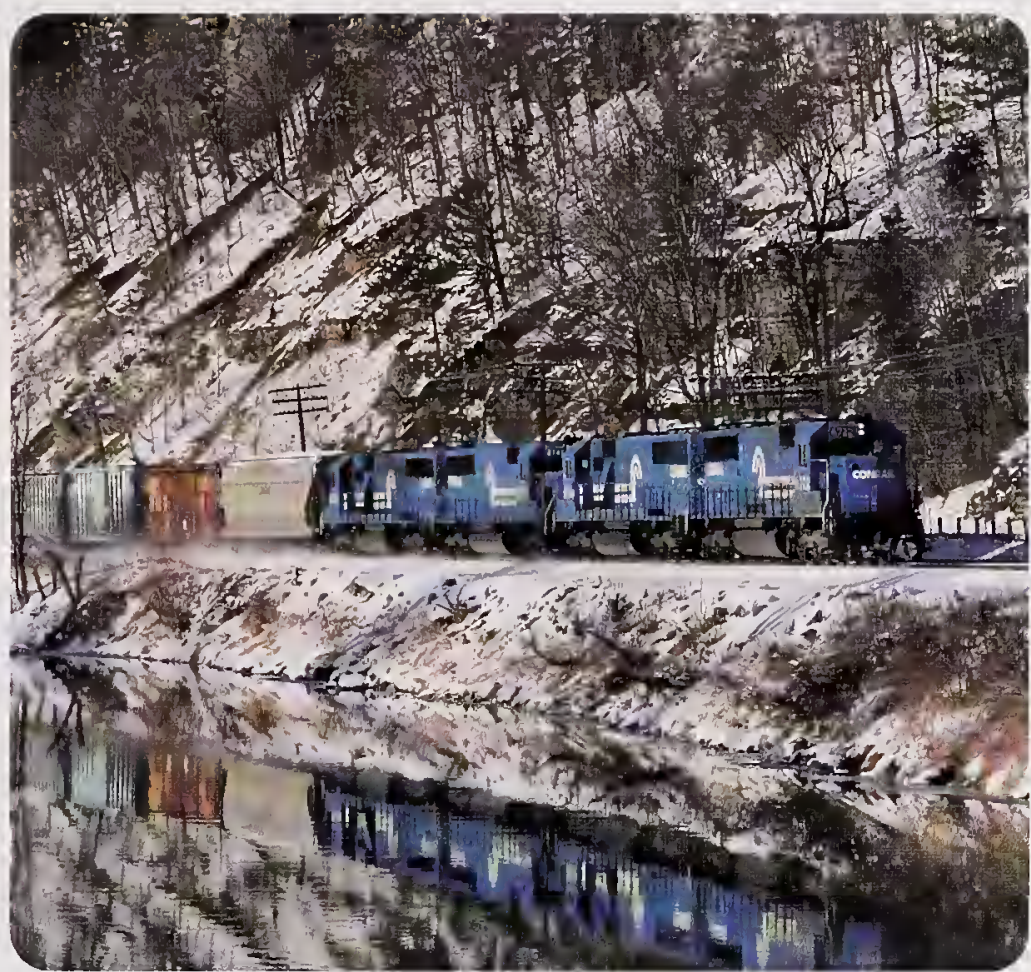

Better tools for railway traffic planning could improve the rate of on-time arrivals.

research that was going on at CMU. US\&S saw an opportunity to build on the research by CMU to break through the technical challenges of optimization for rail traffic scheduling. The optimization research underway at Carnegie Mellon was referred to as the "Asynchronous Teams, or A_Teams technology." Shortly after discovering the A_Teams work at Carnegie Mellon, US\&S invited Sarosh Talukdar, a CMU professor of electrical and 


\section{PROJECT HIGHLIGHTS}

\section{PROJECT:}

To adapt and extend a distributed multiagent-based optimization technology developed by Carnegie Mellon University (CMU) for use in railway traffic planning.

Duration: $1 / 15 / 95-1 / 14 / 97$

ATP Number: 94-01-0063

$\begin{array}{lcc}\text { FUNDING (in thousands): } \\ \text { ATP } & \$ 2,000 & 67 \% \\ \text { Company } & 967 & 33 \% \\ \text { Total } & 2,967 & \end{array}$

\section{ACCOMPLISHMENTS:}

US\&S researchers, working closely with university researchers at CMU, adapted and extended a technology to simulate real-time movement planning for railroads. The project:

developed the basic tools and knowledge needed to construct and implement a better optimization system for railroad use;

developed two different software programs which implement the technology: Real-time Central Traffic Controller, a real-time movement planning software; and Offline Railroad Operations Planner, software allowing railroads to evaluate alternative track layouts and routing plans;

secured funding from a class 1 railroad (one of the six largest North American railroads) to pilot-test the technology; and

achieved a potential 50 percent improvement in rate of on-time arrivals over the use of traditional command-and-control software.

\section{COMMERCIALIZATION STATUS:}

Efforts by US\&S to commercialize work on the optimized traffic planner were focused on two software packages, each with specialized applications: the Real-time Central Traffic Controller and the Offline Railroad Operations
Planner. The Real-time Central Traffic Controller is intended to provide optimized routing plans to central office controllers. The Offline Railroad Operations Planner provides recommendations that can increase the capacity and throughput of a railroad line, e.g., it can identify a bottleneck in a railway line and suggest solutions to increase throughput at the trouble spot. The software has performed well in pilot tests conducted in collaboration with a railroad, but had not been commercialized as of the time of the study.

\section{OUTLOOK:}

The commercialization of the two software packages is contingent on the ability of US\&S to enter into cooperative development arrangements with prospective railroad customers. These customers can provide necessary data to perform additional tests and funding to support continued development of the software. There are several factors supporting a favorable outlook for commercialization: two software programs have been developed; the initial test results were strong; and the railroad companies have demonstrated interest. At the time of the study, however, uncertainties remained about the willingness of the railroad companies to provide the necessary follow-through support for commercialization.

\section{Composite Performance Score: $\star \star$ \\ COMPANY: \\ Union Switch and Signal, Inc. \\ 1000 Technology Drive \\ Pittsburgh, PA 15219 \\ (Parent Company: Ansaldo Signal, the Netherlands)}

Contact: Dr. Frank Boyle

Phone: (412) 688-2400 x3511

Subcontractor: Carnegie Mellon University

In the case of railroads, this might include routing more trains over more tracks, whereas traditional movement planning systems are able to plan the movement of only one train at a time.

Another advantage of A_Teams is that it enables more rapid adaptation to alternative schedules because of changes in the environment (e.g., a track blocked by an accident) and does not require a total reassessment. Teams of agents react to local changes and make appropriate adjustments, testing the new solution by comparing it with the existing pool of solutions. In addition, the A_Teams is a modular approach, which allows networks to be upgraded and modified merely by changing the population of agents. This is important because incompatibility between different generations of software has been a particularly troublesome problem for railway decision-support software: upgrading has meant the complete replacement of software systems.

The university's modular problem-solving software appeared to offer potential for railroad routing, but not without additional research. US\&S wanted to exploit the 
opportunity, but lacked the internal resources to mount the required research effort alone.

\section{With ATP's Support, US\&S Adapts and Extends the A_Teams Approach}

In 1995, the Advanced Technology Group (ATG), an R\&D unit of US\&S, proposed a research project to adapt and extend the A_Teams approach to make it suitable for rail traffic planning. The proposal scored high in technical and economic merit, and US\& $\&$ received a $\$ 2$ million award for research from ATP. The company contributed a cost share of $\$ 967,000$ to the project.

The technical goals of the project centered on developing a distributed optimization approach to railroad routing, and adapted and extended Carnegie Mellon's A_Teams modular problem-solving approach. The research had three major components: 1) decomposing a scheduling problem into subtasks to be pursued by agents, 2) developing a messaging protocol for communication among subtasks, and 3) specifying programming agents to respond to information received.

\section{Technical Goals Reached}

Researchers at US\&S made substantial progress in developing the necessary infrastructure. They developed the basic tools and knowledge needed to construct better A_Teams systems, including libraries of code needed for agent construction, mathematical optimization models, system components, and application interfaces to allow components of the system to work together.

\section{The simulations demonstrated a}

\section{0 percent improvement in the rate of on-time arrivals...}

Researchers at Carnegie Mellon University were contracted to investigate potential organizational designs for individual A_Teams software agents and groups of agents. In addition, they provided expert advice on how the system could be designed to allow software agents to communicate with each other in real time.

\section{Pilot Testing on Trains}

Efforts by US\&S to commercialize work on the optimized traffic planner are focused on two applications. The "Realtime Central Traffic Controller" is software for real-time movement planning that is intended to provide optimized routing plans to central office controllers. The "Offline Railroad Operations Planner" is simulation software that will allow railroads to evaluate alternative track layouts and routing plans. It provides recommendations that can increase the capacity and through put of a railroad line. For example, it might identify a bottleneck in a railway line and suggest laying double track to increase throughput at this trouble spot.

\section{...US\&S was seeking to form cooperative development alliances with class 1 railroads.}

Toward the end of the project, funding was secured from a class 1 railroad (one of the six largest North American railroads) to pilot-test the technology. US\&S researchers performed simulations of real-time movement planning using data from the railroad, including typical schedules, track layout, speed limits, and patterns of movement (e.g., periods of acceleration and deceleration). The simulations demonstrated a 50 percent improvement in the rate of on-time arrivals, a key performance goal, when compared to the performance of traditional command-and-control software.

Unfortunately, the railroad company that was supporting the pilot-testing was acquired by another railroad company, and its new management, preoccupied with consolidation, discontinued support for the project. The company's management has since reconsidered its decision, and, at the time of this study, was negotiating a new arrangement with US\&S. In addition, US\&S at that time was seeking to form cooperative development alliances with other class 1 railroads. 

ADVANCED TECHNOLOGY PROGRAM

CHAPTER 6

Manufacturing 


\section{High-Temperature Superconducting Coils for Electric Motor Efficiency}

\section{I}

large electric motors of 1,000 horsepower (hp) or more are used in many applications across the U.S. economy. If more-efficient motors could be developed and replace older ones, the savings would be substantial. The new motors would consume less electricity than older motors. In addition to cutting electricity bills, the switch to moreefficient motors would decrease the need for electricity production, with concomitant reductions in the burning of fossil fuels and in the resulting air pollution.

COMPOSITE PERFORMANCE SCORE (Based on a four star rating.)

\section{Harnessing Superconductivity to Increase Electric Motor Efficiency}

American Superconductor Corporation (ASC), a young development-stage company, was eager to undertake the long-term research and development needed to capture the advantages offered by high-temperature superconductivity for large electric motors. But it lacked the necessary financial resources to do it. At the time of the ATP award in 1992, there was little competitive pressure in the electric power-generation industry, so few incentives existed to reduce costs. And, although the Department of Energy followed the A'TP award with a contract to ASC, that source of funding was unavailable for the initial research the company proposed to do. ASC reports that the A'TP award made the research project possible. Without the award, the company would have been unable to do the research and development on the new technology, even on a delayeddevelopment schedule.

\section{. . opportunities abound for reducing electric energy use via applications of the ATP-funded technology.}

\section{Superconductivity Reduces Energy Losses}

The most significant energy losses in motors come from resistive heating in the windings, so superconducting motors with almost no electrical resistance in the windings

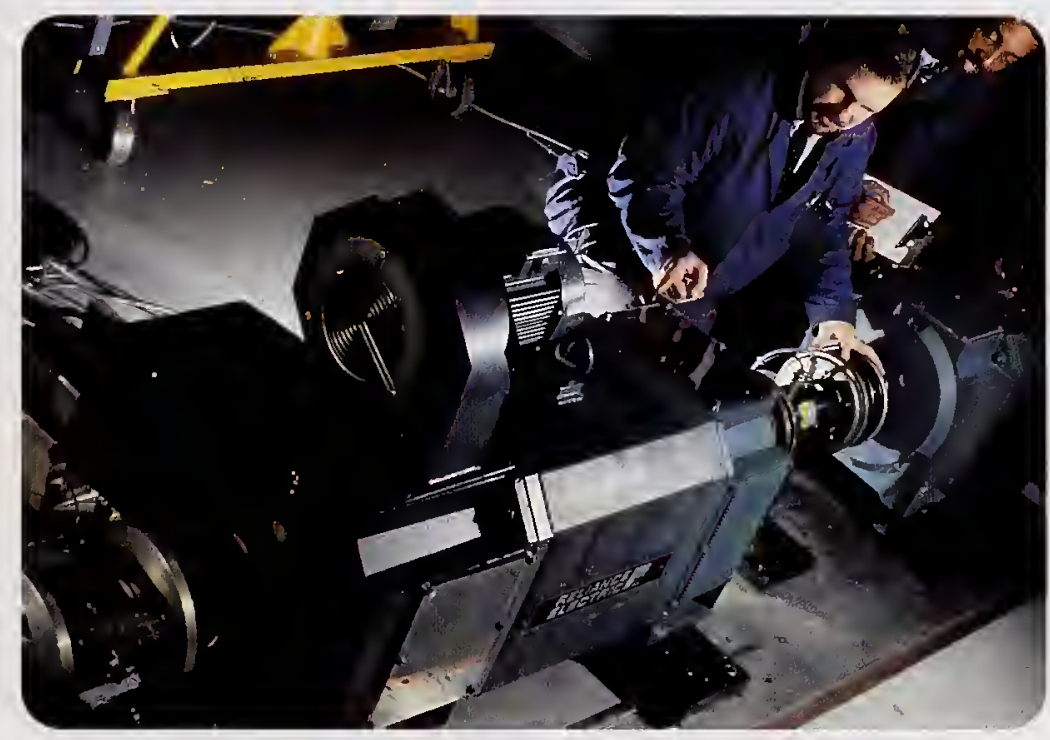

A 286 hp demonstration motor constructed by Reliance Electric with HTS windings supplied by ASC.

could realize important efficiency gains. 'To be able to build such motors required significant advances in the design, fabrication, and winding of H'TS wires in geometries required for motor winding.

In addition to industrial motors, the new technology would be useful in generators, transmission cables, and superconducting magnetic energy storage systems. It also has potential applications in $\mathrm{x}$-ray lithography, ion implantation, medical cyclotrons, magnetically levitated trains, magneto-hydrodynamic ship propulsion systems, and magnetic separation for materials processing and ore recovery. Indeed, opportunities abound for reducing electric energy use via applications of the A'TP-funded technology. 


\section{PROJECT HIGHLIGHTS}

\section{PROJECT:}

To develop high-temperature superconducting (HTS) wire fabrication and winding techniques that will enable the development of large HTS electric motors with almost no electrical resistance. This advance will reduce the motors" electricity consumption and save the country hundreds of millions of dollars in energy costs each year.

Duration: 7/1/1992 - 6/30/1995

ATP Number: 91-01-0146

FUNDING (in thousands):
$\begin{array}{lll}\text { ATP } & \$ 1,883 & 42 \% \\ \text { Company } & 2,579 & 58 \% \\ \text { Total } & \$ 4,462 & \end{array}$

\section{ACCOMPLISHMENTS:}

ASC achieved its goal of developing HTS wire fabrication and winding techniques. It demonstrated the use of racetrack-shaped HTS coils in a 5-hp motor early in the project and in a 200-hp motor soon after project completion. The company also:

received six patents for technologies related to the ATP project: “Current Limiters in Power Utiliry Applications" (No. 5,390,064: filed 7/7/1992, granted 2/14/1995),

"Superconducting Rotor"(No. 5,482,919: filed 9/15/1993, granted 1/9/1996),

"Method of Making Superconducting Wind-and-React Coils" (No. 5,531,015: filed 1/28/1994, granted 7/2/1996),

"Superconducting Magnetic Coil"(No. 5,525,583: filed 2/7/1994, granted 6/11/1996),

"Magnetostrictive Superconducting Actuator" (No. 5,585,772: filed 1/11/1995, granted 12/17/1996), and

"Variable Profile Superconducting Magnetic Coil" (No. 5,581,220: filed 10/10/1995, granted 12/3/1996);

applied for eight additional patents for technologies related to the ATP project;

won Industry Week magazine's Technology of the Year Award in 1996;

a won the 100 Award in 1996 from R\&D magazine, which selects the 100 most important innovations of the year, for its development of CryoSaver current leads, a spin-off product related to the ATP project;

. . received six patents for technologies related to the ATP project . . .

\section{Larger and Larger Motors}

Researchers from ASC and its partner, Reliance Electric Company (now part of Rockwell International), built a 5-hp HTS motor as proof of concept. This team and researchers at Oak Ridge National Laboratory then fabricated and tested a series of racetrack-shaped HTS coils of a type needed for motors. This effort included studies of mechanical and electrical properties that affect perform- received (with partner Reliance Electric) $\$ 10.2$ million in Department of Energy Strategic Partnership Initiative awards in 1996 for cost-shared development of high-horsepower, commercial-scale motors;

a received a \$10-million investment from Électricité de France, the French power company, in April 1997; and

raised \$27 million via a second public stock offering in February 1994.

CITATIONS BY OTHERS OF PROJECT'S PATENTS:

See Figure 6.1.

\section{COMMERCIALIZATION STATUS:}

Commercialization is in progress. A partnership with Reliance Electric will help commercialize the large-motor technology in the form of 1,000 - and 5,000-hp motors. In the meantime, ASC has introduced a related product, CryoSaver current leads, in 1996. Users of this product have already achieved better operating efficiencies in magnetic resonance imaging and commercial energy storage systems.

\section{OUTLOOK:}

The project has progressed as planned, and the outlook for achieving significant energy savings from HTS motors is excellent. Large electric motors account for about 65 percent of all electricity consumption in the United States, so even small efficiency gains in this application are likely to translate into cost savings of several hundreds of millions of dollars for the nation. In the future, large users of electric power will be able to construct new facilities with smaller, more-efficient and reliable motors based on HTS technology. Other applications of the technology could help residential electricity users in the United States save millions of dollars in energy costs each year.

\section{Composite Performance Score: $\star \star \star \star \star$ \\ COMPANY:}

American Superconductor Corporation (ASC)

2 Technology Drive

Westborough, MA 01581

Contact: Joe Sollecito

Phone: (508) 836-4200

Number of employees: 59 at project start, 146 at the end of 1997 Informal collaborators: Reliance Electric Company (acquired by Rockwell International in 1995), Oak Ridge National Laboratory

ance, as well as the development of fabrication techniques for producing flexible, durable wires in increasing lengths. Soon after the project ended in June 1995, ASC built a 200-hp HTS motor for testing and demonstration. The company is planning to complete development work on

\section{This advance will reduce the motors' electricity consumption and save the country hundreds of millions of dollars in energy costs each year.}




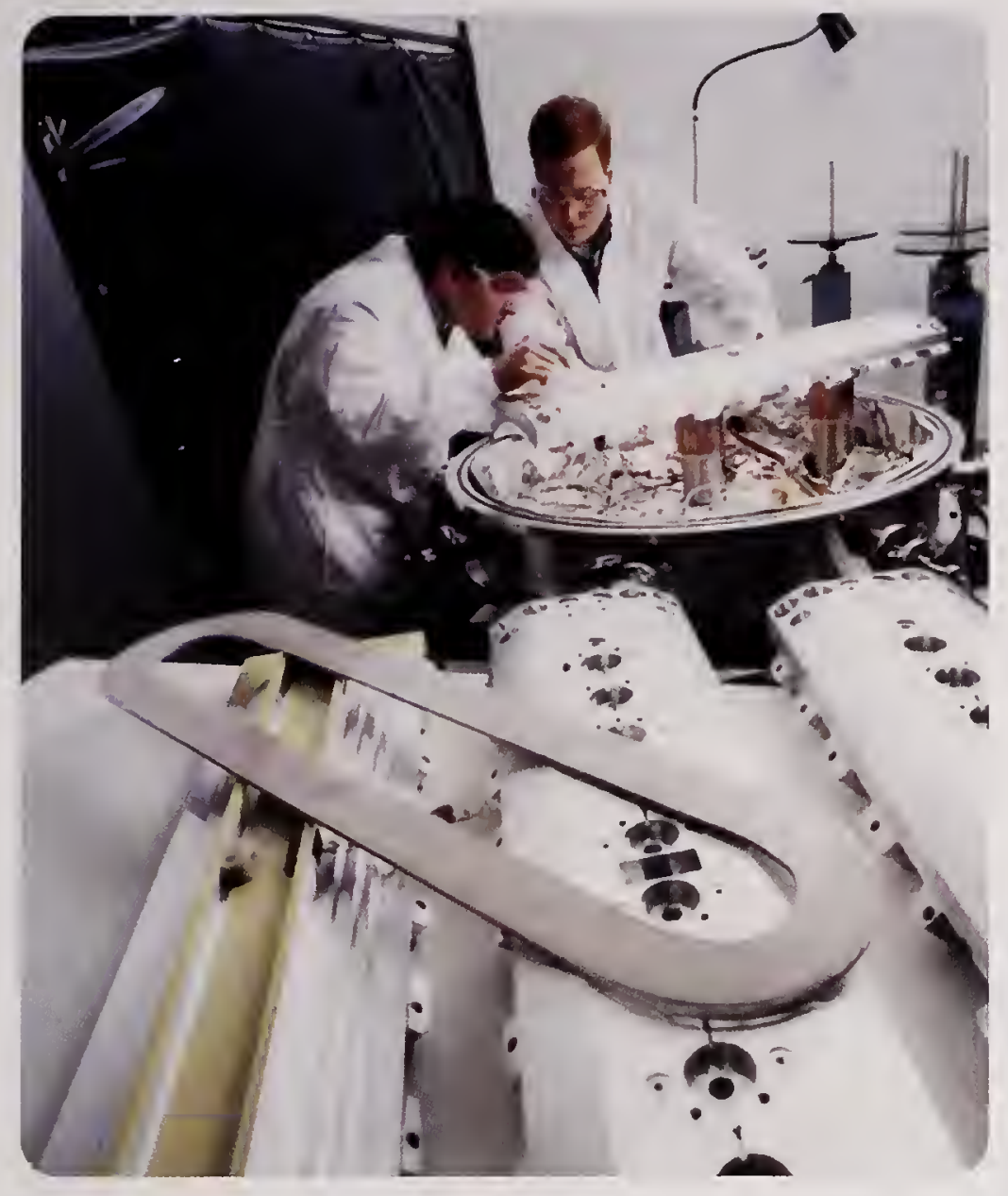

Placing 1000 horsepower HTS motor coils into a cryogenic cooling system.

a laboratory model 1,000-hp HTS motor in late 1998 or early 1999 and then begin development of a 5,000-hp motor. Each increment in motor size represents substantial advances in the underlying technology.

\section{A Long-Term Endeavor on Track}

ASC has viewed this endeavor from the outset as requiring a long-term commitment and substantial infusions of capital along the way to reach full commercial deployment of the H'TS technology in huge electric motors. The effort is on track. In the meantime, ASC has launched its first commercial product related to the ATP-funded technology, the CryoSaver current leads, which carry power into H'TS

\section{... won Industry Week magazine's Technology of the Year Award in 1996 . . .}

devices from external electricity supplies. Although this is not the ultimate commercialization goal envisioned for the technology, CryoSaver current leads provide revenue and help maintain investor interest in the company.

The CryoSaver product has received technical recog- nition as well as early commercial success. In 1996, it won Industry Week magazine's Technology of the Year award and the 100 Award from R\&D magazine, which selects the 100 most important innovations of the year.

An HTS motor of at least $1,000 \mathrm{hp}$ is needed to achieve efficiencies and cost savings in line with the project goals. ASC is deliberately waiting until it proves the concept at the 5,000-hp level before moving the H'TS motor into commercialization. The company expects to demonstrate a commercial-scale 1,000-hp motor in 1999.

\section{... electricity users are likely to benefit from lower electricity costs enabled by electricity producers' use of the new HTS motors.}

Following the ATP award, ASC received funding from the Department of Energy as part of a $\$ 21$ million motor program with Reliance Electric and several other companies to complete the development work. In addition, it raised $\$ 27$ million via a second public stock offering and attracted another $\$ 10$ million in private investment from the electric utility industry. It is actively protecting its intellectual property position through patent filings.

\section{Potential for Huge Benefits}

Users of ASC's CryoSaver current leads have achieved better operating efficiencies by improving the transmission of electricity for cryogenic devices. In the future, users of large electric motors (electric utilities, steel mills, water

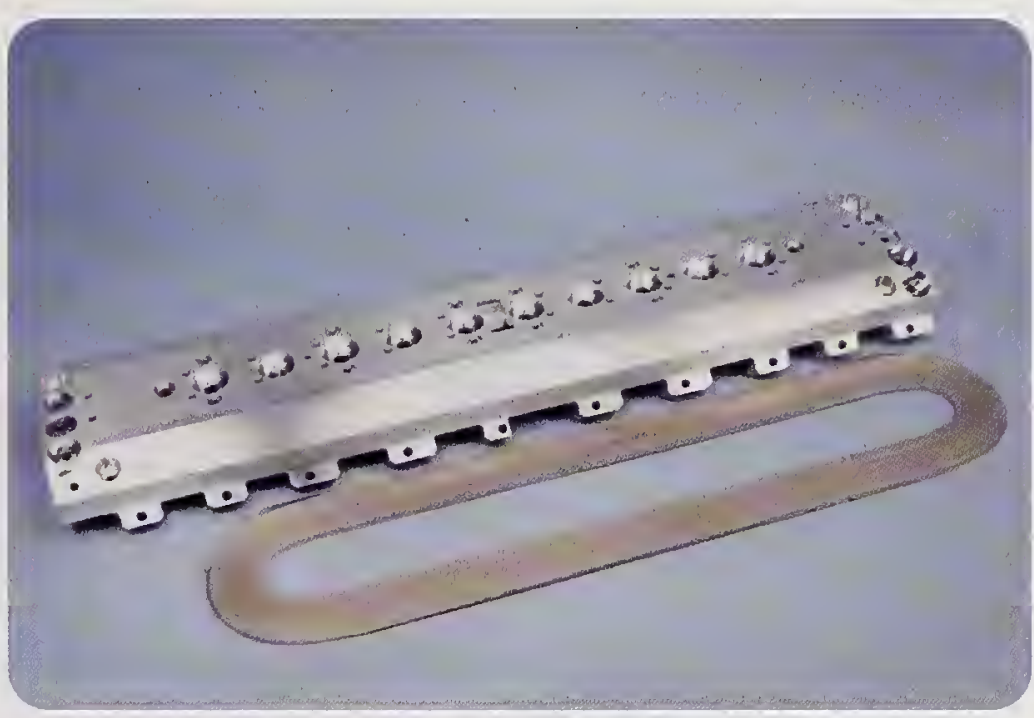

Pole set and double pancacke HTS coils for 1000 horsepower Reliance Electric motor. 
Figure 6.1 Patent Tree for Project Led by American Superconductor

Original Patent

Second Generation Patent

Third Generation Patent

Fourth Generation Patent

Fifth Generation Patent

Corporation (ASC): Citations by Others of American Superconductor

Corporation (ASC) Patents

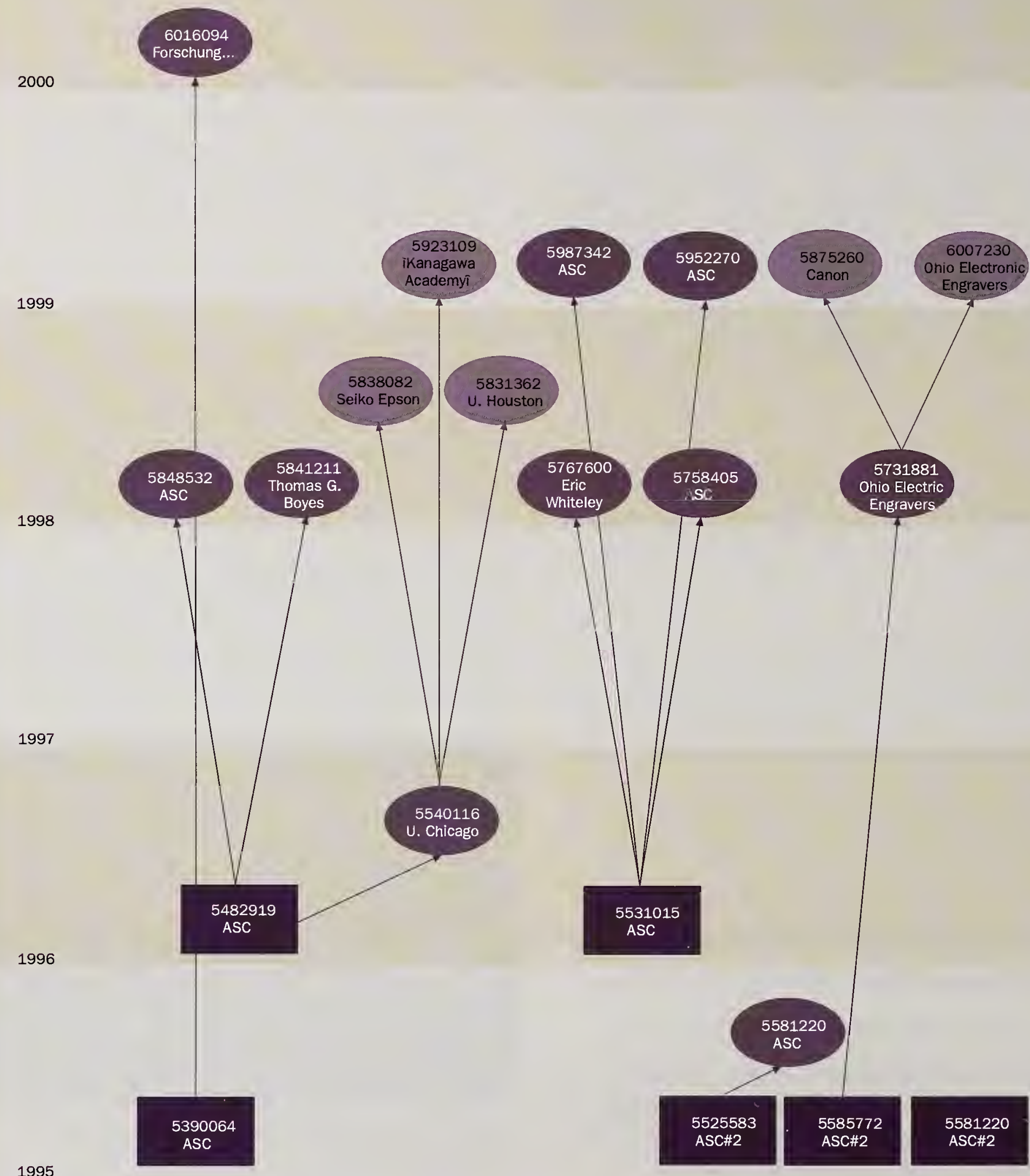


pumping stations) will be able to have motors that are smaller, more reliable, and more efficient than today's motors.

This may be particularly important when competition is introduced into the electric power industry, which ASC has selected as its first commercial target. Companies in that industry have generally operated as regulated monopolies. With competition in the production of electricity, cost savings will be far more important in the electric

The company expects to demonstrate a commercial-scale 1,000-hp motor in 1999.

power generation marketplace. Some of those cost savings are likely to be achieved by electric power generation companies switching from conventional large electric motors to HTS motors from ASC.

Lower costs for power generation companies, together with pricing pressure as several companies compete for the right to supply commercial and residential customers, is likely to result in cost savings at the power generation level being passed on, at least partially, to customers.

The end result of this chain of events, which is still in the future, is that electricity users are likely to benefit from lower electricity costs enabled by electricity producers' use of the new H'TS motors.

The possibility exists for a large return to the economy as a whole from the implementation of this new technology, since even small gains in motor efficiency translate into large energy savings to the companies and to the nation. 


\section{New Materials for New-Generation Thermal Insulation}

A

rmstrong researchers planned to investigate the microstructure of insulation material and the air cells, or pores, within it. The project aimed to learn how to control the molecular morphology - structure - of the solid material (to reduce its thermal conductivity), the geometry and orientation of air cells (to optimize pore morphology), and the size and distribution of air cells (to reduce the thermal conductivity of air within a cell).

COMPOSITE PERFORMANCE SCORE

(Based on a four star rating.)

No Stars

\section{Developing Super Insulating Materials}

Although they were not able to fully achieve their goals, the researchers made important progress in the development of super insulating materials as a result of their study of materials with high porosity and of nonspherical pores that are nanometer in size. The technical work followed two major tracks: the fabrication of polyethylene and polystyrene foams with carbon dioxide blowing while attempting explicitly to control the formation of the air pores, and the development of new process technology for the synthesis of aerogels for use in insulation products.

\section{Researchers achieved more technical success in their work on process technology for the synthesis of aerogels.}

The blowing of polyethylene and polystyrene foams with carbon dioxide entailed substantial challenges in attempting to optimize the mechanics to achieve the foam without a pressure drop leading to collapse of air cells. The researchers ran into problems working with polyethylene and, in addition, concluded that modification to extruder equipment would be necessary to achieve success with carbon dioxide as the blowing agent. Both changes raised production costs. Armstrong subsequently shifted away from polyethylene to other thermoplastics and began blowing with butane, in addition to carbon dioxide, but costs could not be lowered enough to justify commercialization. No patents or papers resulted from this track of the ATP-sponsored research.

Researchers achieved more technical success in their work on process technology for the synthesis of aerogels. The aerogels and xerogels produced by the process have both a high porosity and small pores; that is, the resulting material is microporous, with about 25 percent of the pore volume in pores less than 50 nanometers in diameter. The process also promises to substantially lower the costs of aerogel production. Armstrong received three patents for its technical advances in aerogel synthesis.

\section{Company Shifts}

At the time the project was awarded, Armstrong saw the ATP project as providing an opportunity to broaden the company's capabilities along lines that it otherwise would not have pursued. By developing new forms of insulation with superior performance, Armstrong saw the opportunity to broaden its focus from the technical insulation market (insulation for heating, refrigeration, plumbing, and specialty applications) to the structural insulation market (insulation for buildings and other large structures). Armstrong officials expected their first aerogel application to be for rigid technical insulation, with eventual opportunities in structural applications.

Later company reorganizations and strategy shifts changed the company's plans for applying its new technical know-how. Armstrong officials concluded that despite the remarkable insulating properties of the aerogels 


\section{PROJECT HIGHLIGHTS}

\section{PROJECT:}

To develop process technology for a new-generation insulation material based on controlled morphology (structure) in order to achieve superior insulating properties and associated energy savings.

Duration: 8/1/1992 - 7/31/1995

ATP Number: 91-01-0146

\section{FUNDING (in thousands):}

$\begin{array}{lll}\text { ATP } & \$ 1,868 & 41 \% \\ \text { Company } & \$ 2,650 & 59 \% \\ \text { Total } & \$ 4,518 & \end{array}$

\section{ACCOMPLISHMENTS:}

Armstrong researchers performed research in two major areas: process technology for aerogels and carbon dioxide blowing of polyethylene foams. The company received three patents for technologies related to the ATP project:

-Preparation of High Porosity Xerogels by Chemical Surface Modification"(No. 5,565,142: filed 4/28/1993, granted 10/15/1996);

"Thermally Insulative, Microporous Xerogels and Aerogels" (No. 5,525,643: filed 7/28/1995, granted 6/11/1996); and

-Wet Silica Gels for Aerogel and Xerogel Insulation and Processes for the Wet Gels"(No. 5,762,829: filed 3/5/1997, granted 6/9/1998).

CITATIONS BY OTHERS OF PROJECT'S PATENTS: See Figure 6.2 .

and the new process technology, which dramatically reduced production costs - the unit costs were still too high to penetrate the structural insulation market. The company's initial excitement over the potential of aerogels for the structural market dimmed. Armstrong scaled back its estimated demand for aerogels and decided to procure what it needed through suppliers rather than produce them in-house.

\section{The company's initial excitement over} the potential of aerogels for the structural market dimmed.

The company has decided to license the three aerogel process patents to potential suppliers, and not to be in the aerogel manufacturing business itself. To the extent that suppliers who obtain the licenses can use technology to produce aerogels more cheaply, Armstrong will benefit from its research in terms of a lower-cost supply. Other buyers may also benefit from lower-cost aerogels, depending on the specific licensing arrangements negotiated by the suppliers with Armstrong. Thus far, no licensing agreements have been achieved. But, according to company officials, Armstrong stands ready to negotiate licensing

\section{COMMERCIALIZATION STATUS:}

Armstrong has decided to license its low-cost aerogel synthesis patents to suppliers, rather than to manufacture aerogels directly, but the licensing has not yet occurred.

\section{OUTLOOK:}

Despite extremely good insulating properties of the aerogels and lowered processing costs, early applications of the aerogel are expected to be limited to niche markets, such as rigid technical insulation for heating, refrigeration and plumbing, or to speciality applications such as superconductivity insulation. Even with lowered costs, the aerogels do not at this time appear to be cost-competitive with conventional insulation materials for structural applications. Armstrong is continuing its research on the use of carbon dioxide foaming of thermoplastics, and this approach may hold promise for the future.

\section{Composite Performance Score: No Stars COMPANY:}

Armstrong World Industries, Inc. Innovation Center

2500 Columbia Ave.

Lancaster, PA 17603

Contact: Stephen C. Davis

Phone: (717) 396-5643

agreements for its aeorogel process technology.

In fall 1996 Armstrong combined, with another unit, the research unit where the ATP project was carried out, a consolidation that also entailed personnel changes. The principal investigator on the ATP project left Armstrong and set up a separate business that is reportedly working in areas related to the ATP project. This movement of people who worked on the research project and the establishment of a new business pursuing related technological goals may provide yet another possible path of technology diffusion.

Over time, Armstrong's primary interest has shifted away from the aerogel technology and toward the foam blowing technology, as indicated by the company's continued involvement in this area. Here, too, Armstrong's research effort shifted away from the initial ATP project focus toward techniques and materials that now are seen to offer more promise of achieving the high-performance foam insulating products that were the ultimate goal of the ATP-funded research.

The company has decided to license the three aerogel process patents to potential

suppliers, and not to be in the aerogel manufacturing business itself. 


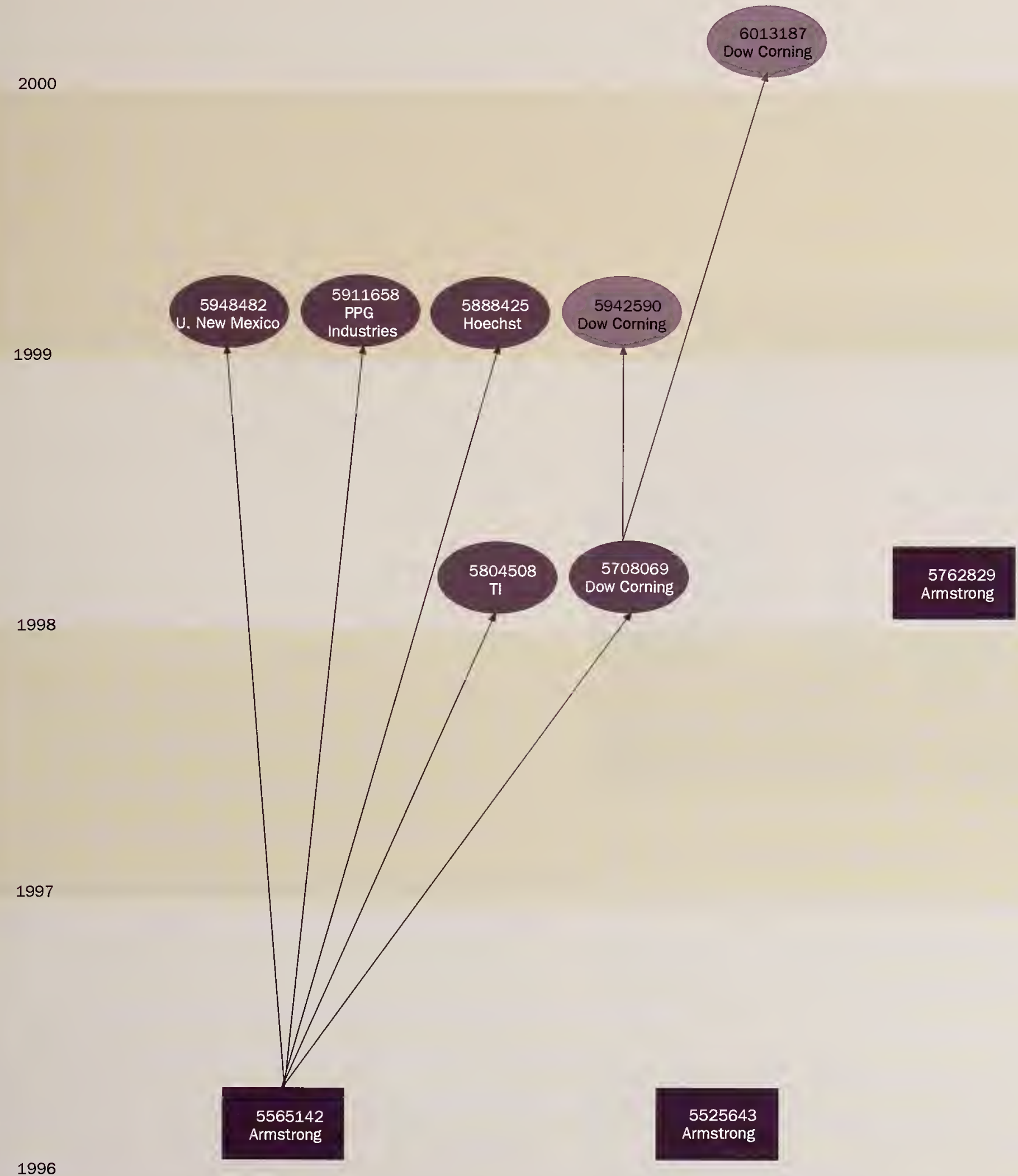





\title{
A Systems Solution to a Quality Problem in Auto Body Manufacturing
}

\begin{abstract}
Tust ed car suffers. When dimensions vary more radically, a BIW may have to be custom-assembled by hand. In addition, if the variations grow too large, the entire BIW may be pulled from the assembly line and junked.
\end{abstract}

ust a few millimeters make a big difference on an automated assembly line as doors, hood, windshield, wheel housings, and other parts are installed on a body-in-white (BIW), the partially completed body of an automobile. If BIW openings are slightly off kilter or parts vary much from specifications, the overall fit and finish of the complet-

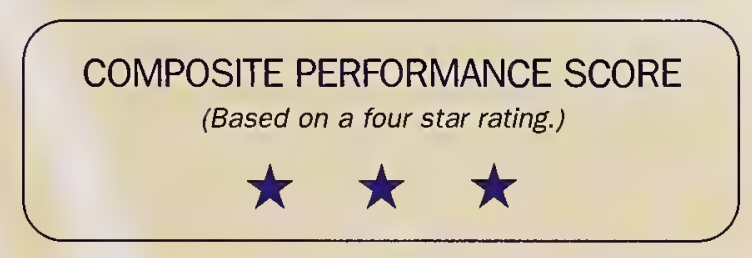

\section{Toward a Tightly Fitted Car Body}

In contrast, a tightly fitted car means fewer defects, less time and money for factory repairs, better appearance and performance for the owner, and lower long-term maintenance costs. And the quicker assembly-line changeovers can be made while retaining tightness of fit, the faster new models can be introduced at reasonable cost.

\section{A U.S. Problem Overcome}

The problem of dimensional variation has cost the U.S. automotive industry dearly in product quality, wasted

\section{The project has published a manual for use in extending the procedures developed during the project.}

materials, increased production time, and lost sales. While European automakers were building cars with dimensional variations less than $2.5 \mathrm{~mm}$ and Japanese manufacturers were achieving results at or below $2 \mathrm{~mm}$, U.S. producers were assembling cars with as much as $5-$ or 6 -mm variation. But with completion of ATP's " $2 \mathrm{~mm}$ Project" in 1995 , American automakers have shown a marked increase in their ability to assemble cars with world-class precision. In all five Chrysler and General Motors (GM) auto assembly plants where the new methods were tested, overall dimensional variation was brought down to, or below, the $2 \mathrm{~mm}$

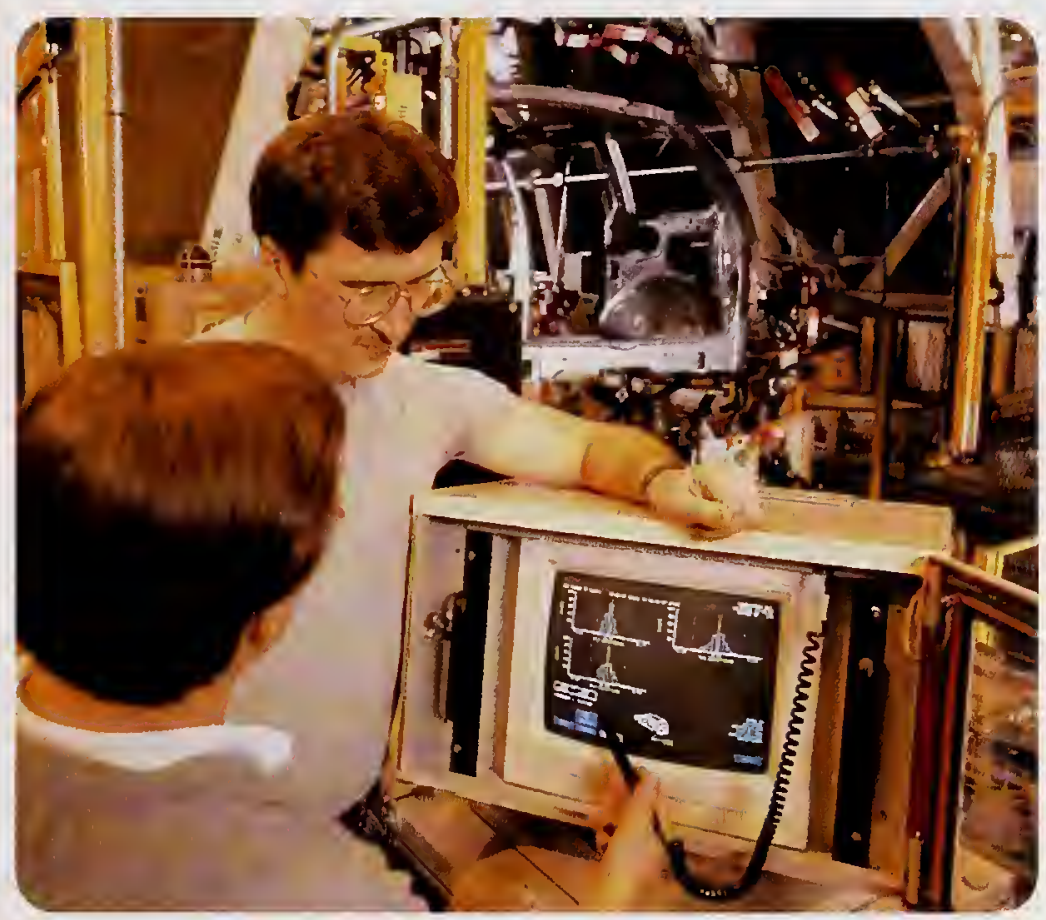

Assembly plant staff members monitor operations using real-time analysis tools developed in the ATP project.

standard. In addition, other technologies developed by the project have yet to reach the assembly line, and their full implementation in auto body plants promises to reduce dimensional variation even further.

\section{Lower Production Costs}

With an investment of $\$ 4.9$ million from the ATP and $\$ 9$ million from the automobile industry, the $2 \mathrm{~mm}$ Project developed a number of interrelated technologies and processes that have already cut net production costs (actual 


\section{PROJECT HIGHLIGHTS}

\section{PROJECT:}

To develop improved measurement technology and process control needed to achieve tighter fit - as well as better quality and lower costs — in auto bodies and other products assembled from sheet metal parts.

Duration: 9/1/1992 - 10/31/1995

ATP Number: 91-01-0177

FUNDING (in thousands):
$\begin{array}{lll}\text { ATP } \$ 4,487 & 43 \% \\ \text { Companies } & \frac{6,048}{510,535} & 57 \% \\ \text { Total } & \$ 10,\end{array}$

\section{ACCOMPLISHMENTS:}

The project achieved the R\&D goal of developing measurement and process control technology, which participating companies verified in several in-plant tests. Widespread adoption of the technology is now underway in auto assembly plants. Indicative of progress, the companies:

cut dimensional variation in auto body assembly to a world-class standard of $2 \mathrm{~mm}$ or less and demonstrated the reduction with existing workforces in all five plants initially targeted by the project;

reduced production costs by $\$ 10$ to $\$ 25$ per vehicle at two plants initially adopting the technology, savings that are expected, according to consortium staff, to be applied eventually in plants which produce all 6.5 million cars and light trucks produced annually by Chrysler and General Motors;

reduced expected future maintenance costs by an estimated $\$ 50-\$ 100$ per vehicle;

published several papers in professional journals;

published The Capture and Communication of Knowledge: A Lessons-Learned Approach, a manual that will speed the adoption of the technologies and processes developed during the ATP project by showing how to implement them;

worked with the University of Michigan to begin transferring the technology to other GM and Chrysler assembly plants beyond the original five, implementing it thus far in 22 plants in the United States and Canada;

generated via ISI Automation Group (formerly ISI Robotics) the spin-off development of a new type of clamp, called the Sof Touch, for holding sheet metal parts during assembly; and

provided member auto assembly companies a quality peg on which to hang marketing literature - Chrysler highlights the fact that its new Concorde "literally has a two-millimeter body."

\section{COMMERCIALIZATION STATUS:}

Some supplier companies have incorporated the new measurement and process technology in assembly line equipment, and the new approach to tighter fit has been put into use in 6 of 10 Chrysler plants and 16 of $31 \mathrm{GM}$ plants in the United States and Canada. Net production cost reductions of $\$ 10$ to $\$ 25$ per vehicle are estimated to have already been achieved using the new approach, meaning millions of dollars saved per year. Higher-quality vehicles from these plants are becoming available to consumers, and U.S. manufacturers are expected to increase their market share.

\section{OUTLOOK:}

Because the technology is being used and being systematically transferred to additional plants, the outlook is excellent. It is now being transferred to all Chrysler and GM plants, and through the supply chain, to Ford Motor Company. The technology is expected also to be adopted or adapted for use by other discrete manufacturers in, for example, the appliance and furniture industries. Auto assembly companies that adopt this new technology can expect to save hundreds of miflions of dollars annually in production and maintenance costs. Consumers will benefit from higher-quality vehicles and will likely see some of the manufacturing cost savings. Producers and consumers are expected to benefit from yearly savings of up to $\$ 650$ million in auto maintenance costs. Quality improvements resulting from the project have been projected to boost U.S. industrial output by the automotive and related industries by more than $\$ 3$ billion in 2000 and to create thousands of new jobs. To the extent the quality improvements extend to other manufacturing industries, the output and employment effects will be even greater.

\section{Composite Performance Score: \\ COMPANY: \\ Auto Body Consortium \\ (joint venture lead; formerly $2 \mathrm{~mm}$ Auto Body Consortium) \\ 2901 Hubbard Road \\ Ann Arbor, MI 48105}

\section{Contact: Ernest Vahala}

Phone: (734) 741-5905

Joint venture participants: CDI-Modern Engineering; Classic Design, Inc.; Detroit Center Tool, Inc.; ISI Robotics; Perceptron, Inc.; Pioneer Engineering \& Manufacturing; Progressive Tool \& Industries, Inc.; Weber Technologies, LLC; Chrysler Corporation; General Motors Corporation (GM), Technical Center; University of Michigan, Mechanical Engineering and Applied Mechanics.

Subcontractor: Wayne State University costs less the cost of implementing $2 \mathrm{~mm}$ technologies) by $\$ 10$ to $\$ 25$ per vehicle in plants where they have been tested. When full adoption by all GM and Chrysler assembly plants is achieved - probably by the year 2000 - annual production cost savings are projected in the range of $\$ 65$ million to $\$ 160$ million on the current production volume of 6.5 million vehicles, which amounts to 48 percent of the cars and light trucks sold in the United States. Some of the cost savings are likely to be passed on to consumers as a result of competition among U.S. and foreign producers in the new vehicle market in the United States.
ATP's financial contribution helped smalland medium-supplier companies pay for an expanded university effort while large assemblers provided most of the industry cost share, which covered their own expenses and joint venture overhead. 


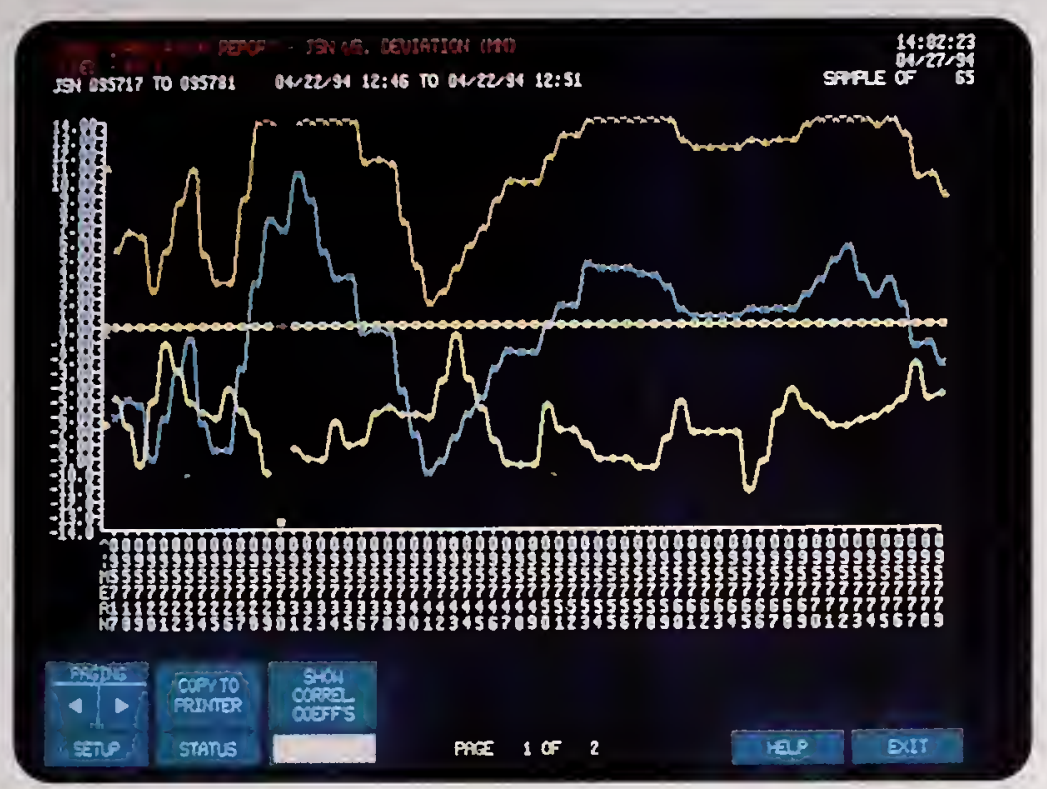

The computer display for one of the many diagnostic procedures provided by the new dimension control system.

\section{Less Maintenance, Faster Launch}

Cars and trucks built with $2 \mathrm{~mm}$ Project innovations should also cost less to maintain as better body fit results in reduced wear, less rust, and fewer other problems. These savings are estimated to range from $\$ 50$ to $\$ 100$ per vehicle over its useful lifetime. Several years after GM and Chrysler have fully implemented the $2 \mathrm{~mm}$ Project results, total maintenance savings are expected to reach $\$ 325$ million to $\$ 650$ million per year based on current production volume. And, although a dollar value has not yet been estimated, the new technology is expected to decrease the time required to launch new auto models.

\section{Higher Quality and Lower Costs Mean Increased Market Share and Jobs}

In addition, assuming the $2 \mathrm{~mm}$ Project quality and cost improvements lead to at least a one percent increase in market share for GM and Chrysler (at the expense of vehicles built abroad), economic projections show an overall increase in U.S. economic output in 2000 of more than $\$ 3$ billion and the creation of around 70,000 new jobs. These estimates take into account the impact of an increase in vehicle sales on related sectors, but they do not include any increases due to adoption of $2 \mathrm{~mm}$ technologies by companies outside the auto industry.

\section{Collaborative Research to Solve a Complex Systems Problem}

The $2 \mathrm{~mm}$ Project was initiated by the Auto Body Consortium (eight small- and medium-size companies that provide tooling and engineering services for auto body assembly lines), two big auto manufacturers (Chrysler and
General Motors), and two universities, one a joint venture partner, and the other a subcontractor. The joint venture treated BIW dimensional variation as a systems problem, selecting 11 subprojects, or tasks, to be accomplished in four general areas. Separate task groups, with staff from various joint venture members, worked on each subproject. After the operational tasks were completed, the final task of the $2 \mathrm{~mm}$ Project was to synthesize the information, processes and lessons learned from the research and incorporate the results into a user-friendly database to help companies adopt the new technologies and methodologies and establish an infrastructure for future improvements.

The $2 \mathrm{~mm}$ Project would have been difficult to achieve without the involvement of the ATP for several reasons. Dimensional variation in auto body production is a systems problem that could not have been solved by any 1 of the 11 project members alone. The ATP encourages formation of joint ventures like the Auto Body Consortium to solve complex systems problems. The

public/private partnership was helpful in the face of a long history of federal antitrust enforcement that has left automakers fearful of cooperating with each other without federal government involvement. Assembly line suppliers are generally small- or medium-size companies without research budgets large enough to fund work of the type undertaken by the $2 \mathrm{~mm}$ Project, and automakers have been reluctant to fund research by their suppliers. The fact that development risks were unevenly born by consortium member firms was another obstacle that ATP participation helped to overcome.

\section{. . organized meetings to share results} with interested people from the aerospace, appliance, and metal furniture industries, as well as other industries that use automation to assemble metal parts.

ATP's participation in the $2 \mathrm{~mm}$ Project proved critical to the formation of this research joint venture. The ATP provided the catalyst needed to overcome multiple barriers. ATP's financial contribution helped small- and medium-supplier companies pay for an expanded university effort while large assemblers provided most of the industry cost share, to cover their own expenses and joint venture overhead.

The $2 \mathrm{~mm}$ Project shows how small- and medium-size supply companies, large auto producers, and universities 
were able to cooperate in the development of an integrated system to reduce dimensional variation in body assembly and to improve the quality of the final product. It also demonstrates the unique role that comparatively modest investments of money and leadership by ATP can play in catalyzing complex, cooperative research ventures that pay off handsomely in technological and economic returns.

\section{Widespread Adoption Underway in Auto Plants}

The new approach to tighter dimensional fit has been put into use in 6 of 10 Chrysler plants and 16 of $31 \mathrm{GM}$ plants in the United States and Canada, and it is being trans-

ferred to the remaining GM and Chrysler plants and to Ford Motor Company through the supplier chain. 


\section{E.I. DUPONT DE NEMOURS AND COMPANY \\ Thallium/Lead Thin Films for Advanced Superconducting Electronic Devices}

1

uperconductivity holds great promise for reducing energy consumption in practically any process that uses or transports electricity. Radar components, power transmission lines, communications satellites, and a host of electronic and electrical devices, for example, are good candidates for superconductor applications.

COMPOSITE PERFORMANCE SCORE

(Based on a four star rating.)

\section{New Technology for Making Superconducting Components}

At the time of its proposal to the ATP, DuPont had carried out a three-year research program to develop high-temperature superconducting (HTS) materials and was debating whether to disband the effort because of its high technical uncertainty. The properties of HTS materials were still not well understood, fabrication processes had not been developed, and the technical and commercial viability of the materials had not been proven. DuPont said later that continuation of its HTS research hinged on receiving an ATP award, which the company considered an indicator of the promising nature of the work.

\section{. . continuation of}

its HTS research hinged on receiving an ATP award...

With its ATP award, DuPont developed thin-film HTS fabrication technology. It is generic enough to use with a variety of HTS materials that have form, structure, and performance properties similar to those of thallium/lead. The technology is particularly useful when using thallium/barium or thallium/lead in the fabrication of HTS electronics components. The company developed two thin-film fabrication processes - a two-step approach using sputtering and post-annealing and a single-step approach with simultaneous sputtering and annealing. Photolithographic and ion-milling techniques are used to form circuits and other electronic features in the films. The viability of the two processes was demonstrated by constructing and testing several basic electronic components, including oscillators, filters, mixers and coplanardesigned transmission lines.

\section{. . . HTS component technology recognized} as one of the "Top Products of 1993" by Microwaves \& RF magazine . . .

\section{Many New and Potential HTS Products}

DuPont has developed six electronic-component products: thin films of two or three inches in diameter made on HTS substrates of erbium/barium, thallium/barium, or thallium/lead. All six of these products use the new HTS thin-film fabrication technology developed in the ATPfunded project. In addition, the company usually fabricates electronic components, on the thin-film wafers, cuts the wafers into discrete components, and encases them in metal casings, all according to customer specifications.

The company has begun substantial marketing efforts and is successfully selling products. Most of these are made with erbium/barium and thallium/barium rather than thallium/lead. Applications requiring the higher operating- 


\section{PROJECT HIGHLIGHTS}

\section{PROJECT:}

To develop thin-film fabrication processes needed to produce high-temperature superconducting (HTS) electronics components at reasonable cost.

Duration: 4/1/1991 - 3/31/1994

ATP Number: 90-01-0064

\begin{tabular}{|c|c|c|}
\hline \multicolumn{3}{|c|}{ FUNDING (in thousands) } \\
\hline ATP & $\$ 1,590$ & $67 \%$ \\
\hline Company & 784 & $33 \%$ \\
\hline Total & $\$ 2,374$ & \\
\hline
\end{tabular}

\section{ACCOMPLISHMENTS:}

DuPont accomplished the R\&D goal and has demonstrated several component products that directly use the new technology. It has also marketed products based in part on procedures developed by the project, but using thallium/ barium as a key ingredient instead of thallium/ lead. Indicators of successful development of the technology are that the company:

published more than 20 research papers on the technology in professional journals;

had its HTS component technology recognized as one of the "Top Products of 1993" by Microwaves \& RF magazine in December 1993;

introduced HTS thin-film products that, when built into larger systems such as magnetic resonance imaging machines and communications satellites, can lead to higher performance at lower overall cost; and

worked with a small equipment-supplier company to develop improved HTS thin-film fabrication equipment.

temperature capabilities of thallium/lead HTS components have not yet developed significantly, due in part to improved cryogenics technology that has increased the number of application areas where the two other HTS materials are useful.

\section{. . this technology . . could make mag-} netic resonance imaging and terrestrial and satellite communications less expensive and more efficient to operate . . .

DuPont has maintained its long-term vision and continues to develop H'TS electronics components based on erbium/barium, thallium/barium and thallium/lead. The payoffs may be coming soon, especially in magnetic resonance imaging (MRI) equipment and possibly in terrestrial and satellite communications. HTS materials also have potential use in nuclear magnetic resonance instruments, superconducting quantum interference devices, and a variety of microwave applications.

\section{COMMERCIALIZATION STATUS:}

The market for new products based on the fabrication technology developed in the project is well established, even though applications that use thallium/lead as the HTS material have been slow to develop. Several products made with the new HTS technology are being marketed. The company has invested large sums to scale up for production in anticipation of increased demand in the near future.

\section{OUTLOOK:}

Use of the new process technology can substantially reduce the cost and improve the quality of superconductors in many applications. Applications based on this technology could, for example, make magnetic resonance imaging and terrestrial and satellite communications less expensive and more efficient to operate, generating widespread benefits valued at tens of millions of dollars.

\section{Composite Performance Score: $\star \star \star \star$ COMPANY:}

E.I. du Pont de Nemours and Company

P.O. Box 80304

Wilmington, DE 19880-0304

Contact: Dennis J. Kountz

Phone: (302) 695-4256

\section{. . published more than 20 research papers on the technology in professional journals...}

For superconductor technology to realize its full potential, however, more advances have to be made in the technology. DuPont continues to fund its HTS research program at significant levels.

\section{Less-Costly, More-Efficient Electronic Equipment}

HTS processes developed in the ATP project could make superconductivity-based equipment less costly and more efficient to operate. HTS-based signal coils, for example, permit the use of a low-cost permanent magnet for MRI, an arrangement that could reduce the installation cost of this MRI machine to as little as one-tenth that of a standard MRI device. In addition, the use of HTS electronics enables equivalent or better MRI performance at much lower cost. IGC, an MRI manufacturer that uses DuPont HTS electronics in its products, reports that operating costs for its MRI machines are expected to be about one- 
sixth those for currently available competitor machines that use low-temperature superconducting technology. Thus, the new technology helps reduce MRI capital and operating costs while improving diagnostic effectiveness.

The benefits of the new HTS technology are likely to be substantial and widespread. In MRI and satellite communications, for example, the chain of events leading from the manufacturer of the components to the end users has many steps. At each step, some benefits from the technology are likely to accrue to intermediate customers and end-users, who pay for only a small part of the value they receive from the technological advance. Given the large number of end users for MRI and satellite services, the aggregate value of those spillover benefits is likely to be in the tens of millions of dollars.

\section{... a small equipment supplier,}

the Kurt J. Lesker Company . . . improved fabrication equipment. . .

During this project, DuPont worked with a small equipment supplier, the Kurt J. Lesker Company, to develop improved fabrication equipment for depositing HTS material on a wafer. Lesker is now making these improved machines available to other companies, as well as to DuPont. 


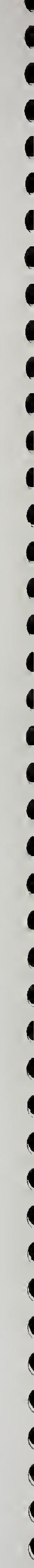


HELPMATE ROBOTICS, INC.

(formerly Transitions Research Corporation)

\section{Robot Navigation Technology}

\section{$R$}

obots are frequently seen as exotic, make-believe objects in science fiction movies. They walk, talk, crack jokes, and worry about whether they are human or have souls. Real robots are much more mundane, but they are becoming increasingly useful in industry. They do work too tedious or dangerous for humans, enduring tedium without erring and danger without harm. They paint cars in factories without needing protective masks. They transport radioactive materials in power plants without suffering from radiation.

COMPOSITE PERFORMANCE SCORE (Based on a four star rating.)

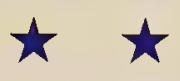

\section{Using Robot Technology for Deliveries in Hospitals}

Robots are also delivering medicines in hospitals faster and more reliably than humans can. "Do you really see hospitals and nursing homes starting to use that kind of technology?" an interviewer asked Paul Hoffman of Discover magazine after he demonstrated robot technology on CBS Good Morning America in May 1996. Replied Hoffman: "They do. This company, HelpMate Robotics in Danbury, is already using it in hospitals, right now."

\section{Improved Navigation Capabilities}

HelpMate Robotics, using ATP funds, has indeed developed the navigational technology needed to create mobile robots that can scurry around a hospital or other industrial environment. And with other funding, it has built them. This advance, set on the technical foundations laid by robotics pioneer and company CEO Joseph Engelberger, has helped to expand the use of mobile robots throughout the country.

\section{They do work too tedious or dangerous for humans, enduring tedium without erring and danger without harm.}

These robots do some of the ambulatory work traditionally done by humans. To work well, the robots must have dependable vision systems that can use light from

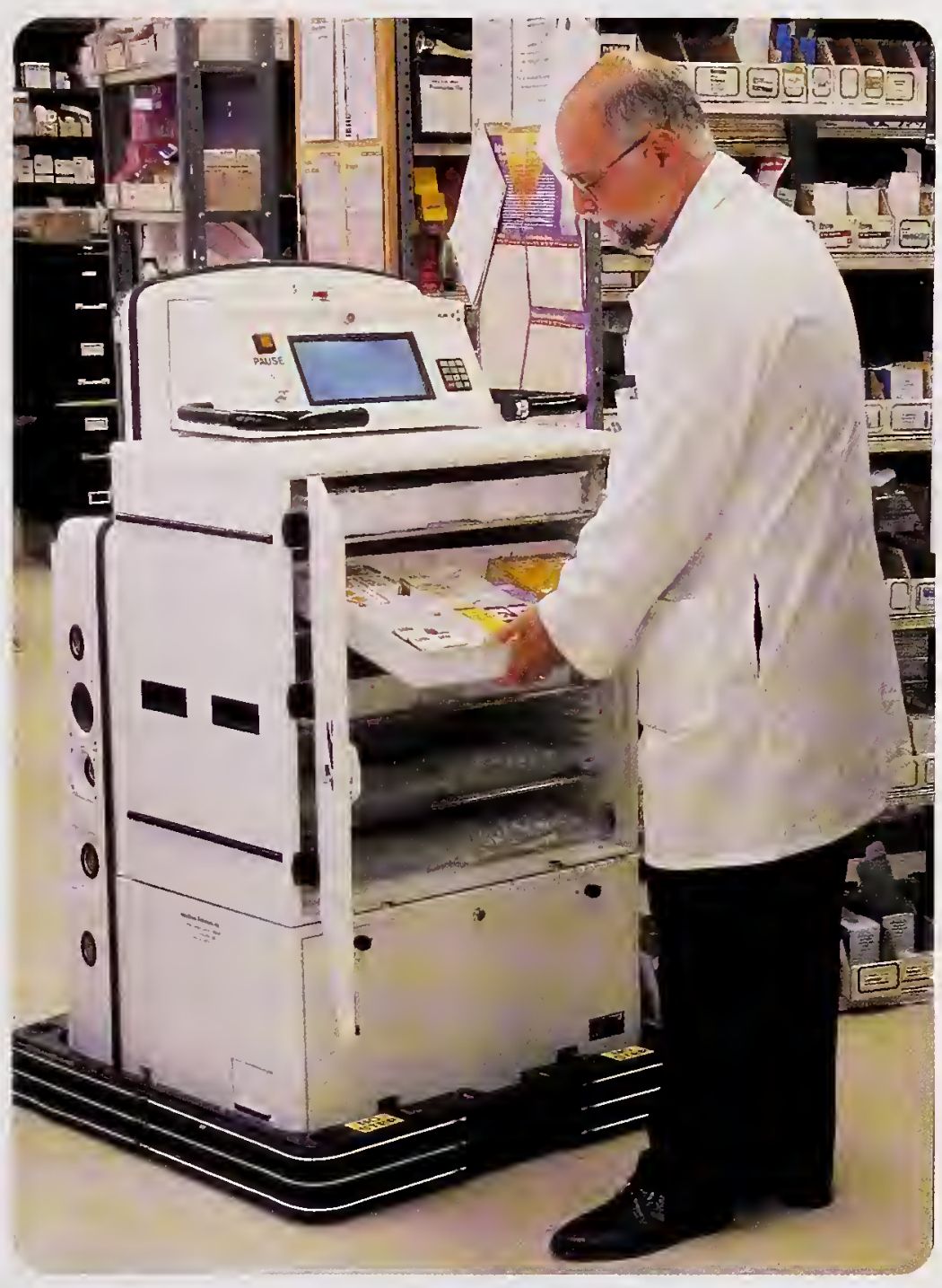

Drugs are loaded on the HelpMate robot by a hospital pharmacist for delivery to staff in one of the hospital's wards. 


\section{PROJECT HIGHLIGHTS}

\section{PROJECT:}

To develop the technology for intelligent, autonomous mobile robots, or robot carts, that can find their way around a factory, hospital, or similar place by sensing and avoiding obstacles and taking alternative routes if a path is blocked. Such robots could reduce costs for delivering materials and supplies in many different environments.

Duration: 6/15/1992 - 3/31/1994

ATP Number: 91-01-0034

\begin{tabular}{llc}
\multicolumn{3}{l}{ FUNDING (in thousands): } \\
ATP $\quad \$ 699$ & $44 \%$ \\
Company & $\frac{875}{51,574}$ & $56 \%$ \\
Total & $\$ 1,57$ &
\end{tabular}

\section{ACCOMPLISHMENTS:}

The company achieved the target navigation capabilities, including successful development of a specialized LIDAR (light direction and range) scanner. Evidence of progress includes the following:

the company incorporated the new navigation capabilities into its original HelpMate robot and is now producing and selling the upgraded version;

HelpMate raised $\$ 6$ million through an initial public stock offering in 1996, and used it to build production and sales capabilities. (A second offering did not go through, and the company temporarily downsized in 1997. New funding commitments are expected to rebuild staff and marketing.);

the upgraded HelpMate robot was named one of 36 finalists in the Discover magazine competition for technology of the year for 1996 ;

many different sources and recognize light-shading differences. They have to be trainable (programmable). They must make quasi-intelligent decisions - "Go around the gurney with the patient on it." And they have to be able to report to their human supervisor and ask for help when encountering problems they cannot handle "There is no one here to sign for the parts."

HelpMate Robots are delivering medicines, supplies, prepared food, $x$-ray images and other material in about 100 hospitals in the United States and Canada.

Specifically, HelpMate researchers successfully developed an improved light direction and range (LIDAR) scanner. LIDAR is a device in the eyes of the robot that
CEO Joseph Engelberger, the principal investigator for the ATP project, received the Japan Prize in "systems engineering for an artifactual environment" in 1997 from the Science and Technology Foundation of Japan;

the company and Otis Elevator entered into an alliance in which Otis is to be the exclusive distributor of HelpMate hospital robots in Europe.

\section{COMMERCIALIZATION STATUS:}

Robots incorporating the new navigational technology have been rented or sold to about 100 hospitals in the United States and Canada, and the company has entered marketing arrangements with parties in Europe and Japan.

\section{OUTLOOK:}

Since the robots are already in use commercially, the outlook for the technology is excellent, despite a temporary downsizing at HelpMate. The company now plans to expand the use of the technology by developing robots that can provide assistance in the home to infirm and elderly persons, a venture that potentially could save billions of dollars by eliminating some need for hospitalization or professional help in the home. Opportunities exist for applying these mobile robots in factories, warehouses, and many other environments. Thus, the potential for future utilization of the technology is high.

\section{Composite Performance Score: $\star \star$}

COMPANY:

HelpMate Robotics, Inc.

(formerly Transitions Research Corporation)

Shelter Rock Lane

Danbury, CT 06810-8159

Contact: J.F. Engelberger

Phone: (203) 798-8988

Number of employees: 27 at project start, 14 at the end of 1997

senses light, calculates direction, and determines the range to objects in its path. This is a clear advance over previous technology, which used sonar to detect shapes.

Researchers also developed navigation capabilities based on new sensing systems and ways of combining data from different sensors. These capabilities permit the control of robots in quasi-structured environments - places with predefined components such as doorways, light fixtures, windows, and elevators that are fixed in place and definable from photos or engineering drawings - and among objects that are not predefined, such as a patient on a gurney and human workers moving about the space.

\section{HelpMate in Hospitals}

Most of the ATP-funded technology has been embedded in the hospital version of the HelpMate robot. More than 150 HelpMate robots have been rented by scores of hospitals in Europe, Japan, Canada, and the United States. Purchased outright, the robots cost about $\$ 110,000$. Most are rented for $\$ 4$ to $\$ 6$ an hour. If a robot is used 100 hours a week, the annual rental fee is about $\$ 25,000$. 
HelpMate plans to expand the use of

\section{the ATP-funded technology by developing \\ robots that can assist infirm and \\ elderly persons at home.}

\section{Marketing Agreements for Distribution Abroad}

Company officials say that ATP funding enabled

HelpMate to achieve its research and development results much sooner than it would otherwise have been able to do. The award also helped it develop strategic marketing arrangements abroad. The company has signed an agreement for Otis Elevator to distribute HelpMate hospital robots exclusively in Europe. It has also developed marketing arrangements with other parties in Europe and Japan.

HelpMate raised $\$ 6$ million through an initial public stock offering in 1996 and used the money to build production and sales capabilities. A second offering of $\$ 5$ million did not go through, and the company had to downsize temporarily. New funding, however, has been committed, which should enable rebuilding of staff and marketing, as well as further work on a home-service version of the robot. In addition, the population of HelpMate robots in the field continues to serve well and will back up the company's renewed sales effort.

\section{Benefits From Robots}

Hospitals using HelpMate robots are benefiting.

HelpMate Robots are delivering medicines, supplies, prepared food, $\mathrm{x}$-ray images, and other material in about 100 hospitals in the United States and Canada. They have lowered the cost and improved the quality of these delivery services. One hospital pharmacy director, for example, reported net annual savings of around $\$ 10,000$ per robot per year. In addition, the robots made the deliveries faster than humans did. There are about 150 HelpMate robots in these hospitals, according to company officials. If the savings for each robot to the hospital is $\$ 5,000$ to $\$ 10,000$ per year, then these hospitals are already realizing an annual savings of $\$ 750,000$ to $\$ 1.5$ million. The cost savings at the 100 hospitals alone over 10 years would be in the millions. These are savings above the rental cost of the robots. As more hospitals, factories and other facilities adopt these robots, cost savings will multiply.

In addition to these cost savings, benefits accrue to hospitals, physicians and patients through improved delivery service. Not only is robot delivery faster than human delivery, but it is also frequently more reliable, according to hospital officials, because of fewer delivery mistakes.

\section{Robots to Serve the Elderly and Infirm}

The analysis above is only for robots already employed in hospitals. For in-home nursing services, the use of robots could generate much larger savings. HelpMate plans to expand the use of the ATP-funded technology by developing robots that can assist infirm and elderly persons at home. But for this application, the company must first solve additional technical problems. These robots must have highly functional arms, improved vision, more sophisticated programming, and some speech recognition capabilities. The company has estimated that, if successful, this development could substantially reduce health care costs by eliminating some of the need to hospitalize or hire home help for the frail elderly.

\section{Other Potential Uses}

Two industrial applications currently being explored are in computer chip fabrication and clinical laboratory work. In clinical labs, vials containing substances, such as the human immunodeficiency virus, that are highly dangerous to human workers could be moved from one workstation to another by robot. In a chip fabrication plant, robots could move supplies to the fabrication line in response to specific orders from operators. For these applications to be realized, capital will have to be raised to support the additional engineering required to tailor robots to the specific needs of each environment. Lab robots, for example, will need to be built to work without bumping into delicate research instruments and materials, and chip-plant robots must be engineered to operate so cleanly they do not contaminate the superclean rooms where chips are fabricated.

\section{Two industrial applications currently being explored are in computer chip fabrication and clinical laboratory work.}

In addition to these applications, company officials say, the ATP-funded technology is expected to be used for mobile robots in all kinds of factories and has potential applications in warehouses, maintenance facilities, mail distribution centers, and shopping malls (for delivery, maintenance, and cleaning services). As in hospitals, the use of robots in these environments is expected to lower costs substantially and improve service. 
. 


\section{Using High-Temperature Superconductivity to Improve Cellular Phone Transmission}

$T_{\text {ren }}$ provided by the Cellular Telecommunications Industry Association are that the number of wireless telephone subscribers was over 50 million as of August 1997. Additional estimates are that by 2001 the cellular subscriber base is expected to grow to more than 75 million subscribers, with an additional 15.1 million subscribers using personal communications services (PCS) by the same year.

COMPOSITE PERFORMANCE SCORE (Based on a four star rating.)

\section{Extending and Improving Cellular Phone Service}

To provide cellular phone or PCS service, a communications company using a land-based approach must place base stations - towers and reception/transmission equipment - at regular intervals throughout its service area. In deciding where to locate these base stations, the company considers the strength and clarity of its communications signals and how customer service will be affected when a signal shifts from one station to the next while the customer is traveling.

\section{Cellular phone users will receive} clearer signals and suffer fewer dropped calls as their signals move from one base station site to the next.

All these factors depend on how well the station's equipment handles the communications signals. And that depends on how well each component of the equipment works as it attempts to distinguish the user's cellular phone signal from the surrounding electronic noise.

\section{A High-Temperature Superconductivity Solution}

This ATP project with Illinois Superconductor Corporation (ISC), a small company founded in 1990, developed technology based on high-temperature super-

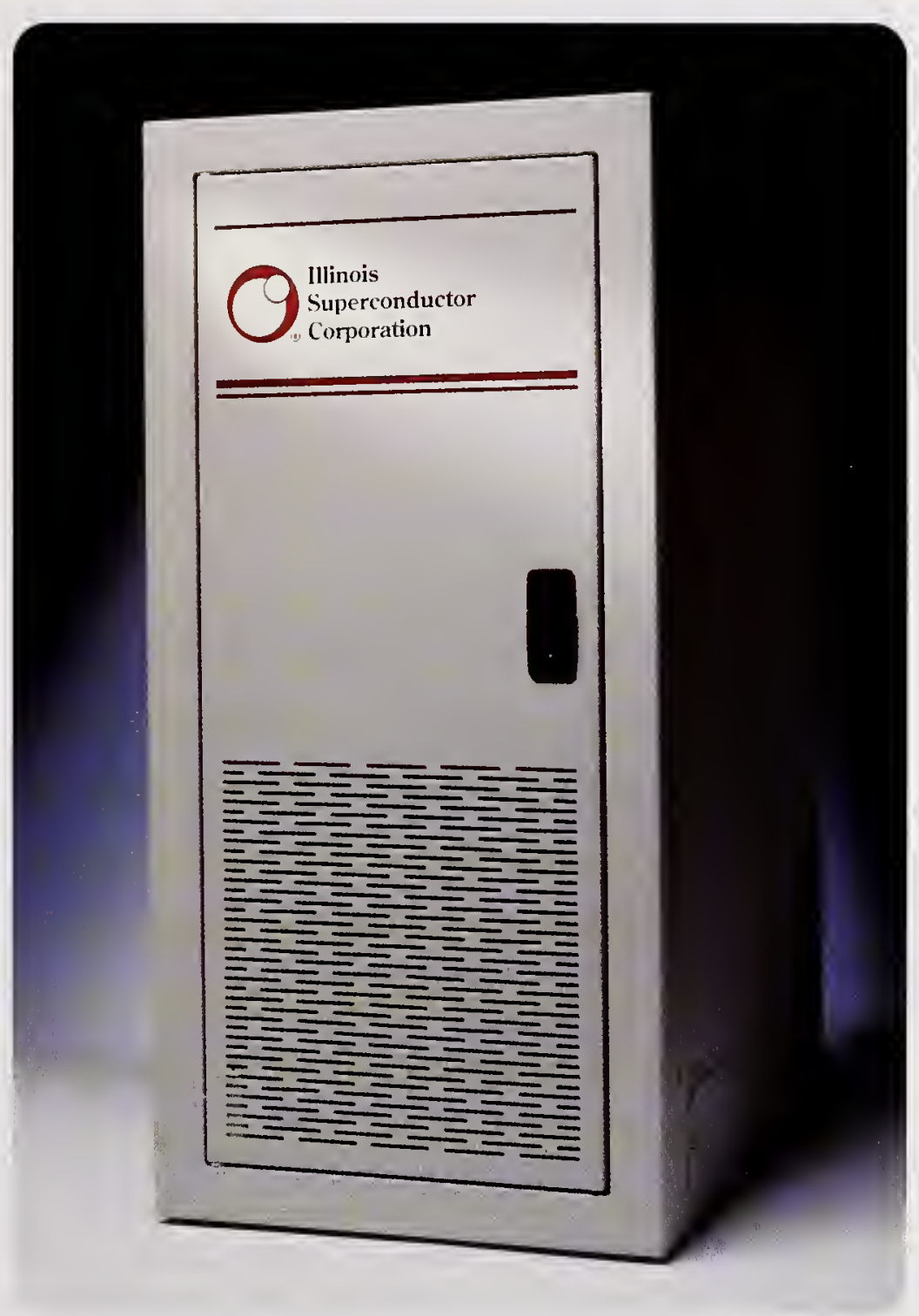

A compact one-box enclosure for RangeMaster ${ }^{\oplus}$ and SpectrumMaster ${ }^{\oplus}$ 


\section{PROJECT HIGHLIGHTS}

\section{PROLECT:}

To develop high-temperature, superconducting thick-film materials for equipment used in the reception/transmission stations of cellular phone and other communications systems.

Duration: 3/1/1993 - 2/29/1996

ATP Number: 92-01-0017

\begin{tabular}{lll}
\multicolumn{4}{l}{ FUNDING (in thousands): } \\
ATP & $\$ 1,980$ & $56 \%$ \\
Company & 1,555 & $44 \%$ \\
Total & $\$ 3,535$ &
\end{tabular}

\section{ACCOMPLISHMENTS:}

ISC developed and demonstrated a robust fabrication process to produce radio-frequency (RF) components using thick-film, high-temperature superconductivity (HTS) technology. It developed a model that predicts the impact of high-performance filters on future digital wireless systems. The company also:

1 received five patents for technologies related to the ATP project:

"Superconducting YBa.sub.2 Cu.sub.3 O.sub.7-x Produced

at Low Temperatures"

(No. 5,527,765: filed 8/23/1994, granted 6/18/1996),

"Electromagnetic Resonant Filter Comprising Cylindrically Curved Split Ring Resonators"

(No. 5,616,540: filed 12/2/1994, granted 4/1/1997),

"Electromagnetic Resonator Comprised of Annular Resonant Bodies Disposed Between Confinement Plates"

(No. 5,629,266: filed 12/2/1994, granted 5/13/1997),

"Resonator Mounting Mechanism"

(No. 5,604,472: filed 12/1/1995, granted 2/18/1997), and

"Superconducting Re-entrant Resonator"

(No. 5,682,128: filed 4/23/1996, granted 10/28/1997);

applied for one additional patent for technology related to the ATP project; raised $\$ 17.4$ million through an initial public stock offering in October 1993;

completed construction of a plant to manufacture RF filters and related products;

began selling SpectrumMaster in 1996 and RangeMasterTM in 1997, both of which are based on the ATP-funded technology;

I. received the Microwave \& $R F$ magazine 1996 Top Product Award for "cellular phone site filters, superconducting ceramics," which were selected from a field of 5,000 new products; and

al received (with subcontractor Lucent Technologies) a Corporate Technical Achievement Award for 1997 from the American Ceramic Society.

\section{CITATIONS BY OTHERS OF PROJECT'S PATENTS:}

See Figure 6.3.

\section{COMMERCIALIZATION STATUS:}

Commercialization is in progress and products are being sold. The benefits of lower costs and higher-quality service are accruing to companies that use ISC's new technology and to their customers.

\section{OUTLOOK:}

The outlook for this new technology is excellent. Its use is expected to spread throughout the economy, lowering the costs and improving the quality of cellular phone and personal communication services.

\section{Composite Performance Score: $\star \star \star \star$}

\section{COMPANY:}

fllinois Superconductor Corporation (ISC)

451 Kingston Court

Mt. Prospect, IL 60056

Contact: Ben Golant

Phone: (847) 391-9416

Number of employees: 8 at project start, 75 at the end of 1997
... received the Microwave \& $\mathrm{RF}$ magazine 1996 Top Product Award for "cellular phone site filters, superconducting ceramics" ...

conductivity (a phenomenon discovered in 1986) to significantly improve the quality of signal transmission.

Superconducting components offer great benefits to cellular phone communications, including improvements in range, receiver sensitivity, and frequency stability. These improvements, in turn, will extend the range of base stations, reducing the number needed to cover a given area and decreasing the costs of cellular phone service. Cellular phone users will receive clearer signals and suffer fewer dropped calls as their signals move from one base station site to the next.
Despite the promise of superconducting components, little prior work had gone into developing HTS components for the radio-frequency (RF) spectrum, which is used by cellular phone systems. Difficulties in economically making the relatively large, geometrically complex structures needed for these frequencies were partly to blame. ISC solved this problem by developing the ability to use thick-film HTS coatings on inexpensive substrates.

\section{Focus on Preselector Receive Filters}

The goal of the ATP project was to develop and demonstrate consistently performing RF superconducting components in a prototype base station. During the ATP project, however, ISC narrowed its focus (with ATP approval) to preselector receive filters, which remove all extraneous RF signals and leave only those within the cellular spectrum allotted to that particular operator. Investigation of the cellular market indicated that the superconducting preselec- 
tor receive filter was of greatest interest to customers in terms of improving system performance. Given the limited resources available to ISC, the company decided to focus on this component as an initial goal and to integrate others later. 'The new HTS technology is useful for other RF equipment and has potential applications in antennas, magnetic resonance imaging machines and other components of communications systems.

ISC successfully incorporated the ATP-funded technology in a preselector receive filter and, in late 1996 , started selling it under the name of SpectrumMaster ${ }^{\circledR}$ to companies operating cellular phone systems. A year later, it launched RangeMaster ${ }^{\circledR}$, which contains the SpectrumMaster ${ }^{\circledR}$ preselector receive filter and a cryogenically cooled low-noise amplifier. By September 1997 , ISC had installed SpectrumMaster ${ }^{\circledR}$ or RangeMaster ${ }^{\circledR}$ in 22 base stations in 12 cities and had successfully completed 16 field trials in 10 cities. Sales at that time amounted to $\$ 1$ million. 'The company has also modified and installed SpectrumMaster ${ }^{\circledR}$ for use in the base stations of personal communications systems.

\section{Improved Communications Service}

The future looks bright for ISC as it uses the A'TP-funded technology to help communications companies serve their customers with greater-quality services at lower costs. Cellular phone service companies can reduce the number of new base station sites they install. They can also

\section{By September 1997, ISC had installed}

\section{SpectrumMaster ${ }^{T M}$ or RangeMaster ${ }^{T M}$}

\section{in 22 base stations in 12 cities and had successfully completed 16 field trials in 10 cities.}

expand by up to 25 percent the range of existing sites by replacing an older filter at the station with a new one based on the ATP-funded technology. A 25 percent range increase corresponds to a 56 percent increase in the area covered and translates into a 40 percent decrease in the number of sites required to cover the area. The cost of the improved filter is around $\$ 25,000$ to $\$ 60,000$, depending on site configuration, whereas the cost of a new site is about $\$ 1$ million to $\$ 2$ million.

The future also looks bright for customers of these
A ceramic torroid form, coated with thick film HTS material, designed to resonate at a specific frequency.

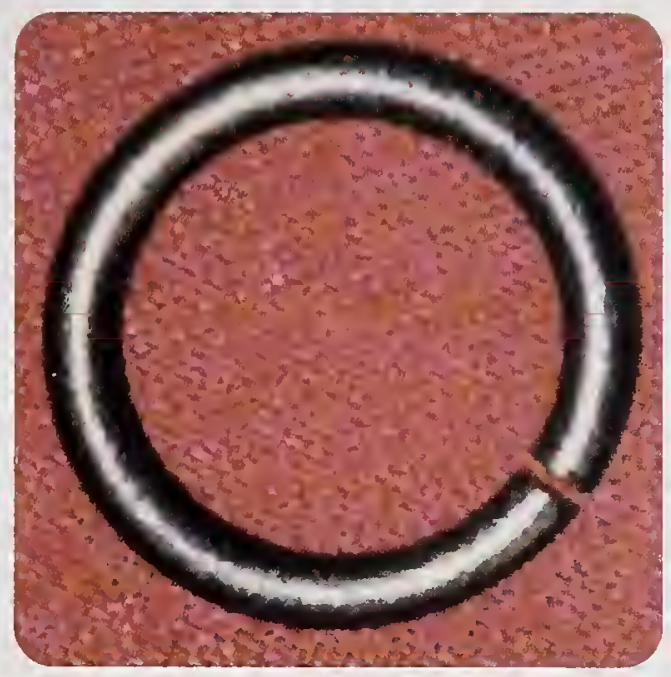

communications companies, as costs drop and service quality improves.

Even greater benefits should accrue to cellular and personal communications customers with the conversion from analog to digital communications. Digital stations must transmit much more data per call, so any quality improvements or cost reductions will apply to a larger volume of signal traffic. As more transmission sites install digital systems, cellular phone users will get clearer signals and fewer dropped calls. Other sectors, such as mobile communications, will experience lower costs and improved quality as the technology is extended to them.

Proliferation of the new technology will provide an additional benefit in terms of aesthetics by reducing the number of signal towers installed for communications systems.

\section{ATP Award Accelerates Development}

Funding from the A'TP enabled ISC to form alliances with research partners and contractors and to achieve its research and development results about 18 months earlier than it would otherwise have been able to do. Company officials say the ATP award also enabled ISC to survive as a company and gave its technology and commercialization plan significant credibility with investors. The increased credibility, in turn, directly helped the company raise private capital, especially during its initial public stock offering in 1993.

\section{A 25 percent range increase corresponds} to a 56 percent increase in the area covered and translates into a 40 percent decrease in the number of sites required to cover the area. 


\section{WLENTREE KEY}

Original Patent

Second Generation Patent

Third Generation Patent

Fourth Generation Patent

Fifth Generation Patent

2000

1999

1998
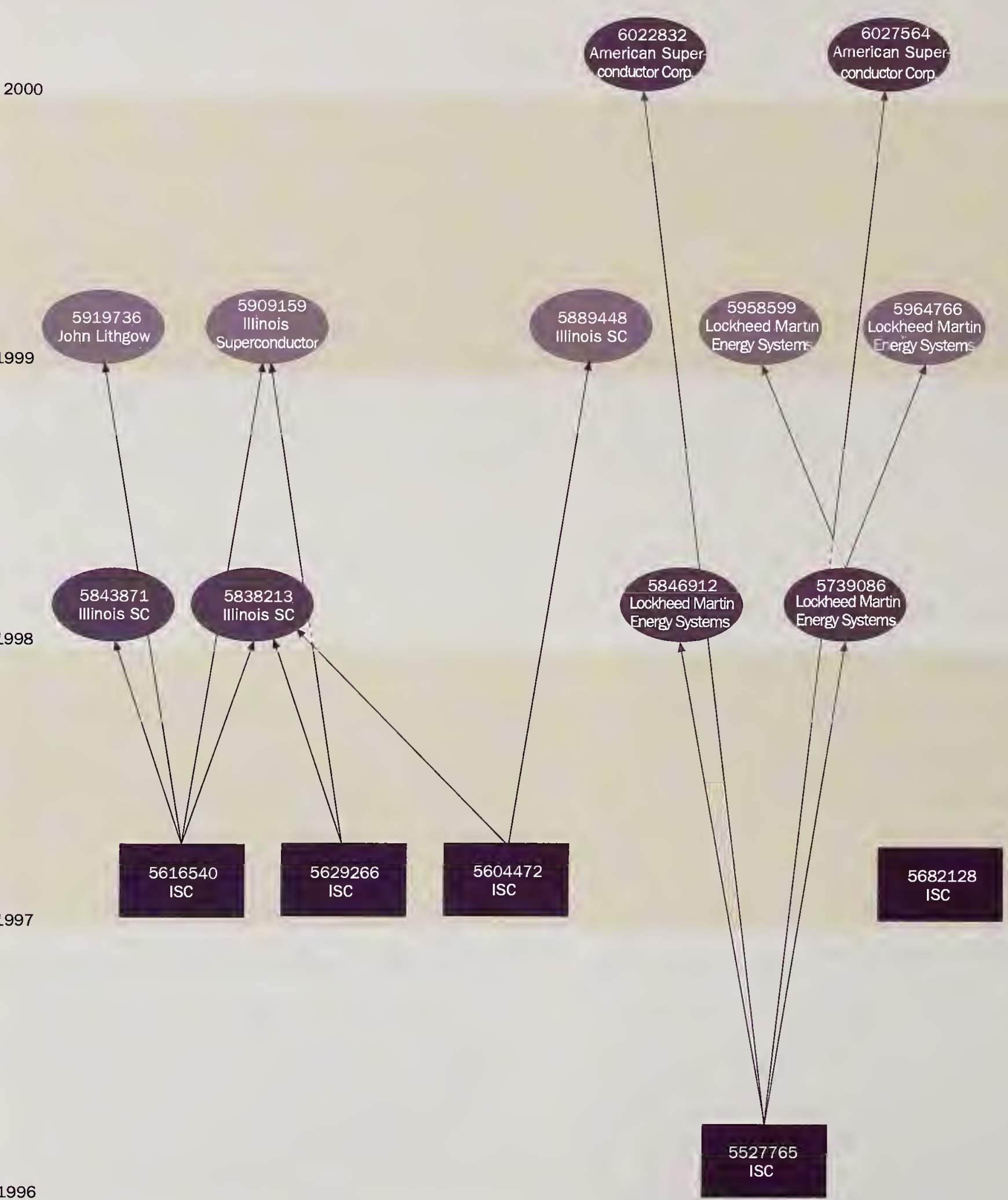

Figure 6.3 Patent Tree for Project Led by Illinois Superconductor Corporation: Citations by Others of Illinois Superconductor

\section{Corporation Patents}




\section{Electronic Muscle: Advanced Microelectromechanical Systems}

1

Ithough electricity has been used to do work and make our lives easier for over 100 years, the technology that converts electrical current to mechanical force has evolved little in the last century. Electric motors, sensors, circuit breakers, and almost all electromechanical devices utilize magnetic fields to create motion from the flow of an electric charge. While machines in general have become smaller per unit of power and more technically efficient, magnetic-based power sources still require large mass and high currents.

COMPOSITE PERFORMANCE SCORE (Based on a four star rating.)

\section{Integrated Force Arrays (IFAs)}

One potential improvement in this area utilizes the attraction of objects with opposite charges to create motion.

The phenomenon, known as electrostatics, is similar to the static cling of a sock to a towel coming out the clothes dryer. Tiny devices using electrostatics convert these electrical charges into precise motion. Combinations of the tiny devices offer the possibilities of larger devices capable of exerting significant force, so-called integrated force arrays (IFAs).

Made up of millions of microscopic cells, the IFA resembles a thin, flexible, plastic membrane. IFAs are part of a group of technologies called microelectromechanical systems (MEMS). Ranging in size from micrometers to millimeters, MEMS are currently used to sense, control, and actuate in such devices as optical scanners, fluid pumps, and pressure and chemical flow sensors.

\section{Combinations of the tiny devices} offer the possibilities of larger devices capable of exerting significant force, so-called integrated force arrays (IFAs).

An IFA can be thought of as analogous to muscle tissue: when an electric signal is sent to the array, it contracts like a muscle, causing displacement and movement. The way

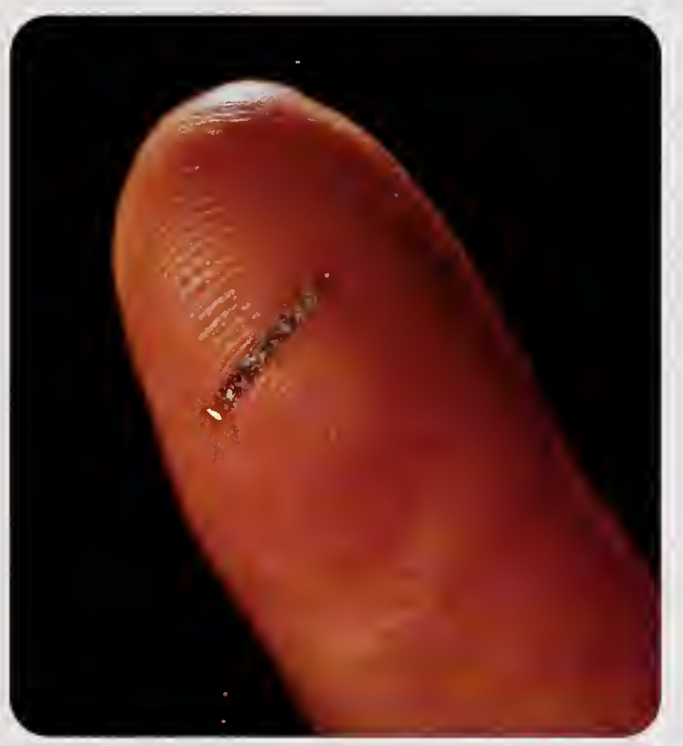

This tiny IFA membrane contains more than 100,000 cells, or building blocks.

this works is that each cell has two conducting sides; when they are charged to opposite electrical polarities, they are attracted like opposite poles of a magnet. Thus, when voltage is applied, the membranes on the individual cells contract, causing the muscle (the IFA) to shrink about 30 percent in length. 'The motions created are precisely controllable, and the mass of the device can be about three orders of magnitude less than that of a magnetically driven solenoid of equivalent power.

IFAs are more durable and lighter than their electromagnetic MEMS counterparts currently in use. They also use less power and can be positioned with more precision than existing mechanisms that create motion from electricity. Although IFAs appear to offer great advantages in principle, processes for making them with large forces and at low cost have yet to be fully developed. 


\section{PROJECT HIGHLIGHTS}

\section{PROJECT:} electrostatically driven structures called integrated force arrays.

Duration: 6/15/92-6/14/95

ATP Number: 91-01-0258

FUNDING (in thousands):

$\begin{array}{lrr}\text { ATP } & \$ 1,206 & 67 \% \\ \text { Company } & \frac{593}{31,799} & 33 \% \\ \text { Total } & \$\end{array}$

\section{ACCOMPLISHMENTS:}

The research conducted by MCNC was successful in meeting many of the project's technical goals. Specifically, the researchers:

produced several IFA working prototypes with desirable force outputs;

abricated IFAs of polyimide coated with chromium and gold that

- published eight articles in refereed journals, and also in conference proceedings and professional society reports; and

applied for and were granted three patents:

"Fabrication method for microelectromechanical transducer"

(No. 5,290,400: filed 12/17/1992, granted 3/1/1994);

"Pleated sheet microelectromechanical transducer"

(No. 5,479,061: filed 12/31/1992, granted 12/26/1995); and

"Unidirectional supporting structure for microelectromechanical transducers"

(No. 5,434,464: filed 5/23/1994, granted 7/18/1995)

CITATIONS BY OTHERS OF PROJECT'S PATENTS: See Figure 6.4
To develop a muscle-like microelectromechanical technology based on were considerably lighter than previous electric mechanisms;

\section{COMMERCIALIZATION STATUS:}

Although the laboratory work to build the first large integrated force array was largely a technical success, the near-term effort for commercialization has been unsuccessful to date. Potential investors have been concerned about the reliability and cost-effectiveness of production processes for large-scale IFA devices. As a result, MCNC has been unable to attract businesses willing to use IFAs in commercial production.

\section{OUTLOOK:}

Although IFA technology continues to be in the early stage of development, numerous applications are envisioned in the future. Potential uses include data storage actuator arms, biomedical devices, robotics, biomechanical prostheses, and optical shutters. The most promising of these applications in the near term is use of IFAs for secondary actuators for the reader arm of disk drives. The dissemination of the research knowledge gained by the ATP project should pay dividends for years to come as the microelectronics machine industry continues to grow and businesses become willing to use IFAs commercially. While the outlook for widespread commercial use of the technology in the near term is weak, the outlook further in the future is strong.

\section{Composite Performance Score: $\star$ \\ COMPANY:}

MCNC

3021 Cornwallis Road

Research Triangle Park NC 27709-2889

Contact: Dr. Scott Goodwin-Johansson

Phone: (919) 248-1964

arrays using common very large-scale integration (VLSI) fabrication techniques. In the next phase of the project, MCNC proposed to develop larger scale and more economical methods of IFA production with the potential of building more powerful and useful IFA devices with potential future applications in fields ranging from robotics and biomedicine to computer data storage. It was a long reach, but one they hoped would bring IFA technology into actuality.

\section{And, if the technology could be pushed} far enough, artificial muscle for prostheses might even be possible. machines that utilize its high power-to-weight ratio over
small distances and loads. And, if the technology could be pushed far enough, artificial muscle for prostheses might even be possible.

In 1992, the Microelectronics Center of North Carolina (MCNC) proposed a two-stage, three-year project to the ATP. The first stage was to develop prototype IFA

\section{North Carolina Research Center}

Researchers at the Microelectronics Center of North Caroenabling technology. They aimed to create an IFA with millions of cells that together would generate linear conchromium, could fit more easily into machines, which would not need to be designed to accommodate the mass and heat dissipation requirements of bulky, heat-generating electric motors. Smaller IFAs could be used in micro- 
research, education, and development of electronic information technologies. Today, the nonprofit center collaborates with companies worldwide in a range of microfabrication and related technology programs. ${ }^{1}$

\section{Successful Prototypes Developed}

During the ATP project, MCNG scientists were able to produce several tiny working prototype IFAs with desired force outputs. They built an IFA actuator that weighed about 60 micrograms, and exerted a force of 12 dynes (enough to push a large sugar cube over a 0.7 -millimeter range). While microscopic, these IFAs have proved both powerful and durable: the work-to-volume ratio for the IFA was among the largest reported in the MEMS literature, and cycle lifetimes of over 10 billion contractions have been measured.

They built an IFA actuator that weighed about 60 micrograms, and exerted a force of 12 dynes (enough to push a large sugar cube over a 0.7-millimeter range).

\section{IFA Commercialization Awaits Further Development}

The success in the laboratory-building the first largescale (although still microscopic) arrays-was significant. But at the end of the project, the process technology was not considered by businesses sufficiently robust to entice them to invest in new product development. Companies have seemed interested in the technology but have been

...at the end of the project, the process technology was not considered by businesses sufficiently robust to entice them to invest in new product development.

hesitant to license IFAs from MCNC without further testing and development. Potential investors have continued to express concern over the capability to produce largescale devices in quantity, both reliably and cost-effectively.
At the conclusion of the ATP program, MCNC made numerous contacts within the magnetic disk drive industry to explore the use of IFAs for secondary actuators. In this application, they had the capability of increasing hard drive storage capacity and data reading rates. The short product cycle of this industry, however, led it to prefer commercially available technology that is ready for immediate inclusion into a new product. The IFA was not at that stage of developrnent, and these attempts failed to lead to commercial development of the IFA. The disk drive industry, however, has shown interest in exploiting such a technology when larger-scale IFAs can be produced by more cost-effective methods.

\section{Interest in IFAs Continues}

MGNC subsequently developed several concepts for fabricating thicker, stronger, and more robust IFA structures. At the time of this study, however, MCNG had continued to be unable to secure additional private sector funds to demonstrate these fabrication methods.

The work, however, has continued to attract government and university attention, as well as research groups in companies. MGNC entered into two contracts with the U.S. military to verify the results of the ATP program and to examine new methods for low-cost fabrication of IFAs. Since late 1999, MCNC has been working on a new DOD contract to explore two of the proposed concepts for

\section{MCNC entered into two contracts with the} U.S. military to verify the results of the ATP program and to examine new methods for low-cost fabrication of IFAs. At the time of the study, MCNC was also working with Duke University on a National Institutes of Health (NIH) contract to fabricate IFAs for an ultrasound scanner.

fabricating the IFA in larger, more robust structures. MCNC expects to fabricate prototypes in 2002. At the time of the study, MCNC was also working with Duke University on a National Institutes of Health (NIH) contract to fabricate IFAs for an ultrasound scanner.

\footnotetext{
${ }^{1}$ Nonprofit institutions, such as MCNC, were eligible to apply to ATP as single applicants only in the first two years of ATP's operation.
} 
Figure 6.4 Patent Tree for Project Led by Microelectronics

Original Patent

Second Generation Patent

Third Generation Patent

Fourth Generation Patent

Fifth Generation Patent

Center of North Carolina: Citations by Others of

Microelectronics Center of North Carolina Patents

2000

1999

1998

1997

1996

1995
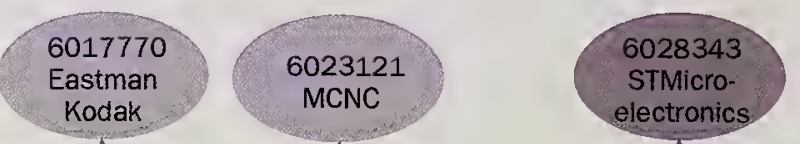

6025763

Oki Electric

6025762
CTS

electronics
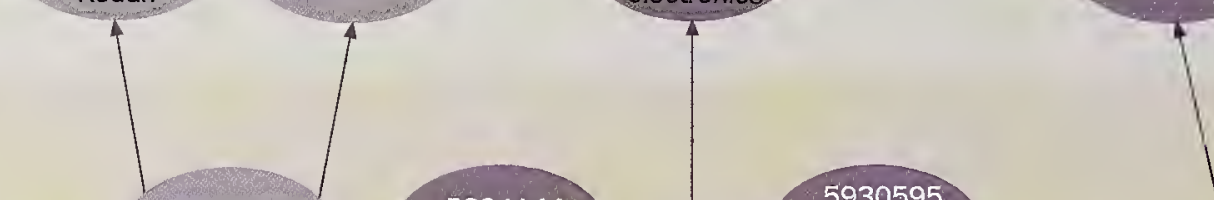

595581
MCNC

Akebono Brake

MCNC

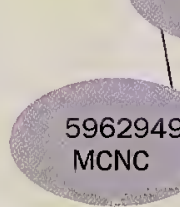

$+$ \begin{tabular}{l|l}
5994816 \\
MCNC
\end{tabular}

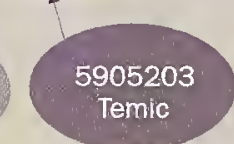

Singapore

STMicro-

electronics

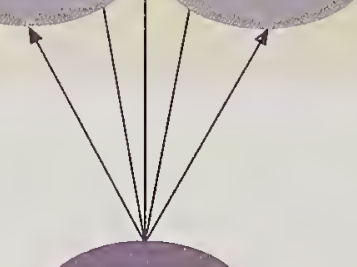

5796152

Roxburgh

$k$

.

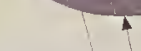

4
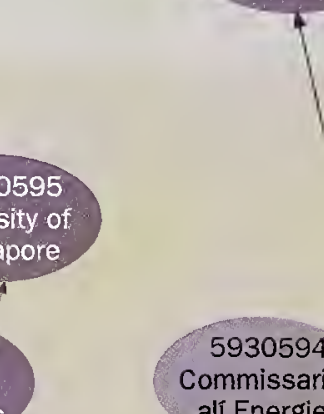

Commissariat

ali Energie

Fujitsu

5949342

Storage

echnology

.

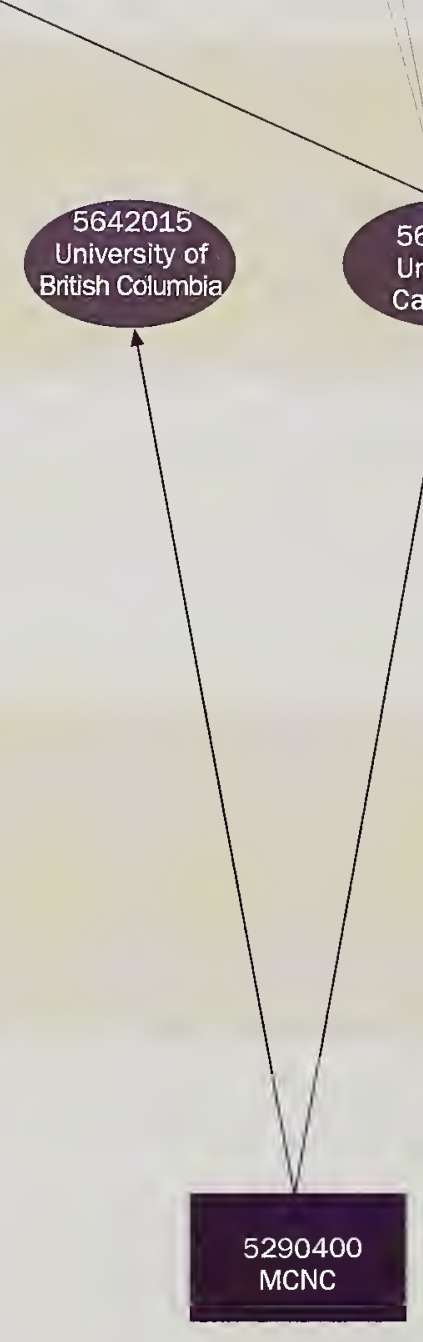

5479061 


\section{Patents and Publications Spread Research Knowledge}

There has been a relatively rapid and diverse dissemination of knowledge from this ATP-sponsored technology. MCNC and its scientists have been granted three IFArelated patents. As illustrated by the patent tree for this project in Figure 6.4, the knowledge gained from the research has begun to spread to other companies and researchers through extensive citing of MCNC's patents by others. Companies and research groups as diverse as Honeywell, Texas Instruments, Cornell Research Foundation, and Siemens, all have cited the MCNC patents developed during the ATP project.

In addition MCNC and its research scientists have spread the knowledge gained from their ATP-sponsored research through publications. As of May 1997, eight refereed journals, including the Journal of Microelectromechanical Systems and Micromachining and Microfabrication, had published articles resulting from the project. Conference and professional society proceedings provided other avenues through which the research results were disseminated. $^{2}$

\section{Growing Interest in MEMs}

MCNC has helped raise the visibility of MEMS devices in the scientific and engineering community. After the ATP project, MCNC created a MEMS Technology Applications Center, jointly funded by the state of North Carolina, the Defense Advanced Research Projects Agency (DARPA), and several large corporations. The MEMS Technology Center focused on developing low-cost fabrication techniques for the development of MEMS devices, including IFAs, for practical applications. In April 1999, MCNG spun off its MEMS business unit into a new company, Cronos Integrated Microsystems, Inc., subsequently bought by JDS Uniphase in April 2000. Although the IFA technology did not go to Cronos (this follow-on effort), the ATP-funded IFA project boosted interest and proved that the technology concepts were valid. Although the ATP project did not take the development of IFAs to the point that private capital alone would take them into commercial development, the ATP investment brought the technology a step closer to realization and helped speed progress in a wide range of MEMS devices.

\section{What Does the Future Hold?}

Although IFA technology continues to be in the early stage of development, numerous applications are envisioned within the next five to ten years, including secondary actuators for hard disk drives, robotics, optical shutters, pumps, valves, and medical devices. A reverse technology is also being developed, where force on the array would cause a current to be generated. These might be used, for example, to make sensors that produce a current when they touch an object. This touch response could be used in robotic sensing systems. ${ }^{3}$ Similar reverse IFAs could also generate power from a person's natural motions, thus, for example, powering devices such as wearable computing systems. Having taken the IFA to its current state of development, MCNC is now looking to customize the technology for use in these and other MEMS applications.

\footnotetext{
${ }^{2}$ MCNC website, February 1998, <http://www.mcnc.org>.

${ }^{3}$ Solid State Technology, Vol. 36, No. 10 (October 1993), p. 36.
} 

PERCEPTRON, I NC.

\section{Machines that See in 3-D}

lan machines see? Not as well as a healthy set of human eyes, but well enough to do certain tasks. Of course, machines at present don't see using biological processes; rather they can be given a form of sight through the use of digital cameras and other imaging devices used in conjunction with computer processing. In fact, prior to recent advances in machine vision technology, machines could only see in two dimensions (2-D), which meant seeing images as flat.

COMPOSITE PERFORMANCE SCORE (Based on a four star rating.)

\section{Limitations of 2-D Vision}

The flat images delivered by 2-D vision are adequate for some industrial purposes, and several firms offer standard 2-D vision systems for use in a variety of markets, such as inspection for quality control of printed circuit boards.

Many automated tasks, however, require geometric spatial information that can only be provided by three-dimensional (3-D) vision capability. This requirement for improved vision with depth perception made the development of affordable 3-D vision technology an important goal in industrial automation. Affordable 3-D vision, for example, is critical to complete automation of inspection tasks and to achieving greatly improved performance of robot guidance tasks.

\section{Technical Barriers to Affordable 3-D Vision}

The recent advent of affordable 3-D imaging deviceshardware components of 3-D vision systems-brought 3-D machine vision a step closer to realization, but the lack of general-purpose 3-D vision software was recognized as a serious technical barrier impeding further progress. Under existing conditions, it was necessary to develop specific software for each application, as well as customized

The high costs of customization have limited the rapid adoption and diffusion of 3-D machine vision technology.

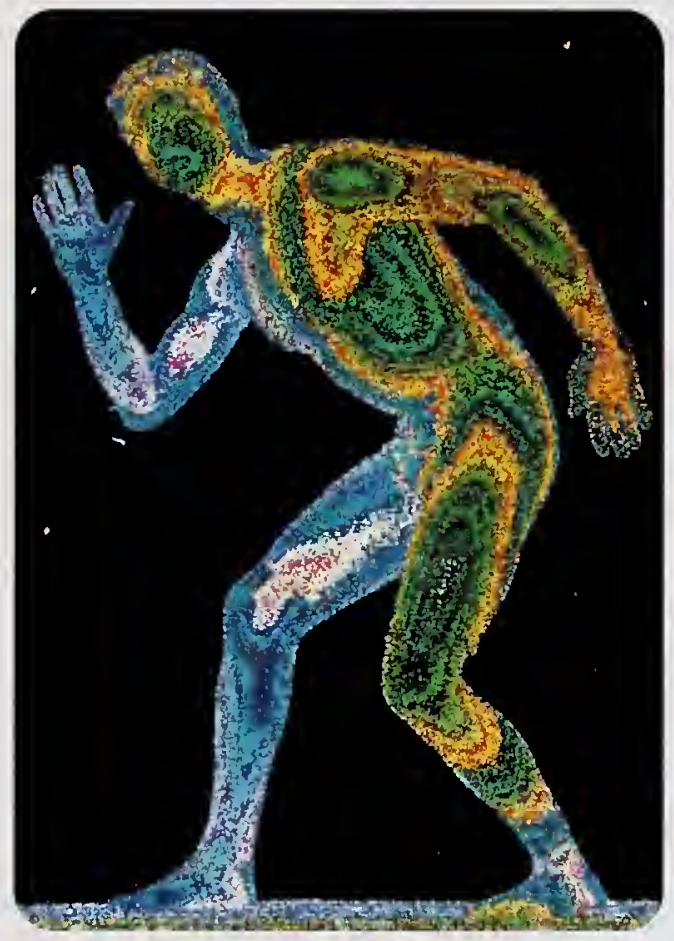

Image processing algorithms developed in the project make it easier to apply 3-D machine vision systems, such as LASAR camera, to see. The different colors of the body indicate depth perception.

hardware to work with that particular software. 'The high costs of such customization have limited the rapid adoption and diffusion of 3-D machine vision technology, despite its large potential for making a wide variety of manufacturing processes more reliable, less expensive, and safer.

\section{A Proposal to Overcome Technical Barriers}

Perceptron, Inc., a small company in Farmington Hills, Michigan, submitted a proposal to ATP's 1993 General Competition with the goal of advancing 3-D machine vision. Perceptron received $\$ 1.219$ million in ATP funding. The company provided $\$ 865$ thousand of its own 


\section{PROJECT HIGHLIGHTS}

\section{PROLET:}

To create generic image processing algorithms - building blocks for costeffective 3-D vision software needed to make industrial machines "see" better-as well as supporting test environment and hardware specifications. Duration: $1 / 1 / 1994-3 / 31 / 96$

ATP Number: 93-01-0071

FUNDING (in thousands):
$\begin{array}{lrr}\text { ATP } & \$ 1,219 & 58 \% \\ \text { Company } & \frac{865}{4} & 42 \% \\ \text { Total } & \$ 2,084 & \end{array}$

\section{ACCOMPLISHMENTS:}

Perceptron met or exceeded its goals for the project. Among its accomplishments, it:

developed image processing techniques and algorithms for developing specialized vision software at lower cost;

constructed a test environment to test these techniques for use in a range of different industrial applications;

- specified the hardware standards to use these tools effectively and inexpensively in an industrial setting;

- developed an interface module that allows data generated by the image processing techniques to be communicated between a range of imaging devices and computing platforms used in industrial machine vision systems;

published 12 technical papers in international conference proceedings and international journals on image processing, pattern recognition, machine vision and industrial automation; and

worked with Trident Systems to develop and install two robot guidance systems using the machine-vision software advances for use in a lumber mill.

funds to mount the $\$ 2.084$ million project. The focus was on developing tools for general-purpose vision software.

More specially, the project aimed at developing standard image-processing algorithms, a test environment for testing, and compatible hardware standards that would provide the basis for the development of a range of affordable machine vision products. These software tools, the test environment, and the hardware standards could then be made available to researchers and companies to push the technology forward and develop applications for various industrial processes, such as automotive drive train assembly and quality control inspections.

\section{The Project Team}

Perceptron subcontracted some of the project's research to the School of Engineering at the University of Michigan at Dearborn (UMD). At the time of the proposal, UMD's Machine Vision Laboratory was engaged in several projects that involved using image analysis methods to solve

\section{COMMERCIALIZATION STATUS:}

The chief focus of Perceptron's efforts in software was robot guidance, which demands a high level of recognition capability, also crucial to other applications such as measurement and inspection. Commercial applications of the new vision software technology have been demonstrated in a lumber mill (where it has reduced timber waste) and to inspection of steel processing furnaces (to achieve safety goals without increasing downtime). In addition, it is feeding into a collaborative effort with Ford Motor Company on the development of robot guidance to automate the assembly of automobile powertrains as part of an ATP project.

\section{OUTLOOK:}

Perceptron's software advances in the ATP project have highlighted the need for improved imaging devices. At present, imaging devices must often be customized, at considerable cost, to meet the precision demands of specific applications. While the development of generic software techniques has extended the range of cost-effective applications of machine vision, the costs associated with the continued need for customization of imaging devices is a remaining barrier that impedes the rapid, widespread applications of 3-D machine vision.

\section{Composite Performance Score: $\star \star \star \star$ \\ COMPANY:}

Perceptron, Inc

47827 Halyard Drive

Plymouth, MI 48170

Contact: Don Holtz

Phone: (734) 414-4842

Number of employees: at project start: 70; number of employees at project end: 300

Subcontractors: ERIM International, a nonprofit research institute; University of Michigan.

practical machine vision problems such as on-line inspection and parts recognition.

\section{Perceptron subcontracted some of the project's research to the School of Engineering at the University of Michigan at Dearborn (UMD).}

Two months into the project, researchers from ERIM International, a nonprofit research institute, joined the project team - made up at the time of Perceptron and University of Michigan researchers. ERIM, headquartered in Ann Arbor Michigan, brought significant experience in image-processing and laser radar systems. ERIM was instrumental in the development of a standard test envi- 
ronment for testing image-processing algorithms and in determining the hardware requirements for executing these algorithms.

ERIM, headquartered in Ann Arbor Michigan, brought significant experience in image-processing and laser radar systems.

Perceptron brought to the research effort a background in producing machine vision systems for a number of industrial applications. The company is primarily engaged in the manufacture and sale of imaging devices. Prior to this ATP project, Perceptron had developed a general-purpose industrial measurement and inspection system, called the P1000, which was based on laser triangulation. Also prior to this ATP project, Perceptron had developed a scanning laser radar called the LASAR, which was the only commercially available scanning laser radar device at the time. This device provided a fundamental advance in the use of machine vision for robot guidance.

\section{Project Goals and Accomplishments}

Perceptron, UMD, and ERIM researchers had four technical objectives in software and hardware development, centered on 1) image preprocessing, 2) image feature extraction, 3) testing, and 4) hardware standardization. The aim was to create a standard set of algorithms for 3-D imageprocessing and object feature analysis, and to demonstrate the effectiveness of these algorithms in a test environment that could simulate the demands of a variety of different manufacturing applications. Such a test environment would allow many different automation vendors to develop general-purpose 3-D vision software products. This would in turn spur hardware production, resulting in widely available 3-D machine vision systems at affordable prices. The advances were expected to make it much more cost-effective to use automated systems in a variety of industrial processes, thus enhancing U.S. manufacturing competitiveness.

Perceptron reached all four of the project's technical objectives. Most significantly, the objectives for software tools were exceeded, with over 200 image processing algorithms developed. According to a company representative, the ATP award accelerated progress towards accomplishing the goals by five years or more. ${ }^{1}$

\section{Progress Toward Commercialization}

The chief focus of Perceptron's subsequent efforts to apply project advances has been in robot guidance. Robot guidance is considered a leading application of machine vision technology because it demands a high level of recognition capability. Technology which can meet the stringent demands of robot guidance systems generally can move into other applications, such as measurement and inspection.

Perceptron worked with Trident Systems, a systems integrator, to develop two related machine vision systems for use in Gulf States Paper Corporation's new \$40 million lumber mill in Moundville, Alabama. The first system decides how to best cut logs crosswise into shorter lengths. The second system calculates the mix of plank sizes that will yield the least waste and most profit from each log.

\section{Perceptron worked with Trident Systems, a systems integrator, to develop two related machine vision systems for use in Gulf States Paper Corporation's new $\$ 40$ million lumber mill in Moundville, Alabama.}

Perceptron also is applying project results in developing machine vision systems to inspect the lining of furnaces used in steel processing. These systems would be able to detect faults in the lining remotely while the furnace is still in operation. Currently, furnaces must be shut down in order to examine the lining for faults pursuant to safety regulations, resulting in substantial downtime and loss of production.

Perceptron is building on the advances in software from the machine vision project to develop prototype automatic inspection devices for automobiles on assembly lines. The company is collaborating with Ford Motor Company as part of a new ATP project to use robot guidance applications in auto industry robotics. ${ }^{2}$

\section{A Remaining Impediment to a Generic System}

Despite the technical advances in software and Perceptron's progress in commercializing results from the project, further improvement is needed to achieve a truly generic machine vision technology. Before the project, software capabilities lagged behind the capabilities of

\footnotetext{
' Interview with Don Holtz of Perceptron, November 28, 2000.

${ }^{2}$ Flexible Robotic Assembly for Powertrain Application (FRAPA). ATP awarded funds to this project in October 1997.
} 
imaging devices then on the market, and the software was considered the major technical barrier. Although the project made progress with software, it made little further progress in the capabilities of imaging devices. By the end of the project, the capability of existing imaging devices was a remaining impediment.

\section{By the end of the project, the capability of existing imaging devices}

was a remaining impediment.

The level of precision required for many of the actual applications, including those currently being developed by Perceptron, can only be achieved by customizing existing imaging devices at considerable cost. The inability of existing imaging devices to meet the demands of varied applications without undergoing customization, limits the ability of companies to take full commercial advantage of the progress made in developing generic software under the ATP project. Thus there is a need for further improvements in imaging devices, and improvements are now being pursued.

\section{Knowledge Sharing}

Perceptron and UMD informed other researchers in the machine vision and related industries of their research findings through a number of published papers. The research led to the publication of 12 technical papers in international conference proceedings and technical journals on image processing, pattern recognition, machine vision, and industrial inspection. Developments were also shared with these industries through trade shows and communication to the Robotics Industry Association, regional organizations such as the Industrial Technologies Institute in Michigan (now the Michigan Manufacturing Technology Center) and the Edison Industrial Systems Center in Ohio.

\section{Gains in Industry Productivity and Safety}

The development of general-purpose 3-D vision software promises to make 3-D machine vision systems more costeffective for a number of industrial applications, which will allow cost savings and increased safety. For example, the use of 3-D vision systems for robot guidance allows for cost savings in dunnage, that is, the pallets, baskets, bins and other containers or platforms from which parts are taken for use in industrial assembly. With the use of 3-D vision systems, general-purpose dunnage can be used, allowing firms to move more quickly from development to production without the need to design specific dunnage for each new project. Successful application of robot guidance in the forest products industry promises to decrease waste substantially, allowing more lumber to be produced from the same amount of timber. In steel processing, the successful application of software advances to remote inspection will allow safety goals to be met without increasing downtime.

In steel processing, the successful application of software advances to remote inspection will allow safety goals to be met without increasing downtime. 


\title{
New Models to Speed the Development of Electronics Components
}

\begin{abstract}
$P$ openers, industrial controls, communications satellites, and numerous other devices.
\end{abstract}

Lrinted circuit boards are ubiquitous. Most people know that boards are in computers, and that each computer actually contains several boards. They are also found in televisions, VCRs and the hand-held controls for these devices, as well as in printers, airplanes, thermostats, automobiles, appliances, calculators, garage-door

COMPOSITE PERFORMANCE SCORE (Based on a four star rating.)

\section{Data Sharing Speeds Component Development} In this ATP project, the PreAmp consortium developed common parts identifiers (a standard product model for components) and fabrication procedures (a generic manufacturing process model for making components) that can be shared among producers and users of printed circuit boards and other electronics components all along the production chain. These models will enable true concurrent (simultaneous) engineering of component design and manufacturing processes, an arrangement that will reduce the cost of developing components, improve their quality and decrease their time-to-market. These improvements, in turn, will lead to similar improvements in finished electronics products that incorporate printed circuit boards and other components developed via this new technology.

\section{These models will enable true concurrent (simultaneous) engineering of component design and manufacturing processes ...}

PreAmp is a joint venture of the South Carolina Research Authority (SCRA) and four large companies that use printed circuit boards in their finished products. Funding from ATP enabled the consortium to conduct research that it otherwise would have been unable to do.
It also facilitated the formation of alliances among the research partners, helping them to demonstrate technology-enhanced concurrent engineering concepts to industry.

The research involved four major tasks: the design of software architecture for electronically sharing component specifics; the development of software prototypes; the implementation, analysis, evaluation, and demonstration of a component database and access mechanism; and the refinement of the manufacturing capability database, its software architecture, and manufacturing process planning.

\section{Easier to Share Information}

The PreAmp product model for electronics components was successfully developed. It is a complete standardsbased, data-sharing framework for automating the design and manufacture of electronic components such as printed circuit boards. It is an extension to the electronics industry of STEP (Standard for Exchange of Product Model Data), an international standard that defines a standard product model for automation systems in order to facilitate the capture and use of all information relevant to product design and manufacture. This extension will speed the development of electronics components (and, ultimately, finished electronics products) by greatly easing the sharing of information among the engineers who design electronics components and those who design the processes for manufacturing these components.

In addition, the PreAmp generic model of manufacturing processes was designed to further aid manufacturing engineers by capturing all relevant data on the manufac- 


\section{PROJECT HIGHLIGHTS}

\section{PROJECT:}

To develop a standards-based data-sharing framework for automating the design and manufacture of electronics components. The framework will enable true concurrent (simultaneous) engineering of component design and manufacturing, which will reduce the cost of developing components, increase their quality and decrease their time-to-market. Such improvements will lead to similar improvements in finished electronics products that incorporate these components.

Duration: $7 / 1 / 1992-7 / 31 / 1996$

ATP Number: 91-01-0267

\begin{tabular}{|c|c|c|}
\hline \multicolumn{3}{|c|}{ FUNDING (in thousands } \\
\hline ATP & $\$ 5,166$ & $37 \%$ \\
\hline \multicolumn{2}{|c|}{ Consortium 8,625} & $63 \%$ \\
\hline Total & $\$ 13,791$ & \\
\hline
\end{tabular}

\section{ACCOMPLISHMENTS:}

PreAmp successfully completed all technical goals, including development of a knowledge-based software system that can extract process "rules" from manufacturing process data. Other accomplishments include:

- STEP Tools, an informal participant in the project, developed prototype software to validate a standard data access interface library that has since become part of its ST-Developer product. ST-Developer has been distributed to more than 100 customers worldwide and is being used to build and maintain STEP (Standard for Exchange of Product Model Data) applications and databases;

researchers presented several papers at professional conferences, including the

- Design and Automation Conference,

- National Electronics Packaging Conference, and

- Reliability in Agile Manufacturing Symposium;

turing capabilities of a particular plant, information such as shop-floor equipment capabilities, equipment layout, and operating requirements, and limits. As part of this effort, researchers developed a knowledge-based software system that can extract process rules from the manufacturing process data - for example, "Given current equipment, interconnects may not be spaced closer than X." Such rules will improve the functioning of the system.

The combination of the full product and manufacturing models allows concurrent (simultaneous) engineering of component design, process design and component manufacturing. Studies cited by the consortium suggest the new technology can reduce time-to-market by 50 percent or more, double component quality levels and reduce development costs by 30 percent to 70 percent. The project's commercialization work is still underway, so it is not yet known whether these expectations will be matched by improvements in the quality of actual component design and manufacturing processes.
PreAmp hosted a "Vendor Opportunity Forum" to give software vendors opportunities to commercialize the technology developed by the project.

\section{COMMERCIALIZATION STATUS:}

A modest amount of commercialization is under way via the product introduced by STEP Tools, but the main commercial goals of the consortium have so far not been accomplished. Boeing is conducting a pilot project, and SCRA continues to develop the technology and promote commercialization.

\section{OUTLOOK:}

The core technology developed by the project may be commercialized in several years, after additional $R \& D$ work. Thus, there is some prospect of benefits to eventual users. If commercialization does occur, the spillover benefits could be large, since so much of the work of this project is in the development and promulgation of data-sharing standards.

\section{Composite Performance Score: $\downarrow$ \\ COMPANIES: \\ PreAmp Consortium \\ South Carolina Research Authority (SCRA, consortium lead) \\ 1330 Lady St., Suite 503 \\ Columbia, SC 29201}

Contact: Gerry Graves

Phone: (803) 760-3793

Other consortium members: Boeing Company, Defense \& Space Group; Hughes Aircraft Company; Martin Marietta Corporation, Electronics Information \& Missiles Group; and Rockwell International Corporation, Collins Avionics \& Communication Division

Informal participants: Rensselaer Polytechnic Institute and STEP Tools, Inc.

\section{Initial Commercialization}

Some of the technology developed by the PreAmp consortium has been adapted and incorporated into software tools by STEP Tools, Inc., an informal participant in the ATP project. STEP Tools developed a prototype STEP data application interface for the project. Afterward, the company enhanced the prototype to make it suitable for commercial use and incorporated it in the ST-Developer ${ }^{\mathrm{TM}}$, an application that already has several hundred customers.

The principal test-bed implementation of the models developed during the ATP project was carried out by PreAmp members. Boeing is conducting a pilot project to determine whether it can use the new software technology in its internal operations to increase the productivity of printed circuit board design work. The company is working with an ATP-project subcontractor in developing software to translate existing database information to work in the new product model system. It will probably be known by 1999 whether the Boeing effort succeeds. If it 
does, the creation of commercial products will be much more likely.

Three members (Boeing, Hughes, and Rockwell) have arranged with SCRA for it to serve as the PreAmp agent with vendors interested in creating commercial software systems that include the A'TP-funded technology. Consortium members, with the help of SCRA, proposed the enhanced STEP procedures to the International Standards Organization for registration, which is expected to be issued as STEP Application Protocol 210.

\section{Studies cited by the consortium suggest}

the new technology can reduce time-tomarket by 50 percent or more, double component quality levels, and reduce development costs by 30 percent to 70 percent.

Reorganization and company upheavals among consortium members, however, seem to be hindering further progress toward commercialization. Organizational energy has been siphoned off to deal with mergers and acquisitions. In addition, reductions in national defense work have caused turmoil in three of the four corporate members of the consortium that have been very active defense contractors. But if energy can be refocused on further developing the ATP-funded technology, it could be commercialized in several years.

\section{Large Potential Benefits From Data-Sharing Standards}

The new technology was intended for use in the production of printed circuit boards, and it has potential applications in the manufacture of other electronics components as well. If widely adopted, the product and manufacturing process models would provide a common language for the production process. In that case, the economic spillover benefits from widespread use of the technology could be large since so much of it involves data-sharing standards. Given the hundreds of millions of printed circuit boards produced for use in the United States each year, the benefits from this kind of standardization would be extremely large. 


\section{Smart-Window Technology}

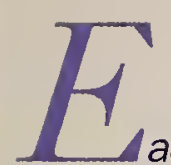

ach day millions of Americans spend the day inside buildings with windows as their only connection to the outside world. Windows allow the sun's warmth and light to permeate our living space and offer views of the outside. Unfortunately this luxury brings with it the high costs of heating, cooling, and shading. Windows, which have largely escaped technological advances, are now being taken into the high-tech arena.

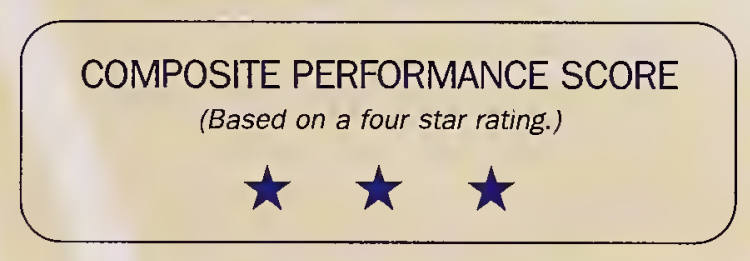

\section{A Strong Potential Seen for Thin-Film Electrochromics}

For years, thin-film electrochromics has been seen as a possible way to make "smart windows"-windows with an electrochromic (EC) coating that can electronically control the flow of solar light and heat in response to changing outdoor conditions. On hot, sunny days the tint in the windows would darken to reduce glare and block out heat. On cold, cloudy days the windows would clear to allow sunlight and heat to fill the office or home. In addition to reducing energy requirements, the electric shading of smart windows may eliminate or reduce the need for expensive blinds or curtains.

\section{On hot, sunny days the tint in the} windows would darken to reduce glare and block out heat. On cold, cloudy days the windows would clear to allow sunlight and heat to fill the office or home.

The race for a profitable and reliable electrochromic production process has been pursued aggressively for more than 15 years. Electrochromic technology is appealing as a potentially broad-based area that promises to be useful not only in windows in buildings, but also for adhesive tape films for automotive windows, electrically adjustable eyewear, advanced flat batteries, and other applications. The
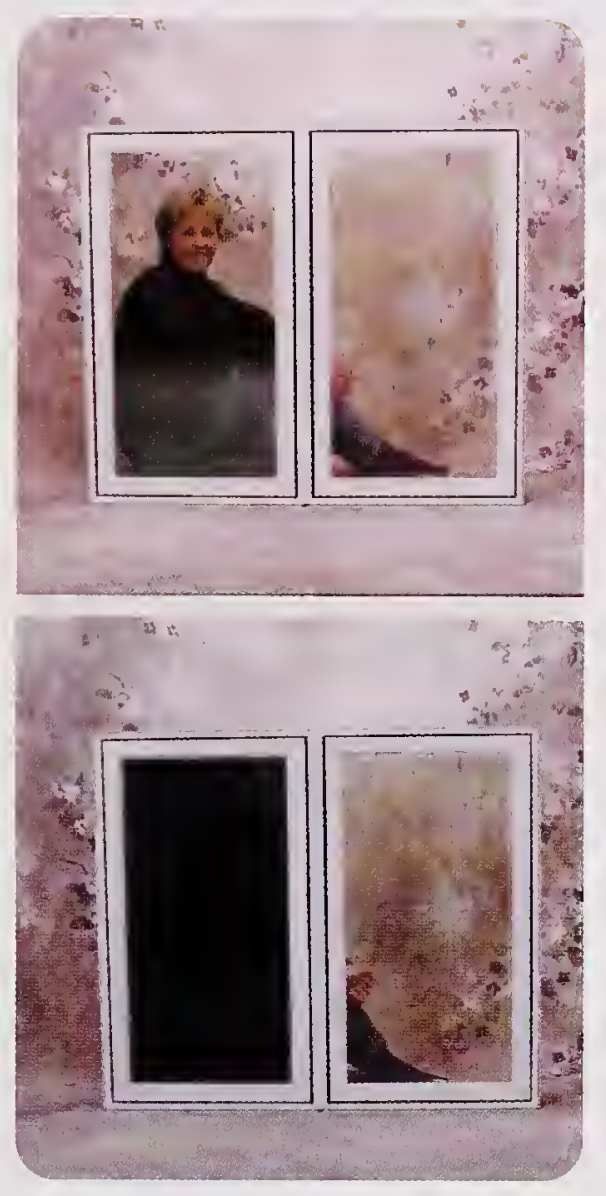

potential for multiple applications and broad benefits of thin film electrochromics has made it one of the most intensely researched areas of material science around the world.

\section{U.S. Partnership Develops to Pursue the Technology}

Against this backdrop of worldwide competition, enters John Van Dine, who in 1990 founded a small company 


\section{PROJECT HIGHLIGHTS}

\section{PROJECT:}

To develop advanced electrochromic materials and production processes leading to devices suitable for electronically controlled smart windows and other applications.

Duration: 6/07/93 - 12/31/96

ATP Number: 92-01-0123

\begin{tabular}{|c|c|c|}
\hline ATP & $\$ 3,472$ & $48 \%$ \\
\hline Company & 3,821 & $52 \%$ \\
\hline Tr & & \\
\hline
\end{tabular}

\section{ACCOMPLISHMENTS:}

This project led to major advances in electrochromic materials and processes and opened up potential applications in a variety of useful products. The project:

developed new understanding of large-area electronic devices;

produced several working prototypes of smart windows for competitive performance testing at the National Renewable Energy Laboratory (NREL) that were rated best overall;

- produced prototypes that tests show are capable of tens of thousands of tint changes (cycling), equivalent to more than 15 years of use, without degrading performance;

produced prototypes that are estimated to reduce the transmittance of light and heat, depending on the setting, by 30-96 percent, and to yield up to a 50 percent reduction in energy costs for commercial buildings, as demonstrated by Berkley National Laboratory and ASHRAE tests;

- produced two patents for technologies developed in the project: "Counterelectrode Layer" (No. 5,919,571: filed 7/14/1997, granted 7/6/1999);

"Sputtering of Lithium" (No. 6,039,850: filed 5/29/1997, granted $3 / 21 / 2000)$.

\section{COMMERCIALIZATION STATUS:}

Sage announced on June 17, 1998, that it had reached an agreement with Apogee Enterprises, Inc., to develop, produce, and market smart windows. This commercialization venture is a direct result of the encouraging test results for the prototype windows developed in the project. A leading fabricator, distributor, and installer of value-added glass products, Apogee, and its subsidiary, Viracon, will target the high performance architectural glass market. In addition, SAGE has recently received a DOE-NETL grant that will help it to focus further on issues affecting efficiency of fabrication.

Sage has successfully set up pilot line operations, including an industrial scale coater and fabrication systems, leading to the production of full size switchable windows measuring up to five square feet in area.

In addition, Sage has entered into a number of industry alliances to develop and commercialize smart window products. In February 2001, Sage and Honeywell, the global home and building controls leader, announced an alliance whereby Honeywell will develop and manufacture the systems for Sage's smart windows, enabling user control of EC glazings to transform windows into comfort-enhancing and energy-saving appliances. Sage and Velux, a leading global producer of skylights and roof windows, have partnered to test market Sage skylight products. Sage also has joint projects with other original equipment manufacturers - i.e., Pella and Four Seasons Solar Products Corporation - for product development, joint testing, and market introduction. Sage expects to move into volume manufacturing by the end of 2002, when it will significantly increase its staffing level

\section{OUTLOOK:}

Industry experts have predicted that electrochromic windows are three-tofive years from wide-scale commercial use. New manufacturing techniques must be developed that will eliminate even the smallest defects in the electrochromic layers. These defects are the major barrier to producing economical, large-size architectural windows. Other potential applications of electrochromic technologies include next-generation flat, compact batteries; new and retrofitted automobile windows; and adjustable eyewear. The outlook appears excellent for this technology.

\section{Composite Performance Score: $\star \star \star$ COMPANY:}

SAGE Electrochromics, Inc.

2150 Airport Drive

Faribault, Minnesota 55021

Contact: Neil Sbar

Phone: (507) 333-0078

Number of employees: 5 at project start; 10 at project end in Piscataway, New Jersey, called Sun Active Glass Electrochromics, Inc. (SAGE), to develop glass coatings. Following an unsuccessful ATP proposal in 1991, he was encouraged to strengthen his plan by finding a technology partner. To that end, in 1992, SAGE formed a joint research and development partnership with the $3 \mathrm{M}$ Corporation, and the two companies brought in scientists from Rutgers University's Center for Ceramic Research as additional collaborators. The joint venture submitted a proposal in A'TP's 1992 General Competition and was successful.

The ATP provided $\$ 3.472$ million, matched by $\$ 3.821$ million from the $3 \mathrm{M}$ Corporation and $\mathrm{SAGE}$, for a project to develop advanced electrochromic materials and production processes. The project was designed to build upon the EC synthesis and processing experience of tiny SAGE, while also drawing upon the module technology and manufacturing and commercialization skills of the Fortune 500

\section{...the two companies brought in scientists from Rutgers University's Center for Ceramic} Research as additional collaborators. 
company, 3M. SAGE was to focus on the technical requirements relating to $\mathrm{EC}$ glass, and $3 \mathrm{M}$ on the technical requirements relating to tape.

\section{What Makes Smart windows Smart?}

The electrochromic (EC) window consists of a series of thin conducting layers that change optical properties when an electrical voltage is applied. Each layer is thinner than a sheet of paper, and together the layers support the transport of electrons and ions. One layer of the film-colorless lithium metal-oxide-acts as the positive electrode, another layer-tungsten oxide-acts as the negative electrode. When voltage is applied, lithium ions begin to traverse from the positive electrode to the negative electrode, a process that turns the tungsten oxide to lithium tungstate (a light absorbing, blue-gray substance), formed by the chemical addition of ions. The longer the voltage is applied, the more ions are transferred, and the darker the window becomes.

During the production process, ceramic thin-film layers containing the electrodes are deposited with great precision onto a transparent substrate primarily by a vacuum coating technique. The multilayered electrochromic device is then mounted inside a conventional glass frame. The conducting layers are connected to a power supply, controlled by a switch. The switch allows the number of ions, and thus the amount of light transmitted in the electrochromic film, to be varied incrementally to satisfy user preferences for heat and sunlight. The opacity of the glass can be controlled by a simple on-off switch, a useradjustable rheostat to meet individual user preferences of heat and sunlight, or an automatic system driven by sensors or timing devices.

\section{Unequal Company Progress}

Previous to the ATP-funded research, the state-of-the-art capability in producing electrochromic materials for windows resulted in a laboratory curiosity, a piece of glass measuring less than two square inches. Furthermore, the EC properties of the tiny piece of glass were not well understood.

During the project, SAGE moved forward successfully with its materials and process research on EC glass, and met with great success. $3 \mathrm{M}$, on the other hand, encountered obstacles in managing the heat level in the production of its tapes. A method of controlling the heat level was needed to avoid melting the tapes. This serious obstacle that the company was not able to solve caused it to reduce its role to a supporting one for SAGE.

\section{SAGE Prototype Smart Windows Best Rivals in Critical Performance Tests}

By the end of the project, SAGE was able to produce prototype smart windows approximately one square foot in size that incorporated the new technology and demonstrated the performance characteristics and decade-long durability of EC glass required by the architectural glass industry. This new capability represented a major step forward, both technically and in terms of demonstrating commercial potential for the technology.

The functional EC window prototypes produced in the ATP research project were subjected to independent performance tests in an outdoor desert environment and at the National Renewable Energy Laboratory (NREL). NREL, the world's leading certification laboratory for energy saving technology, used a solar simulator with xenon lamps to test alternative smart window designs for environmental longevity. Competing technological approaches from other companies each had their relative strengths, but the SAGE smart windows displayed the best overall performance.

The rigorous tests demonstrated that the new SAGE windows are capable of tens of thousands of tint changes (cycling) without degrading. This translates into more than 15 simulated years of harsh sun while maintaining adequate performance.' Architectural consumers currently expect warrantees of at least 15 years and useful lives of at least 20 to 25 years. These tests show that electrochromic windows, especially SAGE's design, hold great promise in meeting the longevity required for commercial building use.

At the end of the project, the company was ready to take the next step: scaling up to full size electrochromic windows for architectural applications on residential and commercial buildings. SAGE moved toward this goal, keeping in mind for commercialization purposes that it was critical the EC windows could be manufactured in volume at reduced cost.

\section{SAGE announced an agreement with Apogee Enterprises, Inc., to develop, produce, and market smart windows.}


Commercialization Agreement with Largest Specialty Glassmaker in North America

SAGE announced on June 17,1998 - about a year and a half after the project completed - that it had reached an agreement with Apogee Enterprises, Inc., to develop, produce, and market smart windows. ${ }^{2}$ The company promptly relocated from New Jersey into a corner of Apogee's Viratec manufacturing plant in Minnesota. This commercialization venture is a direct result of the encouraging test results for the prototype windows. Apogee, a large fabricator, distributor, and installer of high-end, specialty glass products in North America, and its subsidiary Viracon, will commercialize the licensed smart windows for mass distribution in the high performance architectural glass market.

Viracon has extensive experience in producing glass products with high performance coatings, and supplies a large global window market. These two strengths will help the new SAGE-Viracon team take the electrochromic technology more quickly to full-scale production. There is, however, a difficulty that will have to be addressed before cost-competitive architectural windows can be produced: the control of defects in large size films. Since current prototypes had not been produced in a size greater than one square foot, it was critical that Viracon be able to develop a manufacturing capability for producing larger EC windows. SAGE has received a Department of Energy/ National Energy Technology Lab grant from the Department of Energy to improve the manufacture of smart windows on a large scale.

\section{ATP Brings Together Complementary Companies}

The ATP project manager, Dr. Gerald Ceasar, with his extensive industry experience with electrochromics and photovoltaics technology, saw potential commonality of interests of Solarex, a photovoltaic company, and SAGE. He made the introductions and this technology brokering

...technology brokering soon yielded the integration of photovoltaics into the new smart window design. soon yielded the integration of photovoltaics into the new smart window design. The inclusion of photovoltaics (in the form of built-in sensors) will allow engineers to set the windows to adjust automatically to changing sunlight conditions. Photovoltaics (in the form of energy producing solar collectors) can also provide all of the energy needed to power the window, thus eliminating the need for external wiring.

In the future, integrated photovoltaics may even be able to produce excess electricity that could power all or part of the entire building and pay for the new windows many times over. Ultimately, this may reduce the lifecycle costs of purchasing, installing and operating windowed buildings. Technology integration, encouraged by ATP managers, means connecting emerging technologies from different companies and industry sectors together in mutually beneficial ways.

\section{SAGE Moves Ahead of International Rivals in Smart Window Technology}

Although SAGE had been awarded a total of 7 patents for its electrochromic technology before the ATP project, approximately 1,800 patents had been issued worldwide for electrochromic technology. Of those patents, Japanese interests hold 1,500. ${ }^{3}$ The Japanese, Europeans, and Australians have all mounted major efforts to develop EC technology. ${ }^{4}$ In Australia, for example, researchers at Monash University are developing an energy-efficient smart window, an effort that has been underway for the past five years as part of a $\$ 3$ million project. The

The Japanese, Europeans, and

$$
\begin{aligned}
& \text { Australians have all mounted major } \\
& \text { efforts to develop EC technology. }
\end{aligned}
$$

Australian Science and Technology Administration targeted the new windows to be ready for large-scale commercial production around the turn of the century. ${ }^{5}$

The competition for leadership in EC windows around the world is intense. As a result of the ATP award,

\footnotetext{
2 PRN Newswire, June 16, 1998 Press Release.

Michael Rubin, Lawrence Berkeley National Laboratory, personal interview, August 5, 1998.

Monash Publications, University Marketing \& Development, Monash University, Australia;

<www.monash.edu.au/pubs/eureka/Eureka_95/window.html > web page accessed July 8, 1998.
}

Jeffery Kahn, "Researchers Seek Patents on Electrochromic Smart Windows," February 14, 1992, Berkeley Lab Science Articles Archive. 
SAGE was able to speed the research in collaboration with $3 \mathrm{M}$, and get an advanced prototype to product test more quickly than overseas competitors. According to SAGE project manager Neil S. Sbar,

Early support from ATP was critical in enabling SAGE to develop the electrochromic (EC) materials systems and device structure for scaling the technology from a laboratory curiosity to switchable prototype windows nearly one square foot in size. Without ATP, our progress would have been delayed by more than two years. Also, the prestige and credibility derived from the relationship greatly facilitated subsequent industry and government partnerships leading to full size EC window fabrication. ${ }^{\circ}$

And, according to SAGE president John Van Dine,

[ATP] enabled us to accelerate and expand our technology development and put our company into a better internationally competitive position.

\section{Smart Windows Beat Traditional Glazed Windows for Energy Efficiency}

The price-sensitive architectural market will require significant cost savings over the life of the window to justify a major market shift away from single-glazed and multiglazed windows. Based on test results, full-size replacement smart windows can reduce peak loads for lighting, heating, and cooling up to 60 percent when compared to high-end glazed windows. And they can reduce peak loads up to 85 percent compared to single-glazed clear glass, ${ }^{8}$ which blocks only 21 percent of solar heat gain into the room." To accomplish these results, electrochromic smart windows reduce the transmittance of light and heat, depending on the setting, by 30 to 96 percent.

Even at this early stage of electrochromic window development, savings of $\$ 0.21$ per square foot in areas of the country that have cooling-intensive building loads have been calculated, based on $\$ 0.08 / \mathrm{kWh}$ electricity costs. Thus, a medium-sized office building $(100,000$ square feet), with windows covering 60 percent of the outside surface, could see operating savings on the order of $\$ 21,000$ per year if smart windows are used. ${ }^{10}$ Over a 25 -year life, these savings would have a present value of $\$ 365,000$ (based on a 3 percent real [net of inflation] discount rate, and assuming stable energy costs [also net of inflation] ${ }^{11}$ ). Cost analysis that includes direct energy costs, initial chiller investments, utility demand-side management rebates, and lighting savings indicate that smart windows (at an added first cost of $\$ 161 / \mathrm{m} 2$ ) could pay for themselves in as little as four years. ${ }^{12}$

A recent American Society of Heating, Refrigeration,

\section{...Smart windows could pay for themselves in as little as four years.}

and Air-conditioning Engineers (ASHRAE) study showed that EC windows could provide energy efficiency performance comparable to a well-insulated wall. For a building located in a cooling-dominated environment (e.g., Phoenix, Miami, Los Angeles), the study estimates that smart windows will significantly lower heat gain and the energy demands of cooling. The ASHRAE work also found that lighting expenditures could be significantly reduced because smart windows, when bleached, allow more light to enter the room than standard windows. In heating-dominated areas (e.g., Chicago, or Greenbay), smart windows can increase the solar heat gain compared to standard windows, reducing heating costs in winter and cooling costs in summer. The study found that the cooling savings of windows with reflective glazing are comparable to those with electrochromics. The total energy savings, including that from reduced lighting demands, however, favor smart windows technology, in spite of its higher initial costs. ${ }^{13}$

Twenty billion dollars is the estimated value of the energy lost through the windows of buildings in the United States each year. This represents more than five

\footnotetext{
${ }^{6}$ Telephone interview and personal correspondence with Dr. Neil S. Sbar, December 2000.

${ }^{7}$ NIST website: <www.atp.nist.gov/atp/success/sage.htm>.

${ }^{8}$ Facilities Design and Management, April 1996, p. 15.

${ }^{9}$ SRI Report, Smart Glass: Seeking a Clear View of the Future, 1998, p. 12.

${ }^{10}$ Rubin, Selkowitz, Sullivan, ASHRAE Transactions, June 1997, pp.149-153.

${ }^{11}$ U.S. Dept. of Energy, Ammual Energy Outlook 1998, Energy Information Administration, 1998, p. 80.

${ }^{12}$ Lee, Rubin, Selkowitz, Sullivan, Review of Electrochromic Window Performance Factors, Lawrence Berkeley Laboratory Report \# 35486, p. $14,1994$.

${ }^{13}$ Rubin, Selkowitz, Sullivan, ASHRAE Transactions, June 1997, pp.149-153.
} 
percent of total U.S. annual energy use. ${ }^{1+}$ Globally, a phased-in total transition to smart window systems in office buildings could translate into energy savings on the order of $\$ 11.5$ billion to $\$ 22.5$ billion per year. ${ }^{15}$

Although this full potential is unlikely to be realized any time soon, smart windows promise eventually to have a significant impact on world window and energy markets as they enter commercial production and are adopted by architects, builders, and building owners as a means of achieving dynamic control of heat and light gain into a building.

An architectural advantage of electrochromic windows is that they eliminate glare and the need for other shading devices. Automated or manual blinds, curtains, and shutters can be expensive to install, maintain, and clean. Reducing costs in this area will enhance the commercial viability of smart windows. Light has also been shown to be an important factor for the work environment. Studies demonstrate that allowing sunlight to fill offices (otherwise shaded by permanent glazes) can increase productivity, lead to fewer days of absenteeism, and fewer errors on the job. ${ }^{16}$

\section{Smart Window Technology Is Potentially Far Reaching}

Enabling advances in electrochromic technology resulting from this ATP funded project have encouraged the application of large-area electronics to other commercial products, beyond the scope of window applications.

Researchers are currently working to apply the ion shuffling capabilities of electrochromics to thin film flat batteries for use in consumer electronics, such as cellular phones and laptop computers, which may then be able to operate significantly longer and with much lower weight. Automobile windows and adjustable eyewear are examples of where the advances of electrochromics may have future market potential. The future is bright for the broad use of large-area electronics, and the foundations are being laid today.

\footnotetext{
${ }^{14}$ SRI Report, Smart Glass: Seeking a Clear View of the Future, 1998, p. 2.

${ }^{15}$ Ibid.

${ }^{16}$ LaSourd, Selkowitz, Lawrence Berkley Laboratory, June 1994, p. 111.
} 


\section{Better Precision for Machine Tools Through Thermal-Error Correction}

11 and pieces. The interface between the cutting or shaping tool and the material being worked almost always gets hot. In most cases, a coolant is directed onto the interface area to take away enough heat to allow the job to be performed.

COMPOSITE PERFORMANCE SCORE (Based on a four star rating.)

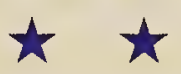

\section{High Heat Degrades Machining Quality}

Even with the coolant, the machine tool itself often becomes warm enough to change shape slightly, and the accuracy of the machining operation degrades. The result can be a finished part that fails to meet specifications. What would have become a salable part becomes scrap metal, and some high-precision parts cannot be made at all.

\section{Thermal-Error Compensation}

With ATP funding, Saginaw Machine Tools - a small, privately held company founded in 1983 to build precision computer-controlled machine tools for high-volume manufacturing - together with researchers at the University of Michigan, developed a solution to the heat problem. Their

\section{Customers manufacturing high-} precision parts realize productivity improvements of 10 percent to 30 percent. . .

technology monitors the temperature gradients in computer numerically controlled (CNC) machine tools and alters the control process dynamically (while the machine is working) to compensate for heat-related changes in the machine tool as the part is being worked. When the new

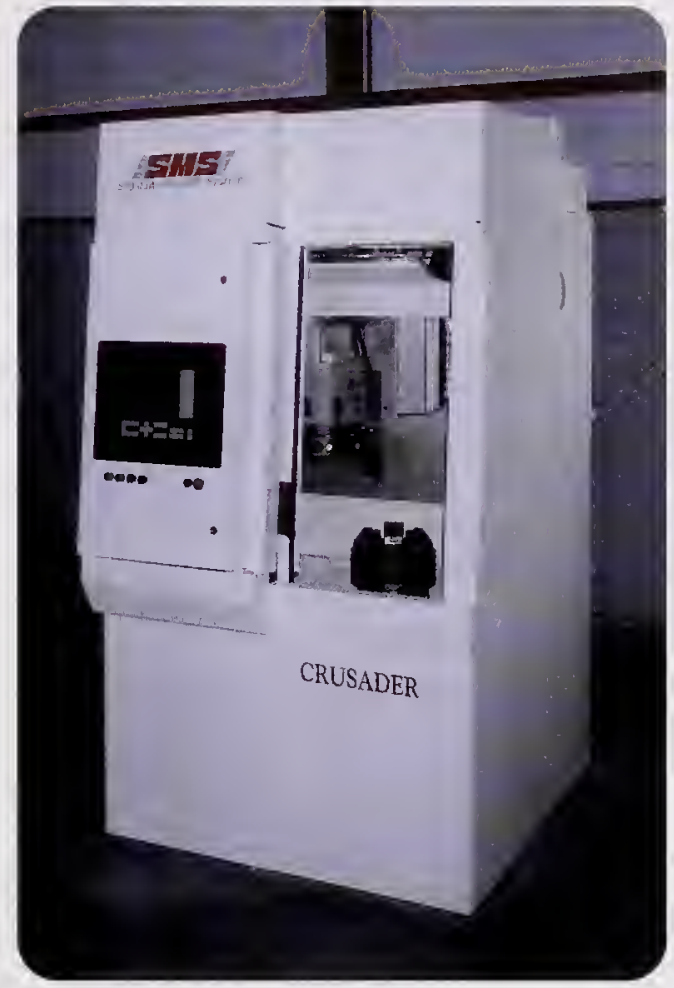

A new high-precision vertical lathe which incorporates the new thermal-error compensation technology, first delivered to customers in 1998. technology is incorporated into machine tools, the result is higher-quality parts.

The technology uses a laser system to measure machine geometric and thermal errors and heat sensors to monitor temperatures near the interface between the cutting tool and the metal being worked. A computer program, using a thermal volumetric error model, processes the laser and sensor data and sends corrective instructions to the machine tool in real time, as it shapes the metal. Use of this thermal-error compensation technology enhances the accuracy of CNC machine-tooled products 


\section{PROJECT HIGHLIGHTS}

\section{PROJECT:}

To develop an easily adaptable thermal-error correction technology for enhancing the accuracy of computer numerically controlled machine tools. Duration: 4/15/1991 - 11/16/1993

ATP Number: 90-01-0232

$\begin{array}{lcc}\text { FUNDING (in thousands): } \\ \text { ATP } \quad \$ 540 & 84 \% \\ \text { Company } & 100 & 16 \% \\ \text { Total } & \$ 640 & \end{array}$

\section{ACCOMPLISHMENTS:}

Saginaw, working closely with researchers at the University of Michigan, accomplished the project's technical goals by developing a generic mathematical model of thermal errors, as well as the sensor and computer-control systems for a thermal-error correction technology. The company also:

developed several prototype tools incorporating the new technology;

submitted a prototype, as did seven other manufacturers, for testing by an independent laboratory, which found that the Saginaw machine was the most accurate of the eight machines, with an overall score $50 \%$ higher than the next best machine; and

developed the Accu-System, which incorporates the ATP-funded technology, offered commercially for the first time in a machine tool in early 1998.

by fourfold to fivefold as measured by spindle drift (shifting of the shaft, in a lathe or other machine tool, that holds the piece being formed), at a commercially viable cost.

\section{First Products to Market}

At the end of the ATP funding period, additional development work not originally foreseen by the company remained to be done. Saginaw continued to advance the technology and has invested as much of its own funds since the close of the project as the ATP put in at the beginning.

Since completing the development work, the company has begun to move its first product, which uses the Accu-System incorporating the A'TP technology, into commercialization. By early 1998, Saginaw had developed prototype tools. One prototype was tested by an independent laboratory and pronounced ready for market. Another tool from Saginaw was subjected to a competitive evaluation process by a large tool buyer, in which the Saginaw tool was pitted against tools from seven other suppliers. The results showed that the Saginaw machine with the AccuSystem was the most accurate. All in all, 30 characteristics of machine performance were measured, and the Saginaw machine had a weighted average score that was 50 percent higher than the next best machine. On the critical characteristic of spindle drift, the Saginaw machine achieved a

\section{COMMERCIALIZATION STATUS:}

Commercial products were introduced to the market in early 1998.

\section{OUTLOOK:}

The outlook for this technology is very promising. Saginaw started receiving orders in early 1998 for machine tools that incorporate the new technology. Machine tools that could benefit from the improved accuracy are used in plants and shops throughout the nation. Other tool producers are likely to imitate the technology, which is not expected to receive patent protection. Users of the tools that incorporate the new technology will benefit from a substantial improvement in machine tool accuracy, increasing the overall precision of the pieces produced by the machines.

\section{Composite Performance Score: $\star \star$}

\section{COMPANY:}

Saginaw Machine Systems, Inc.

301 Park St.

Troy, NII 48083

Contact: Gerald J. Romito

Phone: (248) 583-7200

Number of employees: 120 at project start, 120 at the end of 1997

Subcontractor: University of Michigan

two-thirds reduction in drift compared with the next best machine.

By March 1998, Saginaw had received orders from other companies for eight machines priced at more than $\$ 200,000$ each. Orders for several dozen additional machines of the same type were expected over the next several months.

. . . most machine tools that make high-precision parts are likely to be improved in the long run.

\section{Productivity Improvements}

Users of the technology are able to take advantage, at reasonable cost, of a substantial increase in the accuracy of their machine tools, improving the precision of the workpieces the machines produce. Customers manufacturing high-precision parts realize productivity improvements of 10 percent to 30 percent because of reduced requirements for part testing and rework.

The number of potential applications is large. Because the Saginaw equipment is now in use, other manufacturers 
may imitate the technology. The company has concluded that none of the technology is patentable, and it is likely that competitors will be able to imitate its methods.

Consequently, most machine tools that make high-precision parts are likely to be improved in the long run.

\section{If Saginaw had not received the ATP award, company officials say, it would not have done the project.}

If Saginaw had not received the ATP award, company officials say, it would not have done the project. Being primarily a manufacturing company, it did not have a substantial research and development capability. While working on the ATP project, Saginaw collaborated with the University of Michigan on a subcontractor basis to extend the company's research capabilities. In addition, officials say, having the ATP award helped Saginaw win a subsequent \$1 million award from the Defense Advanced Research Projects Agency for a related project. 

ADVANCED TECHNOLOGY PROGRAM

CHAPTER 7

Appendices 



\title{
Development of New Knowledge and Early Commercial Products and Processes
}

\author{
Advanced Materials and Chemicals I Biotechnology I Electronics/Computer Hardware/Communications I \\ Information Technology I Manufacturing
}

Table A1. Advanced Materials and Chemicals (Chapter 2)

Awardee Name

(A)

AlliedSignal, Inc.

BioTraces, Inc.

Geltech Inc.

IBM Corporation

IBM Corporation

Michigan Molecular Institute
Technology Developed

(B)

Near-net-shape gelcasting process that is safer and less costly than conventional gelcasting based on acrylamide, a cumulative neurotoxin - demonstrated by making structural ceramic parts for very high-temperature applications.

Multiphoton detection (MPD) technologydemonstrated in enhanced immunoassay, chromatography and nucleic acid analysis

Room temperature net-shape gelcasting method-demonstrated in the production of high-quality, silica glass micro-optics.

Nonlinear optical polymeric waveguidesdemonstrated in the development of inexpensive optoelectronic switches for computers and communications systems.

Low-polymer foams-demonstrated as potentially feasible for microelectronics insulators.

Fundamentals of polymer compatibilizationtargeted at demonstrating that mixed plastics (either from waste streams or virgin) can be successfully combined into materials with high performance characteristics.
Product or Process Commercialized (C)

Commercialization likely.
Licensee PetroTraces: applications of the technology in the petrochemical field.

Marketed directly by BioTraces: sSMPDTM, for clinical diagnostics applications.

Materials processing and mold fabrication methods used to develop a porous-glass product which is a component of a home sensor for toxic gases.

Commercialization not likely.

Commercialization not likely until follow-on research takes it further.

Prefabricated wall units using plastic panels made compatible, made by Eagle Plastics Systems of Florida in collaboration with University of Florida researchers. 


\section{Aavarde Rame}

(A)

Westinghouse and SGS Tools

\section{Technology Developed}

(B)

Higher power hot cathode plasma torch technology and integrated gas recycling process technology
Product or Process Commercialized (C)

Commercialization likely by a newly formed company.

\section{Table A2. Biotechnology (Chapter 3)}

\section{Awardee Name}

(A)

Aastrom Biosciences, Inc.

Amersham Pharmacia Biotech

\section{Aphios Corporation}

Integra LifeSciences

Molecular Simulations, Inc.

Thermo Trilogy Corporation

Tissue Engineering, Inc.

\section{Technology Developed}

(B)

Bioreactor technology for expansion of stem and other cells outside the patient's bodyused in tests and clinical trials for more than 60 cancer patients.

Reengineering of thermophilic enzymes and methods for isolation and genomic characterization of hyperthermophiles from deep-sea vents.

Viral deactivation procedures based on critical fluid technology-demonstrated in cleaning contaminated blood supplies.

A scaleable process for manufacturing A new bioabsorbable polymer.

Incorporation of density functional theory (DFT) into easy-to-use software-targeted toward the clinical and biotechnology communities for calculating molecular structures and energies.

Genetic engineering processes-demonstrated in the production of pyrethrin, a natural insecticide that is nontoxic to mammals.

Techniques and procedures for enhancing tissue growth, including processing tissue, extracting and storing collagen, and spinning and weaving collagen fibers into fabrics for rebuilding lost tissues-demonstrated in production of human prostheses.

\section{Product or Process Commercialized} (C)

Commercialization likely.

ThermoSequenase, DNA polymerase for DNA sequencing.

Commercialization possible.

Tyrosorb Synthetic Polymers, a new material for making implantation devices for musculoskeletal surgical applications in clinical trials.

Enhanced Turbomole ${ }^{\mathrm{T} M}$, a software tool that enables researchers to design new target molecules for drugs and other substances at much lower costs.

Commercialization not likely.

Commercialization likely. 


\section{Awardee Name}

(A)

Accuwave Corporation

American Display Consortium

AstroPower, Inc.

Calimetrics, Inc.

Cree Research, Inc.

Cynosure, Inc.,

Diamond Semiconductor Group, LLC

ETOM Technologies, Inc.

FSI International, Inc.

Hampshire Instruments, Inc. (Joint Venture)

\section{Technology Developed}

(B)

A process for producing photorefractive materials based on holographic technologydemonstrated in fiber Optics telecommunications applications.

Tape Automated Bonding (TAB) process for mounting ICs on a display surface

Improved liquid-phase epitaxial growth methods and a high-throughput manufacturing technology-demonstrated in the fabrication of high-performance optoelectronic devices such as ultra-bright light-emitting diodes (LEDs).

Pit Depth Modulation and Multilevel Technology

Methods for increasing the quality and size (to two inches or more) of silicon carbide single crystals-demonstrated in the fabrication of LEDs and other electronic and optoelectronic devices.

A fault-tolerant optical system-demonstrated for a diode-laser array in a laser surgical application.

Compact high-current broad beam ion-implantation technology for altering the electrical properties of materials-enabling production of larger semi-conductor wafers and also useful for other applications.

Techniques for writing and reading more than one bit of information at the same spot of an optoelectronic disk, and new optoelectronic disk materials.

A dry gas wafer cleaning method-demonstrated in the cleaning of computer-chip wafers during manufacturing (which traditionally has used wet chemical processing), and suitable for the ever smaller features on new generations of chips.

Techniques for laser pumping of high-power laser systems--demonstrated using a laser-diode array to pump a neodymium-doped gadolinium gallium garnet laser for producing low-cost x-rays.

\section{Product or Process Commercialized}

(C)

Wavelength division multiplexing components; wavelength controliers, wavelength lockers and fiber-optic collimators.

TAB process used in production

New epitaxy technology incorporated in all company production processes, including the Silicon-Film ${ }^{\mathrm{TM}}$ solar cell.

Licensed for commercialization

Less expensive blue light-emitting diodes, and improved silicon carbide wafers that permit fabrication of electronic devices that deliver more power, last longer, and can withstand very high temperatures.

Commercialization possible.

A new high-current ion implanter, produced by Varian Associates, which incorporates the new techniques developed in the ATP project for implanting dopants on large silicon crystal wafers measuring $300 \mathrm{~mm}$ or more in diameter.

Commercialization not likely.

Commercialization possible.

Commercialization not likely. 


\section{Awaradee Name}

(A)

Light Age, Inc.

Lucent Technologies, Inc.

Multi-Film Venture (Joint Venture)

NCMS (Joint Venture)

NetOptix Corp (formerly Galileo)

Nonvolatile Electronics, Inc.

\section{Spire Corporation}

Thomas Electronics, Inc.

Vitesse Semiconductor

\section{Technology Developed}

(B)

Product or Process Commercialized (C)

Broadly tunable laser source of ultraviolet (UV) light based on alexandrite laser technologyaimed at applications in science, medicine, and photolithography.

Fabrication, testing, and alignment techniques for extremely precise aspherical, multilayercoated mirrors-essential for extreme ultraviolet (EUV) technology, a contender for future lithography systems.

Procedures for interconnecting thin-film integrated circuits-targeted at complex, multi-film module (MFM) electronic device applications and suitable for use when the films are arranged either side by side for flatpanel displays or in layers for compact processor units.

Advanced processes for making printed wiring boards.

New processes for fabricating micro-channel plates (MCPS) using photon detectors and other types of electron multipliers-demonstrated in night vision applications.

New procedures that enhance the producibility, circuit density, and signal strength of giant magneto-resistance (GMR) materialsdemonstrated in random access memory (RAM) and highly sensitive sensor applications.

Feedback-controlled, chemical vapor deposition processes-demonstrated in a reactor in a highthroughput mode for fabricating low-cost, high-quality metallo-organic laser diode arrays and other optoelectronic devices.

A high-efficiency electron source to enable development of new classes of efficient, bright, flat fluorescent lamps-with wide applications in computer and instrument displays and in highdefinition TV screens.

GaAs design innovations.
Three laser products - nUVOTM, PAL/UVTM, and PAL/PROTM - for laser surgery and potentially for other applications, including next-generation chip fabrication and investigation of weather conditions in the upper atmosphere (70 miles above earth).

Subcontractor Tinsley Laboratories: application of improved fabrication methods learned in the project to all its aspherical mirror production.

Subcontractor Tropel: a specialized interferometer it now uses in other contract work.

Commercialization possible for lithography systems.

Commercialization possible.

Single-ply fiberglass boards; thin copper plating; test procedures; plasmas monitoring device; imidazole treatment.

Commercialization possible.

Highly sensitive sensors based on giant magneto-resistance materials that could be used in brakes, pacemakers, and many other applications.

A prototype reactor being used for limited production of epitaxial wafers.

Prototypes and pilot models of flat fluorescent lamps placed with more than a dozen companies for further evaluation and field testing of the new technology in cockpit and other applications.

H-GaAs IV-based transceivers and ATE. 


\section{Awardee Name}

(A)

Communication Intelligence Corporation \#1

\section{Communication Intelligence Corporation \#2}

Engineering Animation, Inc.

Mathematical Technologies, Inc.

Torrent Systems, Inc.

Union Switch and Signal, Inc.

\section{Technology Developed}

(B)

New data-entry software technology that recognizes each user's natural handwriting without "training" the computer of the userintended to allow a pen and tablet to be used instead of a keyboard.

A recognition system for hand-written Chinese - Intended to replace a cumbersome data-entry system that uses a keyboard.

Core algorithms to enable the creation of $3 \mathrm{D}$ images from sets of 2D cross-sectional images, with an initial application targeting animated visualization of the entire human body.

Mathematical methods for managing successive digitized video images-with the purpose of removing defects from one or more individual frames of new or archived movies.

Component-based software and user interface for building parallel processor applicationsa tool for the professional programmer.

Distributed Multi-agent-based optimization technology.

\section{Product or Process Commercialized}

(C)

Enhanced Handwriter(r)MXTM-a stylus-and-pad system that recognizes hand-printed text.

Commercialization likely.

Three CD-ROMS (The Dissectible HumanTM, The Dynamic HumanTM, and CardioViewer 3DTM), plus two medical textbooks that are used to train medical personnel.

Digital Restoration Services ${ }^{\mathrm{TM}}$, integrated into post-production movie processing at a number of facilities in the entertainment industry.

Orchestrate ${ }^{\mathrm{TM}}$ - an innovative component software prototype system that enables a variety of hardware systems to handle massive amounts of data and increase processing efficiency.

"Real-time Control Traffic Controller" and "Offline Railroad Operations Planner" in testing for possible commercialization.

\section{Table A5. Manufacturing (Chapter 6)}

\section{Awardee Name}

(A)

American Superconductor

Corporation

Armstrong World Industries, Inc.

\section{Technology Developad}

(B)

Wire fabrication and winding techniques for high-temperature superconducting materials, with primary applications in the development of extremely efficient large motors.

\section{Process technology for controlling the} microstructure of aerogel insulation materials -targeted toward costeffectively enhancing its thermal insulating properties.

\section{Product or Process Commercialized}

(C)

CryoSaver ${ }^{\mathrm{TM}}$-electrical wires that carry current into and out of cryogenically cooled devices, which reduces electrical resistance and helps users achieve better operating efficiencies.

Commercialization possible through licensing. 


\section{Aิwarlee Name}

(A)

\section{Auto Body Consortium (Joint Venture)}

\section{E.I. Dupont de Nemours} \& Compariy

HelpMate Robotics, Inc.

Illinois Superconductor Corp.

Microelectronics Center

of North Carolina

Perceptron, Inc.

PreAmp Consortium

(Joint Venture)

SAGE Electronchromics, Inc.

Saginaw Machine Systems, Inc. (C)

Measurement and process control technology -demonstrated in reduction of dimensional variation in auto body assembly to two millimeters or less.

Thin-film fabrication processes for hightemperature superconducting materials -targeted toward low-cost electronics components.

Specialized lidar (light direction and range) scanner and related locating technologiesdemonstrated in the development of an intelligent autonomous mobile robot capable of maneuvering around on a factory or hospital floor.

Fabrication process for thick-film, hightemperature superconducting materialsdemonstrated in the production of radio-frequency components for wireless applications.

Integrated Force Array technology, based on electrostatically driven membranes.

Image processing techniques and algorithms for developing specialized vision software.

A knowledge-based software system that can extract process "rules" from manufacturing process data-demonstrated in test automations for designing and manufacturing electronics components.

Electrochromic technology for producing largearea electronic devices.

Intelligent thermal-error correction technology, based on a generic mathematical model of thermal errors - demonstrated in high precision machine tool applications.
New measurement and process control systems in auto assembly plants that cut dimensional variation to a world-class standard of two millimeters and below, being implemented in 22 assembly plants in the United States and Canada.

New thin-film components, incorporated into magnetic resonance imaging equipment for use in hospitals and clinics.

HelpMate Robots in use as delivery devices in about 100 hospitals in the United States and Canada.

Two products-SpectrumMaster ${ }^{\circledR}$ and RangeMaster ${ }^{\circledR}$ _installed in 22 cell phone base stations in 12 cities.

Commercialization possible but not imminent.

Commercially demonstrated in lumber mill and steel mill.

STEP Tools, Inc., an informal participant in the project, has incorporated the project's data application interface in its ST-Developer ${ }^{\mathrm{TM}}$ software tool. Future commercialization possible for the complete system.

Commercialization of electrochromic windows underway.

Accu-System-a new intelligent process controller for increasing the accuracy of machine tools. 


\title{
Terminated Projects
}

\begin{abstract}
1
$t$ the end of an ATP competition, projects are selected for award and the winners are announced. Most of these projects proceed through their multiyear research programs to completion. A few of the projects that are announced, however, never actually start. A few others start, but are not carried through to completion. Rather, they are halted for a variety of reasons. The projects that are announced but do not start, and those that start but are stopped prior to completion, are collectively called by the ATP "terminated projects."
\end{abstract}

During the time that the 50 projects covered in the body of this report completed their research agendas, 16 of the 522 projects announced by the ATP through 2000 were terminated short of completion. This appendix examines the reasons for their termination, and the funding spent on the projects.

In addition, one of the terminated projects is reviewed in detail. The purpose is to provide insight about what can go wrong during the complex, challenging period of research, and also to illustrate that much can be learned despite project derailment.

\section{Reasons for Termination}

Thus far, projects have terminated short of completion for the following six principal reasons:

\section{Reason 1:}

A company leading a project, or one or more companies in a joint venture, may request their project be stopped due to unexpected, adverse changes. Shifts in company strategic goals; major reorganizations, mergers, and changing leadership; changes in market demand and the competitive situation are among the events that may affect the internal and external business climate in which companies operate and plan. Any of these developments may disrupt project plans.

\section{Reason 2:}

Financial distress may cause one or more companies providing matching funds to become unable to meet the resource commitment that is a necessary condition for
ATP funding. Cash-flow difficulties may force a small company to drop its research activities and pursue shortterm survival goals, or it may go bankrupt. Financial backers may pull back or fail to materialize as expected, or they may delay. Corporate internal sources of funds may not be provided as expected.

\section{Reason 3:}

Organizations proposing as a joint venture may find lastminute obstacles to signing their agreement and decide to disband their planned partnership.

\section{Reason 4:}

Lack of technical progress can result when bottlenecks arise or technical problems prove intractable. Technical challenges may be even more difficult than expected. Personnel or management deficiencies, or unavailability of prerequisite materials, components, or equipment may also end a project prematurely.

\section{Reason 5:}

Early success can obviate the need for a project to continue. That is, unexpected events in research can have positive as well as negative effects.

\section{Reason 6:}

Downstream changes may move a project out of compliance with ATP's selection criteria, and cause ATP to stop the project. For example, a project may attempt to shift away from challenging, enabling research toward business as usual approaches; or the loss of key members of a team (without a plan for overcoming the deficiency in a timely way) may threaten the ability of a project to meet its goals. 


\section{Sixteen Torminated Projects}

Figure B-1 shows the distribution of 16 projects terminated during the time the 50 featured in the body of the report were completed. To date, terminations are running from five to six percent of total projects selected and announced. ${ }^{1}$

\section{Figure B-1. Distribution of Terminated Projects by Reason for Termination}
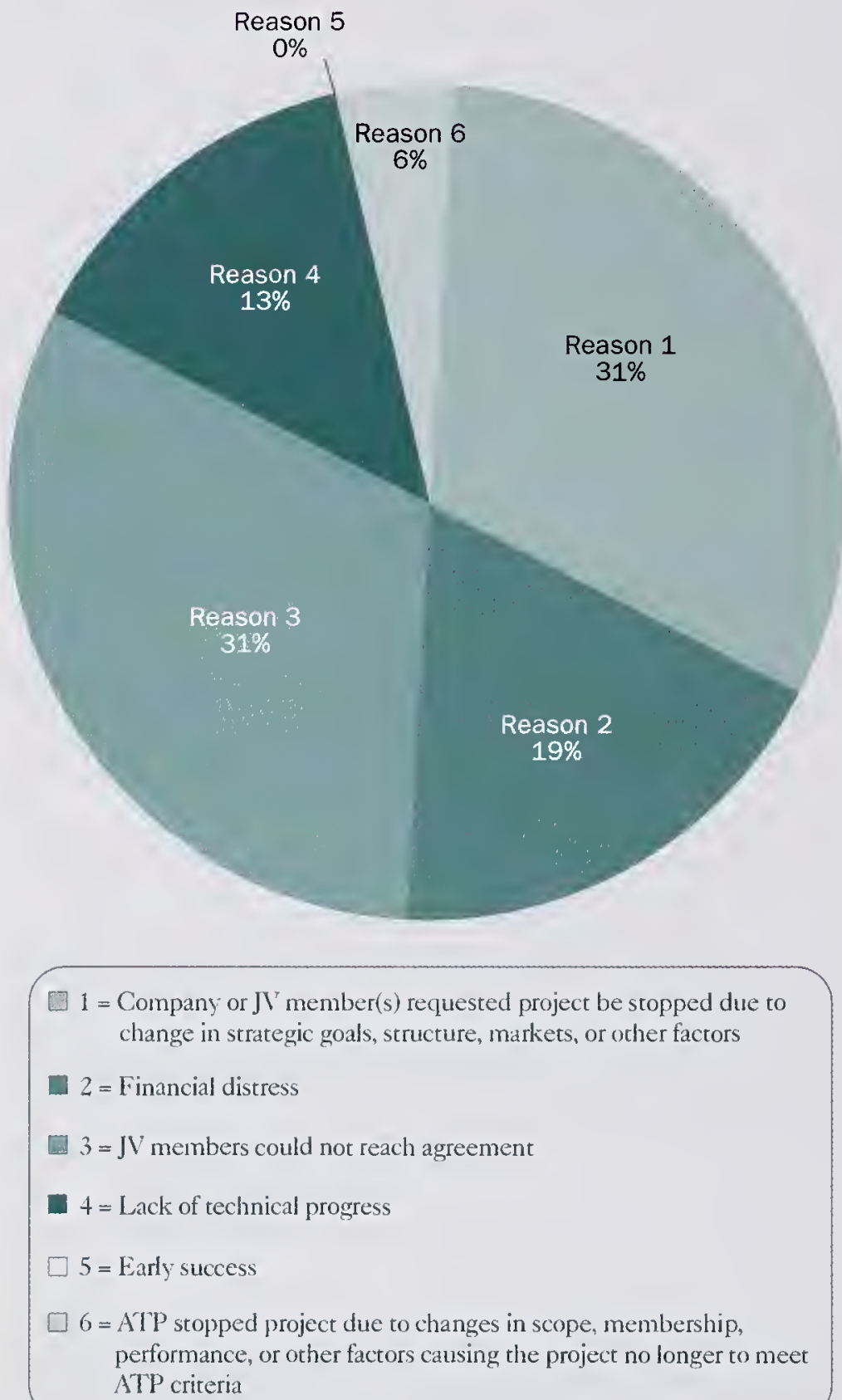

Of the 16 terminated projects, 5 were stopped before they got started. The remaining 11 went varying distances in their research agenda before they were stopped. Thirtyone percent of the projects were joint ventures whose members could not reach final agreement among themselves, and, therefore, never progressed further. An equal percentage got started, but closed down because the project leader or joint-venture members wanted the project stopped due to change in strategic goals, structure, markets, or other factors. Financial distress caused 19 percent of the projects to end prematurely. These were primarily small companies that encountered cash-flow difficulties.

\section{Terminated Does Not Equal Total Failure}

It is an oversimplification to think of the terminated group simply as project failures-although they clearly did not live up to expectations. Terminated projects can produce important knowledge gains even when ultimate goals are not reached. As the following example demonstrates, terminated projects may yield patents, papers, collaborative relationships, and products.

Even projects that stop without ever getting off the ground entail a great deal of integrated planning for research, development, and business activities. They typically entail substantive cross-disciplinary contact among scientists and other researchers, cross talk among technical and business staff, and high-level negotiations among business executives at different companies. Often the planning period brings together business staff with university researchers, federal laboratory specialists, and other nonprofit facilities. The ATP process has been said by many to stretch the thinking and horizons of participants in the process. There are likely to be extended effects of this process that may bear fruit in future diverse and difficult-to-capture ways.

Would-be joint-venture partners may regroup to reapply to ATP, or find other ways to cooperate. Companies may learn about new opportunities. They may apply the integrated planning techniques to other projects. The companies involved, as well as others, may learn from the terminated projects, approaches to avoid or to pursue. In short, terminated projects as a group may yield some positive effects even as they incur costs.

The mini-case treatment of a terminated project that follows illustrates the achievements and failures of a project that went part of the way: the project aimed to develop composite flywheels for electric vehicles. It lasted nine months of an anticipated three-year period, and was terminated when the company requested that it be stopped due to an unanticipated change-in this case, a change in cost targets set by automakers.

\footnotetext{
1 The analysis identifies the distribution of terminated project by reason for termination, while providing anonymity to the companies in order to preserve their rights regarding proprietary information.
} 


\section{Composite Flywheels for Electric Vehicles: A Terminated Project that Produced Partial Results}

\section{E}

lectric Vehicles (EVS) are no longer concept cars of the future. Today, they offer the promise of reduced air pollution and less reliance on imported crude oil, but technical obstacles impede their widespread acceptance. They are powered by an energy storage device, from which energy is converted to either alternating current $(A C)$ or direct current $(D C)$, to drive electric motors that propel the vehicle. Performance demands of the vehicle determine the key performance requirements of the energy storage device: range dictates a minimum energy storage capacity; acceleration rate is tied to the maximum energy dissipation rate (surge or peak power) of the storage device. A power source that is both efficient and light is key to successful commercialization, but thus far available sources have proven inadequate.

\section{Battery Alternatives}

Traditional lead-acid batteries currently used in EVs cannot meet the performance requirements of the automobile market. They have a number of drawbacks. Although they are capable of storing large quantities of energy, they are inefficient at absorbing high power levels (charging) and at dissipating the high power levels needed for acceleration (surging). Moreover, lead-acid batteries are very heavy. Even a small EV such as a converted Geo Metro requires nearly 700 pounds of lead-acid batteries, (at a cost of some $\$ 1,600$ ) for reasonable performance. This weight requires additional energy and power to meet performance goals, and creates problems of crash safety and vehicle handling. A number of alternative chemical battery technologies are under development, but none is yet recognized as a practical alternative.

\section{Hybrid Electric Vehicles}

Problems with conventional EVs have prompted work on hybrid electrical vehicles. The hybrid EV uses two energy sources: one for mass energy storage and the second for power storage. A hybrid vehicle might, for example, employ a lead-acid battery for energy storage and another energy source to meet peak or surge power needs. Flywheel systems are an important contender for the latter application.

\section{Flywheels}

A flywheel is the mechanical equivalent of a rechargeable battery. It operates by storing kinetic energy in the rotary motion of a ring or rotor spinning on an axis. When coupled with an electric generator, its stored kinetic energy can be rapidly converted to electrical energy. Since this power conversion is a mechanical process, energy transfer is direct, not limited by chemical reaction rates as in batteries. The rapid conversion of kinetic energy to electrical energy makes flywheels suitable for use as surge power devices for acceleration of hybrid vehicles. They can be used to complement the steady energy supply from a chemical battery or a heat engine (e.g., internal combustion engine).

In flywheel systems under consideration, a flywheel rotor is attached to a central shaft. 'To reduce friction and increase speed, the shaft is mounted on magnetic bearings and is contained within a vacuum chamber. The central shaft is connected to an electric generator that can absorb or discharge power as needed. The entire apparatus is inside a protective casing to prevent damage to surrounding parts if the flywheel becomes unstable or fails.

\section{The Physics of Flywheels}

The ability of a flywheel to store energy is dependent on two characteristics: the weight of the rotor and its 
rotational speed. The heavier a flywheel's rotor or the faster it spins, the greater the flywheel's energy storage capacity. However, storage capacity increases linearly with weight (in a ratio of one to one), while it is the square of rotational speed. This concept favors efforts to increase energy storage without increasing weight (i.e., energy density). This goal, however, is constrained by limits in the strength of the rotor itself. Increases in rotational speed generate increases in centrifugal forces (the forces that push you to the outside when you are spinning on a merry-go-round). These forces place strain on the flywheel rotor. The rotor must be able to withstand these forces without breaking apart.

To reduce weight, composite materials have been employed in the fabrication of rotors. Composite rotors with the strength to endure the strain imposed by high rotation speeds have had to be made with allgraphite fibers, which are too expensive for all but a few aerospace and defense applications. A promising approach, therefore, was development of new methods for fabricating flywheel rotors with the requisite strength that could use cheaper composite materials.

\section{Dow-UT Pursuit of the Resin Transfer Molding Process}

In late 1989, Dow Chemical Company and United Technologies Corporation (UT) formed a jointventure entity, called Dow-United Technologies Composite Products, Inc., to exploit the commercial potential of a new process, known as Resin Transfer Molding (RTM), for fabricating composite parts. In the subsequent five years, Dow-UT spent $\$ 40$ million to develop RTM into a commercially viable process. It demonstrated the commercial viability of RTM for high-performance aerospace and defense applications. The focus was on using RTM in the production of high-speed rotating parts, such as the fan spacers used in the Pratt and Whitney 4084 commercial jet engine. Dow-UT was also successful in developing RTM for use in the production of high-volume, lower-cost automotive applications. For example, Chrysler used Dow-UT's R'TM process for the production of specialty automotive parts for the Dodge Viper.

\section{A Plan for Developing Strong, Lower Cost Flywheels}

In a 1994 focused program competition, ATP announced the Dow-UT project as an award winner. The planned ATP cost share was $\$ 519,000$ over a three-year period. The goal of the project was to develop cost-effective production methods for strong, lightweight composite flywheel rotors to be used in hybrid electric vehicles.

For the ATP project, Dow-UT obtained the commitment of several other companies in subcontractor roles and several other divisions of UT to contribute essential skills and resources. Suppliers included Fiberite Specialty Weaving Group, with experience in a technique known as polar weaving. ${ }^{2}$ Dow Chemical worked on flow modeling and Test Devices engaged in spin testing. One division of UT provided design and test consulting, and another division was involved in flywheel commercialization.

Dow-UT saw the technology as a multi-use technology with broad application through licensing in the auto industry and beyond. Extensive licensing of a technology tends to yield greater spillovers for the economy.

An example of a potential application-if strong, lightweight composite rotors could be developed-is the use of flywheel systems by utilities in load-leveling devices (LL) and uninterrupted power supplies (UPS). Load-leveling devices allow utilities to store power generated during times of low demand so that it is available in times of high demand. This allows utilities to meet growth in demand without building expensive new plants. Uninterrupted power supply devices are important to manufacturers, hospitals, and others who need to guard against unexpected interruptions in power supply.

The centerpiece of the Dow-UT project was to combine the techniques of resin transfer molding (RTM) and polar weaving in the construction of flywheel rotors. Polar weaving would be used to fabricate material with a continuous woven structure; the RTM process would be used to create the finished rotor from this material.

Composite flywheel rotors had previously been fabricated using a process called filament winding:

${ }^{2}$ After another company bought out Fiberite, Dow-UT undertook the development of the polar weaving technology in-house. 
fibers were woven into flat sheets, treated with epoxy resin, wrapped together, and compressed to create forms. In contrast, polar weaving produces a continuous helix of woven fibers, similar in form to a Slinky ${ }^{\mathrm{TM}}$ toy. This helical weave increases radial tensile strength, that is, the capacity of the material to resist centrifugal forces pulling it away from the center. Lack of radial tensile strength had previously constrained efforts to develop a composite flywheel capable of increased rotational speed.

Resin transfer molding (RTM) involves the use of a vacuum mold into which resin is injected under pressure. The resin permeates the woven structure, which is at the same time shaped under pressure. The resin gels and cures to create a solid piece. By achieving the shaping and curing function in the same step, RTM reduced the cost of the fabrication process. In addition, since R'TM applies pressure through the resin rather than through mechanical means, the piece is shaped continuously, which eliminates the need for expensive secondary machining. Production costs are thus considerably reduced.

\section{Achievements}

The combination of polar weave and RTM techniques allowed Dow-UT to use cheaper materials to create equally strong flywheel rotors. Dow-UT used fibers made from glass mixed with graphite, at a cost of about $\$ 1$ per pound, a considerable cost reduction from graphite fibers at $\$ 7$ per pound. ${ }^{3}$ Although the individual composite (glass and graphite) fibers are weaker than all-graphite fibers, polar weave and RTM allow for the creation of rotors or other parts with the requisite strength.

Dow-UT demonstrated flywheels in the ATP project that were better in four ways. First, they could spin faster. The new flywheels were tested at speeds of up to 40,000 RPM, a 25 percent improvement over older flywheel technology. Second, they had improved lifetimes. Fatigue resistance was improved by a factor of ten compared to older flywheel technology. ${ }^{+}$Third, production costs per pound were cut in half by the new fabrication techniques, to less than $\$ 20$. Fourth, the improved flywheels were lighter. The reduced weight and faster spinning speed increase the energy density, that is, the amount of energy stored per unit weight.

Another useful development from this project was a software package that enabled better computer design of the composite flywheel rotors. This software allows engineers to model the performance of flywheel rotors fabricated with different types of fibers and fiber architectures (the amount of fiber used in hoop and radial directions). This tool should speed future design and development work.

\section{Project Stopped Early}

After the project had been underway for less than a year, the automakers revised their cost targets for $\mathrm{EV}$ flywheel systems sharply downward. 'The revised maximum cost required by the industry was below $\$ 600$ for a complete system, which included not only the rotor, but also the motor/generator, magnetic bearings, vacuum system, housing, and additional elements. This figure was not much more than the actual cost of the fiber for the rotor alone. The most advanced system envisioned by the project would cost more than $\$ 1,800$. Dow-U'T determined that these new cost targets could not be met with existing technology, and discontinued its work on rotors for automotive flywheels. The ATP concurred, and by mutual agreement, the project was stopped after nine months and $\$ 99,035$ in ATP outlays and $\$ 155,072$ in company costs.

\section{Remaining Technical Obstacles to the Commercialization of Automotive Flywheel Systems}

In addition to cost barriers, flywheels still face many technical hurdles. There are the challenges of maintaining rotor integrity over longer lifetimes, containing the flywheel in case of failure, and dissipating friction in the bearings. Vacuum containment and magnetic bearing advancements, which increase lifetimes and reduce friction, will probably be required before flywheels come into widespread automotive use. The safety quesrion also hampers flywheel use. For example, the failure of a $1 \mathrm{kWh}$ flywheel (the size required

\footnotetext{
${ }^{3}$ High Performance Composites, March/April 1996, p. 25; "Cheaper Composite Flywheels," Mechanical Engineering, June 1996

${ }^{+}$Battery and EV Technology, June 1996, p. 25.
} 


\section{PROJECT HIGHLIGHTS}

\section{PROSECT:}

To develop a cost-effective means of fabricating strong, lightweight flywheel rotors from composite materials primarily for use in hybrid electric vehicles, and also potentially for other applications.

\section{DURATION:}

Planned: $8 / 15 / 95-8 / 15 / 98$

Actual: 8/15/95 - 5/15/96

ATP Number: 94-02-0041

\section{FUNDING (in thousands): \\ ATP $\quad 99 \quad 39 \%$ \\ Company $\underline{155} \quad 61 \%$ \\ Total 254}

\section{ACCOMPLISHMENTS:}

Dow-UT met the originally targeted project goals for cost of production that were based on estimates from the automakers. During the course of the project, the automakers revised their cost targets substantially downward. Based on its progress to date, Dow-U'T determined that the new auto industry cost requirements could not be met and chose not to continue with the project. Consequently, the project and ATP funding ended after only nine months. The project nevertheless made substantial accomplishments. A combination of polar weaving and resin transfer molding (RTM) techniques in the construction of composite flywheel rotors allowed Dow-U'T to use less expensive materials than all-graphite models while maintaining structural integrity. The successful development of this combined process allowed Dow-UT to cut the cost of producing flywheel rotors in half. Additionally, the company during and after the award period displayed other accomplishments:

developed a sofrware package that enables better computer design of the composite flywheel rotors;

contracted with NASA and the U.S. Air Force to develop a composite flywheel for aerospace use;

- partnered with SatCon Corporation, a flywheel assembler, on the development of uninterrupted power supplies (UPS) for satellites;

for automotive applications) would release enough energy to blow a 2,500-pound car 1,000 feet into the air. ${ }^{5}$ The safety risks associated with fast spinning rotors were pointed up by an industrial accident during product tests. The accident highlighted the need to improve containment structures.

\section{Flywheel Technology for Other Applications}

Flywheel technology remains promising for applications other than vehicles. One promising potential application is power storage for satellites. Space applications demand extremely low weights since presented a paper and research results at the 1997 and 1998 NASA/USAF Flywheel Conferences; and

received a patent, "Energy Storage Flywheel Device" (No. 5,590,569: filed 6/7/1995, granted 1/7/1997).

\section{COMMERCIALIZATION STATUS:}

The automotive industry requires a total flywheel system that costs below $\$ 600$, while the most advanced system envisioned by this project would cost more than $\$ 1,800$. The upward revision in the cost requirement by automakers stalled development work on flywheel systems for automotive applications. Dow-UT determined that these new cost targets could not be met with the technology under development, and therefore asked that the ATP project be terminated and discontinued its work on rotors for automotive flywheels.

\section{OUTLOOK:}

Under contract with NASA and the U.S. Air Force, Dow-UT has found an alternative application in which to use its knowledge gains developed within the ATP project. The company's state-of-the-art materials and manufacturing processes for flywheel technology have shown promise in space applications, such as for uninterruptible power supply (UPS) for satellites, where cost requirements are not as restrictive as those of the auto industry. The outlook is promising for use of the technology in aerospace applications. Auto use appears delayed.

\section{COMPANY:}

Dow-United Technologies Composite Products, Inc.

KN Westland Aerospace Inc

15 Sterling Drive

Wallingford, C'T 06492-1843

Contact: John Gendreau

Phone: (203) 949-5145

Number of Employees: 3 at project start, 14 at the end of 1997

each pound costs more than $\$ 1,000$ to send into orbit. Light, all-graphite rotors are ideal for the expanding space-use market where material costs are less important than weight factors.

Following the termination of the A'TP project, Dow-UT began a contract with NASA and the U.S. Air Force to develop a composite flywheel for aerospace use. Dow-UT worked with SatCon Corporation, a flywheel assembler, on the development of uninterrupted power supplies (UPS) for satellites. SatCon has aggressively moved into the space market, creating a new subsidiary, Beacon 
Corporation, to manufacture and distribute flywheel energy systems." This work continued following the acquisition of Dow-UT by GKN Westland Aerospace in the fall of 1998. Researchers that were formerly with Dow-UT have been able to apply the combined use of polar weaving and RTM to the manufacture of rotors from all-graphite fibers for these aerospace purposes. Thus, although the project's automotive goals were not met, advances have proved commercially useful in other specialized applications higher up the cost curve.

\section{Knowledge Spillover Benefits}

Dow-UT received a patent for manufacturing the composite rotor that it developed during the ATP project. ${ }^{7}$ In the aerospace field, Dow-UT was among the invited industry guests to present a paper and results at the 1997 and 1998 NASA/USAF Flywheel Conferences. The combined RTM/polar weaving method developed by the project has been applied to the fabrication of rotors for flywheel systems used as uninterrupted power supplies for satellites.

\section{Sidetracked, but Not Off Track}

Dow-UT's effort to develop composite flywheel rotors was guided by the originally estimated technical and cost requirements of automakers for flywheel systems to be used in hybrid electric vehicles. DowUT was on track to meet the originally anticipated requirements. When the cost target was revised sharply lower, however, Dow-UT decided it could not meet the automakers' more demanding requirements with the technology it was developing. Consequently, it decided to terminate the project early, with ATP's concurrence. Cost effectiveness of flywheels for automobile use was not reached.

Process technology that was developed by DowUT researchers in the ATP project has since found another application: the fabrication of flywheel rotors for flywheel systems used as uninterrupted power supplies for satellites. In this application, the cost requirements are less demanding. Further progress in developing flywheel technology in the aerospace area may later feed back to applications in the automotive industry.

\footnotetext{
${ }^{6}$ Battery and EV Technology, July 1997.

${ }^{7}$ Energy Storage Flywheel Device," patent number 5590569, January 7, 1997.
} 


.




\title{
Project-Performance Rating System Status Reports-First 50 Completed Projects
}

\begin{abstract}
0
1 reparation of the overview of the 50 projects included development of a first-generation project performance rating system for 1) knowledge creation and dissemination, 2) commercialization progress, and 3) overall project performance. The rating system was constructed primarily from a set of common project outputs, several of which are used as performance metrics in partial fulfillment of the reporting requirements of the Government Performance and Results Act (GPRA), ${ }^{1}$ to which is added an analytical assessment of outlook for the continued progress of each project.
\end{abstract}

The scores for knowledge creation and dissemination are constructed from the following metrics: a) awards by third-party organizations recognizing the excellence of ATP-funded technology, b) publications and presentations, c) patents filed-granted and not yet granted, d) collaborative activity of awardees as a proxy for transmission of information outside the walls of the project through organizational interactions, and e) commercialization or near commercialization by award recipients of the technology as a proxy for whether knowledge dissemination is occurring through observation and reverse engineering.

The scores for commercialization progress are constructed from the following metrics: a) attraction of additional investment capital by innovators in the post-ATP period, b) commercialization or near commercialization by award recipients of the technology, c) employment gains,

d) awards by third-party organizations in recognition of small-company business performance, and e) analysts' assessment of the outlook for continued progress by ATP award recipients and their close collaborators in applying the new technologies commercially.

The ratings for overall performance are constructed by combining the knowledge creation and dissemination scores and the commercialization progress scores. The combined score is converted to a zero-to-four star rating. Four stars is the highest performance score, and zero stars is the lowest. Two stars is a medium performance ratingsignifying neither particularly weak nor strong performance. The table on the next page summarizes the results of this performance rating system applied to the first 50 projects.

The rating system presented here should be viewed as a prototype. Future status report studies may improve and extend the system. Similarly, the performance rating scores presented here should be taken merely as indicative of project performance as of the date the individual project assessments were made, i.e., as of late 1998 for the group of 38 projects published originally in the previous status report volume $^{2}$ and repeated here (data set A in table), and as of late 1999 and early 2000 for the group of 12 new projects (data set $B$ in table) added here to the 38 to comprise the first 50 completed projects. The conditions of these projects may have improved, worsened, or remained essentially the same since the data were collected.

As was explained in the text, the scores do not measure ultimate national economic benefit, although low scores would cast doubt on the likelihood that the project will attain the

\footnotetext{
${ }^{1}$ The ATP, like other federal programs, is subject to the evaluation requirements of the 1993 GPRA. The GPRA resulted from a bipartisan effort to improve accountability, productivity, and effectiveness of federal programs through strategic planning, goal setting, and performance assessment

${ }^{2}$ Long (1999).
} 


\section{ATP Project Performance Ratings-First 50 Completed Awards}

\section{project No. Organization}

90-01-0154 A Collaborative Effort to Address Advanced Technology Needs of the U.S. Printed Wiring Board Industry (National Center for Manufacturing Sciences, AT\&T Micro Electronics, Lucent Technologies, Inc., Texas Instruments, Inc., Sandia National Laboratories, Allied Signal Laminate Systems, Hughes Aircraft Company, IBM Corporation, United Technologies Corporation/ Hamilton Standard Division)

91-01-0146 High-temperature superconducting coils for electric motor efficiency (American Superconductor Corp.)

B

A

A for medical training (Engineering Animation, Inc.)

91-01-0243 A patient-friendly approach to human cell transplantation (Aastrom Biosciences, Inc.)

A

A (Cree, Inc.)

92-01-0133 Prostheses made of biomaterials that regenerate body parts (Tissue Engineering, Inc.)

93-01-0085 A New Bioabsorable Polymer: The Ideal Material for Medical Implants? (Integra LifeSciences Corporation)

A

B

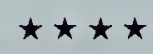

A

A A user-friendly programmer's too
software (Torrent Systems, Inc.)

90-01-0064

90-01-0166

Thallium/lead thin films for advanced superconducting electronic devices (E.I. Du Pont de Nemours \& Company)

Computer RAM chips that hold memory when power is off (Nonvolatile Electronics, Inc.)

A

A

A systems solution to a quality problem in auto body manufacturing (Auto Body Consortium; CDI-Modern Engineering; Classic Design, Inc.; Detroit Center Tool, Inc.; ISI Robotics; Perceptron, Inc.; Pioneer Engineering and Manufacturing; Progressive Tool and Industries, Inc.; Weber Technologies, LLC; Chrysler Corporation; General Motors Corporation, Technical Center; University of Michigan; Mechanical Engineering; and Applied Mechanics)

A

Powerful software for designing new molecules and therapeutic drugs (Molecular Simulations, Inc.)

91-01-0262 Joining several chips into one complex integrated circuit (Kopin Corporation and MCC, Inc.)

A

A

Using high-temperature superconductivity to improve cellular phone transmission (Illinois Superconductor Corporation)

92-01-0017

92-01-0115

92-01-0123

Lowering the cost and improving the quality of computer chips (Diamond Semiconductor Group, LLC)

Smart Window Technology (SAGE, Inc., 3M Company)

92-01-0136

Harnessing cheap diode lasers to power a low-cost surgical laser (Cynosure, Inc.)

A
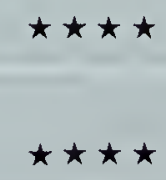
93-01-0071

Machines that See 3-D (Perceptron, Inc.)

B

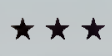

93-01-0113

Searching for New Enzymes in Deep-Sea Microorganisms (Amersham Pharmacia Biotech)

B

Gallium Arsenide: A Faster Alternative to Silicon for

Microprocessors and Telecommunications Applications

(Vitesse Semiconductor Corporation)

B

Pit Depth Modulation: Multiplying the Capacity and Speed of CDs and DVDs (Calimetrics, Inc.)

94-01-0115

A Technology Boost for U.S. Manufacturers of Flat Panel Displays (American Display Consortium; Photonics Imaging, Inc., Electro-Plasma, Inc., Kent Display, Inc., Westinghouse Norden Systems, Inc., Planar America, Inc.)

B

Precision mirrors for advanced lithography (Lucent Technologies Inc.)

A

90-01-0121

Computer recognition of natural handwriting (Communication Intelligence Corporation)

A

90-01-0212

Exploiting alexandrite's unique properties for a less-expensive, more-reliable tunable laser (Light Age, Inc.)

A

90-01-0232 Better precision for machine tools through thermal-error correction (Saginaw Machine Systems, Inc.)

91-01-0034 Robot navigation technology (HelpMate Robotics, Inc.)

91-01-0088 Recycling mixed plastics (Michigan Molecular Institute)

91-01-0142 Manufacturing technology for high-performance optoelectronic devices (AstroPower, Inc.)

91-01-0187 A process for making ceramic parts (AlliedSignal, Inc.)

91-01-0261 Plasma Technology for Production of Low-cost Diamond Film (Westinghouse Plasma Corporation, SGS Tool Company)

A

A

A

$\star \star \star$

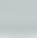
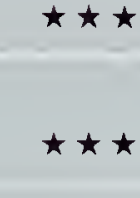


\section{ATP Project Performance Ratings-First 50 Completed Awards, continued...}

\section{Project No. Organization}

91-01-0258

91-01-0267

93-01-0109

90-01-0126

91-01-0017

91-01-0025

91-01-0071

91-01-0135

92-01-0055

92-01-0103

92-01-0122

92-01-0124

Technologies, Inc.)
Electronic Muscle: Advanced Microelectromechanical Systems (Microelectronics Center of North Carolina)

New models to speed the development of electronics components (PreAmp Consortium; Boeing Company, Defense and Space Group; Hughes Aircraft Company; Martin Marietta Corporation, Electronic Information and Missiles Group; and Rockwell International Corporation, Collins Avionics and Communications Division)

Flat Fluorescent lamps for display (Thomas Electronics, Inc.)

Large-scale diode-array laser technology for $\mathrm{x}$-ray lithography (Hampshire Instruments, Inc.; McDonnell Douglas Corporation, now merged with Boeing Company)

Methods for making new optical switches (IBM Corporation)

New materials for new-generation thermal insulation (Armstrong World Industries, Inc.)

Bioengineering of a safe, organic/chemical insecticide (Thermo Trilogy Corporation)

Reducing viral contamination in donated blood (Aphios Corporation)

Expanding the number of light signals in an optical fiber (Accuwave Corporation)

Insulating Foams for Microelectronics (IBM Corporation)

Packing more data into optical data-storage disks (ETOM

Low-cost night vision technology (NetOptix Corporation, formerly Galileo Corporation)
A

A

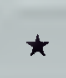

Overall Project Success*
A

A

A

B

A

A A

$A$

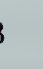

\author{
A
}

large benefits originally envisioned, and high scores would convey continued strong expectations that the project is on track to deliver large benefits. Projects with the same scores are not necessarily equal in their benefits potential or in the value of their achievements to date. Similar scores do, however, suggest roughly comparable levels of project outputs and outlooks for the future at the time the projects were assessed. Both the absolute values and the relative positions assigned to the individual projects in the table could change in the future.

\section{DETAILS OF SCORING SYSTEM}

Knowledge Creation and Dissemination: This score is constructed in two parts-1) Knowledge Creation and 2)

Knowledge Dissemination, and the two parts are combined.

\section{The Knowledge Creation part of the score is calculated as follows:}

Technical Awards - The number of technical awards for the 50 projects ranged from 0 to 4 . Because the outside recognition of technical excellence is considered a good indicator that significant new knowledge has been created, the count of such awards forms one part of this score and each award received is counted fully. Thus, the weight in the raw scores for this element among the 50 projects also ranged from 0 to 4 .

Patent Filings - The presence of a patent filing is taken as an indicator that new knowledge has been created. The number of patent filings among the 50 projects 
ranged from 0 to 26 . Patent filings are set to add to the raw score at a sharply declining rate, calculated as 0.5 times the square root of the number of additional patents. The weight in the raw score for this element among the 50 projects ranged from 0 to 2.5 .

Publications and Presentations - The existence of a publication or presentation is taken as another indicator that new knowledge has been created. The number of publications and presentations ranged from 0 to 214 among the 50 projects. Publications and presentations add to the raw score at a rate calculated as 0.5 times the fourth root of the number of publications and presentations. The aim is to give only a small additional credit to the raw score for numbers in excess of one. The resulting weight in the raw score for this element among the 50 projects ranged from 0 to 1.2 .

Product Now or Expected Soon - New product or process is taken as another indicator that new knowledge has been created. The number of products, now or expected, ranged from 0 to 5 . Having product now or expected is set to add half as much to the raw score as does a technical award, and the same as does a patent filing or a publication or patent. But no additional credit is assigned for having more than one. This decision was made because often multiple products reflect the same underlying new technical knowledge.

Total Knowledge Creation Raw Score - The raw scores for the above elements are summed. For the group of 50, total raw scores ranged from 0 to 4.5 .

\section{The Knowledge Dissemination part of the score is calculated as follows:}

Technical Awards - Technical awards are also included in the Knowledge Dissemination score because they raise awareness of the new technology and thereby may stimulate others to seek knowledge about it. However, the award does not itself convey much detailed knowledge. Therefore, this element is given only a small weight in the raw score. Calculated as 0.25 times the square root of the number of technical awards, the first award counts as 0.25 in the raw score. For the group of 50 projects, the maximum number of technical awards is 4 . Thus this element ranges from a value of 0 to 0.5 in the raw score.
Collaborations - The following forms of collaboration were taken as indicative of knowledge flows from the innovators to others via contact among scientific and technical researchers and managers: a) R\&D collaboration with nonuniversity organizations, b) collaboration for commercialization, and c) close university ties. Projects were assigned a score from 0 to 3 points depending on how many of these forms of collaboration they had. Note that these forms of collaboration observed for the project participants are used here as a proxy for collaboration with others outside the project leading to knowledge flows.

Patents - By disclosing information, patents serve to disseminate project knowledge. Patents are set to add to the score at a declining rate. The raw-score value of the first 10 patents is calculated as 1 times the square root of the number of patents, and patents in excess of 10 contribute to the score at the rate of 0.1 times the square root of the number of patents greater than 10 . The weight of this element in the raw score among the 50 projects ranged from 0 to 3.6. The decision is to give very little weight to additional patents in excess of 10 in the scoring system, and perhaps further analysis of patents as disseminators of knowledge will support a different decision.

Publications and Presentations - Publications and presentations are treated the same as patents in calculating the score for knowledge dissemination. Their weight in the knowledge dissemination raw score for the 50 projects ranged from 0 to 4.6. In both cases, the influence on the overall scores of extremely large numbers in just several of the projects is greatly moderated by the calculation procedure that is used.

Products and Processes Now or Expected - Products and processes are included in the knowledge dissemination measure because they embody the new know-how, and technical knowledge can be extracted through inspection and reverse engineering of products. They are assigned less weight than publications and presentations and patents, however, because they convey the knowledge less explicitly. This element is calculated as 0.5 times the square root of the number of products. 
Knowledge Dissemination Raw Score - The components of the knowledge dissemination score are summed to calculate the aggregate raw score. The aggregate raw score for the 50 projects ranged from 0.7 to 9.4 .

Commercialization Progress: The commercialization progress part of the score is calculated as follows:

\section{Products and Processes Now or Expected - Having a}

product or process is assigned a greater weight than having any one of the other elements comprising this total score. Having a single project or process, now or expected, is assigned a raw score of 4.25 . Additional products add at a rate of 1.25 times the square root of the number of products and processes. Their weight in the raw score for the 50 projects ranged from 0 to 5.8 .

Capital Attraction - Attracting capital in any of several ways, such as from private investors, from other government sources, or through collaborative commercialization agreements with other investing companies, was assigned a value of 3 points in computing the raw score-less than having a product or process. Because of the lack of information about the relative amounts of capital attracted from various sources for the different projects and the terms of use, no attempt was made here to assign different weights for attracting different sources or amounts of capital. Moreover, the weights were not additive for attracting multiple types of capital. The weight for this element in the raw score for the 50 projects was either 0 or 3 . Further refinement of how this metric is included in the scoring system may be possible.

Employment Gains - Employment data were recorded at the project start and near project finish by project analysts, but only for small, single-applicant projects. The data were not provided for most other single-applicant projects and none for joint-venture projects. A value of 1.5 is assigned for this element to those types of projects for which data were not collected to reduce the bias against them in the scores. This again is a place for further possible refinement to the scoring system. In the case where a small-company leader of a single-applicant project had gone bankrupt, a negative value of -6 was assigned as the raw-score weight-rather than a zero employment gainto signal that there is a serious impediment at this time to commercial progress. If employment for a small-company leader of a single-applicant project increased 50 percent or less, it is assigned a weight of 0 in the raw score. If the employment for this type of project increased more than 50 percent, a weight of 2.5 times the fourth root of the gain in excess of 50 percent was assigned. The objective of this method of scoring is to give a relatively strong weight to those projects that exhibited large employment growth among company leaders, but not to have this one factor dominate the other elements in the total scores (which otherwise would have happened in the face of growth rates ranging nearly as high as 2000 percent for several of the projects). Using this weighting system, the weights for employment gains in the raw scores for the 50 projects ranged from -6 to 5.2 .

Business Awards - Business-related awards were included in computing commercialization progress scores because they generally signal unusually strong business strength or acumen on the part of the project leaders. For business-related awards, a raw score of 0 is assigned for no awards and 3.25 for one award, less than commercialized product or process based on the new technology, but slightly more than attracting capital. Additional awards are set to increase the raw score at a rate of 0.25 per additional award (i.e., only partial credit is given because additional awards largely signal the same factor of relative company strength). The number of business awards among the 50 projects ranged from 0 to 3 . The weight for this element in the raw scores for the 50 projects ranged from 0 to 3.8 .

Outlook - The qualitative outlooks for the individual projects described by analysts in chapters two through six were translated into values from one to four by the developer of the prototype performance rating system. Hence, the values for this element are strongly analytical. If the analyst described the outlook as highly promising, excellent, or on track, the project outlook was assigned a value of 1 to indicate a strong outlook. If the analyst described the outlook as promising but with reservations or qualifications, or as indeterminate, the project outlook was assigned a value of 2 to indicate an outlook neither strong nor necessarily poor. If the analyst portrayed a pessimistic outlook, or if the leading company had gone bankrupt or was experiencing severe financial difficulties, the project outlook was assigned a value of 3 to indicate a poor outlook. To convert the outlook rating system to values 
that would be compatible with the performance scoring system, an outlook value of 1 was assigned a raw score of +4 ; an outlook value of 2 was assigned a raw score of 0 ; and an outlook value of 3 was assigned a raw score of -4 .

Commercialization Progress Raw Score - The components are summed for the aggregate raw score. For the 50 projects, the aggregate raw score ranged from -10 to 21.7.

Overall Performance Rating - A combined raw score for knowledge creation and dissemination and commercialization progress of zero or less, resulted in the assignment of a final score of zero. Projects with combined raw scores greater than zero were divided into four groups, corresponding to the four-star rating system. Scores equal or greater than four are assigned four stars; scores equal or greater than three but less than four are assigned three stars; scores equal or greater than two but less than three are assigned two stars; and scores equal or greater than one but less than two are assigned one star.

Again, the reader is reminded that the performance ratings shown in the table are based on the projects observed at a time in the past, and their conditions may have since improved, worsened, or remained essentially the same. Future updates on subsequent project developments may result in changes in their performance ratings. In addition, the reader is cautioned that the first-generation performance rating system presented and applied here may be refined in the future, and the absolute values and relative positions assigned to the individual projects changed. 


